(2) Richtiger Kostenschuldner -604

(3) Richtige Höhe -605

(4) Verhältnismäßigkeit -605

(5) Verjährung - 607

dd) Überblick über die Entschädigungsansprüche - 607

f) Literaturhinweise - 608

V. Der Vollzugsfolgenbeseitigungsanspruch (Jana Himstedt) $-\mathbf{6 0 8}$

VI. Die Begründetheitsprüfung bei der Anfechtung von Nebenbestimmungen (Christian Kaerkes) 609

1. Rechtswidrigkeit der Nebenbestimmung - $\mathbf{6 1 0}$

a) Ermächtigungsgrundlage $-\mathbf{6 1 0}$

b) Formelle Rechtmäßigkeit $-\mathbf{6 1 0}$

c) Materielle Rechtmäßigkeit -611

aa) Spezialgesetzliche Ermächtigung — 611

bb) Regelfall des § 36 VwVfG — 611

(1) Gebundene Entscheidung - 611

(2) Ermessensentscheidung - 612

(3) Weitere Voraussetzungen -612

2. Verletzung subjektiver Rechte -613

3. Sinnvoller und rechtmäßiger Rest-Verwaltungsakt -613

3. Literaturhinweise -615

\title{
A. Die Statthaftigkeit der Anfechtungsklage
}

Wurde der Verwaltungsrechtsweg für eröffnet erkannt (s. ausführlich zur Prüfung 2 $\S 1$ Rn. 162ff.), so ist im Rahmen der Zulässigkeit als nächstes die statthafte Klagebzw. Antragsart zu untersuchen. Die Prüfung der statthaften Klage-/Antragsart ist das zentrale Scharnier für die gesamte restliche Klausur. Nach ihr richten sich sowohl die weiteren Zulässigkeitsvoraussetzungen als auch die Struktur der Begründetheitsprüfung. Entsprechend wichtig ist die saubere Prüfung, welche Klage- bzw. Antragsart einschlägig ist (eine erste Übersicht über die Klage- und Antragsarten der VwGO findet sich in $\S 1 \mathrm{Rn}$. 222ff.).

Die Anfechtungsklage stellt die in der juristischen Ausbildung am umfas- 3 sendsten behandelte Klageart der VwGO dar, sodass entsprechend umfassende Kenntnisse in Prüfungsarbeiten erwartet werden. Die Anfechtungsklage ist deshalb so bedeutsam, weil sie am engsten mit der in der Ausbildung zentralen Eingriffsverwaltung und der dafür wichtigsten Handlungsform, dem (belastenden) Verwaltungsakt, verknüpft ist. Denn nach § 42 I Var. 1 VwGO kann mittels der Anfechtungsklage die Aufhebung eines Verwaltungsakts begehrt werden.

Nach einer einen ersten Überblick gebenden Einführung in die Anfechtungsklage (Rn. $4 \mathrm{ff}$.) wird der für das gesamte Verwaltungsrecht zentrale Begriff des Verwaltungsakts vertieft (Rn. $38 \mathrm{ff}$.). Ob über den Wortlaut des § $42 \mathrm{I}$ 
Var. 1 VwGO hinaus auch die Wirksamkeit des Verwaltungsakts Voraussetzung für seine Anfechtbarkeit ist, wird ab Rn. 98 behandelt. Als besondere Klausurkonstellation wird abschließend die Statthaftigkeit der Anfechtung von Nebenbestimmungen vertieft dargestellt (Rn. 204ff.).

\section{Einführung in die Anfechtungsklage (Jens Milker)}

4 Die Anfechtungsklage gemäß $§ 42$ I Var. 1 VwGO bietet vornehmlich die prozessuale Möglichkeit, die Wirksamkeit eines nicht erledigten Verwaltungsakts durch dessen „anderweitige“ Aufhebung ${ }^{1}$ gerichtlich zu beseitigen. ${ }^{2}$

$5 \quad$ Zudem kann sie auch bei einem nichtigen ${ }^{3}$ (vgl. dazu Rn. 19) und rein formellen Verwaltungsakt ${ }^{4}$ (vgl. dazu Rn. $21 \mathrm{ff}$.) sowie einem Scheinverwaltungsakt ${ }^{5}$ (dazu Rn. 20) statthaft sein.

Im Folgenden soll zur Verdeutlichung der Stellung der Anfechtungsklage im Rechtschutzsystem der VwGO zunächst allgemein auf ihre Rechtsnatur (Rn. $6 \mathrm{ff}$.), das für ihre Statthaftigkeit erforderliche Klägerbegehren (Rn. 9 ff.) und schließlich ihren Gegenstand (Rn. 25 ff.) eingegangen werden.

\section{Die Rechtsnatur der Anfechtungsklage}

6 Ihrer Art nach ist die Anfechtungsklage eine Gestaltungsklage, ${ }^{6}$ d. h., ihre Wirkungen treten bereits kraft Gesetzes ein und bedürfen keiner Vollstreckungsmaßnahme. ${ }^{7}$ Damit scheidet im Urteil auch der Ausspruch einer vorläufigen

1 Vgl. § 43 II Alt. 3 VwVfG; die Verwaltungsverfahrensgesetze der Länder enthalten insoweit identische oder jedenfalls ähnliche Regelungen. Im Folgenden wird ausschließlich auf das VwVfG des Bundes Bezug genommen.

2 Vgl. BVerwG, Beschl.v. 21.03.1990, Az.: 9 B 276/89 = NVwZ 1990, 774; in der Regel wird es sich dabei um einen belastenden Verwaltungsakt handeln, vgl. dazu etwa Pietzcker, in: Schoch/ Schneider/Bier, VwGO, 36. EL Februar 2019, § 42 I VwGO, Rn. 7 ff.

3 Vgl. BGH, Urt. v. 09.02.1979, Az.: RiZ (R) 6/78 = NJW 1979, 1710; s. auch R. P. Schenke, in: Kopp/ Schenke, VwGO, 25. Aufl. 2019, § 42 VwGO, Rn. 3.

4 Dabei handelt es sich um eine behördliche Handlungsform, die nur nach dem äußeren Anschein einen Verwaltungsakt darstellt, die Voraussetzungen eines Verwaltungsakts in materieller Hinsicht aber nicht erfüllt, vgl. dazu Stelkens, in: Stelkens/Bonk/Sachs, VwVfG, 9. Aufl. 2018, § 35 VwVfG, Rn. 16.

5 Vgl. dazu Blunk/Schroeder, JuS 2005, 602 (603f.); im Ergebnis die Statthaftigkeit der Anfechtungsklage ablehnend: Bickenbach, JA 2015, 481 (487).

6 Pietzcker, in: Schoch/Schneider/Bier, VwGO, 36. EL Februar 2019, § 42 I VwGO, Rn. 2; R. P. Schenke, in: Kopp/Schenke, VwGO, 25. Aufl. 2019, § 42 VwGO, Rn. 2.

7 Pietzcker, in: Schoch/Schneider/Bier, VwGO, 36. EL Februar 2019, § 42 I VwGO, Rn. 2.

Nikolas Eisentraut/Jens Milker 
Vollstreckbarkeit in Bezug auf die Hauptsacheentscheidung konsequenterweise aus, wie daher auch $\S 167$ II VwGO ausdrücklich festlegt. Das Gericht hebt bei Erfolg der Klage im Urteilsausspruch den angegriffenen Verwaltungsakt auf und gestaltet damit - anders als etwa bei Leistungsklagen - unmittelbar die Rechtslage. ${ }^{8}$ Einer Aufhebung durch die Behörde - beispielsweise gemäß §§ 48, 49 VwVfG - bedarf es dann nicht mehr.

Bei nichtigen oder auch rein formellen Verwaltungsakten ist eine insoweit 7 gerichtlich im Tenor ausgesprochene Aufhebung allerdings rein deklaratorisch, da diese Akte von vornherein keine Rechtswirkungen, sondern nur einen Rechtsschein entfalten. ${ }^{9}$ Bei einer Verpflichtungsklage hingegen, die auch an den Begriff des Verwaltungsakts anknüpft (s. dazu ausführlich Rn. $38 \mathrm{ff}$.), wird der Klagegegner zum Erlass eines Verwaltungsakts verpflichtet, den das Gericht nicht selbst erlässt. ${ }^{10}$ Ebenso wie bei der Verurteilung des Klagegegners zur Vornahme eines Realakts im Rahmen der allgemeinen Leistungsklage (s. dazu §5) bedarf es zur Durchsetzung eines Verpflichtungsurteils grundsätzlich einer daran anschließenden Vollstreckungsmaßnahme, wenn der Klagegegner das Urteil nicht freiwillig umsetzt. ${ }^{11}$ Dies ist bei der Anfechtungsklage nicht notwendig. Materiellrechtlich betrachtet, setzt der Kläger mit der Anfechtungsklage schließlich seinen - gesetzlich regelmäßig nicht ausdrücklich formulierten ${ }^{12}$ - Anspruch auf Aufhebung eines rechtswidrigen Verwaltungsakts durch. ${ }^{13}$

Beispiel 1: A erhält für sein Haus eine rechtswidrige Beseitigungsverfügung vom 15. Mai 2018 der zuständigen Bauaufsichtsbehörde. Er geht dagegen mit einem fristgerechten Widerspruch

8 Pietzcker, in: Schoch/Schneider/Bier, VwGO, 36. EL Februar 2019, § 42 I VwGO, Rn. 2.

9 Vgl. zur möglichen (deklaratorischen) Aufhebung bei nichtigen Verwaltungsakten: BFH, Urt. v. 26.03.1985, Az.: VIII R 225/83 = NVwZ 1986, 156 (157), OVG Rheinland-Pfalz, Urt. v. 25.06. 1986, Az.: 8 A 92/85 = NVwZ 1987, 899: „Dabei kann die Nichtigkeit eines Verwaltungsakts auch im Wege der Anfechtungsklage geltend gemacht werden, denn es ist anerkannt, daß auch bei nichtigen Verwaltungsakten aus Gründen der Rechtsklarheit die Aufhebung des nur dem Rechtsschein nach bestehenden Bescheids formell ausgesprochen werden kann“; a. A. Pietzcker, in: Schoch/Schneider/Bier, VwGO, 36. EL Februar 2019, § 42 I VwGO, Rn. 18.

10 Es findet auch keine Fiktion eines Verwaltungsakts statt, wie etwa bei einer Willenserklärung (vgl. § 173 S. 1 VwGO i.V.m. § 894 I ZPO).

11 S. zu den insoweit bestehenden Vollstreckungsmöglichkeiten gegen die öffentliche Hand etwa $\S 172$ VwGO. Besonders aktuell dürfte hier die Frage nach einer möglichen Zwangshaft von hochrangigen Verwaltungsmitarbeitern/Politikern sein, s. dazu BayVGH, Beschl. v. 09.11.2018, Az.: 22 C 18.1718 = BeckRS 2018, 29302).

12 Pietzcker, in: Schoch/Schneider/Bier, VwGO, 36. EL Februar 2019, § 42 I VwGO, Rn. 3: „wird in den Verhaltensnormen ebenso wie in Art. 19 Abs. 4 GG vorausgesetzt“.

13 Vgl. BVerwG, Urt. v. 21.05.1976, Az.: IV C 80/74 -, NJW 1976, 1760 (1761); Pietzcker, in: Schoch/ Schneider/Bier, VwGO, 36. EL Februar 2019, § 42 I VwGO, Rn. 3 m.w. N. 
vor, der allerdings mit Widerspruchsbescheid vom 21. November 2018 zurückgewiesen wird. Seiner zulässigen und begründeten Anfechtungsklage gibt das zuständige Verwaltungsgericht vollumfänglich statt. In der Hauptsache tenoriert das Gericht daher wie folgt: „Der Bescheid des Beklagten vom 15. Mai 2018 in der Gestalt des Widerspruchsbescheids vom 21. November 2018 wird aufgehoben".

\section{Das Begehren: Aufhebung eines noch nicht erledigten Verwaltungsakts}

9 Zentraler Anknüpfungspunkt zur Bestimmung der statthaften Klageart ist das Begehren des Klägers (vgl. § 88 VwGO).

\section{a) Allgemeines}

10 Damit eine Anfechtungsklage statthaft ist, muss sich dem Begehren des Klägers (ggf. durch Auslegung) entnehmen lassen, dass er einen jedenfalls für ihn belastenden ${ }^{14}$ noch nicht erledigten Verwaltungsakt beseitigen möchte. Bei erledigten Verwaltungsakten ist die in $\S 113$ I 4 VwGO geregelte Fortsetzungsfeststellungsklage die richtige Klageart (s. dazu ausführlich §4). Der Begriff des Verwaltungsakts im Rahmen der Statthaftigkeit ist grundsätzlich nach Maßgabe der VwGO zu beurteilen. Da sich in der VwGO keine Legaldefinition findet, ist der Begriff nach dem bundesrechtlichen $\S 35 \mathrm{VwVfG}^{15} \mathrm{zu}$ bestimmen, auch wenn eine Landesbehörde gehandelt hat. ${ }^{16}$ Sind dessen Voraussetzungen erfüllt (dazu noch näher Rn. $38 \mathrm{ff}$.), ist die Anfechtungsklage ohne weiteres statthaft.

11 Gleichwohl erfasst der Verwaltungsaktbegriff der VwGO gegenüber dem des VwVfG weitergehende behördliche Maßnahmen, etwa solche, die nur dem äußeren Anschein nach einen Verwaltungsakt darstellen (sog. formelle Verwaltungsakte; zu den damit einhergehenden weiteren prozessualen Besonderheiten s. unten Rn. $21 \mathrm{ff}$.). ${ }^{17} \mathrm{Ob}$ die Anfechtungsklage statthaft ist, setzt daher Kenntnisse des Verwaltungsaktbegriffs voraus (s. hierzu ausführlich Rn. 42ff.).

14 Die Anfechtung eines Verwaltungsakts durch den insoweit Begünstigten dürfte in der Praxis ausgeschlossen sein. Gleichwohl wäre auch in diesen Fällen die Anfechtungsklage statthaft; üblicherweise dürfte aber dann die Klagebefugnis fehlen; vgl. auch Brenner, in: Sodan/Ziekow, VwGO, 5. Aufl. 2018, § 79, Rn. 26: fehlende „Beschwer“.

15 Dahingehend enthalten $\S 118$ AO bzw. § 31 SGB X denselben Wortlaut und wären im Rahmen ihres Anwendungsbereichs vorzuziehen.

16 Sodan, in: Sodan/Ziekow, VwGO, 5. Aufl. 2018, § 42 VwGO, Rn. 99 m.w. N.; W. R. Schenke, in: Kopp/Schenke, VwGO, 25. Aufl. 2019, Anh $\S 42$ VwGO, Rn. 2; a. A. Stelkens, in: Stelkens/Bonk/ Sachs, VwVfG, 9. Aufl. 2018, §35 VwVfG, Rn. 15: Abstellen auf einen „gemeindeutschen“ Rechtsgedanken; kritisch hingegen Rusteberg, ZJS 2012, 450.

17 Vgl. Ramsauer, in: Kopp/Ramsauer, VwVfG, 19. Aufl. 2018, § 35 VwVfG, Rn. 52; Stelkens, in: Stelkens/Bonk/Sachs, VwVfG, 9. Aufl. 2018, § 35 VwVfG, Rn. 16; eine solche Differenzierung Jens Milker 
Bei einer Verpflichtungsklage als besondere Form der Leistungsklage ${ }^{18}$ begehrt der Kläger hingegen den Erlass eines Verwaltungsakts, wobei die kassatorische Wirkung der Verpflichtungsklage dazu führt, dass ein entgegenstehender Ablehnungsbescheid mit ihr gleichsam (ex nunc) aufgehoben werden kann, ohne dass es einer zusätzlichen Anfechtungsklage bedarf. ${ }^{19}$ Es ist daher in der Klausursituation und auch in der Praxis genau zu untersuchen, ob der Kläger sein Rechtsschutzziel bereits durch reine Aufhebung eines Verwaltungsakts erreichen kann ${ }^{20}$ oder ob darüber hinaus noch der Erlass eines begünstigenden Verwaltungsakts notwendig ist. Dabei ist der Wortlaut des Klageantrags nur ein Anhaltspunkt (vgl. § 88 VwGO). Im Zweifel ist dann das Begehren - besonders bei nicht anwaltlich vertretenen Privatpersonen - im Lichte des Art. 19 IV GG möglichst rechtsschutzintensiv auszulegen. ${ }^{21}$ Die verwaltungsgerichtliche Praxis ist insoweit auch recht großzügig, sodass diese Herangehensweise ebenso bei Klausurbearbeitungen im ersten und zweiten Staatsexamen übernommen werden kann. Insgesamt gilt es, aus dem unter Umständen nicht mit juristischen Fachbegriffen formulierten Vortrag des Klägers dessen tatsächliches Rechtsschutzziel herauszuarbeiten und dann ,die Klageart zu wählen, mit der er weder weniger als das Begehrte erreicht, noch auch mehr, als zur Erfüllung seines Begehrens nötig ist". ${ }^{22}$

Beispiel 2: B hat eine Erlaubnis zum Betrieb einer Spielhalle erhalten, einige Zeit später bemerkt die Behörde, dass bei der Erteilung ein Fehler gemacht worden ist und sendet dem $B$ einen „Rücknahmebescheid“ zu. Hier wäre nur die Anfechtungsklage gegen den „Rücknahmebescheid“ statthaft, da dann die (zurückgenommene) Erlaubnis als begünstigender Verwaltungsakt „wieder auflebt“ und B so schon vollumfänglich sein Rechtsschutzziel erreichen würde.

zwischen verfahrens- und prozessrechtlichem Verwaltungsaktbegriff ausdrücklich ablehnend: Pietzcker, in: Schoch/Schneider/Bier, VwGO, 36. EL Februar 2019, § 42 I VwGO, Rn. 23; ebenso jedenfalls nicht ausdrücklich derart differenzierend: BVerwG, Beschl. v. 9. November 1984, Az.: 7 C 5/84, Amtlicher Leitsatz 1: ,anfechtbarer Verwaltungsakt im Sinne des § 35 Satz 1 VwVfG“; in der Tendenz anders allerdings: BVerwG, Beschl. v. 18. Januar 1993, Az.: 6 B 5/92 = NVwZ-RR 1993, 251 (252): „Akt“.

18 Vgl. schon BVerwG, Urt. v. 25.02.1969, Az.: I C 65/67 = VerwRspr 1969, 1006 (1007); s. auch Sodan, in: Sodan/Ziekow, VwGO, 5. Aufl. 2018, § 42 VwGO, Rn. 29 m.w. N.

19 BVerwG, Urt. v. 19.05.1987, Az.: 1 C 13/84 = NVwZ 1987, 893 (894f.): Anders könne die Situation liegen, wenn der Kläger ein besonderes Rechtsschutzinteresse an der Aufhebung (ex tunc) des ablehnenden Bescheides habe; dazu auch Pietzcker, in: Schoch/Schneider/Bier, VwGO, 36. EL Februar 2019, § 42 I VwGO, Rn. 96.

20 Vgl. auch Pietzcker, in: Schoch/Schneider/Bier, VwGO, 36. EL Februar 2019, § 42 I VwGO, Rn. 5.

21 Vgl. dazu näher BVerwG, Urt. v. 27.04.1990, Az. 8 C 70/88 = NJW 1991, 508 (510).

22 Pietzcker, in: Schoch/Schneider/Bier, VwGO, 36. EL Februar 2019, § 42 I VwGO, Rn. 106.

Jens Milker 
Beispiel 3: Die C betreibt einen Auto-Scooter. Sie möchte daher auf das große Volksfest mit mehreren hundert Schaustellerinnen und Schaustellern in der Stadt $M$ und bewirbt sich auf einen Standplatz. Dieser wird ihr allerdings versagt, da das Kontingent erschöpft sei. Sie ist weiter der Ansicht, dass ihr Fahrgeschäft viel attraktiver sei, als das der anderen Schausteller. Wenn die $C$ nun tatsächlich einen Standplatz erhalten möchte und ausdrücklich etwa eine Verpflichtungsklage auf Neubescheidung ( $\$ 113 \mathrm{~V} 2 \mathrm{VwGO}$ ) erhebt, müsste sie hier nicht gleichzeitig eine (Dritt-)Anfechtungsklage gegen die Bescheide gegenüber anderen Schaustellerinnen oder Schaustellern erheben, um sozusagen einen Platz „frei zu räumen“. Aufgrund der hohen Zahl der weiter ansonsten notwendigen Anfechtungsklagen wäre dies wohl für die $C$ unzumutbar. ${ }^{23}$

\section{b) Einzelfälle (insbesondere Abgrenzung zu anderen Klagearten)}

15 Folgende Konstellationen bedürfen regelmäßig einer genaueren Abgrenzung.

\section{aa) Nebenbestimmungen, Wiederaufgreifen des Verfahrens und Zurückstellung von Baugesuchen}

16 Besondere Probleme der Abgrenzung von Anfechtungs- und Verpflichtungsklage ergeben sich bei der (isolierten) Anfechtung von Nebenbestimmungen (s. dazu Rn. 204 ff.). Darüber hinaus kann, wenn der Kläger sich gegen einen belastenden, aber bestandskräftigen (s. dazu Rn. 115) Verwaltungsakt wendet, dessen Begehren dahingehend $\mathrm{zu}$ verstehen sein, dass er die Verpflichtung der Behörde zum Wiederaufgreifen des Verfahrens im Sinne des $\S 51$ VwVfG begehrt. ${ }^{24}$

Beispiel 4: A hat eine Baugenehmigung bei der Stadtverwaltung der kreisfreien Stadt B beantragt. Diese stellt sein Baugesuch gemäß $\S 15$ BauGB rechtswidrig zurück. Nun möchte A gerichtlich erreichen, dass möglichst zügig über seinen Bauantrag entschieden wird. Welcher Antrag wäre statthaft?

Hier könnte A bereits durch Erhebung der Anfechtungsklage sein Rechtsschutzziel erreichen. ${ }^{25}$ Es wird schon alleine mit der Aufhebung der Zurückstellungs-

23 BVerwG, Urt. v. 07.10.1988, Az.: 7 C 65/87 = NJW 1989, 1749 (1750); anders kann die Lage natürlich sein, wenn es nur wenige Konkurrenten gibt.

24 Pietzcker, in: Schoch/Schneider/Bier, VwGO, 36. EL Februar 2019, § 42 I VwGO, Rn. 106.

25 Vgl. NdsOVG, Beschl.v. 28.11.2006, Az.: 1 ME 147/06 = BeckRS 2006, 27262; OVG RP, Beschl.v. 23.05.2002, Az.: 8 B 10633/02 = NVwZ-RR 2002, 708 (709); anders VGH BW, Beschl.v. 09.08.2002, Az.: 3 S 1517/02 = NVwZ-RR 2003, 333: Das eigentliche Ziel des Bauherrn sei erst erreicht, wenn er die Baugenehmigung erlangt habe. Für einen isolierten Eilantrag nach $\S 80 \mathrm{~V}$ VwGO fehle daher das erforderliche Rechtsschutzbedürfnis.

Jens Milker 
verfügung der ursprüngliche Zustand dahingehend hergestellt, dass nun im „normalen“ Tempo über den Antrag des A entschieden wird. Es handelt sich bei der Zurückstellung nach §15 I 1 BauGB um eine eigenständige Rechtsbeeinträchtigung durch eine qualifizierte Form der Verfahrensaussetzung. ${ }^{26}$

\section{bb) Bereits erledigte Verwaltungsakte}

Zudem muss schließlich die nicht immer einfache Abgrenzung zur Fortset- 18 zungsfeststellungsklage anhand des Merkmals der „Erledigung“ des Verwaltungsakts gemäß § 113 I 4 VwGO erfolgen (s. dazu ausführlich § 4 Rn. 2ff.).

\section{cc) Nichtige Verwaltungsakte}

$\mathrm{Zu}$ Abgrenzungsproblemen kommt es regelmäßig auch bei nichtigen Verwal- 19 tungsakten (s. dazu auch weiterführend Rn. $197 \mathrm{ff}$.). Dabei sieht der Gesetzgeber eine spezielle Klageart vor, nämlich die Nichtigkeitsfeststellungsklage gemäß $\S 43$ I Alt. 2 VwGO. Gleichzeitig ergibt sich mittelbar aus § 43 II 2 VwGO, dass die Anfechtungsklage auch bei einem nichtigen Verwaltungsakt statthaft sein kann. ${ }^{27}$ Schließlich ist die Frage, ob ein Verwaltungsakt nichtig oder „nur“ rechtswidrig ist, nicht immer mit hinreichender Sicherheit vor Klageerhebung zu beantworten. ${ }^{28}$ Folglich ist es nur naheliegend, dass beide Klagearten parallel zur Anwendung kommen können. ${ }^{29}$ Denn der Kläger soll nicht das Risiko einer unstatthaften Anfechtungsklage gegen einen nicht bloß rechtswidrigen, sondern nichtigen Verwaltungsakt tragen. ${ }^{30}$ Insgesamt wäre hier daher ein Anfechtungsantrag auch von vornherein nicht etwa von Amts wegen als Nichtigkeitsfeststel-

26 OVG RP, Beschl. v. 23.05.2002, Az.: 8 B 10633/02 = NVwZ-RR 2002, 708 (709); OVG Berlin, Beschl. v. 21.11.1994, Az.: 2 S 28/94 = NVwZ 1995, 399.

27 Vgl. BVerwG, Urt. v. 20.03.1964, Az.: VII C 10/61 = VerwRspr 1964, 938 (939); BFH, Urt. v. 26. 03. 1985, Az.: VIII R 225/83 = NVwZ 1986, 156 (157), OVG Rheinland-Pfalz, Urt.v. 25.06.1986, Az.: 8 A 92/ 85 = NVwZ 1987, 899; Beschl. v. 12.05.1998, Az.: 12 A 12501/97 = NVwZ 1999, 198; Pietzcker, in: Schoch/Schneider/Bier, VwGO, 36. EL Februar 2019, § 42 I VwGO, Rn. 18; a. A. Sodan, in: Sodan/ Ziekow, VwGO, 5. Aufl. 2018, § 42, Rn. 23: Der Kläger müsse, sofern sich die Nichtigkeit des Verwaltungsakts im Laufe des Prozesses herausstelle, seinen Antrag (ggf. nach Hinweis des Vorsitzenden) auf eine Nichtigkeitsfeststellungsklage umstellen.

28 BFH, Urt.v. 26.06.1985, Az.: IV R 62/83 = NVwZ 1987, 359 (360); BGH, Urt.v. 09. 02.1979, Az.: RiZ (R) 6/78 = NJW 1979, 1710; Pietzcker, in: Schoch/Schneider/Bier, VwGO, 36. EL Februar 2019, § 42 I VwGO, Rn. 18.

29 Vgl. für Schein-Verwaltungsakte: Blunk/Schroeder, JuS 2005, 602 (606f.): „Wahlrecht“. 30 Vgl. Sodan, in: Sodan/Ziekow, VwGO, 5. Aufl. 2018, § 42, Rn. 23. 
lungsantrag auszulegen, ${ }^{31}$ da auch grundsätzlich eine deklaratorische Aufhebung „aus Gründen der Rechtsklarheit“"32 im Tenor erfolgen kann. ${ }^{33}$ Dies soll nach wohl überwiegender Ansicht in der Rechtsprechung allerdings nur dann möglich sein, wenn der nichtige Verwaltungsakt noch nicht formell bestandskräftig geworden ist. ${ }^{34}$ Dann wäre allerdings auch die - ggf. auf Hinweis des Vorsitzenden gemäß § 86 III VwGO erfolgende ${ }^{35}$ - Umstellung auf einen Feststellungsantrag (§ 43 I VwGO) nicht als Klageänderung im Sinne des § 173 Satz 1 VwGO i.V.m. § 264 Nr. 2 ZPO anzusehen. ${ }^{36}$

\section{dd) Nicht bekanntgegebene Verwaltungsakte}

20 Eine Sonderstellung nehmen Verwaltungsakte ein, die etwa mangels ordnungsgemäßer Bekanntgabe nicht wirksam und daher von vornherein nicht existent sind (sog. „Scheinverwaltungsakte“377 s. dazu auch noch Rn. 97) bzw. „Nichtakte“38). Dabei handelt es sich nicht um eine Nichtigkeit im Sinne des $§ 44$ VwVfG, ${ }^{39}$ da kein inhaltlicher Fehler vorliegt. ${ }^{40}$ Das Bundesverwaltungsgericht

31 Vgl. BayVGH, Urt. v. 15.09.1983, Az.: 23 B 80 A 861 = NJW 1984, 626: „Die Nichtigkeit des zulässigerweise angefochtenen ,Verwaltungsakts‘ war deshalb als im Anfechtungsantrag enthaltenes Minus festzustellen“; s. dazu auch Sodan, in: Sodan/Ziekow, VwGO, 5. Aufl. 2018, §42, Rn. 23.

32 OVG Rheinland-Pfalz, Urt. v. 25.06.1986, Az.: 8 A 92/85 = NVwZ 1987, 899.

33 BFH, Urt. v. 26.03.1985, Az.: VIII R 225/83 = NVwZ 1986, 156 (157), OVG Rheinland-Pfalz, Urt. v. 25.06.1986, Az.: 8 A 92/85 = NVwZ 1987, 899: „Dabei kann die Nichtigkeit eines Verwaltungsakts auch im Wege der Anfechtungsklage geltend gemacht werden, denn es ist anerkannt, daß auch bei nichtigen Verwaltungsakten aus Gründen der Rechtsklarheit die Aufhebung des nur dem Rechtsschein nach bestehenden Bescheids formell ausgesprochen werden kann“; Happ, in: Eyermann, VwGO, 15. Aufl. 2019, § 42, Rn. 15; a. A. Pietzcker, in: Schoch/Schneider/Bier, VwGO, 36. EL Februar 2019, § 42 I VwGO, Rn. 18; Sodan, in: Sodan/Ziekow, VwGO, 5. Aufl. 2018, § 42, Rn. 23.

34 Vgl. BVerwG, Urt.v. 30.01.1990, Az.: 1 A 36/86 = NJW 1990, 1804 (1806); BFH, Urt.v. 26.06.1985 Az.: IV R 62/83 = NVwZ 1987, 359 (360); OVG Rheinland-Pfalz, Beschl.v. 12.05.1998, Az.: 12 A 12501/ 97 = NVwZ 1999, 198; in diesem Sinne auch BT-Drs. 3/55 Anl. 1, S. 32; a.A. BFH, Urt. v. 17.07.1986, Az.: V R 96/85 = NVwZ 1987, 920.

35 Sodan, in: Sodan/Ziekow, VwGO, 5. Aufl. 2018, § 42, Rn. 23.

36 Happ, in: Eyermann, VwGO, 15. Aufl. 2019, § 42, Rn. 15.

37 Vgl. Blunk/Schroeder, JuS 2005, 602 (603f.); Bickenbach, JA 2015, 481 (487) jeweils mit dem Hinweis auf weitere Fallgruppen.

38 BVerwG, Urt. v. 21.11.1986, Az.: 8 C 127/84 = NVwZ 1987, 330.

39 BVerwG, Urt.v. 21.11.1986, Az.: 8 C 127/84 = NVwZ 1987, 330: „Es handelte sich dann um einen rechtlich nicht existent gewordenen Bescheid (Nichtakt), der in seiner rechtlichen Unwirksamkeit einem nichtigen Verwaltungsakt gleicht“; Stelkens, in: Stelkens/Bonk/Sachs, VwVfG, 9. Aufl. 2018, § 41 VwVfG, Rn. 224 m.w. N. auch zur a.A. 
nimmt in den Fällen einer unwirksamen Bekanntgabe an, dass die Feststellung der Nichtigkeit gemäß § 43 I Alt. 1VwGO und nicht im Wege der Nichtigkeitsfeststellungsklage möglich sein soll. ${ }^{41}$ Die Feststellung sei dann darauf gerichtet, dass der Verwaltungsakt nicht wirksam (geworden) sei und deshalb die mit ihm beabsichtigte Regelungswirkung nicht erreicht habe. Gleichwohl wird auch hier alternativ die Anfechtungsklage zur Anwendung kommen können, um einen eventuell bestehenden Rechtsschein durch deklaratorische Aufhebung zu beseitigen. $^{42}$

\section{ee) Rein formelle Verwaltungsakte}

Bei der Anfechtung von rein formellen Verwaltungsakten ist ebenso die An- 2 fechtungsklage statthaft. ${ }^{43}$ Dies sind Verwaltungsakte, die tatsächlich nicht die Voraussetzungen des $\S 35 \mathrm{VwVfG}$ erfüllen, das behördliche Handeln aber nach dem äußeren Erscheinungsbild einen Verwaltungsakt darstellt. ${ }^{44}$ Dies kann beispielsweise durch die Bezeichnung als „Bescheid“ erfolgen oder durch das Anfügen einer Rechtsbehelfsbelehrung, die auf die mögliche Erhebung eines Widerspruchs hinweist. ${ }^{45}$

Eine Maßnahme, die kein Verwaltungsakt im materiellen Sinne ist, wird nicht 22 allein durch ihre äußere Form zu einem solchen Verwaltungsakt. ${ }^{46}$ Die in $\S 35$ Satz 1 VwVfG statuierten Voraussetzungen sind damit keine Elemente der Rechtmäßigkeit, sondern materiell-rechtliche Wesensmerkmale des Verwal-

40 Stelkens, in: Stelkens/Bonk/Sachs, VwVfG, 9. Aufl. 2018, § 41 VwVfG, Rn. 224; Beaucamp, JA 2016, 436 (438f.).

41 BVerwG, Urt. v. 21.11.1986, Az.: 8 C 127/84 = NVwZ 1987, 330.

42 OVG Rheinland-Pfalz, Urt. v. 25.6.1986, Az.: 8 A 92/85 = NVwZ 1987, 899; Blunk/Schroeder, JuS 2005, 602 (606f.): „Wahlrecht“.

43 Vgl. BSG, Urt. v. 5.9. 2006, Az.: B 4 R 71/06 R = BeckRS 2006, 44566, Rn. 16; BVerwG, Beschl.v. 18.1.1993, Az.: 6 B 5/92 = NVwZ-RR 1993, 251 (252); s. ferner BayVGH, Urt. v. 2.8.2016, Az.: 22 B 16.619 = BeckRS 2016, 50120, Rn. 35, 41 ff.; VG Mainz, Urt.v. 3.7.2018, Az.: 1 K 1463/17 = BeckRS 2018, 20916, Rn. 17; a. A. VG Wiesbaden, Urt. v. 5.5.2007, Az.: 7 E 1536/06 = NVwZ-RR 2007, 613: Feststellungsklage; Bickenbach, JA 2015, 481 (486f.).

44 Vgl. Stelkens, in: Stelkens/Bonk/Sachs, VwVfG, 9. Aufl. 2018, § 35 VwVfG, Rn. 16.

45 S. dazu BSG, Urt. v. 5.9.2006, Az.: B 4 R 71/06 R = BeckRS 2006, 44566, Rn. 20; BayVGH, Urt. v. 2. 8.2016, Az.: 22 B 16.619 = BeckRS 2016, 50120, Rn. 43; VG Mainz, Urt.v. 3.7.2018, Az.: 1 K 1463/17 = BeckRS 2018, 20916, Rn. 17.

46 Vgl. Stelkens, in: Stelkens/Bonk/Sachs, VwVfG, 9. Aufl. 2018, § 35, Rn. 72; Ramsauer, in: Kopp/ Ramsauer, VwVfG, 19. Aufl. 2018, § 35 VwVfG, Rn. 52; s. auch BVerwG, Beschl. v. 18.1.1993, Az.: 6 B 5/92 = NVwZ-RR 1993, 251 (252): Aufhebung „eines offensichtlich rechtswidrigen Aktes“ (Hervorhebung durch den Verfasser). 
tungsakts. ${ }^{47}$ Hier besteht damit „trotz des äußeren Scheins in Wahrheit kein Verwaltungsakt“. ${ }^{48}$ Gleichwohl gilt auch hier, dass die Anfechtungsklage zulässig sein kann, mit dem Ergebnis, dass der formelle Verwaltungsakt im Tenor deklaratorisch aufgehoben wird (s. für ein Beispiel auch Rn. 51).

\begin{abstract}
Beispiel 5: Der Bürgermeister der Stadt X bestellt beim Versandhandel A Büromaterial für seine Stadtverwaltung. Als zunächst keine Lieferung erfolgt, sendet er ein mit „Bescheid“ überschriebenes Schreiben einschließlich Rechtsbehelfsbelehrung an A und fordert zur unverzüglichen Lieferung auf. Sofern A nun vor dem Verwaltungsgericht (ausschließlich) gegen diesen „Akt ${ }^{\text {“49 }}$ vorgehen möchte, wäre die Anfechtungsklage statthaft, obwohl der Bürgermeister ein fiskalisches Hilfsgeschäft getätigt und sich infolgedessen eigentlich im Bereich des Privatrechts bewegt hat..$^{50}$ Insoweit durfte etwa „nur durch bürgerlichrechtliche Willenserklärung“ gehandelt werden. ${ }^{51}$ Überdies könnte möglicherweise auch die Regelungswirkung des „Bescheids“ fraglich sein. ${ }^{52}$ Der A könnte allerdings dennoch „zulässigerweise [...] Anfechtungsklage vor dem $V G^{* 53}$ gegen den „Bescheid“ erheben, während eine darüber hinausgehende Verpflichtung allerdings nicht mehr auf dem Verwaltungsrechtsweg durchzusetzen wäre. ${ }^{54}$
\end{abstract}

24 Hausarbeitswissen: Ob bei der Anfechtung von formellen Verwaltungsakten auch die in $\$ \S 68 f f$. VwGO vorgesehenen Fristen zur Anwendung kommen ${ }^{55}$ oder dies - mangels Bestandskraftfähigkeit - jedenfalls nicht zwingend ist ${ }^{56}$, ist in Rechtsprechung und Literatur nicht abschließend geklärt. Richtigerweise dürfte anzunehmen sein, dass formelle Verwaltungsakte nicht der Bestandskraft fähig sind, da ansonsten die Behörde in die Lage versetzt würde, insoweit auch solchen Maßnahmen

47 Vgl. Stelkens, in: Stelkens/Bonk/Sachs, VwVfG, 9. Aufl. 2018, § 35, Rn. 17.

48 BVerwG, Beschl.v. 18.1.1993, Az.: 6 B 5/92 = NVwZ-RR 1993, 251 (252); tendenziell anders noch BVerwG, Beschl. v. 9. November 1984, Az.: 7 C 5/84 = NVwZ 1985, 264, Amtlicher Leitsatz 1: „anfechtbarer Verwaltungsakt im Sinne des $\S 35$ Satz 1 VwVfG“.

49 So BVerwG, Beschl. v. 18.1.1993, Az.: 6 B 5/92 = NVwZ-RR 1993, 251 (252).

50 Vgl. Papier/Shirvani, in: Münchener Kommentar zum BGB, 7. Aufl. 2017, § 839, Rn. 151.

51 BVerwG, Urt. v. 23.1.1990, Az.: 8 C 37/88 = NJW 1990, 2482.

52 Die Regelungswirkung für eine mit Rechtsbehelfsbelehrung ergangene „Zahlungsaufforderung“ im Einzelfall annehmend: HambOVG, Urt. v. 10.4.2003, Az.: 2 Bf 432/99 = NVwZ-RR 2004, 402; zur Abgrenzung von einer bloßen Mitteilung der (vermeintlichen) Rechtslage insoweit auch Stelkens, in: Stelkens/Bonk/Sachs, VwVfG, 9. Aufl. 2018, § 35, Rn. 73a, 82ff..

53 BVerwG, Beschl. v. 18.1.1993, Az.: 6 B 5/92 = NVwZ-RR 1993, 251 (252).

54 Vgl. BVerwG, Beschl. v. 18.1.1993, Az.: 6 B 5/92 = NVwZ-RR 1993, 251 (252); Urt. v. 23. Januar 1962, Az.: III C 203/60 = NJW 1962, 830; BayVGH, Beschl. v. 14.6.2002, Az.: 7 B 01.2030 = NVwZ 2002, 1392; s. insbesondere auch bei einer fehlenden Regelungs- und Außenwirkung der Maßnahme: BayVGH, Urt. v. 2.8.2016, Az.: 22 B 16.619 = BeckRS 2016, 50120, Rn. $36 \mathrm{ff.}$. $41 \mathrm{ff}$.

55 Ramsauer, in: Kopp/Ramsauer, VwVfG, 19. Aufl. 2018, § 35 VwVfG, Rn. 52: Unter Bezugnahme auf „§§ 42, 68, 113 VwGO“; s. auch die Nachweise bei Stelkens, in: Stelkens/Bonk/Sachs, VwVfG, 9. Aufl. 2018, § 35, Rn. 17 (Fn. 74).

56 Vgl. BSG, Urt. v. 5.9.2006, Az.: B 4 R 71/06 R = BeckRS 2006, 44566, Rn. 20; VG Mainz, Urt. v. 03.07.2018, Az.: 1 K 1463/17 = BeckRS 2018, 20916, Rn. 19; Stelkens, in: Stelkens/Bonk/Sachs, VwVfG, 9. Aufl. 2018, § 35, Rn. 17 mit Verweis auf BVerwG, Beschl. v. 18.1.1993, Az.: 6 B 5/92 = NVwZ-RR 1993, 251 (252).

Jens Milker 
außerhalb der (Wesens-)Merkmale des $\S 35$ VwVfG eine (materielle) Verwaltungsaktqualität zuzuweisen, für die der Gesetzgeber dies nicht vorgesehen hat. ${ }^{57}$

\section{3. Überblick über den Gegenstand der Anfechtungsklage}

Der Gesetzgeber sieht im Regelfall Ausgangsverwaltungsakt ${ }^{58}$ und Wider- 25 spruchsbescheid als prozessuale Einheit an (§ 79 I Nr. 1 VwGO), die nur in den gesondert normierten Einzelfällen durchbrochen werden darf (§79 I Nr. 2, II VwGO). ${ }^{59}$ Damit wird eine möglichst ökonomische Verfahrensabwicklung gewährleistet.

\section{a) § 79 I Nr. 1 VwGO als Regelfall}

Gegenstand der Anfechtungsklage ist im Regelfall der Ausgangsverwaltungs- 26 akt in der Gestalt ${ }^{60}$, die er durch den Widerspruchsbescheid gefunden hat (§ $79 \mathrm{I}$ Nr. 1 VwGO), sodass es sich am Ende um eine einheitliche Verwaltungsentscheidung handelt. ${ }^{61}$ Dabei kommt mittelbar zum Ausdruck, dass gerade im Widerspruchsbescheid Formfehler geheilt ${ }^{62}$ (z. B. Nachholen einer Anhörung oder einer Begründung) und auch Ermessenserwägungen ergänzt werden können. ${ }^{63}$ Auch

57 Vgl. Stelkens, in: Stelkens/Bonk/Sachs, VwVfG, 9. Aufl. 2018, § 35, Rn. 17.

58 Das Gesetz spricht vom „ursprünglichen Verwaltungsakt“; § 79 II 1 VwGO; im Folgenden wird hier allerdings der allgemein ebenfalls übliche Begriff „Ausgangsverwaltungsakt“ verwendet; vgl. Pietzcker, in: Schoch/Schneider/Bier, VwGO, 36. EL Februar 2019, § 79 VwGO, Rn. 3.

59 Siehe dazu eingehend etwa auch: Möstl, in: Posser/Wolff, VwGO, 47. Ed., Stand: 1.10.2018, $\S 79$, Rn. 2; Pietzcker, in: Schoch/Schneider/Bier, VwGO, 36. EL Februar 2019, § 79 VwGO, Rn. 3. 60 Bei einer bloßen Bestätigung des Ausgangsbescheids durch Zurückweisung des Widerspruchs nimmt ein Teil in der Literatur der Begrifflichkeit nach keine Gestaltänderung an; vgl. Happ, in: Eyermann, VwGO, 15. Aufl. 2019, § 79, Rn. 5; Brenner, in: Sodan/Ziekow, VwGO, 5. Aufl. 2018, § 79, Rn. 25; a. A. BVerwG, Beschl.v. 30.4.1996, Az.: 6 B 77/95 = NVwZ-RR 1997, 132 (133): „Vom Sinn und Zweck der gesetzlichen Regelung her ist es gerechtfertigt, auch dann von einer ,Gestaltung، des Ausgangsbescheids zu sprechen, wenn dieser von dem Widerspruchsbescheid ohne inhaltliche Änderungen bekräftigt worden ist“.

61 Happ, in: Eyermann, VwGO, 15. Aufl. 2019, § 79, Rn. 5 unter Verweis auf BVerwG, Urt. v. 23. 8. 2011, Az: 9 C 2/11 = NVwZ 2012, 506, Rn. 20.

62 Vgl. Kastner, in: Fehling/Kastner/Störmer, Verwaltungsrecht, 4. Aufl. 2016, § 79 VwGO, Rn. 9. 63 Vgl. BVerwG, Beschl.v. 30.4.2010, Az.: 9 B 42/10 = NVwZ-RR 2010, 550; s. auch BVerwG, Urt. v. 18.5.1990, Az.: 8 C 48/88 = NJW-RR 1990, 1351 (1352): „Ob die Behörde eine derartige Änderung mit im Prozeß beachtlicher mängelheilender Wirkung vornehmen, namentlich eine Ermessensentscheidung noch während des Verwaltungsstreitverfahrens ergänzen oder nachholen, darf, ergibt sich in erster Linie aus dem jeweiligen Fachrecht.“

Jens Milker 
der Widerspruchsbescheid stellt seinem Wesen nach einen Verwaltungsakt dar. ${ }^{64}$ Da dies aber einen an sich einheitlichen Sachverhalt unnötig aufteilen würde, betrachtet der Gesetzgeber gemäß § 79 I Nr. 1 VwGO Ausgangs- und Widerspruchsbescheid grundsätzlich als (prozessuale) Einheit. ${ }^{65}$ Er stellt damit klar, dass nicht etwa zwei Klagen gegen den Ausgangs- und den Widerspruchsbescheid erhoben werden müssen. ${ }^{66}$ Natürlich kann aber auch der Ausgangsverwaltungsakt alleiniger Gegenstand der Anfechtungsklage sein, wenn von vornherein kein Widerspruchsverfahren durchzuführen war oder ein Fall des §75 VwGO (sog. Untätigkeitsklage) vorliegt. Dann existiert von Beginn an kein Widerspruchsbescheid, der dem Verwaltungsakt seine finale Gestalt geben konnte. Eine gesonderte ausdrückliche Regelung für diese Fälle hat der Gesetzgeber nicht vorgesehen, sie dürften allerdings ebenfalls unter § 79 I Nr. 1 VwGO fallen.

\section{b) Der Abhilfe- oder Widerspruchsbescheid als alleiniger Gegenstand der Anfechtungsklage}

27 In gesetzlich festgelegten Ausnahmefällen kann auch der Abhilfe- oder Widerspruchsbescheid alleiniger Gegenstand der Anfechtungsklage sein. Denn in bestimmten Konstellationen ist es für den Kläger sinnvoll, ausschließlich gegen den Abhilfe- oder Widerspruchsbescheid vorzugehen.

\section{aa) Isolierte Anfechtung des Abhilfe-/Widerspruchsbescheids bei „erstmaliger Beschwer“ (\$ 79 I Nr. 2 VwG0)}

28 Ausweislich dieser Norm ist der Widerspruchs- (§73 VwGO) oder der Abhilfebescheid (§ 72 VwGO) dann alleiniger Gegenstand der Anfechtungsklage, wenn er „erstmalig eine Beschwer enthält“. Dies kann nur dann der Fall sein, wenn der Ausgangsverwaltungsakt für den Adressaten oder einen Dritten begünstigend ist und im Abhilfe- oder Widerspruchsverfahren zum Nachteil des Begünstigten abgeändert wird. ${ }^{67}$ In dieser Situation wäre es für den Begünstigten unzweckmäßig, auch den Ausgangsverwaltungsakt anzugreifen, da er damit zum einen eine bereits erreichte für ihn günstige Rechtsposition wieder zur Disposition stellen würde und zum anderen eine Anfechtungsklage hinsichtlich des Aus-

64 Vgl. statt vieler: Möstl, in: Posser/Wolff, VwGO, 47. Ed., Stand: 1.10.2018, § 79, Rn. 1.

65 Vgl. BVerwG, Urt. v. 23.08. 2011, Az.: 9 C 2/11 = NVwZ 2012, 506, Rn. 20; Urt. v. 21.10.1964, Az.: V C 14.63 = BeckRS 1964, 30422805; Möstl, in: Posser/Wolff, VwGO, 47. Ed., Stand:1.10.2018, § 79, Rn. 15.

66 Möstl, in: Posser/Wolff, VwGO, 47. Ed., Stand: 1.10.2018, § 79, Rn. 2.

67 Brenner, in: Sodan/Ziekow, VwGO, 5. Aufl. 2018, § 79, Rn. 26.

Jens Milker 
gangsverwaltungsaktes mangels Beschwer (s. näher zur Klagebefugnis Rn. 281ff.) unzulässig wäre. ${ }^{68}$ Daher kann sich in diesen Konstellationen eine Anfechtungsklage nur gegen den Abhilfe- oder Widerspruchsbescheid richten, ein Wahlrecht steht dem Kläger damit schon von vornherein nicht zu. ${ }^{69}$

Erfasst sind daher vor allem die Fälle einer sog. Drittanfechtung bei Ver- 29 waltungsakten mit Doppelwirkung. Dies sind Verwaltungsakte, die für einen Beteiligten begünstigend sind, aber gleichzeitig für einen anderen Beteiligten belastend wirken. ${ }^{70}$ Sie kommen insbesondere in baurechtlichen Nachbarstreitigkeiten vor. Der Begriff der Drittanfechtung folgt daraus, dass der Verwaltungsakt nicht von seinem Adressaten angefochten wird, sondern von einem Dritten. Probleme treten bei dieser Konstellation regelmäßig im Rahmen der Klagebefugnis auf, da dort eine Betroffenheit in eigenen Rechten erforderlich ist. In dieser Situation ist es üblicherweise so, dass die Behörde einen für den Adressaten begünstigenden Verwaltungsakt (z. B. eine Baugenehmigung) erlässt, der aber für Dritte (z. B. die Nachbarn) belastend wirkt (etwa durch Immissionen, die von der baulichen Anlage ausgehen). Erhebt nun ein Nachbar gegen die dem Bauherren erteilte Baugenehmigung Widerspruch und hilft die Ausgangsbehörde diesem ab (§ 72 VwGO) oder gibt die Widerspruchsbehörde dessen Widerspruch statt ( $73 \mathrm{VwGO}$ ), ist es für den Bauherren möglich, nun isoliert gegen den Abhilfe- oder Widerspruchsbescheid im Wege der Anfechtungsklage vorzugehen. Auf diese Weise bleibt der ursprüngliche für ihn begünstigende (Ausgangs-)Verwaltungsakt unberührt und es muss keine Verpflichtungsklage auf (erneute) Erteilung der Baugenehmigung erhoben werden. Der für den Kläger begünstigende Ausgangsverwaltungsakt lebt dann wieder auf.

Darüber hinaus sind ebenso noch Konstellationen denkbar, in denen die 30 Rechtsstellung eines Dritten durch den Ausgangsverwaltungsakt in keiner Weise berührt wird, die Regelung im Abhilfe- oder Widerspruchsbescheid allerdings in belastender Weise auf ihn wirkt. ${ }^{71}$

68 Vgl. BVerwG, Urt. v. 11.05.1962, Az.: VII C 27/61 = BeckRS 9998, 181335; Brenner, in: Sodan/ Ziekow, VwGO, 5. Aufl. 2018, § 79, Rn. 26.

69 Brenner, in: Sodan/Ziekow, VwGO, 5. Aufl. 2018, § 79, Rn. 26.: „obligatorischer Natur“; FunkeKaiser, in: Bader/Funke-Kaiser/Stuhlfauth/von Albedyll, VwGO, 7. Aufl. 2018, §79, Rn. 8: Anfechtung des Ausgangsbescheids sei hier wegen fehlender Beschwer „undenkbar“; a. A. Happ, in: Eyermann, VwGO, 15. Aufl. 2019, § 79, Rn. 16.

70 Puttler, in: Sodan/Ziekow, VwGO, 5. Aufl. 2018, § 80a, Rn. 25; diese Situation ist nunmehr in $\S 80$ a I, II VwGO umschrieben.

71 Sodan, in: Sodan/Ziekow, VwGO, 5. Aufl. 2018, § 79, Rn. 29: „Von einer solchen Konstellation ist z. B. auszugehen, sobald eine den Nachbarn in seinen Rechten verletzende Baugenehmigung von der Ausgangsbehörde versagt, auf den Widerspruch des Adressaten hin aber von der Wi- 
31 Der erstmalig Beschwerte „soll“72 vor Erlass des Abhilfe- oder Widerspruchsbescheids gemäß $\S 71$ VwGO angehört werden. Eine daher regelmäßig gebotene Anhörung kann insbesondere ausnahmsweise dann unterbleiben, wenn die Fallgruppen des § 28 II, III VwVfG einschlägig sind. ${ }^{73}$ Gemäß § 68 I 2 Nr. 2 VwGO ist gegen den Abhilfe- oder Widerspruchsbescheid kein erneutes Vorverfahren durchzuführen. Dabei ist der vorgenannten Norm der allgemeine Rechtsgedanke zu entnehmen, dass immer nur ein Vorverfahren durchzuführen ist. Es kann demzufolge unmittelbar innerhalb der Frist des §74 I 2 VwGO Klage erhoben werden. Klagegegner wäre dann nach allgemeinen Regeln - bei Abhilfebescheid - die Ausgangs- oder - bei Widerspruchsbescheid - die Widerspruchsbehörde (§ 78 I Nr. 2 VwGO) bzw. deren Rechtsträger (§ 78 I Nr. 1 VwGO). ${ }^{74}$

\section{bb) Isolierte Anfechtung des Widerspruchsbescheids bei „zusätzlicher und selbstständiger Beschwer“ ( 79 II VwG0)}

32 Gemäß §79 II 1 VwGO kann der Widerspruchsbescheid auch dann alleiniger Gegenstand der Anfechtungsklage sein, wenn er „,im Vergleich zum ursprünglichen Verwaltungsakt eine zusätzliche, selbstständige Beschwer“ enthält. Im Gegensatz zu § 79 I Nr. 1 VwGO enthält hier schon der Ausgangsbescheid eine Beschwer, sodass dem Kläger insoweit ein Wahlrecht zukommt, ob er im Wege der „Einheitsklage“"75 nach § 79 I Nr. 1 VwGO (Ausgangs- und Widerspruchsbescheid) oder nach $\S 79$ II VwGO (nur Widerspruchsbescheid) vorgeht. ${ }^{76}$ Für den Kläger wird es in der Regel zweckmäßig sein, isoliert den Widerspruchsbescheid anzugreifen, wenn er nur gegen die Verschärfung vorgehen möchte - etwa weil ein weiteres Vorgehen gegen den Ausgangsbescheid aussichtslos erscheint - oder erreichen will, dass die Widerspruchsbehörde ihr Ermessen erneut (fehlerfrei) ausübt. ${ }^{77}$

derspruchsbehörde erteilt wird“; siehe zu weiteren Fallgruppen auch Happ, in: Eyermann, VwGO, 15. Aufl. 2019, § 79, Rn. 14.

72 Damit unterscheidet sich die Rechtsfolge etwa von § 28 I VwVfG und seinen landesrechtlichen Pendants (,ist [...] Gelegenheit zur Äußerung zu geben“).

73 Kastner, in: Fehling/Kastner/Störmer, Verwaltungsrecht, 4. Aufl. 2016, § 71 VwGO, Rn. 5.

$74 \S 79$ II 3 VwGO findet keine Anwendung.

75 Vgl. etwa Möstl, in: Posser/Wolff, VwGO, 47. Ed., Stand: 1.10.2018, § 79, Rn. 15.

76 Pietzcker, in: Schoch/Schneider/Bier, VwGO, 36. EL Februar 2019, § 79 VwGO, Rn. 11; in der Literatur wird § 79 II VwGO in Bezug auf einen Abhilfebescheid für nicht anwendbar gehalten, vgl. Möstl, in: Posser/Wolff, VwGO, 47. Ed., Stand:1.10.2018, § 79, Rn. 20. Dies wird wesentlich durch den Wortlaut (,Widerspruchsbescheid“) und den systematischen Vergleich mit § 79 I Nr. 1 VwGO gestützt.

77 Pietzcker, in: Schoch/Schneider/Bier, VwGO, 36. EL Februar 2019, § 79 VwGO, Rn. 11.

Jens Milker 
Einen Hauptanwendungsfall der Vorschrift stellt die Reformatio in Peius (sog. „Verböserung“) dar (näher dazu Rn. 344 ff.). Gemeint sind damit Situationen, in denen im Rahmen des Widerspruchsverfahrens gegen einen für den Adressaten belastenden Verwaltungsakt dessen Situation verschlechtert wird; die Behörde also eine weitere Belastung ausspricht. ${ }^{78}$ In $\S 79$ II VwGO sind allerdings keine Aussagen zur materiell-rechtlichen Zulässigkeit der Reformatio in Peius getroffen worden; darin wird nur der prozessuale Umgang mit einer derartigen Situation geregelt. ${ }^{79}$

Beispiel 6: Gastwirtin Renate erhält einen Auflagenbescheid gemäß $\S 5$ GastG, dass sie ihre Gaststätte von 01:00 Uhr bis 6:00 Uhr zu schließen hat (Sperrzeit). Dagegen erhebt sie Widerspruch. Die Widerspruchsbehörde verlängert die Sperrzeit um zwei Stunden, sodass die Gaststätte schon um 23:00 Uhr schließen muss. Hier wäre es unter Umständen (aus anwaltlicher Sicht) zweckmäßig, nur gegen den Widerspruchsbescheid vorzugehen, wenn der Ausgangsbescheid mit großer Wahrscheinlichkeit rechtmäßig ist. Aus richterlicher Sicht wäre dann das Begehren der Klägerin auszulegen ( $(88 \mathrm{VwGO})$.

In $\S 79$ II 2 VwGO ist zudem ein besonderer Fall der zusätzlichen und selbst- 35 ständigen Beschwer geregelt bzw. fingiert. ${ }^{80}$ Demnach „gilt“ als eine zusätzliche Beschwer auch die Verletzung einer wesentlichen Verfahrensvorschrift, sofern der Widerspruchsbescheid auf dieser Verletzung beruht.

In Rechtsprechung und Literatur ist allgemein anerkannt, dass § 68 I 2 Nr. 236 VwGO auch auf die Fälle des $§ 79$ II VwGO (unmittelbare) Anwendung findet. ${ }^{81}$ Eines Vorverfahrens bedarf es demnach auch hier nicht. Gleichsam ist $\S 71$ VwGO - nach Auffassung in der Literatur - auch in diesen Fällen anzuwenden, ${ }^{82}$ obwohl der Wortlaut eher einen ausschließlichen Bezug zu § 79 I Nr. 2 VwGO nahe legt. Insgesamt kann demnach hier auch innerhalb der Frist des § 74 I 2 VwGO unmittelbar Klage erhoben werden. Der Klagegegner ist gemäß § 79 II 3 i.V.m. $\S 78 \mathrm{I}$, II VwGO zu bestimmen.

78 Vgl. dazu Pietzcker, in: Schoch/Schneider/Bier, VwGO, 36. EL Februar 2019, § 79 VwGO, Rn. 13 mit Beispielen aus der Rechtsprechung.

79 Vgl. BVerwG, Urt. v. 12.11.1976, Az.: IV C 34/75 = NJW 1977, 1894; Pietzcker, in: Schoch/ Schneider/Bier, VwGO, 36. EL Februar 2019, § 79 VwGO, Rn. 13.

80 Pietzcker, in: Schoch/Schneider/Bier, VwGO, 36. EL Februar 2019, § 79 VwGO, Rn. 11.

81 Vgl. nur Funke-Kaiser, in: Bader/Funke-Kaiser/Stuhlfauth/von Albedyll, VwGO, 7. Aufl. 2018, $\S 68, \mathrm{Rn} .22$.

82 Vgl. Kastner, in: Fehling/Kastner/Störmer, Verwaltungsrecht, 4. Aufl. 2016, § 71 VwGO, Rn. 4. 


\section{c) Vorgehen in der Klausur}

37 Zusammenfassend bleibt festzuhalten, dass der Gesetzgeber grundsätzlich davon ausgeht, dass Ausgangs- und Widerspruchsbescheid gemeinsam angegriffen werden (müssen). Sollte dieser Regelfall in einer Klausursituation vorliegen, sind Ausführungen zu § 79 I Nr. 1 VwGO üblicherweise nicht erforderlich. Sofern sich aus dem Klagebegehren allerdings ergibt, dass sich die Klage ausschließlich gegen den Widerspruchsbescheid richten soll, dann muss zwingend im Rahmen der Statthaftigkeit eine Auseinandersetzung mit den in $\S 79$ I Nr. 2, II VwGO angelegten Ausnahmekonstellationen erfolgen. ${ }^{83}$

\section{Der Begriff des Verwaltungsakts (Jens Milker)}

38 Der Verwaltungsakt ist die zentrale - aber natürlich nicht die einzige - behördliche Handlungsform. Nachdem überblicksartig auf die Funktionen des Verwaltungsakts eingegangen wurde (1.), werden die Begriffsmerkmale des Verwaltungsakts vertieft erläutert (2.). Abschließend werden die prozessualen Folgen aufgezeigt, wenn Definitionsmerkmale einmal nicht erfüllt sein sollten (3.).

\section{Funktionen des Verwaltungsakts}

39 Mit ihm kann die Behörde Einzelfälle verbindlich einseitig regeln, sodass durch die damit einhergehende behördliche Subsumtion eine Individualisierungs- und Klarstellungsfunktion erfüllt wird. ${ }^{84}$

40 Da ein Verwaltungsakt - ähnlich wie ein Urteil - auch nach Maßgabe des Verwaltungsvollstreckungsrechts vollstreckt werden kann, kommt ihm insbesondere eine sog. Titelfunktion $\mathrm{zu}^{85}$ Gleichzeitig schafft ein Verwaltungsakt für Behörde und Bürger Rechtssicherheit, da er - sofern einmal wirksam erlassen nur unter bestimmten Voraussetzungen vom Bürger (durch Widerspruch und

83 Vgl. in diesem Sinne auch Schildheuer/Kues, Verwaltungsprozessrecht, 4. Aufl. 2018, Rn. 77. 84 Vgl. Stelkens, in: Stelkens/Bonk/Sachs, VwVfG, 9. Aufl. 2018, § 35, Rn. 31; Ramsauer, in: Kopp/ Ramsauer, VwVfG, 19. Aufl. 2018, § 35, Rn. 10: „Konkretisierungs- und Umsetzungsfunktion“.

85 Vgl. Stelkens, in: Stelkens/Bonk/Sachs, VwVfG, 9. Aufl. 2018, § 35, Rn. 39 ff.; Ramsauer, in: Kopp/Ramsauer, VwVfG, 19. Aufl. 2018, §35, Rn. 9, 11f. (mit Ausnahme bei feststellenden Verwaltungsakten).

Jens Milker 
Klage) oder von der Behörde (durch Aufhebung; vgl. insbesondere §§ $48 \mathrm{ff}$. VwVfG, s. dazu ausführlich Rn. $836 \mathrm{ff}$.) beseitigt werden kann. ${ }^{86}$

Schließlich bestimmt sich nach der Einordnung des behördlichen Handelns als Verwaltungsakt auch die statthafte Rechtschutzform (zum verwaltungsaktbezogenen Rechtsschutz bereits näher § 1 Rn. 238; § 2 Rn. 4 ff., $\S 3$ Rn. 2ff.), ${ }^{87}$ nämlich das „Wie“ des Rechtsschutzes. Ob überhaupt Rechtsschutz gewährt wird, hängt hingegen nicht (mehr) vom Vorliegen eines Verwaltungsakts ab. ${ }^{88}$ Die Frage, ob ein Verwaltungsakt gegenständlich ist, gegen den sich der Kläger wendet oder dessen Erlass der Kläger begehrt, ist dennoch eine zentrale prozessuale Weichenstellung für die Klausurbearbeitung und die Praxis, da damit insbesondere die Einhaltung von Fristen verbunden ist (vgl. §§ 68ff. VwGO). ${ }^{89}$ Der Begriff des Verwaltungsakts ist sowohl in Landes-VwVfG als auch in dem VwVfG des Bundes (legal-)definiert. ${ }^{90}$ Bei der Prüfung der statthaften Klageart ist allerdings insoweit immer - unabhängig davon, ob eine Landes- oder Bundesbehörde gehandelt hat - das VwVfG des Bundes heranzuziehen (s. bereits Rn. 10). ${ }^{91} \mathrm{Im}$ Übrigen sind die Landes-VwVfG und das VwVfG des Bundes in ihrem Anwendungsbereich zu differenzieren (näher dazu § 1 Rn. 95 ff. und § 2 Rn. 621).

\section{Merkmale eines Verwaltungsakts}

Gemäß $\S 35$ Satz 1 VwVfG ist ein Verwaltungsakt jede Verfügung, Entscheidung 42 oder andere hoheitliche Maßnahme, die eine Behörde zur Regelung eines Einzelfalls auf dem Gebiet des öffentlichen Rechts trifft und die auf unmittelbare Rechtswirkung nach außen gerichtet ist. Allgemeinverfügung ist ein Verwaltungsakt, der sich an einen nach allgemeinen Merkmalen bestimmten oder bestimmbaren Personenkreis richtet oder die öffentlich-rechtliche Eigenschaft einer Sache oder ihre Benutzung durch die Allgemeinheit betrifft (§ 35 Satz 2 VwVfG).

86 Vgl. allgemein zur Rechtssicherheit: Stelkens, in: Stelkens/Bonk/Sachs, VwVfG, 9. Aufl. 2018, $\S 35$, Rn. 34 ff.; speziell zur „Rechtsgrundfunktion“: Stelkens, in: Stelkens/Bonk/Sachs, VwVfG, 9. Aufl. 2018, §35, Rn. 42.

87 Ramsauer, in: Kopp/Ramsauer, VwVfG, 19. Aufl. 2018, § 35, Rn. 13.

88 Vgl. zu der insoweit abweichenden früheren Rechtslage: Stelkens, in: Stelkens/Bonk/Sachs, VwVfG, 9. Aufl. 2018, § 35, Rn. 47.

89 Vgl. Ramsauer, in: Kopp/Ramsauer, VwVfG, 19. Aufl. 2018, § 35, Rn. 13.

90 Dabei haben $\S 31$ SGB X und $\S 118$ AO denselben Wortlaut, vgl. Sodan, in: Sodan/Ziekow, VwGO, 5. Aufl. 2018, § 42, Rn. 99.

91 Vgl. Sodan, in: Sodan/Ziekow, VwGO, 5. Aufl. 2018, § 42, Rn. 99 m.w. N.; Stelkens, in: Stelkens/ Bonk/Sachs, VwVfG, 9. Aufl. 2018, § 35, Rn. 48; s. im Ergebnis auch BVerwG, Urt. v. 26.9.1996, Az.: 2 C 39.95 = NJW 1997, 1248 (1249): „Begriff des Verwaltungsakts i.S. des § 42 I VwGO, § 35 S. 1 VwVfG“. 


\section{a) „Verfügung, Entscheidung oder andere hoheitliche Maßnahme“}

43 Den Anfang der Prüfung bildet das Merkmal der „hoheitlichen Maßnahme“. Die Begriffe „Verfügung“ und „Entscheidung“ sind nur spezielle Arten hoheitlicher Handlungsformen und haben keine eigenständige Bedeutung. ${ }^{92}$

\section{aa) Maßnahme}

44 Der Begriff „Maßnahme“ erfasst jedes Handeln mit Erklärungsgehalt. ${ }^{93}$ Sie besteht zunächst aus dem Vorgang der (inneren) Willensbildung in Gestalt eines Entscheidungs- oder Regelungswillens und anschließender Willensäußerung der Behörde (z.B. durch Erstellung eines Bescheids), die schließlich in die Bekanntgabe (§ $41 \mathrm{VwVfG}$ ) mündet (z. B. Übersendung des Bescheids an den Adressaten, s. dazu näher Rn. 120 ff.). ${ }^{94}$ Dahingehend schreibt $§ 37$ II 1 VwVfG vor, dass ein Verwaltungsakt schriftlich, elektronisch, mündlich oder in anderer Weise erlassen werden kann. An die unterschiedlichen Erlassarten knüpfen dann § 39 (Begründung) und §41 VwVfG (Bekanntgabe) unterschiedliche Rechtsfolgen (näher dazu Rn. 157 ff., 638ff.), sodass der Einordnung ein nicht unerhebliches Gewicht in der rechtlichen Prüfung zukommen kann. Regelfall dürfte aber - auch aufgrund der nur langsam voranschreitenden Digitalisierung in der Verwaltung der schriftliche Verwaltungsakt sein. Der „elektronische Verwaltungsakt“ scheint insoweit (noch) eine untergeordnete Rolle spielen. ${ }^{95}$

45 Maßgeblich für die Auslegung behördlichen Verhaltens ist der objektive Erklärungswert, also wie es vor allem der Adressat bei verständiger Würdigung unter Einbeziehung der für ihn erkennbaren Umstände interpretieren musste. ${ }^{96}$ Hier sind die $\S \S 133,157$ BGB in analoger Anwendung maßgeblich. ${ }^{97}$ Dahingehend

92 Vgl. Stelkens, in: Stelkens/Bonk/Sachs, VwVfG, 9. Aufl. 2018, § 35, Rn. 69; von Alemann/ Scheffczyk, in: Bader/Ronellenfitsch, VwVfG, 42. Ed., Stand: 1.1.2019, § 35, Rn. 115 ff.; Müller, in: Huck/Müller, VwVfG, 2. Aufl. 2016, § 35, Rn. 29; W. R. Schenke, in: Kopp/Schenke, VwGO, 25. Aufl. 2019, Anh. § 42, Rn. 13: Sie können allerdings zur näheren Konkretisierung des Merkmals der „hoheitlichen Maßnahme“ genutzt werden.

93 Vgl. Stelkens, in: Stelkens/Bonk/Sachs, VwVfG, 9. Aufl. 2018, § 35, Rn. 69: ,verwaltungsrechtliche Willenserklärung“.

94 Stelkens, in: Stelkens/Bonk/Sachs, VwVfG, 9. Aufl. 2018, § 35, Rn. 70.

95 Vgl. zur Ersetzung der gesetzlich vorgeschriebenen Schriftform durch die elektronische Form: Stelkens, in: Stelkens/Bonk/Sachs, VwVfG, 9. Aufl. 2018, § 37, Rn. $117 \mathrm{f}$.

96 St. Rspr., vgl. etwa BVerwG, Urt. v. 15.6.2016, Az.: 8 C 5/15 = NVwZ 2017, 326, Rn. 20; BVerwG, Urt. v. 22.3.2012, Az.: 1 C 3/11 = NVwZ-RR 2012, 529, Rn. 24 m.w. N.; Stelkens, in: Stelkens/Bonk/ Sachs, VwVfG, 9. Aufl. 2018, § 35, Rn. 71.

97 Vgl. BVerwG, Urt. v. 15.6.2016, Az.: 8 C 5/15 = NVwZ 2017, 326, Rn. 20; Stelkens, in: Stelkens/ Bonk/Sachs, VwVfG, 9. Aufl. 2018, § 35, Rn. 71 m.w. N. aus der Rspr. 
können Unklarheiten nicht durch bloß vernünftig erscheinende Ergebnisse korrigiert werden, ${ }^{98}$ sondern gehen zum Nachteil der Verwaltung. ${ }^{99}$ Die inhaltliche Auslegung eines Verwaltungsakts orientiert sich am Wortlaut seines ,verfügenden Teils“100 (auch als „Tenor“101 , „Spruch“102 oder „Verfügungssatz“103 bezeichnet) ${ }^{104}$ unter ergänzender Heranziehung seiner Begründung. ${ }^{105}$ Insbesondere konkludentes Verhalten kann daher auch einen Verwaltungsakt darstellen, ${ }^{106}$ der „in anderer Weise“ (vgl. § 37 II 1 VwVfG) erlassen wird. ${ }^{107}$

Beispiel: Das Handzeichen eines Polizeibeamten zum Zwecke der Verkehrsregelung. ${ }^{108}$

So können auch etwa Erstattungs- bzw. Rückforderungsbescheide (z. B. in Be- 47 zug auf Subventionen) dahingehend ausgelegt werden, dass sie gleichzeitig konkludent die Aufhebung des früheren Bewilligungsbescheides enthalten, der ansonsten noch einen Rechtsgrund zum Behaltendürfen darstellen würde. ${ }^{109}$ Ebenso kann etwa auch die Auszahlung von Geld eine konkludente Erklärung über die Berechtigung der Zahlung enthalten. ${ }^{110}$ Wesentlich ist dabei, dass dem

98 BayVGH, Urt. v. 22.5.1997, Az.: 22 B 96. 3646 und 3732 = LKV 1998, 67; Stelkens, in: Stelkens/ Bonk/Sachs, VwVfG, 9. Aufl. 2018, § 35, Rn. 71.

99 St. Rspr., vgl. etwa BVerwG, Urt. v. 22.3.2012, Az.: 1 C 3/11 = NVwZ-RR 2012, 529, Rn. 24 m.w. N. 100 Vgl. § 41 IV 1 VwVfG.

101 So etwa von Alemann/Scheffczyk, in: Bader/Ronellenfitsch, VwVfG, 42. Ed., Stand:1.1.2019, $\S 35, \mathrm{Rn} .46$.

102 Vgl. BVerfG, Beschl. v. 9.1.1991, Az.: 1 BvR 207/87 = NJW 1991, 1878.

103 Vgl. BVerwG, Urt. v. 5.11.2009, Az.: 4 C 3/09 = NVwZ 2010, 133.

104 Vgl. insgesamt auch Stelkens, in: Stelkens/Bonk/Sachs, VwVfG, 9. Aufl. 2018, § 35, Rn. 143. 105 Stelkens, in: Stelkens/Bonk/Sachs, VwVfG, 9. Aufl. 2018, § 35, Rn. 76.

106 Vgl. Barczak, JuS 2018, 238 (244); Stelkens, in: Stelkens/Bonk/Sachs, VwVfG, 9. Aufl. 2018, $\S 35$, Rn. 81; Schwarz, in: Fehling/Kastner/Störmer, Verwaltungsrecht, 4. Aufl. 2016, § 35 VwVfG, Rn. 52 m.w. N.; von Alemann/Scheffczyk, in: Bader/Ronellenftisch, VwVfG, 42. Ed., Stand: 1.1. 2019, § 35, Rn. 119.

107 Vgl. HambOVG, Urt. v. 25.7.2017, Az.: 3 Bf 96/15 = BeckRS 2017, 131008, Rn. 39; Barczak, JuS 2018, 238 (244).

108 Ramsauer, in: Kopp/Ramsauer, VwVfG, 19. Aufl. 2018, § 35, Rn. 61.

109 Vgl. BVerwG, Urt. v. 19.3.1992, Az.: 5 C 41/88 = NVwZ-RR 1992, 423 m.w. N.; s. weiter zur stillschweigenden Aufhebung des Bewilligungsbescheids mit Rückforderung der Subvention: BVerwG, Urt. v. 13.12.1984, Az.: 3 C 79/82 = NVwZ 1985, 488 (489); BremOVG, Beschl.v. 18.11.2015, Az.: 2 B 221/15 = BeckRS 2015, 55026, Rn. 15; s. auch mit weiteren Beispielen: Ramsauer, in: Kopp/ Ramsauer, VwVfG, 19. Aufl. 2018, §35, Rn. 61.

110 Vgl. HambOVG, Urt. v. 25.7.2017, Az.: 3 Bf 96/15 = BeckRS 2017, 131008, Rn. 37: „Wird eine Leistung beantragt, und erfolgt daraufhin eine Auszahlung der Leistung, ohne dass zuvor eine ausdrückliche Bewilligung vorgenommen wurde, so kommt es in Betracht, die Zahlung nicht lediglich als einen schlicht-hoheitlichen Realakt, sondern (auch) als konkludenten Verwal- 
Verhalten ein hinreichend bestimmter Erklärungs- bzw. Regelungsgehalt entnommen werden kann und die übrigen Voraussetzungen des $§ 35$ VwVfG erfüllt sind. ${ }^{111}$

Beispiel: A wird am 21. Juni 2018 wegen drohender Obdachlosigkeit für die Dauer von drei Monaten in eine (Privat-)Wohnung durch die zuständige Ordnungsbehörde eingewiesen. Da zwischenzeitlich ein Platz in einer städtischen Obdachlosenunterkunft frei geworden ist, gibt die Behörde dem A am 3. Juli 2018 auf, die „Wohnung zu räumen““ ${ }^{112}$ Hier kann der behördlichen „Räumungsverfügung“ unter Umständen gleichzeitig entnommen werden, dass die zuvor erfolgte (und hier noch wirksame) Einweisung notwendigerweise jedenfalls konkludent mit aufgehoben wird, da diese ansonsten den Aufenthalt des A in der Wohnung formell legalisieren würde und dementsprechend Eingriffsmaßnahmen der Behörde ausschlösse. ${ }^{113}$

\section{bb) „Hoheitlich“}

49 Der Begriff der „hoheitlichen“ Maßnahme hat nach zutreffender Auffassung eine zweifache Bedeutung. ${ }^{114}$ Diese kann sich - schon aufgrund der eigenständigen Erwähnung des Merkmals - nicht in der Bedeutung ,auf dem Gebiet des öffentlichen Rechts“ erschöpfen. ${ }^{115}$ Zunächst kennzeichnet das Merkmal damit insbesondere die Einseitigkeit der Maßnahme in Abgrenzung zum öffentlich-rechtlichen Vertrag, ${ }^{116}$ der zwei korrespondierende Willenserklärungen voraussetzt (vgl. §54ff. VwVfG) und bei dem sich die Beteiligten daher auf Gleichordnungsebene gegenüberstehen. ${ }^{117}$ Als einseitig können demzufolge auch mitwirkungs-

tungsakt anzusehen. Denn die Zahlung schließt dann die Entscheidung ein, ob und in welcher Höhe gezahlt werden soll. Mit ihr wird gleichzeitig festgestellt, dass dem Leistungsempfänger der der Zahlung zugrunde liegende Anspruch zusteht. Dies kann jedenfalls und zumal dann gelten, wenn der Auszahlung [...] eine behördliche Prüfung vorausgeht und dies für den Leistungsempfänger erkennbar ist“ (dazu ausführlich unten Ziffer 2. d) bb)).

111 Barczak, JuS 2018, 238 (244); Stelkens, in: Stelkens/Bonk/Sachs, VwVfG, 9. Aufl. 2018, § 35, Rn. 81; s. dazu auch VGH BW, Urt. v. 25.5.1987, Az.: 11 S 1699/85 = NVwZ 1988, 184 (185).

112 Vgl. Barczak, JuS 2018, 238 (244).

113 Vgl. im Ergebnis auch Barczak, JuS 2018, 238 (244).

114 Stelkens, in: Stelkens/Bonk/Sachs, VwVfG, 9. Aufl. 2018, § 35, Rn. $104 \mathrm{ff.}$

115 Vgl. Windoffer, in: Mann/Sennekamp/Uechtritz, VwVfG, 1. Aufl. 2014, § 35, Rn. 37; Schwarz, in: Fehling/Kastner/Störmer, Verwaltungsrecht, 4. Aufl. 2016, § 35 VwVfG, Rn. 83; a. A. Ramsauer, in: Kopp/Ramsauer, VwVfG, 19. Aufl. 2018, § 35, Rn. 59; Müller, in: Huck/Müller, VwVfG, 2. Aufl. 2016, § 35, Rn. 29.

116 Dies bereits aus den Begriffen „Verfügung, Entscheidung, Maßnahme“ folgernd: Ramsauer, in: Kopp/Ramsauer, VwVfG, 19. Aufl. 2018, § 35, Rn. 59 f.

117 Vgl. W. R. Schenke, in: Kopp/Schenke, VwGO, 25. Aufl. 2019, Anh. § 42, Rn. 14; von Alemann/ Scheffczyk, in: Bader/Ronellenfitsch, VwVfG, 42. Ed., Stand: 1.1.2019, § 35, Rn. 120 ff.; Voßkuhle/ Kaufhold, JuS 2011, 34 (35); Schwarz, in: Fehling/Kastner/Störmer, Verwaltungsrecht, 4. Aufl. 
bedürftige Maßnahmen eingeordnet werden, bei denen der Adressat an dem Verwaltungsverfahren beteiligt werden muss (z.B. durch das Erfordernis einer Antragsstellung), da damit zwar der Erlass verhindert, aber nicht auf den Inhalt Einfluss genommen werden kann. ${ }^{118}$ Es muss sich konsequenterweise auch um eine Maßnahme in einem Über-/Unterordnungsverhältnis handeln, ${ }^{119}$ also grundsätzlich „Ausdruck der ,Andersordnung“ von Staat und Bürger“ sein. ${ }^{120}$ Dann äußert sich die Hoheitlichkeit darin, dass zumindest hinsichtlich der konkreten Maßnahme eine besondere Befugnis der Verwaltung besteht, die dem Adressaten in dieser Form ohne weiteres nicht zustehen kann. ${ }^{121}$ Die Aufrechnung etwa ist mangels hoheitlichem Element daher kein Verwaltungsakt, sondern die Ausübung eines schuldrechtlichen Gestaltungsrechts, das ebenso dem Bürger potentiell zur Verfügung steht.. ${ }^{122}$

Insgesamt ist vor allem dann keine hoheitliche Maßnahme gegeben, wenn 50 eine entsprechende Willenserklärung mit gleichen Wirkungen auch von Privaten abgegeben werden könnte. ${ }^{123}$ Dies ist zum Beispiel der Fall bei privatrechtlichem Handeln oder auch der Kündigung öffentlich-rechtlicher Verträge. ${ }^{124}$ Ein Über-/ Unterordnungsverhältnis fehlt ebenso grundsätzlich bei Maßnahmen zwischen

2016, § 35 VwVfG, Rn. 83; Windoffer, in: Mann/Sennekamp/Uechtritz, VwVfG, 1. Aufl. 2014, § 35, Rn. 37.

118 Voßkuhle/Kaufhold, JuS 2011, 34 (35).

119 Vgl. BSG, Urt. v. 9. Mai 1957, Az.: 4 RJ 228/55 = BeckRS 1957, 00099, Rn. 21; BeckRS 1985, 5642, Rn. 15; Urt. v. 2. 2.1978, Az.: 12 RK 29/77 = BeckRS 1978, 388, Rn. 15; NJW-RR 1994, 788 (790); OVG SH, Urt. v. 22.12.1999, Az.: 2 L 208/98 = BeckRS 2000, 21738, Rn. 38; VG Mainz, Urt. v. 22.2. 2018, Az.: 1 K 862/17.MZ = BeckRS 2018, 18583, Rn. 24; Windoffer, in: Mann/Sennekamp/Uechtritz, VwVfG, 1. Aufl. 2014, § 35, Rn. 37; kritisch Emmerich-Fritsche, NVwZ 2006, 762 (763): „Mit einem demokratisch-republikanischen Staatsverständnis, welches die Menschen nicht als Untertanen, sondern als (selbstbestimmte) Bürger wahrnimmt, ist die Subordinationslehre nicht mehr vereinbar".

120 Stelkens, in: Stelkens/Bonk/Sachs, VwVfG, 9. Aufl. 2018, Rn. 104; s. auch Windoffer, in: Mann/Sennekamp/Uechtritz, VwVfG, 1. Aufl. 2014, § 35, Rn. 37: „die Inanspruchnahme von Sonderrecht durch die Behörde“.

121 Stelkens, in: Stelkens/Bonk/Sachs, VwVfG, 9. Aufl. 2018, §35, Rn. 104; von Alemann/ Scheffczyk, in: Bader/Ronellenfitsch, VwVfG, 42. Ed., Stand: 1.1.2019, § 35, Rn. 121; Windoffer, in: Mann/Sennekamp/Uechtritz, VwVfG, 1. Aufl. 2014, § 35, Rn. 37; insoweit auf die Rechtsgrundlage als „öffentliches Sonderrecht“ abstellend: SächsOVG, Beschl.v. 7.3.2014, Az.: 3 A 798/13 = BeckRS 2014, 49259, Rn. 12.

122 Vgl. etwa BVerwG, Urt.v. 27.10.1982, Az.: 3 C 6/82 = NJW 1983, 776; ThürOVG, Urt. v. 24. 2.2004, Az.: 2 KO 434/03 = NVwZ-RR 2004, 781 (782).

123 Stelkens, in: Stelkens/Bonk/Sachs, VwVfG, 9. Aufl. 2018, § 35, Rn. 104 m.w. N.; Windoffer, in: Mann/Sennekamp/Uechtritz, VwVfG, 1. Aufl. 2014, § 35, Rn. 38.

124 Stelkens, in: Stelkens/Bonk/Sachs, VwVfG, 9. Aufl. 2018, § 35, Rn. 104.

Jens Milker 
Hoheitsträgern, die sich prinzipiell auf gleichgeordneter Ebene begegnen; ${ }^{125}$ es sei denn, der Gesetzgeber weist einem Hoheitsträger spezifische einseitige Regelungsbefugnisse zu (z. B. Aufsichtsbefugnisse). ${ }^{126}$ Diese Konstellation kann etwa bei der Geltendmachung von Erstattungsansprüchen im Bereich des Sozialrechts anzutreffen sein (vgl. zum Beispiel §§ 89 ff. SGB VIII, 102ff. SGB X). ${ }^{127}$

Beispiel $^{128}$ : Die Stadt X begehrt die Erstattung von im Rahmen der Jugendhilfe für einen unbegleiteten minderjährigen Ausländer aufgewendeten Kosten nach Maßgabe des §89d SGB VIII von dem Bundesland Y. Dafür wendet sie sich fristgerecht an die zuständige Landesbehörde. Diese sieht die Forderung nur zum Teil als berechtigt an und erlässt daraufhin einen „Kürzungsbescheid“, dem eine Rechtsbehelfsbelehrung mit dem Hinweis auf die Möglichkeit der Erhebung eines Widerspruchs angefügt war. In diesem Fall liegt nur dem äußeren Anschein nach ein Verwaltungsakt vor (ein sog. formeller Verwaltungsakt, s. zum prozessualen Umgang damit bereits Rn. 21ff.). Es fehlt insoweit an dem Über-/Unterordnungsverhältnis zwischen den beiden Behörden, sodass das Merkmal „hoheitlich" nicht erfüllt ist. Hier besteht „trotz des äußeren Scheins in Wahrheit kein Verwaltungsakt“. ${ }^{129}$

\section{b) Maßnahme einer „Behörde“}

52 Weitere Voraussetzung ist, dass es sich um eine Maßnahme einer „Behörde“

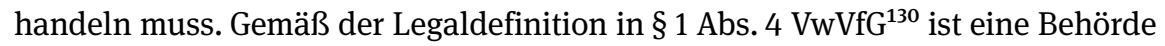
jede Stelle, die Aufgaben der öffentlichen Verwaltung wahrnimmt. Damit legt das

125 Vgl. BSG, Urt. vom 9.5.1957, Az.: 4 RJ 228/55 = BeckRS 1957, 00099, Rn. 21: „Wo sich zwei Rechtsträger des öffentlichen Rechts in ihrer Eigenschaft als Hoheitsträger begegnen, ist ein Verwaltungsakt nicht denkbar“; Urt.v. 21.2.1985, Az.: 11 RK 2/84 = BeckRS 1985, 5642, Rn. 15; Urt.v. 2.2.1978, Az.: 12 RK 29/77 = BeckRS 1978, 388, Rn. 15; BSG, Urt. v. 21.4.1993, Az.: 14a RKa 6/92 = NJW-RR 1994, 788 (790); OVG SH, Urt. v. 22.12.1999, Az.: 2 L 208/98 = BeckRS 2000, 21738, Rn. 38; VG Mainz, Urt. v. 22. 2. 2018, Az.: 1 K 862/17.MZ = BeckRS 2018, 18583, Rn. 24; unter Verneinung der „Verwaltungsaktbefugnis“: Maslaton/Koch, NVwZ 2003, 1347 (1348); a. A. Stelkens, in: Stelkens/ Bonk/Sachs, VwVfG, 9. Aufl. 2018, § 35, Rn. 185.

126 Vgl. BSG, Urt. v. 21.4.1993, Az.: 14a RKa 6/92 = NJW-RR 1994, 788 (790) m.w. N.; Urt. v. 21.2. 1985, Az.: 11 RK 2/84 = BeckRS 1985, 5642, Rn. 15; Urt. v. 2.2.1978, Az.: 12 RK 29/77 = BeckRS 1978, 388, Rn. 15; VG Mainz, Urt. v. 22.2.2018, Az.: 1 K 862/17.MZ = BeckRS 2018, 18583, Rn. 24.

127 S. dazu etwa VG Mainz, Urt.v. 22.2.2018, Az.: 1 K 862/17.MZ = BeckRS 2018, 18583; Urt.v. 15.11. 2018, Az.: 1 K 1434/17.MZ = BeckRS 2018, 36229; Urt.v. 3.7.2018, Az.: 1 K 1463/17.MZ = BeckRS 2018, 20916; Urt. v. 10. 8.2017, Az.: 1 K 1419/16.MZ = BeckRS 2017, 121948; s. ferner OVG SH, Urt. v. 22.12. 1999, Az.: 2 L 208/98 = BeckRS 2000, 21738, Rn. 38.

128 Vgl. dazu unter Anwendung des § 89d Abs. 3 SGB VIII (a. F.): VG Mainz, Urt. v. 22.2.2018, Az.: $1 \mathrm{~K}$ 862/17.MZ = BeckRS 2018, 18583.

129 Vgl. BVerwG, Beschl. v. 18. Januar 1993, Az.: 6 B 5/92 = NVwZ-RR 1993, 251 [252].

130 Zur Anwendbarkeit im Rahmen des $\S 35$ Satz 1 VwVfG: BVerwG, Urt. v. 23.8.2011, Az.: 9 C $2.11=$ NVwZ 2012, 506, Rn. 9. 
Verwaltungsverfahrensrecht einen funktionellen Behördenbegriff zu Grunde. ${ }^{131}$ Es kommt demnach immer darauf an, welche Aufgaben im konkreten Fall wahrgenommen werden. So können etwa auch Verfassungsorgane, die grundsätzlich keine Exekutivaufgaben erfüllen (z.B. der Bundestag und seine Untergliederungen als Legislativorgan), „in einem Teilbereich ihrer verfassungsrechtlichen Kompetenzen Verwaltungstätigkeiten ausüben“. ${ }^{132}$

Beispiel: Der Bundestagspräsident kann als Teil des Bundestages neben der Ausübung der Legislativfunktion auch etwa bei der Ausübung der Polizeigewalt nach Art. 40 II 1 GG als Behörde im Sinne der $\$ 1$ IV, 35 Satz 1 VwVfG einzustufen sein, wenn er etwa eine die Sitzung störende Person aus dem Zuschauerraum des Bundestages verweist. ${ }^{133}$ Gleiches gilt insoweit etwa für die Ausübung des Hausrechts durch den oder die Präsident(-in) eines Gerichts als Teil der Judikative. ${ }^{134}$

Examenswissen: Da eine Behörde nicht selbst handlungsfähig ist, sondern faktisch nur durch die für sie nach außen auftretenden Personen, geht es bei der Prüfung, ob eine Maßnahme einer Behörde vorliegt, schließlich auch um die Frage der Zurechenbarkeit. Sofern die Behörde durch eigene Organwalter handelt, ist die Zurechnung in der Regel wenig problematisch. Dabei entspricht es allgemeiner Verwaltungspraxis, dass der Leiter einer Behörde (z. B. der Bürgermeister) die in deren Zuständigkeit fallenden hoheitlichen Aufgaben nicht persönlich wahrnehmen muss. ${ }^{135}$ Vielmehr können diejenigen Beamten bzw. Angestellten für die Behörde tätig werden, denen nach Maßgabe der behördeninternen Organisationsregelungen die eigenverantwortliche Wahrnehmung der jeweiligen Aufgabe zugewiesen ist. ${ }^{136}$ Dabei ist zwischen Organwaltern im engeren Sinne, also solchen deren Handeln kraft Gesetzes der Behörde zugerechnet wird (,geborene“ Behördenvertreter; z.B. Bürgermeister), und Organwaltern im weiteren Sinne, d.h. sonstigen Bediensteten (Angestellte, Beamte), die ihre Vertretungsmacht schließlich von dem jeweiligen Organwalter im engeren Sinne ableiten (sog. Zeichnungsbefugnis), zu unterscheiden. ${ }^{137}$

Beispiel: In der Stadtverwaltung einer kreisfreien Stadt werden regelmäßig Verwaltungsakte „Im Auftrag“ des Oberbürgermeisters als Behördenleiter von den dort tätigen Mitarbeiterinnen und Mitarbeitern gezeichnet.

131 Vgl. BremOVG, Beschl. v. 7.4.2011, Az.: 1 A 200/09 = NVwZ 2011, 1146 (1147); von Alemann/ Scheffczyk, in: Bader/Ronellenfitsch, VwVfG, 42. Ed., Stand: 1.1.2019, § 35, Rn. 125.

132 OVG NRW, Beschl. v. 23.9.1986, Az.: 15 B 2039/86 = NVwZ 1987, 608 (609).

133 Müller, in: Huck/Müller, VwVfG 2. Aufl. 2016, § 1, Rn. 29. Keine Verwaltungstätigkeit wäre hingegen anzunehmen, wenn der Bundestagspräsident die Diensthoheit gegenüber den Bundestagsabgeordneten wahrnimmt (vgl. W. R. Schenke, in: Kopp/Schenke, VwGO, 25. Aufl. 2019, Anh. § 42, Rn. 17).

134 Vgl. BayVGH, Urt. v. 9.7.1980, Az.: 9 CS 80 A. 268 = NJW 1980, 2722; s. zum Hausrecht des Gerichtspräsidenten auch BVerwG, Urt. v. 17.5.2011, Az.: 7 B 17/11 = BVerwG, NJW 2011, 2530.

135 BVerwG, Beschl. v. 26.2.2008, Az.: 2 B 122/07 = NVwZ-RR 2008, 477, Rn. 17.

136 BVerwG, Beschl. v. 26.2.2008, Az.: 2 B 122/07 = NVwZ-RR 2008, 477, Rn. 17.

137 Vgl. Stelkens, in: Stelkens/Bonk/Sachs, VwVfG, 9. Aufl. 2018, § 35, Rn. 56.

Jens Milker 
56 Besonderheiten ergeben sich insoweit regelmäßig bei kommunalen Verpflichtungserklärungen, für die die Gemeindeordnungen der Länder spezielle Anforderungen vorsehen. ${ }^{138}$ So sieht etwa § 49 I 2 GemO RP ${ }^{139}$ vor, dass Erklärungen, durch die die Gemeinde verpflichtet werden soll, nur rechtsverbindlich sind, wenn sie vom Bürgermeister oder dem zur allgemeinen Vertretung berufenen Beigeordneten oder einem ständigen Vertreter unter Beifügung der Amtsbezeichnung handschriftlich unterzeichnet sind. Obwohl der Wortlaut prima facie eine Interpretation als Formvorschrift nahelegt, besteht Einigkeit darüber, dass die Norm aufgrund der insoweit jedenfalls bei privatrechtlichen Verpflichtungserklärungen fehlenden Gesetzgebungskompetenz der Länder als eine Beschränkung der Vertretungsmacht $\mathrm{zu}$ interpretieren ist. ${ }^{140}$ Gleichwohl ist umstritten, ob dies auch für öffentlich-rechtliche Verpflichtungserklärungen gilt. ${ }^{141}$ Schließlich kann die unterschiedliche Interpretation der Vorschrift nach öffentlich-rechtlichen und privatrechtlichen Erklärungen nicht überzeugen, da bei genauer Interpretation des Wortlauts ${ }^{142}$ (,sind nur rechtsverbindlich“) bereits insgesamt das Verständnis als Vertretungsregel vorzugswürdig sein dürfte.

Sofern sich die Behörde zu ihrer Aufgabenerfüllung (privater) Dritter bedient, ist eine vertiefte Prüfung erforderlich, ob ein hinreichender Zurechnungszusammenhang besteht. Auch natürliche ${ }^{143}$ und juristische ${ }^{144}$ Personen des $^{2}$ Privatrechts können selbst als Behörde im Sinne des $§ 1$ IV VwVfG einzuordnen sein. Dies kann durch „Beleihung“ erfolgen. Beliehene sind Privatpersonen, die mit der selbstständigen, hoheitlichen Wahrnehmung bestimmter Verwaltungsaufgaben im eigenen Namen durch ein formelles Gesetz betraut sind. ${ }^{145}$ Während

138 Vgl. dazu im Überblick: Burgi, Kommunalrecht, 3. Aufl. 2010, § 13, Rn. 33ff.; Stelkens, in: Stelkens/Bonk/Sachs, VwVfG, 9. Aufl. 2018, § 35, Rn. 58.

139 S. zu vergleichbaren Regelungen in anderen Bundesländern: Burgi, Kommunalrecht, 3. Aufl. 2010, § 13, Rn. 33.

140 Vgl. OVG RP, Urt. v. 17.12.1997, Az.: 8 A 12998/98 = NVwZ 1998, 655.

141 Insoweit für eine Einordnung als Formvorschrift: OVG RP, Urt. v. 17.12.1997, Az.: 8 A 12998/ 98 = NVwZ 1998, 655; vgl. für eine Einordnung als Vertretungsregel zu den jeweiligen landesrechtlichen Regelungen: OVG NRW, Urt.v. 19.3.2002, Az.: 15 A 4043/00 = NVwZ-RR 2003, 147 (148); HessVGH, Urt. v. 15.2.1996, Az.: 5 UE 2836/95 = NVwZ 1997, 618.

142 So auch Stelkens, in: Stelkens/Bonk/Sachs, VwVfG, 9. Aufl. 2018, § 35, Rn. 58.

143 Z.B. wird der „Luftfahrzeugführer“ (Flugkapitän) gemäß § 12 LuftSiG mit der luftpolizeilichen Hoheitsgewalt betraut, vgl. BVerwG, Beschl. v. 7.6.1984, Az.: 7 B 153/83 = NVwZ 1985, 48; weitere Beispiele etwa bei Kastner, in: Fehling/Kastner/Störmer, Verwaltungsrecht, 4. Aufl. 2016, $\S 1$ VwVfG, Rn. 35.

144 Z.B. die Deutsche Flugsicherungs GmbH; vgl. Verordnung zur Beauftragung eines Flugsicherungsunternehmens vom 11. November 1992 (BGBl. I S. 1928); s. auch VG Frankfurt a. M., Beschl. v. 22.6.1994, Az.: 9 E 895/94 = NVwZ 1995, 410.

145 Stelkens, NVwZ 2004, 304 (305) m.w. N.

Jens Milker 
der Beliehene selbst Behörde ist, wird etwa der sog. „Verwaltungshelfer“146 unselbstständig für die Behörde tätig, die sich sodann dessen Verhalten (vor allem in Bezug auf Haftungsfragen) zurechnen lassen muss. ${ }^{147}$ Er handelt sozusagen als „als Werkzeug oder verlängerter Arm der Behörde“. ${ }^{148}$ Wie sich aus § 35a VwVfG nunmehr ausdrücklich ergibt, kann ein Verwaltungsakt auch „vollautomatisiert“ erlassen werden, sofern dies durch Rechtsvorschrift zugelassen ist und weder ein Ermessen noch ein Beurteilungsspielraum besteht; auch dann kann es sich demnach um eine der Behörde zurechenbare Maßnahme handeln. ${ }^{149}$ Es gelten dann hinsichtlich der Zurechnung dieselben Grundsätze. ${ }^{150}$

Beispiel: Beauftragt die zuständige Behörde ein privates Abschleppunternehmen, um ein Auto aus dem Haltverbot abschleppen zu lassen, handelt es sich um einen Verwaltungshelfer. Letztlich wird dann das Handeln des Abschleppunternehmens der Behörde zugerechnet. Hier tritt das Abschleppunternehmen auch regelmäßig nicht nach außen auf, sondern liquidiert in der Praxis die Kosten des Abschleppvorgangs zunächst im Innenverhältnis bei der Behörde, die dann wiederum den Falschparker in Regress nimmt.

Dabei gilt das sog. „Prinzip der Selbstorganschaft““. ${ }^{151}$ Behörden dürfen ihre 59 gesetzlich zugewiesenen Aufgaben demnach grundsätzlich nur durch die Organwalter und Bediensteten erfüllen, die ihnen nach Maßgabe der jeweiligen Stellenpläne bzw. Stellenübersichten zugeordnet sind. ${ }^{152}$ Das schließt - soweit (wie üblich) gesetzlich nichts anderes vorgesehen ist - aus, dass die Behörde jedenfalls die Letztentscheidungskompetenz bei in ihren Zuständigkeitsbereich fallenden Aufgaben im hoheitlichen Bereich an Dritte überträgt. ${ }^{153}$ Die ergänzende (unselbstständige) Einschaltung privater Dritter (als Verwaltungshelfer), anderer

146 Vgl. Weber, in: Creifelds, Rechtswörterbuch, 22. Ed., 2016.

147 Vgl. etwa Sodan, in: Sodan/Ziekow, VwGO, 5. Aufl. 2018, § 40, Rn. 365.

148 Schönenbroicher, in: Mann/Sennekamp/Uechtritz, VwVfG, 1. Aufl. 2014, § 1, Rn. 76.

149 S. dazu etwa Stelkens, in: Stelkens/Bonk/Sachs, VwVfG, 9. Aufl. 2018, § 35, Rn. 67 f.: § 35 a VwVfG hat nur „klarstellenden Charakter“.

150 Stelkens, in: Stelkens/Bonk/Sachs, VwVfG, 9. Aufl. 2018, § 35, Rn. 67 f.

151 Der Begriff geht zurück auf Hufeld, Vertretung der Behörde, 2003, S. 21 ff.; dies übernehmend etwa Stelkens, in: Stelkens/Bonk/Sachs, VwVfG, 9. Aufl. 2018, § 35, Rn. 59; vgl. BVerwG, Urt. v. 23.8. 2011, Az.: 9 C 2/11 = NVwZ 2012, 506, Rn. 14: „Grundsatz der Eigenverantwortlichkeit“.

152 Stelkens, in: Stelkens/Bonk/Sachs, VwVfG, 9. Aufl. 2018, § 35, Rn. 59; s. auch BremOVG, Urt.v. 20.3.2018, Az.: 1 LB 55/17 = NordÖR 2018, 230 (231): Verstoß gegen diesen Grundsatz führt zur formellen Rechtswidrigkeit des Verwaltungsakts.

153 Stelkens, in: Stelkens/Bonk/Sachs, VwVfG, 9. Aufl. 2018, § 35, Rn. 59; BVerwG, Beschl.v. 26. 2. 2008, Az.: 2 B 122/07 = NVwZ-RR 2008, 477, Rn. 17: „Der Behördenleiter darf die Wahrnehmung von Behördenzuständigkeiten im hoheitlichen Bereich nur dann auf andere Behörden oder auf nicht seiner Behörde angehörende Personen übertragen, wenn er hierzu durch Rechtssatz ermächtigt ist". 
Behörden (im Wege der Amtshilfe) oder die Automatisierung einzelner Arbeitsschritte (vgl. § 35a VwVfG) ${ }^{154}$ bleibt hingegen zulässig. ${ }^{155}$ Letztlich müssen dabei die wesentlichen Entscheidungen von der zuständigen Behörde selbst getroffen werden. Sofern die Maßnahme keiner Behörde zurechenbar ist, liegt ein sogenannter Scheinverwaltungsakt vor. ${ }^{156}$

60

Beispiel: Anwohnerin A beantragt für ihren Umzug das Aufstellen von Haltverbotsschildern vor ihrem Haus. Die zuständige Behörde teilt ihr mit, dass die betreffenden Schilder auf dem Betriebshof ausgeliehen werden könnten. Gleichzeitig wird darauf hingewiesen, dass die Schilder ausschließlich in dem beantragten Bereich aufgestellt werden dürfen und nur für die dort genannte Dauer Geltung entfalten. In diesem Fall führt A nur die behördliche Anordnung aus, sodass die Aufstellung der Schilder der Behörde (noch) hinreichend zurechenbar ist. ${ }^{157}$

61 Ein fiktiver Verwaltungsakt - wie etwa eine Genehmigungsfiktion (z. B. §42a VwVfG oder § 6a I GewO; s. dazu näher Rn. 123) - ist hingegen keine einer bestimmten Behörde zurechenbare Maßnahme, sondern insgesamt kraft Gesetzes ein Verwaltungsakt. ${ }^{158}$ Auch fingierte Verwaltungsakte sind mit den Rechtsbehelfen der VwGO angreifbar, z.B. kommt eine Drittanfechtung der Genehmigungsfiktion in Betracht. ${ }^{159}$ Der Klagegegner ist dann die Behörde bzw. ihr Rechtsträger, für den bzw. die der Verwaltungsakt als erlassen gilt. ${ }^{160}$

\section{c) Maßnahme „auf dem Gebiet des öffentlichen Rechts“}

62 Wann eine Maßnahme auf dem Gebiet des öffentlichen Rechts vorliegt, bestimmt sich nach denselben Kriterien wie bei der Eröffnung des Verwaltungsrechtswegs nach § 40 I $1 \mathrm{VwGO}^{161}$ (dazu bereits ausführlich $\S 1 \mathrm{Rn}$. 162ff.) und ist damit im Regelfall bei einer prozessual eingekleideten Klausur bereits geprüft worden. Bei

154 S. dazu Stelkens, in: Stelkens/Bonk/Sachs, VwVfG, 9. Aufl. 2018, § 35a, Rn. 26 ff.: Anwendung der Grundsätze der automatisierten Willenserklärung.

155 Vgl. Stelkens, in: Stelkens/Bonk/Sachs, VwVfG, 9. Aufl. 2018, § 35, Rn. 59.

156 Vgl. Stelkens, in: Stelkens/Bonk/Sachs, VwVfG, 9. Aufl. 2018, § 35, Rn. 56, 62f.; zu den Rechtsfolgen s. Rn. 97.

157 Vgl. BVerwG, Urt. v. 6.4.2016, Az.: 3 C 10/15 = NJW 2016, 2353, Rn. $11 \mathrm{ff}$.

158 Vgl. dazu Barczak, JuS 2018, 238 (244) mit weiteren Beispielen.

159 Vgl. Stelkens, in: Stelkens/Bonk/Sachs, VwVfG, 9. Aufl. 2018, § 42a, Rn. 70 f.

160 Stelkens, in: Stelkens/Bonk/Sachs, VwVfG, 9. Aufl. 2018, § 42a, Rn. 70.

161 Vgl. Schwarz, in: Fehling/Kastner/Störmer, Verwaltungsrecht, 4. Aufl. 2016, § 35 VwVfG, Rn. 101; Voßkuhle/Kaufhold, JuS 2011, 34 (35); s. dazu ausführlich Kapitel Nr. 2.

Jens Milker 
einer verwaltungsgerichtlichen Entscheidung hat das Merkmal daher an dieser Stelle regelmäßig keine eigenständige Bedeutung. ${ }^{162}$

\section{d) „Regelung“}

Zentrales Merkmal eines Verwaltungsakts ist die sog. Regelungswirkung. Das Merkmal dient insbesondere der Abgrenzung zu einem Realakt, also schlichtem Verwaltungshandeln (z. B. (Meinungs-) Äußerungen von Hoheitsträgern ${ }^{163}$ ), das nicht auf das Bewirken einer Rechtsfolge, sondern auf einen tatsächlichen Erfolg gerichtet ist. ${ }^{164}$

\section{aa) Allgemeines}

Eine Maßnahme hat Regelungscharakter, wenn sie nach ihrem Erklärungsgehalt - 64 im Gegensatz zum Realakt - darauf gerichtet ist, eine verbindliche Rechtsfolge zu setzen. ${ }^{165}$ Das ist zunächst dann anzunehmen, wenn Rechte des Betroffenen begründet, geändert oder aufgehoben werden (sog. gestaltender oder befehlender Verwaltungsakt). ${ }^{166}$ Regelungscharakter liegt aber auch dann vor, wenn Rechte mit bindender Wirkung festgestellt oder verneint werden (sog. feststellender Verwaltungsakt). ${ }^{167}$ Schließlich wird mit einem Verwaltungsakt von dem Adressaten ein Tun, Dulden oder Unterlassen gefordert oder diesem ein solches erlaubt bzw. eine derartige Pflicht festgestellt. ${ }^{168}$ Gerade hier gilt das Gebot der „Formenklarheit“, sodass aus dem behördlichen Handeln deutlich werden muss, dass das Verwaltungsverfahren (vgl. § 9 VwVfG) durch die Erklärung - bestandskraftfähig - abgeschlossen werden soll. ${ }^{169}$ Nur vorbereitende Handlungen sind damit keine Verwaltungsakte. ${ }^{170}$ Das Merkmal „Regelung“ ist

162 So auch Schwarz, in: Fehling/Kastner/Störmer, Verwaltungsrecht, 4. Aufl. 2016, § 35 VwVfG, Rn. 101.

163 Dazu ausführlich im Überblick Milker, JA 2017, 647.

164 von Alemann/Scheffczyk, in: Bader/Ronellenfitsch, VwVfG, 42. Ed., Stand: 1.1.2019, §35, Rn. 46; Ramsauer, in: Kopp/Ramsauer, VwVfG, 19. Aufl. 2018, § 35, Rn. 39.

165 BVerwG, Urt. v. 5.11.2009, Az.: 4 C 3/09 = NVwZ 2010, 133, Rn. 15; von Alemann/Scheffczyk, in: Bader/Ronellenfitsch, VwVfG, 42. Ed., Stand: 1.1.2019, § 35, Rn. 141.

166 BVerwG, Urt. v. 5.11.2009, Az.: 4 C 3/09 = NVwZ 2010, 133, Rn. 15.

167 BVerwG, Urt. v. 5.11.2009, Az.: 4 C 3/09 = NVwZ 2010, 133, Rn. 15.

168 von Alemann/Scheffczyk, in: Bader/Ronellenfitsch, VwVfG, 42. Ed., Stand: 1.1.2019, §35, Rn. 142.

169 Vgl. Stelkens, in: Stelkens/Bonk/Sachs, VwVfG, 9. Aufl. 2018, §35, Rn. 73 m.w. N. aus der Rechtsprechung.

170 von Alemann/Scheffczyk, in: VwVfG, 42. Ed., Stand:1.1.2019, § 35, Rn. 171.

Jens Milker 
zudem eng verknüpft mit dem der Außenwirkung. ${ }^{171}$ Problematisch ist die Frage der Regelungswirkung insbesondere in den im Folgenden aufgeführten Fallgruppen.

\section{bb) Vorgelagerter Verwaltungsakt}

65 Viel diskutiert und daher besonders hervorzuheben ist die Frage, ob in bestimmten Fällen behördlichen Realakten ein (unter Umständen auch konkludenter) Verwaltungsakt (jedenfalls gedanklich) vorgelagert ist. Dies nimmt die Rechtsprechung insbesondere in Fällen an, in denen vor Durchführung des Realakts über schwierige Sach- oder Rechtsfragen entschieden (z. B. bei Auskunftserteilung ${ }^{172}$ ) oder eine Auswahlentscheidung getroffen werden muss (z. B. Gewährung von Subventionen $\left.{ }^{173}\right) .{ }^{174}$ Es ist insoweit maßgeblich, ob der Schwerpunkt des behördlichen Verhaltens auf dem Realakt selbst oder der vorgelagerten Entscheidung über dessen Durchführung liegt. ${ }^{175}$ Bei letzterem wird dann durch die Vornahme bzw. Nichtvornahme des Realakts eine Regelung getroffen. ${ }^{176}$ Maßgeblich für die Schwerpunktsetzung sind insbesondere die ausdrückliche Erwähnung der Behördenentscheidung im Gesetz sowie die an sie gestellten rechtlichen Anforderungen. ${ }^{177}$

66 Dies kann insbesondere bei Ansprüchen auf Auskunftserteilung relevant werden. ${ }^{178}$ Dabei ist stets das jeweilige Fachrecht (z.B. das IFG) heranzuziehen und die einschlägigen Bestimmungen für den Informations- bzw. Auskunftsan-

171 Vgl. BVerwG, Urt.v. 20.11.2003, Az.: 3 C 29/02 = NVwZ 2004, 349 (350): „zwar begrifflich, aber kaum sachlich trennbar“.

172 Vgl. BVerwG, Urt. v. 20.2.2013, Az.: 6 A 2/12 = NVwZ 2013, 1006, Rn. 15; NVwZ 2008, 580, Rn. 13; von Alemann/Scheffczyk, in: Bader/Ronellenfitsch,VwVfG, 42. Ed., Stand: 1.1.2019, § 35, Rn. 148.

173 Vgl. BVerwG, Urt. v. 19.11.2009, Az.: 3 C 7.09 = NVwZ 2010, 643.

174 von Alemann/Scheffczyk, in: Bader/Ronellenfitsch,VwVfG, 42. Ed., Stand: 1.1.2019, §35, Rn. 148.

175 Vgl. schon BVerwG, Urt. v. 25.2.1969, Az.: I C 65/67 = NJW 1969, 1131 (1132); s. auch BVerwG, Urt. v. 28.11.2007, Az.: 6 A 2/07 = NVwZ 2008, 580, Rn. 13.

176 Stelkens, in: Stelkens/Bonk/Sachs, VwVfG, 9. Aufl. 2018, §35, Rn. 99; von Alemann/Scheffczyk, in: Bader/Ronellenfitsch,VwVfG, 42. Ed., Stand: 1.1.2019, § 35, Rn. 148; s. auch BVerwG, Urt. v. 25.2.1969, Az.: I C 65/67 = NJW 1969, 1131; BFH, Urt.v. 25.7.1978 Az.: VII R 77/74 = NJW 1979, 735 (736); OVG NRW, Urt. v. 23.5.1995 Az.: 5 A 2875/92 = NJW 1995, 2741.

177 Vgl. BVerwG, Urt. v. 28.11.2007, Az.: 6 A 2/07 = NVwZ 2008, 580.

178 Vgl. von Alemann/Scheffczyk, in: Bader/Ronellenfitsch,VwVfG, 42. Ed., Stand:1.1.2019, § 35, Rn. $148 \mathrm{ff}$. 
spruch auszulegen. ${ }^{179}$ Insoweit können etwa auch Bestimmungen zur Durchführung eines Widerspruchsverfahrens (z. B. §9 IV IFG) ein wesentliches Indiz dafür sein, dass der Gesetzgeber davon ausgeht, dass sich die Auskunftserteilung schwerpunktmäßig im Rahmen der Entscheidung darüber bewegt. ${ }^{180}$ Die Rechtsprechung nimmt dabei stets den Einzelfall in den Blick. So wird etwa beim presserechtlichen Auskunftsanspruch unmittelbar aus Art. 5 I 2 GG die Leistungsklage für einschlägig gehalten, da der Erteilung der Auskunft keine davon gesonderte und als Verwaltungsakt zu qualifizierende „Entscheidung“ des Behördenleiters oder einer von ihm beauftragten Person vorausgehe, ${ }^{181}$ während diese bei Ansprüchen gemäß § 7 BNDG i.V.m. § 15 BVerfSchG schon im Gesetz ausdrücklich erwähnt sei. ${ }^{182}$

Ähnliches gilt insoweit bei Geldzahlungen. Dabei kann es unter Umständen 67 dem behördlichen Handeln $\mathrm{zu}$ entnehmen sein, dass mit der Auszahlung als Realakt ein Rechtsgrund zum Behaltendürfen geschaffen werden soll bzw. über den Anspruch auf die (Aus-)Zahlung konkludent entschieden wird. ${ }^{183}$ Dies ist dann unproblematisch, wenn etwa das Gesetz einen Festsetzungsbescheid ausdrücklich vorschreibt (z. B. § 49 I 2 VwVfG). In sonstigen Fallkonstellationen dürfte eine Einzelfallbetrachtung geboten und der Schwerpunkt des behördlichen Handelns herauszuarbeiten sein. In Anbetracht der mittlerweile ausufernden Kasuistik, dürften sich Klausuren insbesondere hier nicht zwingend am „richtigen“ Ergebnis, sondern an der nachvollziehbaren argumentativen Herleitung messen lassen.

Als aktuell diskutierter Fall sei noch die Ausübung eines „virtuellen Hausrechts“ durch Hoheitsträger genannt. ${ }^{184}$ Dabei geht die Rechtsprechung bei der Nutzung der Blockierungs- bzw. Sperrfunktion in sozialen Netzwerken durch Hoheitsträger überwiegend davon aus, dass es sich dabei um einen bloßen Realakt handele. ${ }^{185}$ Im Schrifttum wird hingegen überwiegend vom Vorliegen eines jedenfalls konkludenten (vorgelagerten) Verwaltungsakts ausgegangen, da

179 von Alemann/Scheffczyk, in: Bader/Ronellenfitsch,VwVfG, 42. Ed., Stand: 1.1.2019, §35, Rn. 149.

180 Vgl. von Alemann/Scheffczyk, in: Bader/Ronellenfitsch,VwVfG, 42. Ed., Stand:1.1.2019, § 35, Rn. 149; VG Karlsruhe, Urt. v. 5. 8.2011, Az.: 2 K 765/11 = BeckRS 2011, 53817, Rn. 12.

181 BVerwG, Urt. v. 20.2.2013, Az.: 6 A 2/12 = NVwZ 2013, 1006, Rn. 15.

182 BVerwG, Urt. v. 28.11.2007, Az.: 6 A 2/07 = NVwZ 2008, 580, Rn. 13.

183 Vgl. etwa HambOVG, Urt. v. 25.7.2017, Az.: 3 Bf 96/15 = BeckRS 2017, 131008, Rn. 37.

184 Dazu ausführlich etwa Kalscheuer/Jacobsen, NJW 2018, 2358; Milker, NVwZ 2018, 1751.

185 Vgl. VG Mainz, Urt. v. 13.4.2018, Az.: 4 K 762/17.MZ = MMR 2018, 556, Rn. 69; VG München, Urt. v. 27.10. 2017, Az.: M 26 K 16.5928 = MMR 2018, 418, Rn. 14; a. A. wohl VG Düsseldorf, Beschl.v. 28.6.2018, Az.: 15 L 1022/18 = BeckRS 2018, 14305, Rn. 11.

Jens Milker 
der Schwerpunkt des behördlichen Handelns auf der Entscheidung über die Blockierung nach Durchführung einer umfassenden Interessenabwägung liegt. ${ }^{186}$

\section{cc) Polizeiliche Standardmaßnahmen und Vollstreckungshandlungen}

69 Problematisch ist das Vorliegen einer Regelung auch in Bezug auf polizeiliche Standardmaßnahmen (s. auch Rn. 1045ff.) und Vollstreckungshandlungen (s. auch Rn. $1311 \mathrm{ff}$.). Hier ist auf die jeweils durchgeführte Maßnahme im Einzelfall abzustellen. ${ }^{187}$ Nicht jede Maßnahme zur Durchsetzung einer öffentlichrechtlichen Verpflichtung ist notwendig ein Verwaltungsakt.

70 Die dafür erforderliche Regelungswirkung kann nach zutreffender Ansicht etwa bei der Androhung ${ }^{188}$ und Festsetzung ${ }^{189}$ im Verwaltungsvollstreckungsrecht angenommen werden. ${ }^{190}$ Während ein Zwangsgeld alleine durch seine Festsetzung „Vollstreckungswirkung“ entfaltet, ist die Anwendung des Zwangsmittels der Ersatzvornahme (z. B. das Abschleppen eines PKW) ${ }^{191}$ oder des unmittelbaren Zwangs (z. B. Einsatz eines Wasserwerfers) ${ }^{192}$ nach Vollstreckungsrecht bzw. die unmittelbare Ausführung nach Polizeirecht mangels Regelungswirkung kein Verwaltungsakt, da sich diese auf rein tatsächliches Handeln beschränken. ${ }^{193}$

186 Eingehend dazu: Milker, NVwZ 2018, 1751 (1756); so im Ergebnis auch unter allgemeinem Verweis auf behördliche (analoge) Hausverbote: Kalscheuer/Jacobsen, NJW 2018, 2358 (2359); a. A. Libertus, CR 2019, 262 (265).

187 Vgl. Ramsauer, in: Kopp/Ramsauer, VwVfG, 19. Aufl. 2018, § 35, Rn. 114.

188 Vgl. BVerwG, Urt. v. 17.6.2014, Az.: 10 C 7/13 = BeckRS 2014, 54339, Rn. 35; OVG RP, Urt.v. 27.3. 2014, Az.: 7 A 10993/13.0VG = LKRZ 2014, 363; s. auch von Alemann/Scheffczyk, in: Bader/Ronellenfitsch,VwVfG, 42. Ed., Stand: 1.1.2019, § 35, Rn. 154: nicht hingegen die bloße Vollstreckungsankündigung.

189 OVG RP, Urt. v. 22.1.1986, Az.: 8 B 44/85 = NVwZ 1986, 762: „[D]ie Festsetzung der Ersatzvornahme stellt einen belastenden Verwaltungsakt mit - gegenüber der Androhung - eigenständigem Regelungsgehalt dar“.

$190 \mathrm{~S}$. zu weiteren Beispielen: von Alemann/Scheffczyk, in: Bader/Ronellenfitsch,VwVfG, 42. Ed., Stand: 1.1.2019, §35, Rn. 154.

191 Vgl. etwa OVG RP, Urt. v. 25.1.2005, Az.: 7 A 11726/04 = NVwZ-RR 2005, 577.

192 Vgl. etwa VG Stuttgart, Urt. v. 18.11.2015, Az.: 5 K 1265/14 = BeckRS 2015, 56039; zur Versiegelung eines Geländes: VG Weimar, Beschl. v. 3.5.1999, Az.: 7 E 964/99 = NVwZ-RR 2000, 478. 193 Vgl. zur unmittelbaren Ausführung: BVerwG, Urt. v. 12.1.2012, Az.: 7 C 5/11 = NVwZ 2012, 1184, Rn. 19ff.; VG Karlsruhe, Urt. v. 5.5.2008, Az.: 11 K 645/08 = BeckRS 2008, 34709, Rn. 29; zur Ersatzvornahme: HessVGH, Urt. v. 30.4.1982, Az.: III TG 119/82 = NVwZ 1982, 514; zum unmittelbaren Zwang: VG Stuttgart, Urt. v. 18.11.2015, Az.: 5 K 1265/14 = BeckRS 2015, 56039. 
Das offenbar immer noch - vor allem in der älteren Rechtsprechung ${ }^{194}$ - 71 verbreitete (Hilfs-)Konstrukt einer konkludenten Duldungsverfügung ${ }^{195}$ ist als realitätsfern abzulehnen, ${ }^{196}$ zumal auch der Grund für dessen „Einführung“ längst weggefallen ist. ${ }^{197}$ Gleichwohl kann die Duldungspflicht im Einzelfall durch einen (ausdrücklichen) Verwaltungsakt („Anordnung“ einer Maßnahme) konkretisiert werden. ${ }^{198}$ Daher kommt es stets auf den Einzelfall an.

Die jedenfalls mittelbar dem Vollstreckungsrecht zuzuordnende Anordnung der sofortigen Vollziehung (§ 80 II 1 Nr. 4 VwGO) hat keine Regelungswirkung, da sie nicht den Abschluss eines (eigenständigen) Verwaltungsverfahrens bezweckt, sondern nur ein Teil einer anderen Verwaltungssache ist, nämlich für die Frage, ob eine bereits getroffene Regelung schon vor ihrer formellen Bestandskraft vollzogen werden kann. ${ }^{199}$

Auch bei der Rechtsnatur von Standardmaßnahmen (s. dazu auch noch 73 Rn. 1004) ist die jeweils durchgeführte Maßnahme in den Blick zu nehmen, sodass sich pauschale Aussagen verbieten. ${ }^{200}$ Beispielsweise ist in einem Platzverweis (z.B. nach $\S 38$ BPolG) ohne weiteres eine Regelungswirkung erkennbar, ${ }^{201}$ während sich dies etwa bei der Ingewahrsamnahme - außer bei der (abzulehnenden)

194 S. dazu VG Frankfurt a.M., Urt. v. 20.1.1993, Az.: V/3 E 1210/90 = NVwZ 1994, 720 (Ingewahrsamnahme); VG Bremen, Urt.v. 5.12.1988, Az.: 4 A 226/86 = NVwZ 1989, 895 (Anfertigung von Videoaufnahmen von einer Versammlung); BayVGH, Urt. v. 16.5.1982, Az.: 21 B 87.02889 = NVwZ 1988, 1055 (Tränengaseinsatz als polizeiliche Zwangsmaßnahme); anschaulich zum Einsatz eines Schlagstocks: Pfeiffer/Buchinger, JA 2006, 102.

195 S. dazu insgesamt von Alemann/Scheffczyk, in: Bader/Ronellenfitsch,VwVfG, 42. Ed., Stand: 1.1.2019, § 35, Rn. 150.

196 So auch von Alemann/Scheffczyk, in: Bader/Ronellenfitsch, VwVfG, 42. Ed., Stand:1.1.2019, $\S 35$, Rn. 151; Finger, JuS 2005, 116 (117f.); dies auch aus Gründen der fehlenden „Formenklarheit“ ablehnend: Stelkens, in: Stelkens/Bonk/Sachs, VwVfG, 9. Aufl. 2018, § 35, Rn. 95, 98; a. A. OVG RP, Urt. v. 27.3.2014, Az.: 7 A 10993/13.0VG = LKRZ 2014, 363.

197 Schwarz, in: Fehling/Kastner/Störmer, Verwaltungsrecht, 4. Aufl. 2016, § 35 VwVfG, Rn. 94; VG Stuttgart, Urt.v. 18.11.2015, Az.: 5 K 1265/14 = BeckRS 2015, 56039 = BeckRS 2015, 56039; Finger, JuS 2005, 116 (117); s. auch Rachor/Graulich, in: Lisken/Denninger, Handbuch des Polizeirechts 6. Aufl. 2018, Kapitel E, Rn. 35 f.

198 Vgl. BVerwG, Beschl. v. 14.7.2014 Az.: 6 B 2/14 = NVwZ-RR 2014, 848, Rn. 4.

199 OVG RP, Urt. v. 25.11.1987, Az.: 12 B 112/87 = NVwZ 1988, 748; von Alemann/Scheffczyk, in: Bader/Ronellenfitsch,VwVfG, 42. Ed., Stand: 1.1.2019, § 35, Rn. 156.

200 von Alemann/Scheffczyk, in: Bader/Ronellenfitsch,VwVfG, 42. Ed., Stand: 1.1.2019, §35, Rn. 153; Ramsauer, in: Kopp/Ramsauer, VwVfG, 19. Aufl. 2018, § 35, Rn. 114; insoweit auch differenzierend etwa OVG RP, Urt. v. 21.4.2016, Az.: 7 A 11108/14.OVG = NJW 2016, 2820, Rn. 25.

201 Vgl. OVG RP, Urt. v. 27.3.2014, Az.: 7 A 10993/13.OVG = LKRZ 2014, 363; BremOVG, Urt. v. 24. 3. 1998, Az.: 1 BA 27/97 = NVwZ 1999, 314 (315); von Alemann/Scheffczyk, in: VwVfG, 42. Ed., Stand: 1.1.2019, § 35, Rn. 153. 
Konstruktion einer konkludenten Duldungsverfügung ${ }^{202}$ - generell nicht annehmen lässt. ${ }^{203}$

\section{e) Maßnahme „zur Regelung eines Einzelfalls“}

74 Das Merkmal der Maßnahme „zur Regelung eines Einzelfalls“ ist nur schwer im herkömmlichen Sinne positiv definierbar. Klassisch meint „Einzelfall“ jedenfalls konkret-individuelle Regelungen (dazu Rn. 76). Es dient (negativ) der Abgrenzung zur Rechtsnorm als abstrakt-generelle Regelung, ${ }^{204}$ die eine unbestimmte Vielzahl von Personen und Sachverhalten erfasst (dazu Rn. 88 ff.). ${ }^{205}$ Dazwischen finden sich Mischkonstellationen, also konkret-generelle (sog. Allgemeinverfügung, dazu Rn. 77 ff.) und abstrakt-individuelle (dazu Rn. 87) Regelungen, die ebenfalls Verwaltungsakte darstellen. Diese vier Konstellationen sollen im Folgenden näher erläutert werden.

75 Examenswissen: Der Behörde kommt grundsätzlich ein Wahlrecht zu, ob sie per Verwaltungsakt oder (materiellem) Gesetz handelt. ${ }^{206}$ Abgrenzungsprobleme treten regelmäßig dann auf, wenn die Maßnahme nicht eindeutig bezeichnet ist und daher die äußere Form als primäres Kriterium keine hinreichenden Rückschlüsse zulässt. ${ }^{207}$

\section{aa) Konkret-individuelle Maßnahmen}

76 Die klassische Konstellation beschreibt Maßnahmen, die sich auf einen bestimmten Adressatenkreis zur Regelung einer konkreten Situation beziehen. ${ }^{208}$ Dies kann etwa der polizeiliche Platzverweis gegenüber einer Person sein, die einen Polizeieinsatz behindert und von einem Polizeibeamten direkt persönlich angesprochen wird. Dabei wird dann der Adressat individualisiert und ihm gleichzeitig in der konkreten Situation des stattfindenden Polizeieinsatzes eine Rechtspflicht auferlegt.

202 So aber VG Frankfurt a. M., Urt. v. 20.1.1993, Az.: V/3 E 1210/90 = NVwZ 1994, 720 (721) ohne dies allerdings näher zu begründen.

203 Vgl. dazu ausführlich: Finger, JuS 2005, 116 (117); Müller, in: Huck/Müller, VwVfG, 2. Aufl. 2016, §35, Rn. 41.

204 Ramsauer, in: Kopp/Ramsauer, VwVfG, 19. Aufl. 2018, § 35, Rn. 118.

205 Schwarz, in: Fehling/Kastner/Störmer, Verwaltungsrecht, 4. Aufl. 2016, § 35 VwVfG, Rn. 97; Ramsauer, in: Kopp/Ramsauer, VwVfG, 19. Aufl. 2018, § 35, Rn. 121.

206 Vgl. Ramsauer, in: Kopp/Ramsauer, VwVfG, 19. Aufl. 2018, § 35, Rn. 119 m.w. N.

207 Vgl. Ramsauer, in: Kopp/Ramsauer, VwVfG, 19. Aufl. 2018, § 35, Rn. 120.

208 Siehe dazu etwa auch Schwarz, in: Fehling/Kastner/Störmer, Verwaltungsrecht, 4. Aufl. 2016, § 35 VwVfG, Rn. 97.

Jens Milker 


\section{bb) Konkret-generelle Maßnahmen}

Eine weitere häufig anzutreffende Variante von Verwaltungsakten sind konkret- 77 generelle ${ }^{209}$ Maßnahmen (sog. Allgemeinverfügungen im Sinne des $\S 35$ Satz 2 VwVfG). Dabei wird nicht - wie soeben in Rn. 76 - von vornherein eine bestimmte Person bzw. ein Personenkreis konkret individualisiert und damit als Adressat festgelegt; vielmehr sind andere Anknüpfungspunkte relevant. Mit der Einordnung als Allgemeinverfügung sind zudem verwaltungsverfahrens- und prozessrechtliche Sonderregelungen verbunden (insbesondere hinsichtlich Bekanntgabe und Anhörung). ${ }^{210}$ Der Gesetzgeber sieht in $\S 35$ Satz 2 VwVfG insgesamt drei Varianten der Allgemeinverfügung vor. Die genaue Zuordnung hat zwar rechtlich keine Auswirkungen, erleichtert aber die Bildung von Fallgruppen und trägt so zum Verständnis der Reichweite des Begriffs der Allgemeinverfügung bei.

Die personenbezogene Allgemeinverfügung (Var. 1) ${ }^{211}$ richtet sich an einen 78 bestimmten oder bestimmbaren Personenkreis. ${ }^{212}$ Es findet keine individuelle Bestimmung des Adressaten (etwa durch persönliches oder namentliches Ansprechen bzw. Anschreiben) statt, diese erfolgt vielmehr anhand allgemeiner Merkmale. ${ }^{213}$ Gleichzeitig wird aber nur ein konkreter Sachverhalt geregelt und dieser nicht etwa anhand von abstrakten Merkmalen beschrieben. Dies unterscheidet schließlich die Allgemeinverfügung von der Rechtsnorm. ${ }^{214}$ Die genaue Zahl der Adressaten muss dabei nicht abschließend feststehen. ${ }^{215}$

Beispiel: Eine Verfügung, mit der alle öffentlichen Versammlungen unter freiem Himmel und 79 Aufzüge für einen Zeitraum von mehreren Tagen untersagt werden und die sich räumlich auf die genau beschriebene Umgebung der Route eines konkret geplanten „Castortransports“ beschränkt, ist als ein präventives Versammlungsverbot im Wege der Allgemeinverfügung ( $\$ 35$

209 Vgl. BremOVG, Beschl. v. 21.10.2011, Az.: 1 B 162/11 = NordÖR 2012, 38.

210 S. dazu Ramsauer, in: Kopp/Ramsauer, VwVfG, 19. Aufl. 2018, § 35, Rn. 159 f.

211 Vgl.von Alemann/Scheffczyk, in: Bader/Ronellenfitsch,VwVfG, 42. Ed., Stand:1.1.2019, § 35, Rn. 255; s. insbesondere mit zahlreichen Fallgruppen und Beispielen: Stelkens, in: Stelkens/ Bonk/Sachs, VwVfG, 9. Aufl. 2018, § 35, Rn $284 \mathrm{ff}$.

212 Vgl. von Alemann/Scheffczyk, in: Bader/Ronellenfitsch,VwVfG, 42. Ed., Stand:1.1.2019, § 35, Rn. 255.

213 Vgl. von Alemann/Scheffczyk, in: Bader/Ronellenfitsch,VwVfG, 42. Ed., Stand:1.1.2019, § 35, Rn. 255; Schwarz, in: Fehling/Kastner/Störmer, Verwaltungsrecht, 4. Aufl. 2016, § 35 VwVfG, Rn. 120: „der Gattung nach bestimmbar“.

214 Vgl. OVG Nds., Urt. v. 29.5.2008, Az.: 11 LC 138/06 = BeckRS 2008, 36232; von Alemann/ Scheffczyk, in: VwVfG, 42. Ed., Stand: 1.1.2019, §35, Rn. 255; Ramsauer, in: Kopp/Ramsauer, VwVfG, 19. Aufl. 2018, § 35, Rn. 161.

215 Stelkens, in: Stelkens/Bonk/Sachs, VwVfG, 9. Aufl. 2018, §35, Rn. 282; von Alemann/ Scheffczyk, in: Bader/Ronellenfitsch,VwVfG, 42. Ed., Stand: 1.1.2019, § 35, Rn. 255.

Jens Milker 
Satz. 2 Var. 1 VwVfG) einzuordnen. ${ }^{216}$ Eine Allgemeinverfügung ist „bei versammlungsbeschränkenden Maßnahmen anzunehmen, wenn sich die Maßnahmen vor dem Hintergrund eines bestimmten Ereignisses oder Anlasses an alle Personen wenden, die zu einem bestimmten Zeitpunkt bzw. innerhalb eines bestimmten Zeitraums an einem bestimmten Ort oder innerhalb eines näher bezeichneten räumlichen Bereichs zu Versammlungen zusammenzukommen beabsichtigen“. ${ }^{217}$

Beispiel: Am 11. Mai findet um 15:30 Uhr das Fußballspiel zwischen dem 1. FSV Mainz 05 und Eintracht Frankfurt statt. Eine polizeiliche Verfügung, in der Linie S8 von Mainz nach Frankfurt am Main (Stadion) am 11. Mai 2019 mit Abfahrtszeiten zwischen 12:00 Uhr und 16:00 Uhr keine Glasflaschen mitzuführen, ließe sich aufgrund des hinreichend konkret umschriebenen Sachverhalts als Allgemeinverfügung einordnen. Eine Rechtsnorm würde hingegen vorliegen, wenn die Regelung dahingehend gefasst wäre, dass anlässlich jeder Begegnung der beiden Vereine in der Zukunft das oben angeführte Glasflaschenverbot am Spieltag greifen soll.

81 Der Behörde steht ein Wahlrecht $\mathrm{zu}$, ob sie eine Allgemeinverfügung oder ein „Bündel von Einzelverfügungen“218 (sog. „Sammelverwaltungsakt“219) erlassen möchte; die Abgrenzung bereitet dahingehend oftmals Schwierigkeiten. ${ }^{220}$ Maßgeblich dürfte es darauf ankommen, ob und inwieweit die individuellen Verhältnisse der Adressaten zu berücksichtigen sind. ${ }^{221}$ Zudem betreffen Sammelverwaltungsakte typischerweise eine bestimmte (nicht nur bestimmbare) und damit von vornherein feststehende Zahl von Personen. ${ }^{222}$

82 Die sachbezogene Allgemeinverfügung (Var. 2) ${ }^{223}$ betrifft die öffentlichrechtliche Eigenschaft einer Sache. Unmittelbarer Bezugspunkt ist schließlich

216 Vgl. VGH BW, Urt. v. 6.11.2013, Az.: 1 S 1640/12 = BeckRS 2013, 58560; OVG Nds., Urt. v. 29.5. 2008, Az.: 11 LC 138/06 = BeckRS 2008, 36232: „Dies ist bei versammlungsbeschränkenden Maßnahmen der Fall, wenn sich die Maßnahmen vor dem Hintergrund eines bestimmten Ereignisses oder Anlasses an alle Personen wenden, die zu einem bestimmten Zeitpunkt bzw. innerhalb eines bestimmten Zeitraums an einem bestimmten Ort oder innerhalb eines näher bezeichneten räumlichen Bereichs zu Versammlungen zusammenzukommen beabsichtigen“; von Alemann/Scheffczyk, in: Bader/Ronellenfitsch,VwVfG, 42. Ed., Stand: 1.1.2019, § 35, Rn. 261.1.

217 OVG Nds., Urt. v. 29.5.2008, Az.: 11 LC 138/06 = BeckRS 2008, 36232.

218 von Alemann/Scheffczyk, in: Bader/Ronellenfitsch,VwVfG, 42. Ed., Stand: 1.1.2019, §35, Rn. 259.

219 Vgl. von Alemann/Scheffczyk, in: Bader/Ronellenfitsch,VwVfG, 42. Ed., Stand:1.1.2019, § 35, Rn. 259; Stelkens, in: Stelkens/Bonk/Sachs, VwVfG, 9. Aufl. 2018, § 35, Rn. 277.

220 Vgl. dazu von Alemann/Scheffczyk, in: Bader/Ronellenfitsch,VwVfG, 42. Ed., Stand:1.1.2019, $\S 35$, Rn. 259 f.; Stelkens, in: Stelkens/Bonk/Sachs, VwVfG, 9. Aufl. 2018, § 35, Rn. 277 ff.; Ramsauer, in: Kopp/Ramsauer, VwVfG, 19. Aufl. 2018, § 35, Rn. 163.

221 Vgl. von Alemann/Scheffczyk, in: Bader/Ronellenfitsch,VwVfG, 42. Ed., Stand:1.1.2019, § 35, Rn. 260; dabei auch wesentlich auf die Art des Erlasses abstellend: Stelkens, Rn. 279.

222 Ramsauer, in: Kopp/Ramsauer, VwVfG, 19. Aufl. 2018, § 35, Rn. 163.

223 Vgl. von Alemann/Scheffczyk, in: Bader/Ronellenfitsch,VwVfG, 42. Ed., Stand:1.1.2019, § 35, Rn. 262.

Jens Milker 
eine bestimmte Sache, wobei mittelbar die Rechte und Pflichten von Personen geregelt werden, die mit der Sache in Berührung kommen. ${ }^{224}$ Es handelt sich damit um einen „adressatenlosen“ Verwaltungsakt. ${ }^{225}$ Der Sachbegriff ist verwaltungsrechtlich $\mathrm{zu}$ bestimmen ${ }^{226}$ und erfasst neben Sachen im Sinne des $§ 90$ BGB auch „Sachgesamtheiten“ (z. B. öffentliche Anstalten und Einrichtungen). ${ }^{227}$ Erfasst sind insoweit etwa die Umbenennung einer Straße $\mathrm{e}^{228}$ oder auch die Widmung einer öffentlichen Einrichtung. ${ }^{229}$

Mit der benutzungsregelnden Allgemeinverfügung (Var. 3) ${ }^{230}$ wird die 83 Benutzung einer (bereits als solchen gewidmeten) öffentlichen Sache näher ausgestaltet (etwa im Hinblick auf Öffnungszeiten). ${ }^{231}$ Auch hier ist unmittelbarer Bezugspunkt schließlich die bestimmte Sache, während sie gleichzeitig (mittelbar) an einen anhand abstrakter Merkmale bestimmbaren Personenkreis (die „Benutzer“) gerichtet ist. ${ }^{232}$

Beispiel: Die Benutzungsordnung einer Stadthalle mit der etwa die zugelassenen Veranstaltungsarten (insbesondere der Ausschluss politischer Veranstaltungen) festgelegt werden. ${ }^{233}$

224 Vgl. von Alemann/Scheffczyk, in: Bader/Ronellenfitsch,VwVfG, 42. Ed., Stand:1.1.2019, § 35, Rn. 262; s. auch Ramsauer, in: Kopp/Ramsauer, VwVfG, 19. Aufl. 2018, §35, Rn. 164: Aus dem Bezug zur bestimmten Sache folgt die hinreichende Konkretheit der Regelung.

225 Vgl. OVG NRW, Urt. v. 29.10.2007, Az.: 15 B 1517/07 = NVwZ-RR 2008, 487; s. auch BVerwG, Beschl. v. 24.4.1978, Az.: 7 B 111/77 = NJW 1978, 2211: „intransitive Zustandsregelung“.

226 von Alemann/Scheffczyk, in: Bader/Ronellenfitsch,VwVfG, 42. Ed., Stand: 1.1.2019, §35, Rn. 263.

227 von Alemann/Scheffczyk, in: Bader/Ronellenfitsch,VwVfG, 42. Ed., Stand: 1.1.2019, §35, Rn. 263; Stelkens, in: Stelkens/Bonk/Sachs, VwVfG, 9. Aufl. 2018, § 35, Rn. 316.

228 Vgl. OVG NRW, Urt. v. 29.10.2007, Az.: 15 B 1517/07 = NVwZ-RR 2008, 487.

229 Vgl. BayVGH, Urt. v. 31.3.2003, Az.: 4 B 00.2823 = NVwZ-RR 2003, 771 (771); VGH BW, Urt. v. 11.4.1994, Az.: 1 S 1081/93 = NVwZ 1994, 920 (921); Schoch, NVwZ 2016, 257 (260); von Alemann/ Scheffczyk, in: Bader/Ronellenfitsch,VwVfG, 42. Ed., Stand: 1.1.2019, §35, Rn. 263; auf die ausdrückliche Widmung beschränkend: Stelkens, in: Stelkens/Bonk/Sachs, VwVfG, 9. Aufl. 2018, $\S 35, \mathrm{Rn} .325$.

230 von Alemann/Scheffczyk, in: Bader/Ronellenfitsch,VwVfG, 42. Ed., Stand: 1.1.2019, § 35, Rn. 266.

231 von Alemann/Scheffczyk, in: Bader/Ronellenfitsch,VwVfG, 42. Ed., Stand: 1.1.2019, §35, Rn. 266; Stelkens, in: Stelkens/Bonk/Sachs, VwVfG, 9. Aufl. 2018, § 35, Rn. 338; tendenziell auf Var. 2 abstellend: BVerwG, NVwZ 2007, 340, Rn. 7.

232 von Alemann/Scheffczyk, in: Bader/Ronellenfitsch,VwVfG, 42. Ed., Stand: 1.1.2019, §35, Rn. 266.

233 Vgl. etwa VG Bayreuth, Beschl. v. 16.2.2009, Az.: B 2 E 08.1234 = BeckRS 2009, 48133; von Alemann/Scheffczyk, in: Bader/Ronellenfitsch,VwVfG, 42. Ed., Stand: 1.1.2019, § 35, Rn. 267. 
85 Eine Sonderstellung der benutzungsregelnden Allgemeinverfügungen nehmen sofern sie eine Regelung enthalten ${ }^{234}$ - Verkehrszeichen (z. B. Haltverbote) ein. ${ }^{235}$ Deren Adressat sind die Verkehrsteilnehmer, für die das Verkehrszeichen in einer konkreten Verkehrssituation Rechte und Pflichten begründet, ${ }^{236} \mathrm{z}$. B. das Verbot des Parkens in einem bestimmten Straßenabschnitt. ${ }^{237}$ Dabei ergeben sich aufgrund der Bedürfnisse des Straßenverkehrs und der einschlägigen Spezialregelungen der StVO besondere Einzelfragen hinsichtlich der Bekanntgabe und des Wirksamwerdens (s. näher Rn. $117 \mathrm{ff}$.) sowie der Anfechtungsfrist (s. näher Rn. 166). ${ }^{238}$

86 Hausarbeitswissen: In der älteren Rechtsprechung wurden Verkehrszeichen noch als Rechtsverordnungen angesehen. ${ }^{239} \mathrm{Da}$ auch der Gesetzgeber in der amtlichen Begründung zu § 35 S. 2 VwVfG davon ausgeht, dass Verkehrszeichen als Verwaltungsakte einzuordnen sind, ${ }^{240}$ und sich die ganz herrschende Meinung ${ }^{241}$ insoweit schon länger gewandelt hat, ${ }^{242}$ muss dieser Streit in einer Klausur nicht mehr zwingend thematisiert werden, kann aber ggf. in Hausarbeiten Erwähnung finden. ${ }^{243}$

\section{cc) Abstrakt-individuelle Maßnahme}

87 Eine abstrakt-individuelle Regelung wird getroffen, wenn für eine unbestimmte Anzahl an Lebenssachverhalten einer bestimmten Person oder einem bestimmten Personenkreis eine bestimmte Handlungspflicht auferlegt wird. ${ }^{244}$ Als Beispiele

234 Vgl. zur Differenzierung der Arten von Verkehrszeichen etwa: Milker, Jura 2017, 271; Kümper, JuS 2017, 731.

235 Vgl. zur Zuordnung zu §35 Satz 2 Var. 3 VwVfG: von Alemann/Scheffczyk, in: Bader/Ronellenfitsch,VwVfG, 42. Ed., Stand: 1.1.2019, § 35, Rn. 269; Kümper, JuS 2017, 731 (732).

236 Vgl. BVerwG, Urt v. 13.12.1979, Az.: 7 C 46/78 = NJW 1980, 1640: „Entscheidend ist, (...) daß Verkehrszeichen eine konkrete örtliche Verkehrssituation betreffen und eine situationsbezogene Verkehrsregelung zum Inhalt haben. Sie vertreten gleichsam die Stelle von Polizeivollzugsbeamten“; s. dazu auch Milker, Jura 2017, 271 (272f.); Kümper, JuS 2017, 731 (732).

237 Milker, Jura 2017, 271 (273).

238 Vgl.von Alemann/Scheffczyk, in: Bader/Ronellenfitsch,VwVfG, 42. Ed., Stand:1.1.2019, § 35, Rn. 270; s. dazu ausführlich Milker, Jura 2017, 271; Kümper, JuS 2017, 731; aus der Rechtsprechung etwa BVerwG, Urt. v. 6.4.2016, Az.: 3 C 10/15 = NJW 2016, 2353, Rn. 16.

239 Vgl. BayVGH, Urt. v. 21.12.1977, Az.: 141 XI/76 = NJW 1978, 1988; dazu auch Maurer/Waldhoff, Allgemeines Verwaltungsrecht, 19. Aufl. 2017, § 9, Rn. $35 \mathrm{ff}$.

240 BT-Drs.7/910, S. 57; s. auch Milker, Jura 2017, 271 (273); Kümper, JuS 2017, 731 (733).

241 Vgl. auch Kümper, JuS 2017, 731 (732) m.w. N.: „Gegenwärtig werden Verkehrszeichen praktisch einhellig als Verwaltungsakte in Form der Allgemeinverfügung (...) angesehen“.

242 Näher dazu Kümper, JuS 2017, 731 (733) m.w. N.

243 Milker, Jura 2017, 271 (273).

244 Schwarz, in: Fehling/Kastner/Störmer, Verwaltungsrecht, 4. Aufl. 2016, § 35 VwVfG, Rn. 97; von Alemann/Scheffczyk, in: Bader/Ronellenfitsch,VwVfG, 42. Ed., Stand: 1.1.2019, § 35, Rn. 193 (diese Konstruktion aber als überflüssig ansehend). 
werden dazu etwa die „Beseitigung wiederkehrender Verschmutzungen oder das Ergreifen bestimmter Sicherheitsmaßnahmen bei wiederholten Sprengungen“ genannt. ${ }^{245}$ Teilweise wird diese Konstellation als überflüssig angesehen, da es sich um eine „Bündelung konkret-individueller“ Regelungen handele. ${ }^{246}$

\section{dd) Abstrakt-generelle Maßnahme}

Eine abstrakt-generelle Maßnahme bezeichnet schließlich Gesetze bzw. Rechts- 88 normen, die nicht als Verwaltungsakte einzuordnen sind. Abgrenzungsprobleme ergeben sich regelmäßig zur Allgemeinverfügung. ${ }^{247}$ Die Verwaltung hat dabei grundsätzlich die Wahl, ob sie ein (materielles) Gesetz (z. B. eine Gefahrenabwehrverordnung) oder eine Allgemeinverfügung erlässt; anders liegt die Sache hingegen, wenn das Gesetz eine bestimmte Handlungsform zwingend vorschreibt. ${ }^{248}$

Beispiel $^{249}$ : Die Stadt M erlässt zur Eindämmung von Lärm und Verunreinigungen eine Gefahrenabwehrverordnung, die u. a. folgenden Inhalt hat:

\section{$\S 2$ Alkoholverbot}

(1) Im Geltungsbereich der Verordnung ist es auf den öffentlich zugänglichen Flächen außerhalb konzessionierter Freisitzflächen verboten:

- alkoholische Getränke jeglicher Art zu konsumieren

- alkoholische Getränke jeglicher Art mit sich zu führen, wenn auf Grund der konkreten Umstände die Absicht erkennbar ist, diese im Geltungsbereich der Verordnung konsumieren zu wollen.

(2) Dieses Verbot gilt in den Nächten von Freitag auf Samstag, Samstag auf Sonntag, Sonntag auf Montag jeweils von 22 bis 6 Uhr. Gleiches gilt für die Zeit von 00:00 bis $6 \mathrm{Uhr}$ morgens an einem gesetzlichen Feiertag und die zwei Stunden davor (d.h. von 22 bis 6 Uhr). Gemäß § 4 I GefahrenabwehrVO kann ein Verstoß gegen dieses Verbot als Ordnungswidrigkeit geahndet werden.

Bei der vorgenannten Gefahrenabwehrverordnung handelt es sich um eine abstrakt-generelle Regelung, weil schon das Gebiet, auf dem das Alkoholverbot gelten soll, abstrakt umschrieben ist, nämlich alle „öffentlich zugänglichen Flächen“ im Geltungsbereich. Zudem spricht hier

245 von Alemann/Scheffczyk, in: Bader/Ronellenfitsch,VwVfG, 42. Ed., Stand: 1.1.2019, § 35, Rn. 193; weitere Beispiele bei Heyle, NVwZ 2008, 390.

246 von Alemann/Scheffczyk, in: Bader/Ronellenfitsch,VwVfG, 42. Ed., Stand: 1.1.2019, § 35, Rn. 194; so auch VGH BW, Urt. v. 5.12.2002, Az.: 5 S 2625/01 = NZV 2003, 301: Zur Anordnung gegenüber einem bestimmten Adressaten, mit dem Liegefahrrad Radwege zu benutzen.

247 von Alemann/Scheffczyk, in: Bader/Ronellenfitsch,VwVfG, 42. Ed., Stand: 1.1.2019, §35, Rn. $195 \mathrm{ff}$.

248 von Alemann/Scheffczyk, in: Bader/Ronellenfitsch,VwVfG, 42. Ed., Stand: 1.1.2019, § 35, Rn. 196 m.w.N.

249 Vgl. VGH BW, Urt. v. 28.7.2009, Az.: 1 S 2200/08 = NVwZ-RR 2010, 55. 
auch schon die gewählte Form als Gefahrenabwehrverordnung indiziell für eine abstrakt-generelle Regelung (zur Rechtmäßigkeit von Alkoholverbotsverordnungen näher $\S 7$ Rn. 118). ${ }^{250}$

\section{f) Außenwirkung}

90 Die Maßnahme muss schließlich darauf gerichtet sein, ${ }^{251}$ Rechtswirkungen gegenüber einer Person zu erzeugen, die außerhalb des handelnden Verwaltungsträgers steht. ${ }^{252}$ Sie muss nach ihrem objektiven Sinngehalt dazu bestimmt sein, Außenwirkung zu entfalten, unabhängig davon, wie sie sich im Einzelfall auswirkt. ${ }^{253}$ Von wesentlicher Bedeutung ist dabei, ob der Adressat in seiner Eigenschaft als Teil der Verwaltung oder als selbstständiges Rechtssubjekt angesprochen wird. ${ }^{254}$ Die Außenwirkung ist nur dann als „unmittelbar“ einzuordnen, wenn keine weiteren Umsetzungsmaßnahmen notwendig sind, damit die Rechtsfolgen bei dem Adressaten eintreten. ${ }^{255}$ Schließlich geht es um die Abgrenzung zu rein verwaltungsinternen Vorgängen. ${ }^{256}$ Dazu zählen insbesondere - jedenfalls im Verhältnis zum Bürger - die Zustimmungs- und Genehmigungsakte anderer Behörden bei Erlass von mehrstufigen Verwaltungsakten ${ }^{257}$ (wie etwa die Erteilung des gemeindlichen Einvernehmens nach $\S 36 \mathrm{BauGB}^{258}$ ). ${ }^{259}$ Anders ist die Lage dann, wenn die Entscheidung der mitwirkenden Behörde dem Betroffenen als selbstständiger Verwaltungsakt bekannt gegeben wird. ${ }^{260} \mathrm{Ge}$ meinderatsbeschlüsse haben regelmäßig keine Außenwirkung, da sie grundsätzlich einer Umsetzung durch den Bürgermeister als monokratisches Ausfüh-

250 Vgl.von Alemann/Scheffczyk, in: Bader/Ronellenfitsch,VwVfG, 42. Ed., Stand:1.1.2019, § 35, Rn. 197 f.; Ramsauer, in: Kopp/Ramsauer, VwVfG, 19. Aufl. 2018, § 35, Rn. 120.

251 Vgl. BVerwG, Urt. v. 19.4. 2011, Az.: 1 C 2/10 = BeckRS 2011, 52368, Rn. 14: „Indem das Gesetz normiert, dass der Verwaltungsakt auf eine Rechtswirkung ,gerichtet‘ ist, betont es die Finalität des Verwaltungshandelns in dieser Handlungsform“; Stelkens, in: Stelkens/Bonk/Sachs, VwVfG, 9. Aufl. 2018, § 35, Rn. 147.

252 Vgl. statt vieler Schwarz, in: Fehling/Kastner/Störmer, Verwaltungsrecht, 4. Aufl. 2016, § 35 VwVfG, Rn. 103 m.w. N.

253 BVerwG, Urt. v. 26.4.2012, Az.: 2 C 17/10 = NVwZ 2012, 1483, Rn. 15; Stelkens, in: Stelkens/ Bonk/Sachs, VwVfG, 9. Aufl. 2018, § 35, Rn. 147.

254 Vgl. BVerwG, Urt.v. 2.3.2006, Az.: 2C 3/05 = NVwZ-RR 2007, 781; von Alemann/Scheffczyk, in: Bader/Ronellenfitsch,VwVfG, 42. Ed., Stand: 1.1.2019, § 35, Rn. 223.

255 von Alemann/Scheffczyk, in: Bader/Ronellenfitsch, VwVfG, 42. Ed., Stand: 1.1.2019, § 35, Rn. 224 m.w. N.; Müller, in: Huck/Müller, VwVfG, 2. Aufl. 2016, § 35, Rn. 45.

256 Vgl. Stelkens, in: Stelkens/Bonk/Sachs, VwVfG, 9. Aufl. 2018, § 35, Rn. 146.

257 Vgl. Ramsauer, in: Kopp/Ramsauer, VwVfG, 19. Aufl. 2018, § 35, Rn. 129.

258 Vgl. etwa BVerwG, NVwZ 1986, 556; Ramsauer, in: Kopp/Ramsauer, VwVfG, 19. Aufl. 2018, $\S 35$, Rn. 129 m.w. N.

259 Ramsauer, in: Kopp/Ramsauer, VwVfG, 19. Aufl. 2018, § 35, Rn. 131.

260 Ramsauer, in: Kopp/Ramsauer, VwVfG, 19. Aufl. 2018, § 35, Rn. 131.

Jens Milker 
rungsorgan bedürfen. ${ }^{261}$ Probleme hinsichtlich der Abgrenzung treten darüber hinaus im Beamtenrecht und bei Maßnahmen zwischen unterschiedlichen Behörden auf.

Bei Maßnahmen des Dienstherrn im öffentlichen Dienstrecht gegen- 91 über Beamten ist - auch nach berechtigter Ablehnung eines grundrechts- und rechtsschutzfreien Raums im Rahmen eines „besonderen Gewaltverhältnisses“262 - weiterhin zwischen dem Grund- und Betriebsverhältnis zur Feststellung der Außenwirkung einer Maßnahme zu unterscheiden. ${ }^{263}$

Hausarbeitswissen: Seit der sog. „Strafgefangenenentscheidung“ des Bundesverfassungsgerichts ${ }^{264}$ ist es in Rechtsprechung und Literatur allgemein anerkannt, dass auch in „Sonderstatusverhältnissen“, also etwa im Beamten- oder Soldatenverhältnis, ${ }^{265}$ kein ,besonderes Gewaltverhältnis“266 besteht, das „als eine eigenständige, implizite Beschränkung der Grundrechte“267 fungieren kann. ${ }^{268}$ Grundrechte gelten damit auch dem Grunde nach im Sonderstatusverhältnis, wobei im Rahmen der Rechtfertigung von Grundrechtseingriffen vor allem bei Beamten aufgrund des Näherverhältnisses zum Staat Besonderheiten gelten (insbesondere Art. 33 Abs. 5 GG). ${ }^{269}$ Insgesamt sind Maßnahmen in Sonderstatusverhältnissen allgemein einer verwaltungsgerichtlichen Kontrolle zugänglich, unabhängig davon, ob sie das Grund- oder Betriebsverhältnis betreffen. ${ }^{270}$

Dem Betriebsverhältnis sind solche Maßnahmen zuzuordnen, die bestimmen, 93 auf welche Art und Weise der Beamte seinen dienstlichen Verrichtungen nachzukommen hat (auch wenn sie - wie etwa die Anpassung der Haartracht - in der

261 Vgl. dazu (mit weiteren Beispielen): Pietzcker, in: Schoch/Schneider/Bier, VwGO, 36. EL Februar 2019, § 42 I, Rn. 60.

262 Vgl. dazu BVerfG, Beschl.v. 14.3.1972, Az.: 2 BvR 41/71 = NJW 1972, 811; Ramsauer, in: Kopp/ Ramsauer, VwVfG, 19. Aufl. 2018, § 35, Rn. 134.

263 Vgl. Ramsauer, in: Kopp/Ramsauer, VwVfG, 19. Aufl. 2018, § 35, Rn. 134f.; von Alemann/ Scheffczyk, in: Bader/Ronellenfitsch, VwVfG, 42. Ed., Stand: 1.1.2019, § 35, Rn. 239; Stelkens, in: Stelkens/Bonk/Sachs, VwVfG, 9. Aufl. 2018, § 35, Rn. 198; diese begriffliche Differenzierung ablehnend: Schwarz, in: Fehling/Kastner/Störmer, Verwaltungsrecht, 4. Aufl. 2016, § 35 VwVfG, Rn. 107.

264 BVerfG, Beschl.v. 14.3.1972, Az.: 2 BvR 41/71 = NJW 1972, 811.

265 S. zu einer ausführlichen Betrachtung weiterer Sonderstatusverhältnisse: Stelkens, in: Stelkens/Bonk/Sachs, VwVfG, 9. Aufl. 2018, § 35, Rn. 198 ff.; die „Sonderstatusverhältnisse“ bzw. „Sonderrechtsverhältnisse“ und damit die Differenzierung zwischen Grund- und Betriebsverhältnis auf das Beamten- und Soldatenverhältnis beschränkend: von Alemann/Scheffczyk, in: Bader/Ronellenfitsch, VwVfG, 42. Ed., Stand: 1.1.2019, § 35, Rn. $236 \mathrm{ff}$.

266 Vgl. zur historischen Entwicklung: v. Kielmansegg, JA 2012, 881.

267 BVerfG, Beschl.v. 14.3.1972, Az.: 2 BvR 41/71 = NJW 1972, 811 (812).

268 Vgl. statt vieler: Ramsauer, in: Kopp/Ramsauer, VwVfG, 19. Aufl. 2018, § 35, Rn. 134.

269 Vgl. dazu v. Kielmansegg, JA 2012, 881.

270 Ramsauer, in: Kopp/Ramsauer, VwVfG, 19. Aufl. 2018, § 35, Rn. 134. 
privaten Lebenssphäre fortwirken). ${ }^{271}$ Es kommt insoweit nicht allgemein auf die faktischen Auswirkungen, sondern auf die Zielrichtung der Maßnahme und deren beabsichtigte unmittelbare Folgen an. ${ }^{272}$ Demgegenüber zählen zum Grundverhältnis nicht nur die Begründung ${ }^{273}$, Beendigung ${ }^{274}$ und wesentliche Änderung ${ }^{275}$ des Sonderstatusverhältnisses, sondern alle Maßnahmen, die unmittelbar auf die Veränderung des individuellen Rechtsstatus des Betroffenen abzielen (z. B. Bewilligung von Urlaub $\left.{ }^{276}\right){ }^{277}$ Dementsprechend werden etwa Umsetzungen ${ }^{278}$ und sonstige dienstliche Weisungen ${ }^{279}$ mangels Außenwirkung regelmäßig nicht als Verwaltungsakte eingeordnet. ${ }^{280}$ Im Gegensatz dazu haben etwa die Ernennung ${ }^{281}$ und die Versetzung ${ }^{282}$ eines Beamten Außenwirkung. ${ }^{283}$ Ebenso wird überwiegend (besonders aktuell!) dem gegenüber einer Beamtin ausge-

271 Vgl. BVerwG, Urt.v. 2.3.2006, Az.: 2C 3/05 = NVwZ-RR 2007, 781 (allerdings ohne Verwendung des Begriffs „Betriebsverhältnis“); BVerwG, Urt. v. 22.5.1980, Az.: 2 C 30/78 = NJW 1981, 67: „Behördeninterne Maßnahmen sind insbesondere (...) die an einen Beamten allein in seiner Eigenschaft als Amtsträger und Glied der Verwaltung gerichteten, auf organisationsinterne Wirkung zielenden Weisungen des Dienstherrn und die auf die Art und Weise der dienstlichen Verrichtung bezogenen innerorganisatorischen Maßnahmen der Behörde, in deren Organisation der Beamte eingegliedert ist“.

272 Stelkens, in: Stelkens/Bonk/Sachs, VwVfG, 9. Aufl. 2018, §35, Rn. 198 m.w. N.

273 BVerwG, Urt. v. 1.2.1978, Az.: VI C 9/77 = BeckRS 1978, 00835, Rn. 17.

274 BVerwG, Urt. v. 12.4.1978, Az.: VIII C 70/76 = BeckRS 1978, 00897, Rn. 9.

275 z. B. Versetzung und Abordnung vgl. BVerwG, Urt. v. 22.5.1980, Az.: 2 C 30/78 = NJW 1981, 67 (68)).

276 Vgl. BVerwG, Urt. v. 15.3.1973, Az.: II C 7/71 = BVerwG, NJW 1973, 1242.

277 Vgl. BVerwG, Urt. v. 22.5.1980, Az.: 2 C 30/78 = NJW 1981, 67; Ramsauer, in: Kopp/Ramsauer, VwVfG, 19. Aufl. 2018, § 35, Rn. 136; von Alemann/Scheffczyk, in: Bader/Ronellenfitsch,VwVfG, 42. Ed., Stand: 1.1.2019, § 35, Rn. 239.

278 BVerwG, Urt. v. 19.11.2015, Az.: 2 A 6/13 = NVwZ 2016, 460, Rn. 18; BVerwG, Urt. v. 22.5.1980, Az.: 2 C 30/78 = NJW 1981, 67 (68).

279 BVerwG, Urt. v. 26.4.2012, Az.: 2 C 17/10 = NVwZ 2012, 1483, Rn. 15 (zur Anordnung einer ärztlichen Begutachtung); s. auch Ramsauer, in: Kopp/Ramsauer, VwVfG, 19. Aufl. 2018, §35, Rn. 139.

280 Dazu insgesamt auch mit weiteren Beispielen: von Alemann/Scheffczyk, in: Bader/Ronellenfitsch,VwVfG, 42. Ed., Stand:1.1.2019, § 35, Rn. 240.1 ff.; Ramsauer, in: Kopp/Ramsauer, VwVfG, 19. Aufl. 2018, § 35, Rn. 136 ff.; W. R. Schenke, in: Kopp/Schenke, VwGO, 25. Aufl. 2019, Anh. § 42, Rn. 70.

281 BVerwG, Urt. v. 1.2.1978, Az.: VI C 9/77 = BeckRS 1978, 00835, Rn. 17: „Die Ernennung, ein rechtsgestaltender formaler Verwaltungsakt, erlangt - wie andere Verwaltungsakte auch mit der Bekanntgabe - durch die Aushändigung an den Betroffenen äußere Wirksamkeit“.

282 BVerwG, Beschl. v. 18.2.2013, Az.: 2 B 51/12 = NVwZ 2013, 797, Rn. 16.

283 Weitere Beispiele auch bei von Alemann/Scheffczyk, in: Bader/Ronellenfitsch, VwVfG, 42. Ed., Stand: 1.1.2019, § 35, Rn. 240.1 ff. und W. R. Schenke, in: Kopp/Schenke, VwGO, 25. Aufl. 2019, Anh. § 42, Rn. 69. 
sprochenen Verbot des religiös motivierten Tragens eines Kopftuchs Außenwirkung zuerkannt. ${ }^{284}$

Sofern es sich um Maßnahmen zwischen mehreren Behörden handelt, 94 muss differenziert werden. Zunächst ist stets Außenwirkung anzunehmen, soweit die Behörde wie eine Privatperson betroffen ist, also die Maßnahme auf Grundlage einer Norm erfolgt, die die Behörde auch zum Erlass von Verwaltungsakten gegenüber Privatpersonen berechtigt (z.B. Festsetzung von Gebühren ${ }^{285}$ ). ${ }^{286} \mathrm{Im}$ Gegensatz dazu haben (Aufsichts-)Maßnahmen gegenüber Behörden desselben Rechtsträgers keine Außenwirkung. ${ }^{287}$

Bei Aufsichtsmaßnahmen zwischen Behörden unterschiedlicher 95

Rechtsträger sind bei Selbstverwaltungskörperschaften (z. B. Gemeinden, Universitäten oder Rundfunkanstalten) Maßnahmen der Rechts- und Fachaufsicht zu unterscheiden. ${ }^{288}$ Während bei der Fachaufsicht ${ }^{289}$ die beaufsichtigte Behörde in der Regel keine „geschützte Rechtsstellung“ gegenüber der Aufsichtsbehörde innehat und daher wie eine (staatliche) Behörde desselben Rechtsträgers zu behandeln ist, kann insoweit auch grundsätzlich keine Außenwirkung angenommen werden; sie bewegt sich dabei in dem ihr übertragenen (staatlichen) Aufgabenbereich. ${ }^{290}$ Bei der Rechtsaufsicht ${ }^{291}$ hingegen befindet sich die beaufsichtigte

284 Vgl.VGH BW, Urt. v. 14. 3.2008, Az.: 4 S 516/07 = BeckRS 2008, 34909, Rn. 22; W. R. Schenke, in: Kopp/Schenke, VwGO, 25. Aufl. 2019, Anh. § 42, Rn. 69; so wohl auch BayVGH, BeckRS 2018, 7009; a. A. wohl: Windoffer, in: Mann/Sennekamp/Uechtritz, VwVfG, 1. Aufl. 2014, § 35, Rn. 119; s. aktuell zu der Zulässigkeit solcher Verbote für Rechtsreferendarinnen: BVerfG, Beschl. v. 27.6. 2017, Az.: 2 BvR 1333/17 = NJW 2017, 2333.

285 Vgl. BVerwG, Urt. v. 19.1.2000, Az.: 11 C 6/99 = NVwZ 2000, 673 (674).

286 Vgl. Stelkens, in: Stelkens/Bonk/Sachs, VwVfG, 9. Aufl. 2018, § 35, Rn. 189 f.; von Alemann/ Scheffczyk, in: Bader/Ronellenfitsch,VwVfG, 42. Ed., Stand: 1.1.2019, §35, Rn. $233 \mathrm{ff}$.

287 Vgl. zu einer Weisung des Bundesministeriums des Innern gegenüber dem BND: BVerwG, Urt. v. 23.1.2008, Az.: 6 A 1/07 = NJW 2008, 2135 (2136); s. allgemein auch Ramsauer, in: Kopp/ Ramsauer, VwVfG, 19. Aufl. 2018, § 35, Rn. 151.

288 Vgl. von Alemann/Scheffczyk, in: Bader/Ronellenfitsch,VwVfG, 42. Ed., Stand:1.1.2019, § 35, Rn. $228 \mathrm{ff}$.

289 Dabei wird die Recht- und Zweckmäßigkeit überprüft, vgl. von Alemann/Scheffczyk, in: Bader/Ronellenfitsch,VwVfG, 42. Ed., Stand: 1.1.2019, § 35, Rn. 231.

290 Vgl. BVerwG, Beschl. v. 27.2.1978, Az.: 7 B 36/77 = NJW 1978, 1820 (1821); s. auch BVerwG, Urt. v. 14.12.1994, Az.: 11 C 4/94 =NVwZ 1995, 910: Daher kann auch eine fachaufsichtliche Weisung nach § 44 I 2 StVO ihrem objektiven Sinngehalt nach auf Außenwirkung gerichtet und damit Verwaltungsakt sein, wenn ihre Rechtswirkung unter Berücksichtigung des zugrundeliegenden materiellen Rechts nicht im staatlichen Innenbereich verbleibt, sondern auf den rechtlich geschützten Bereich der Gemeinde in Selbstverwaltungsangelegenheiten übergreift und damit Außenwirkung erzeugt“; Ramsauer, in: Kopp/Ramsauer, VwVfG, 19. Aufl. 2018, § 35, Rn. 156; insoweit a. A. Stelkens, in: Stelkens/Bonk/Sachs, VwVfG, 9. Aufl. 2018, § 35, Rn. 181.

Jens Milker 
Stelle in ihrem eigenen Wirkungskreis (z. B. Art. 28 II GG) und hat daher eine geschützte Rechtsposition inne, die sie gleichsam aus dem Verwaltungsaufbau heraushebt und ihr im Verhältnis zur Aufsichtsbehörde eine bürgerähnliche Stellung zuschreibt. ${ }^{292}$ Infolgedessen haben etwa Maßnahmen der Kommunalaufsicht (z. B. die Beanstandung ${ }^{293}$ ) Außenwirkung. ${ }^{294}$

\section{Prozessuale Folgen bei Fehlen der Voraussetzungen}

96 Fehlt zumindest eine der oben dargestellten (Wesens-)Voraussetzungen, liegt jedenfalls kein Verwaltungsakt im materiellen Sinne vor. ${ }^{295}$ Für den prozessualen Umgang mit solchen Handlungen ist allerdings eine differenzierte Betrachtung geboten. Sofern es sich etwa um einen Realakt oder Regelungen ohne Außenwirkung handelt, wäre die allgemeine Leistungsklage (s. $§ 5$ Rn. 2 ff.) oder ggf. die Feststellungsklage statthaft (s. §6 Rn. 2ff.). Ist hingegen eine Rechtsnorm der prüfungs- bzw. Streitgegenstand, wäre die verwaltungsgerichtliche Normenkontrolle in den Blick zu nehmen (§ 47 VwGO; s. näher dazu § 7). Besteht allerdings zumindest formal der Anschein eines Verwaltungsakts, unterscheidet die Rechtsprechung und Literatur im Wesentlichen zwischen „Scheinverwaltungsakten“296 und rein formellen Verwaltungsakten ${ }^{297}{ }^{298}$

97 Ein sog. „Scheinverwaltungsakt“ bzw. „Nichtakt“ ist bei drei Fallgruppen anzunehmen: die unwirksame Bekanntgabe eines Verwaltungsakts (s. dazu Rn. 20), ${ }^{299}$ den fehlenden Willen der Behörde zum Erlass eines Verwaltungsakts ${ }^{300}$ und den Fall, dass die Maßnahme nicht durch eine Behörde erfolgte bzw. die-

291 Dabei wird - vergleichbar mit der gerichtlichen Prüfungsdichte - nur die Recht- und nicht auch die Zweckmäßigkeit geprüft, vgl. Franz, JuS 2004, 937 unter Hinweis auf § 114 VwGO analog. 292 Vgl. im Ergebnis: von Alemann/Scheffczyk, in: Bader/Ronellenfitsch,VwVfG, 42. Ed., Stand: 1.1.2019, § 35, Rn. 232; Schwarz, in: Fehling/Kastner/Störmer, Verwaltungsrecht, 4. Aufl. 2016, § 35 VwVfG, Rn. 106; Ramsauer, in: Kopp/Ramsauer, VwVfG, 19. Aufl. 2018, § 35, Rn. 155.

293 Vgl. OVG NRW, Urt. v. 12.3.2013, Az.: 20 A 1564/10 = ZUR 2013, 547.

294 von Alemann/Scheffczyk, in: Bader/Ronellenfitsch,VwVfG, 42. Ed., Stand: 1.1.2019, § 35, Rn. 232; Ramsauer, in: Kopp/Ramsauer, VwVfG, 19. Aufl. 2018, § 35, Rn. 155.

295 Stelkens, in: Stelkens/Bonk/Sachs, VwVfG, 9. Aufl. 2018, § 35, Rn. 16.

296 Vgl. etwa Barczak, JuS 2018, 238 (244); eingehend auch Blunk/Schroeder, JuS 2005, 602. 297 Stelkens, in: Stelkens/Bonk/Sachs, VwVfG, 9. Aufl. 2018, § 35, Rn. 16; Barczak, JuS 2018, 238 (244): „Verwaltungsakt kraft Form“; Bickenbach, JA 2015, 481 (483).

298 Vgl. zum Ganzen auch Barczak, JuS 2018, 238 (244).

299 Vgl. dazu BVerwG, Urt. v. 21.11.1986, Az.: 8 C 127/84 = NVwZ 1987, 330: „Nichtakt“.

300 Vgl. Bickenbach, JA 2015, 481 (487): ,[E]in Schriftstück wurde für interne Zwecke gefertigt, ist aber aus Versehen verschickt worden und sieht aus wie ein Verwaltungsakt“.

Jens Milker 
ser nicht zugerechnet werden $\mathrm{kann}^{301} .^{302}$ Gemeint mit dem Begriff des formellen Verwaltungsakts ,sind Maßnahmen, die eine Behörde willentlich in Form eines Verwaltungsakts kleidet, obgleich gesetzliche Merkmale nicht erfüllt sind, die daher ohne die Form keine Verwaltungsakte wären“ (näher dazu schon Rn. $21 \mathrm{ff}$.). ${ }^{303}$ Als statthafte Klagearten werden insoweit die Anfechtungsklage ${ }^{304}$ und die (negative) Feststellungsklage gemäß § 43 I VwGO ${ }^{305}$ diskutiert (s. näher dazu Rn. 20 ff.), wobei auch ein Nebeneinander beider Klagearten denkbar erscheint. ${ }^{306}$

\section{Die Wirksamkeit des Verwaltungsakts (Tobias Brings-Wiesen)}

Die Anfechtungsklage gemäß § 42 I Var. 1 VwGO ist statthaft, wenn der Kläger 98 gegen einen (ihn belastenden) Verwaltungsakt aufbegehrt (s. zum Klagebegehren Rn. 9 ff.). Dies setzt (zumindest grundsätzlich) nicht nur voraus, dass es sich rechtsförmlich um einen Verwaltungsakt i.S.v. § 35 VwVfG (zum Begriff des Verwaltungsakts Rn. $38 \mathrm{ff}$. und zum Umgang mit sog. „formellen Verwaltungsakten“ Rn. 21ff.) handelt, sondern auch, dass der Verwaltungsakt wirksam i.S.v. § 43 VwVfG ist. Bereits Wortlaut und Systematik der Norm verdeutlichen, dass dafür drei Voraussetzungen erfüllt sein müssen:

- Der Verwaltungsakt muss durch Bekanntgabe überhaupt wirksam geworden sein (§ 43 I VwVfG);

301 Stelkens, in: Stelkens/Bonk/Sachs, VwVfG, 9. Aufl. 2018, § 35, Rn. 56, 62f.; s. auch das Beispiel bei Bickenbach, JA 2015, 481 (487): Eine Privatperson stellt ohne wirksame Beleihung ein in der StVO geregeltes Verkehrsschild auf.

302 Vgl. Blunk/Schroeder, JuS 2005, 602 (603f.); Bickenbach, JA 2015, 481 (487).

303 Bickenbach, JA 2015, 481 (483); Barczak, JuS 2018, 238 (244).

304 Für formelle Verwaltungsakte: BSG, Urt.v. 5.9.2006, Az.: B 4 R 71/06 R = BeckRS 2006, 44566, Rn. 16; BVerwG, Beschl.v. 18.1.1993, Az.: 6 B 5/92 = NVwZ-RR 1993, 251 (252); BayVGH, Urt. v. 2. 8. 2016, Az.: 22 B 16.619 = BeckRS 2016, Rn. 35, 41 ff.; VG Mainz, Urt. v. 3.7.2018, Az.: 1 K 1463/17.MZ = BeckRS 2c018, 20916, Rn. 17; für nicht wirksam bekannt gegebene Verwaltungsakte: OVG RP, Urt.v. 25.6.1986, Az.: 8 A 92/85 = NVwZ 1987, 899; allgemein für Scheinverwaltungsakte: Blunk/Schroeder, JuS 2005, 602 (603).

305 So für Scheinverwaltungsakte und formelle Verwaltungsakte: Bickenbach, JA 2015, 481 (486f.); für formelle Verwaltungsakte: VG Wiesbaden, Urt. v. 5.3.2007, Az.: 7 E 1536/06 = NVwZ-RR 2007, 613; für nicht wirksam bekanntgegebene Verwaltungsakte: BVerwG, Urt. v. 21.11.1986, Az.: 8 C 127/84 = NVwZ 1987, 330.

306 Insoweit bei Scheinverwaltungsakten ein „Wahlrecht“ des Klägers annehmend: Blunk/ Schroeder, JuS 2005, 602 (603). 
- $\quad$ sodann darf er seine Wirksamkeit nicht (von Anfang an oder nachträglich) aufgrund von Nichtigkeit gemäß § 44 VwVfG (§ 43 III VwVfG) oder

- durch spätere Aufhebung oder Erledigung wieder eingebüßt haben (§ 43 II VwVfG). ${ }^{307}$

99 Steht die Wirksamkeit eines Verwaltungsakts in Frage, bieten sich den Betroffenen diverse Möglichkeiten, ein etwaiges Rechtsschutzbegehren zu realisieren. Nach herrschender Meinung bleibt indes gegen nicht wirksam gewordene oder nichtige Verwaltungsakte auch die Anfechtungsklage eine Option (s. auch Rn. 19 ff. sowie näher noch Rn. 174 ff. und 197 ff.).

100 Darüber hinaus gilt es zu bedenken, dass sich die Frage der Wirksamkeit eines Verwaltungsakts vielfach auch inzident im Rahmen der Prüfung anderer Verwaltungsmaßnahmen stellen kann. Ein regelrechter Klausurklassiker ist die Frage der Wirksamkeit einer Grundverfügung im Rahmen der Verwaltungsvollstreckung (für die Vollstreckung im sog. gestreckten Verfahren sowie den folgenden Kostenbescheid; zum Vollstreckungsrecht Rn. $1327 \mathrm{ff}$.). Besonderer Beliebtheit erfreuen sich dabei die Fälle von Vollstreckungsmaßnahmen auf Grundlage von nach einem Verkehrsvorgang (wie dem Parken) aufgestellten mobilen Verkehrsschildern (s. dazu sogleich Rn. 165ff.). Prüfungsrelevant ist zudem die Frage der Wirksamkeit von Nebenbestimmungen im Falle des Widerrufs von Verwaltungsakten (s. dazu näher Rn. 959, 962). Fragen der Nichtigkeit gemäß §44 VwVfG können sich schließlich auch bei der Prüfung subordinationsrechtlicher Verträge gemäß § 54 S. 2 VwVfG stellen (§ 59 II Nr. 1 VwVfG) (s. dazu näher $§ 5$ Rn. 99).

101 Vor diesem Hintergrund ist es elementar, sich mit der Systematik und den Voraussetzungen der Wirksamkeit von Verwaltungsakten eingehend vertraut zu machen.

\section{Die Wirksamkeit von Verwaltungsakten i.S.v. § 43 VwVfG}

102 Ausgangspunkt eines umfassenden Verständnisses der Wirksamkeit von Verwaltungsakten ist \$ 43 VwVfG. Die Vorschrift enthält Vorgaben zu Beginn und Ende der Wirksamkeit, setzt den „Begriff“ der Wirksamkeit damit aber nur voraus, ohne ihn selbst zu definieren. ${ }^{308}$ Auch eine allgemein anerkannte Definition

307 S. für einen guten Überblick auch die Aufbauhilfe für die Prüfung der Wirksamkeit eines Verwaltungsakts des öffentlich-rechtlichen Online-Lernprojekts „Saarheim“ von Grupp und Stelkens, abrufbar unter: http://saarheim.de/Anmerkungen/vawirksamkeit.htm.

308 Ramsauer, in: Kopp/Ramsauer, VwVfG, 20. Aufl. 2019, § 43 Rn. 3; Sachs, in: Stelkens/Bonk/ Sachs, VwVfG, 9. Aufl. 2018, § 43 Rn. 163; Schwarz, in: Fehling/Kastner/Störmer, Verwaltungsrecht, 4. Aufl. 2016, § 43 VwVfG Rn. 1, 6. 
des Begriffs existiert nicht. ${ }^{309}$ Dies ist auch der Tatsache geschuldet, dass sich die hinter dem Begriff verbergende Dogmatik nur schwer in wenige griffige Worte fassen lässt. Stark verallgemeinernd lässt sich festhalten: „Wirksamkeit“ beschreibt den Zustand, währenddessen ein Verwaltungsakt die mit seiner Regelung (zu diesem Merkmal näher Rn. 63ff.) verfolgten Rechtswirkungen gegenüber einem durch diese Regelung näher bestimmten Personenkreis entfaltet. ${ }^{310}$

Diese Entfaltung von Rechtswirkungen muss in materieller, persönlicher 103 und insbesondere zeitlicher Hinsicht noch weiter konkretisiert werden. ${ }^{311}$ Dies soll hier im Interesse der Verständlichkeit nur überblicksartig geschehen. ${ }^{312}$

\section{a) Die Wirksamkeit von Verwaltungsakten in materieller und persönlicher Hinsicht}

In materieller Hinsicht kommt es auf den Regelungsinhalt des Verwaltungsakts an. Dieser muss gegebenenfalls unter Heranziehung der zugrundeliegenden materiellen Vorschriften näher bestimmt werden. Für den Zeitraum der Wirksamkeit eines Verwaltungsakts besteht insofern eine Bindungswirkung ${ }^{313}$ an die Regelung. Sie ist grundsätzlich auf diesen verfügenden Teil des Verwaltungsakts, den Tenor der Entscheidung, beschränkt und nach dem objektiven Empfängerhorizont zu bestimmen. ${ }^{314}$ Nur in gesetzlich vorgesehenen Fällen kann es über den verfügenden Teil des Verwaltungsakts hinaus zu einer Bindungs-

309 Leisner-Egensperger, in: Mann/Sennekamp/Uechtritz, VwVfG, 2. Aufl. 2019, § 43 Rn. 2.

310 Vgl. auch Maurer/Waldhoff, Allgemeines Verwaltungsrecht, 19. Aufl. 2017, § 10 Rn. 5; Peuker, in: Knack/Henneke, VwVfG, 10. Aufl. 2014, § 43 Rn. 6.

311 Anschaulich auch Leisner-Egensperger, in: Mann/Sennekamp/Uechtritz, VwVfG, 2. Aufl. 2019, § 43 Rn. 3, 5 ff.; vgl. entsprechend Ramsauer, in: Kopp/Ramsauer, VwVfG, 20. Aufl. 2019, § 43 Rn. $3 \mathrm{ff}$.

312 S. zu den Bindungswirkungen ausführlich Randak, JuS 1992, 33; Schroeder, DÖV 2009, 217. 313 Die Terminologie zur Beschreibung der Bindungswirkung - insbesondere in ihren verschiedenen Wirkungsfacetten - divergiert stark, sodass bei ihrer Verwendung und Rezeption stets Vorsicht geboten ist, s. dazu nur Ramsauer, in: Kopp/Ramsauer, VwVfG, 20. Aufl. 2019, § 43 Rn. 14. Im Folgenden werden die Begrifflichkeiten im Anschluss an die gängige Lehrbuchliteratur verwendet, s. nur Maurer/Waldhoff, Allgemeines Verwaltungsrecht, 19. Aufl. 2017, §10 Rn. 18; Detterbeck, Allgemeines Verwaltungsrecht, 17. Aufl. 2019, Rn. 544; Peine/Siegel, Allgemeines Verwaltungsrecht, 12. Aufl. 2018, Rn. 462. Es ist jedoch zu bedenken, dass darüber hinaus auch ganz andere Ausgangspunkte einer Systematisierung gewählt werden, s. bspw. Sachs, in: Stelkens/Bonk/Sachs, VwVfG, 9. Aufl. 2018, § 43 passim (insbesondere Rn. 7f.); so auch Windoffer, JURA 2017, 1274 (1275f.): Terminologischer Ausgangspunkt „Bestandskraft“.

314 Die Begründung des Verwaltungsakts kann nur ergänzend zur Bestimmung des Regelungsinhalts herangezogen werden, BVerwG, Urt. v. 11.12.2014, Az.: 3 C 6.13 = BVerwGE 151, 129 (132, Rn. 18). So auch Ramsauer, in: Kopp/Ramsauer, VwVfG, 20. Aufl. 2019, § 43 Rn. 15. 
wirkung kommen (sog. „Feststellungswirkung“, s. dazu Rn. 110). ${ }^{315}$ Die besondere Schwierigkeit besteht darin, im Einzelfall den Regelungsinhalt genau und abgrenzend $\mathrm{zu}$ bestimmen.

Diese Bindungswirkung besteht grundsätzlich unabhängig von der Rechtskonformität des wirksam gewordenen Verwaltungsakts. ${ }^{316}$ Die „Wirksamkeit“ eines Verwaltungsakts ist entsprechend der gesetzlichen Grundsystematik zwingend von seiner „Rechtmäßigkeit“ abzugrenzen. Diese Abgrenzung ist bereits in § 43 II, III VwVfG angelegt. Die Vorschriften bestimmen eine fortwährende Wirksamkeit, solange und soweit es nicht zu einem aktiven Einwirken Dritter auf eben diese Wirksamkeit (durch Rücknahme, Widerruf oder anderweitige Aufhebung) oder zum Eintritt bestimmter, die Regelungswirkung des Verwaltungsakts tilgender Ereignisse (seiner Erledigung durch Zeitablauf oder auf andere Weise) kommt. Ansonsten ist von einer Unwirksamkeit nur dann auszugehen, wenn ein Verwaltungsakt nichtig ist. ${ }^{317}$ Diese Unterscheidung ist gar einer der zentralen Anreize der Verwaltung, auf das Handlungsinstrument des Verwaltungsakts zurückzugreifen (s. dazu Rn. 40). Im Interesse der Sicherung von Rechtssicherheit und Rechtsfrieden ${ }^{318}$ sowie der Funktionsfähigkeit der Verwaltung tritt der Grundsatz der Gesetzmäßigkeit der Verwaltung (s. dazu $\S 1$ Rn. 13) unter den Bedingungen des $\S 43$ VwVfG in der Abwägung zurück. Dies hat zur Folge, dass auch rechtswidrige Verwaltungsakte bestandskräftig werden können und somit ihre Wirksamkeit grundsätzlich dauerhaft behalten (s. dazu Rn. 115). Nach ganz herrschender Meinung kann die Behörde sie auch trotz ihrer Rechtswidrigkeit im Wege der Verwaltungsvollstreckung durchsetzen (s. dazu § 2 Rn. 1327 f.).

315 Vgl. für den Regelfall beispielhaft BVerwG, Urt. v. 1.9.2011, Az.: 5 C 27.10 = BVerwGE 140, 311 (316, Rn. 20): Durch eine unbefristete Aufenthaltserlaubnis wird nur die Rechtmäßigkeit des dauerhaften Aufenthalts einer Person begründet. Die Identität einer Person muss zwar als Erteilungsvoraussetzung geklärt sein (§ 5 I Nr. 1a AufenthG), sie ist jedoch bloße Vorfrage, sodass deren Richtigkeit nicht Teil des Regelungsinhalts wird. Dem Verwaltungsakt liegt die Tatsachenfeststellung nur zugrunde, sie wird nur implizit festgestellt. Die Identität kann daher im Rahmen eines späteren Einbürgerungsverfahrens uneingeschränkt geprüft werden.

316 S. nur Maurer/Waldhoff, Allgemeines Verwaltungsrecht, 19. Aufl. 2017, § 10 Rn. 6.

317 An der Regelung des $§ 44$ VwVfG - insbesondere wegen der Voraussetzung des „besonders schwerwiegenden Fehlers“ - zeigt sich jedoch, dass zwischen der Rechtmäßigkeit und der Wirksamkeit des wirksam gewordenen Verwaltungsakts durchaus ein sachlicher Zusammenhang besteht; s. dazu noch § $6 \mathrm{Rn}$. $149 \mathrm{ff}$.

318 Ramsauer, in: Kopp/Ramsauer, VwVfG, 20. Aufl. 2019, § 43 Rn. 1b; Sachs, in: Stelkens/Bonk/ Sachs, VwVfG, 9. Aufl. 2018, § 43 Rn. 9 ff. m.w. N. 
Die Bindungswirkung des Verwaltungsakts kann in persönlicher Hinsicht 106 unterschiedlich ausfallen. Dabei kann grundsätzlich binär zwischen der privaten und der staatlichen Seite unterschieden werden.

Der Kreis der Privatpersonen, für die die Wirksamkeit eines Verwaltungs- 107 akts relevant sein kann, wird in $\S 43$ I 1 VwVfG bestimmt. Demnach wird ein Verwaltungsakt gegenüber demjenigen wirksam, für den er bestimmt ist oder der von ihm betroffen wird. ${ }^{319}$ Die Bestimmung ergibt sich dabei maßgeblich aus dem Regelungsinhalt des Verwaltungsakts, wie die Behörde ihn festlegt. ${ }^{320}$ Die so identifizierte Person wird gemeinhin als Adressat des Verwaltungsakts ${ }^{321}$ bezeichnet. Je nach Regelungsinhalt des Verwaltungsakts kann sich darüber hinaus die Frage stellen, ob der Verwaltungsakt auch einen Rechtsnachfolger binden kann. ${ }^{322}$ Dafür bedarf es des Eintretens eines Nachfolgetatbestands und - wichtiger noch - der grundsätzlichen Nachfolgefähigkeit eines Rechts oder einer Pflicht. ${ }^{323}$ Sofern eine Nachfolge nicht bereits ausdrücklich gesetzlich vorgesehen ist, ${ }^{324}$ muss die Nachfolgefähigkeit unter Berücksichtigung der Regelungszwecke eines Verwaltungsakts und des ihm zugrundeliegenden Rechts via Auslegung ermittelt werden. Insbesondere im Falle sog. höchstpersönlicher Verwaltungsak$t^{325}$ fehlt eine Nachfolgefähigkeit. Von einem Verwaltungsakt sonst betroffen ist die Person, die vom Regelungsinhalt des Verwaltungsakts unter Berücksichtigung der aus dem einschlägigen materiellen Recht resultierenden Rechtsfolgewirkun-

319 Die Begriffe entsprechen weitestgehend denen in $\S 41 \mathrm{I} 1 \mathrm{VwVfG}$ mit der zentralen Ausnahme, dass nicht an die Beteiligtenstellung gemäß $§ 13$ VwVfG angeknüpft wird. Dies ändert jedoch nichts daran, dass auch ein nicht am Verfahren Beteiligter betroffen sein und ihm der Verwaltungsakt entsprechend bekanntgegeben werden kann, s. dazu noch Rn. 126.

320 Ramsauer, in: Kopp/Ramsauer, VwVfG, 20. Aufl. 2019, § 43 Rn. 10; Leisner-Egensperger, in: Mann/Sennekamp/Uechtritz, VwVfG, 2. Aufl. 2019, § 43 Rn. 29.

321 Wobei der Sprachgebrauch stets auf seinen Sachzusammenhang hin zu prüfen ist; s. nur Stelkens, in: Stelkens/Bonk/Sachs, VwVfG, 9. Aufl. 2018, § 41 Rn. 29, der zu Recht gleich zwischen „materiellem Adressat“, „Inhaltsadressat“ und „Bekanntgabeadressat“ unterscheidet.

322 S. dazu näher Erbguth/Guckelberger, Allgemeines Verwaltungsrecht, 9. Aufl. 2018, § 13 Rn. 14.

323 S. dazu näher Ramsauer, in: Kopp/Ramsauer, VwVfG, 20. Aufl. 2019, § 43 Rn. $13 \mathrm{ff}$.

324 S. dazu insbesondere die verschiedenen Vorschriften zur Nachfolgefähigkeit bauaufsichtlicher Maßnahmen in den Landesbauordnungen, bspw. § 58 III BauO NRW.

325 S. dazu die griffige Definition des OVG Münster, Urt. v. 27.2.2013, Az.: 13 A 2661/11= juris, Rn. 36. Dies sind bspw. solche Verwaltungsakte, die an besondere persönliche Merkmale oder Fähigkeiten gebunden sind, wie die Gaststättenerlaubnis gemäß § 2 I 1 GastG, die die für den Gewerbebetrieb erforderliche Zuverlässigkeit des Antragsstellers voraussetzt (§ 4 I 1 Nr. 1 GastG), oder die Fahrerlaubnis gemäß § 2 I 1 StVG, für die die Befähigung zum Führen von Kraftfahrzeugen in einer theoretischen und praktischen Prüfung nachzuweisen ist (§ 2 II 1 Nr. 5, V StVG). 
gen in ihren rechtlich geschützten Interessen berührt wird. ${ }^{326}$ Diese Personen trifft im Hinblick auf den Regelungsinhalt des ihnen bekanntgegebenen Verwaltungsakts ein Beachtungsgebot.

108

Zumindest expressis verbis blendet die Vorschrift des $\S 43 \mathrm{VwVfG}$ die staatliche Seite komplett aus. Aus Gründen der Rechtssicherheit und des Vertrauensschutzes der Betroffenen kann der Staat jedoch nicht von jeglicher Bindungswirkung freigestellt werden. Primär ist die Wirksamkeit des Verwaltungsakts für die ihn erlassende Behörde (s. zum Behördenbegriff näher Rn. $52 \mathrm{ff}$.) und ihren Rechtsträger ${ }^{327}$ von Relevanz. Auch sie trifft ein Beachtungsgebot. Darüber hinaus können sie den Verwaltungsakt nur noch unter den Voraussetzungen der §§ $48 \mathrm{ff}$. VwVfG (oder ggf. einschlägiger Spezialvorschriften) wieder aufheben (sog. „Aufhebungsverbot“328); sie können hinsichtlich seines Regelungsgegenstandes auch keine neue abweichende Entscheidung treffen (sog. „Abweichungsverbot“329).

Die Wirkung des Verwaltungsakts kann indes auch über diesen Personenkreis hinausgehen. ${ }^{330}$ Wegen der mit ihm verbundenen sog. „Tatbestandswirkung“331 erlangt er grundsätzlich auch für alle anderen Behörden und Rechtsträger ${ }^{332}$ und sogar die Gerichte ${ }^{333}$ Bedeutung. Soweit der Verwaltungsakt nicht selbst Gegenstand der rechtlichen Überprüfung ist, haben sie ihn ihren Entscheidungen zugrunde zu legen. ${ }^{334}$ Diese Tatbestandwirkung trägt grundsätzlich jeder Verwaltungsakt ohne besondere gesetzliche Anordnung ${ }^{335}$ in sich. ${ }^{336}$

326 Vgl. Leisner-Egensperger, in: Mann/Sennekamp/Uechtritz, VwVfG, 2. Aufl. 2019, § 43 Rn. 30. 327 Ramsauer, in: Kopp/Ramsauer, VwVfG, 20. Aufl. 2019, § 43 Rn. 12; Leisner-Egensperger, in: Mann/Sennekamp/Uechtritz, VwVfG, 2. Aufl. 2019, § 43 Rn. 31; s. zu Fragen der Verwaltungsorganisation ausführlich Rn. $582 \mathrm{ff}$.

328 Ramsauer, in: Kopp/Ramsauer, VwVfG, 20. Aufl. 2019, § 43 Rn. 14c.

329 Ramsauer, in: Kopp/Ramsauer, VwVfG, 20. Aufl. 2019, § 43 Rn. 14d.

330 Ausführlich zu Tatbestands- und Feststellungswirkung Rebler, DVBl 2017, 1279.

331 Der Begriff wird heute weiterhin nicht einheitlich gebraucht, seine Verwendung scheint jedoch von einer erkennbaren Mehrheit in Rechtsprechung und Literatur zumindest akzeptiert, s. nur die Nachweise bei Sachs, in: Stelkens/Bonk/Sachs, VwVfG, 9. Aufl. 2018, § 43 Rn. 140. Bedeutsamer ist vor diesem Hintergrund, die hinter dem Begriff stehende Idee verstanden zu haben. 332 BVerwG, Urt. v. 4.7.1986, Az.: 4 C 31.84 = BVerwGE 74, 315 (320); BVerwG, Beschl.v. 11.2.2016, Az.: 4 B 1.16 = NVwZ-RR 2016, 471.

333 BVerwG, Urt. v. 30.1.2003, Az.: 4 CN 14.01 = BVerwGE 117, 351 (354f.). Dies gilt grundsätzlich auch gegenüber Zivilgerichten, vgl. nur BGH, Urt. v. 4.2.2004, Az.: XII ZR 301/01 = BGHZ 158, 19 (22); Beschl.v. 16.12. 2014, Az.: EnVR 54 /13 = juris, Rn. 19. Ausnahmen hat der BGH jedoch für den wichtigen Bereich des Staatshaftungsrechts angenommen, s. dazu Ramsauer, in: Kopp/Ramsauer, VwVfG, 20. Aufl. 2019, § 43 Rn. 22 m.w. N.; ausführlich Beaucamp, DVBl 2004, 352.

334 BVerwG, Urt. v. 10.10.2006, Az.: 8 C 23.05 = juris, Rn. 22; Maurer/Waldhoff, Allgemeines Verwaltungsrecht, 19. Aufl. 2017, § 10 Rn. 20; Leisner-Egensperger, in: Mann/Sennekamp/Uecht-

Tobias Brings-Wiesen 
Auch die sog. „Feststellungswirkung“ eines Verwaltungsakts geht über den 110 besagten Personenkreis hinaus. Ihre Besonderheit ist jedoch, dass sie in materieller Erweiterung der Tatbestandswirkung über den Regelungsinhalt des Verwaltungsakts hinaus auch die ihm zugrundeliegenden tatsächlichen und rechtlichen Feststellungen erfasst. ${ }^{337}$ Die Feststellungswirkung eines Verwaltungsakts muss daher gesetzlich angeordnet sein. ${ }^{338}$

\section{b) Die Wirksamkeit von Verwaltungsakten in zeitlicher Hinsicht}

Auch in zeitlicher Hinsicht gelingt es dem Begriff der „Wirksamkeit“ allein 111 nicht, den durchaus komplexen und von verschiedenen (äußeren wie inneren) Faktoren beeinflussten Lebenszyklus eines Verwaltungsakts ${ }^{339} \mathrm{zu}$ umschreiben. Es ist dogmatisch wie begrifflich weiter zu differenzieren $z_{\text {wischen }}{ }^{340}$ seiner rechtlichen Existenz, seiner äußeren Wirksamkeit, seiner inneren Wirksamkeit sowie seiner Bestandskraft. ${ }^{341}$

Gemäß § 43 I 1 VwVfG wird ein Verwaltungsakt gegenüber demjenigen, für 112 den er bestimmt ist oder der von ihm betroffen wird, in dem Zeitpunkt wirksam, indem er ihm bekannt gegeben wird. Zentraler Anknüpfungspunkt des Wirk-

ritz, VwVfG, 2. Aufl. 2019, § 43 Rn. 39f.; s. aber zur Problematik im Straf- und Ordnungswidrigkeitenrecht Leisner-Egensperger, a. a. O., Rn. 42.

335 BVerwG, Urt. v. 23.4.1980, Az.: 8 C 82.79 = BVerwGE 60, 111 (116f.). Der Gesetzgeber kann die Tatbestandswirkung indes auch gesetzlich näher ausgestalten, Leisner-Egensperger, in: Mann/ Sennekamp/Uechtritz, VwVfG, 2. Aufl. 2019, § 43 Rn. 43. Insbesondere kann er sie gesetzlich ausdrücklich anordnen, vgl. bspw. $\S 6$ und $\S 42$ AsylG.

336 Davon abzugrenzen sind Konstellationen sog. „erweiterter besonderer Tatbestandswirkung“, Ramsauer, in: Kopp/Ramsauer, VwVfG, 20. Aufl. 2019, § 43 Rn. 24 f., bzw. sog. „Tatbestandswirkung im engeren Sinne“, Sachs, in: Stelkens/Bonk/Sachs, VwVfG, 9. Aufl. 2018, § 43 Rn. 154, bei denen das Vorliegen eines Verwaltungsakts als Voraussetzung für den Eintritt eine Rechtsfolge bestimmt ist.

337 Maurer/Waldhoff, Allgemeines Verwaltungsrecht, 19. Aufl. 2017, § 10 Rn. 21; Ramsauer, in: Kopp/Ramsauer, VwVfG, 20. Aufl. 2019, § 43 Rn. 26.

338 BVerwG, Urt. v. 27.10.1998, Az.: 1 C 19.97 = NVwZ-RR 1999, 243; Urt. v. 10.10.2006, Az.: 8 C 23.05 = juris, Rn. 22; s. auch Sachs, in: Stelkens/Bonk/Sachs, VwVfG, 9. Aufl. 2018, § 43 Rn. 160, m.w.N.

339 Vgl. zu diesem Bild auch die Ausführungen von Gröpl, JA 1995, 904 und 983, sowie Herrmann, ZJS 2011, 25.

340 Bisweilen wird - insbesondere angesichts des Wortlauts von § 9 VwVfG - die Frage des Zeitpunkts des Erlasses eines Verwaltungsakts diskutiert, s. nur Detterbeck, Allgemeines Verwaltungsrecht, 17. Aufl. 2019, Rn. 540 f., der indes zu Recht darauf hinweist, dass dieser Zeitpunkt zumindest für die Frage der Wirksamkeit des Verwaltungsakts keine Rolle spielt.

341 Vgl. entsprechend Maurer/Waldhoff, Allgemeines Verwaltungsrecht, 19. Aufl. 2017, §10 Rn. 5 ff.; Detterbeck, Allgemeines Verwaltungsrecht, 17. Aufl. 2019, Rn. 537 ff. (insbesondere 548). 
samwerdens eines Verwaltungsakts ist demnach die Bekanntgabe, auf die im Folgenden noch genauer einzugehen sein wird (s. dazu Rn. $117 \mathrm{ff}$.). Diese hat potentiell gegenüber mehreren Personen zu erfolgen (§ 41 I 1 VwVfG). Der Verwaltungsakt erlangt jedoch bereits dann rechtliche Existenz, wenn er der ersten dieser Personen wirksam bekanntgegeben wird. ${ }^{342} \mathrm{Ab}$ dem Zeitpunkt seiner rechtlichen Existenz gilt:

- Der Verwaltungsakt entfaltet seine ersten Bindungswirkungen: Die ihn erlassende Behörde (und deren Rechtsträger) trifft das Aufhebungs- und Abweichungsverbot. Soweit die Wirkungen nicht erst verzögert eintreten soll (s. zur sog. „inneren Wirksamkeit“ sogleich Rn. 114), setzen mit der rechtlichen Existenz des Verwaltungsakts auch seine über den Kreis der Bekanntgabeempfänger hinaus geltenden Tatbestands- sowie Feststellungswirkungen ein. ${ }^{343}$

- In der juristischen Sekunde seines rechtlichen Entstehens kann der Verwaltungsakt gemäß $\S 43$ III VwVfG sogleich aufgrund von Nichtigkeit unwirksam sein.

- Der Verwaltungsakt kann nun grundsätzlich von jeder Person - nicht nur von der Person, der er zuerst bekanntgegeben wurde - mit den verschiedenen statthaften Rechtsbehelfen angegriffen und schließlich aufgehoben werden. ${ }^{344}$

- Der Verwaltungsakt kann sich nun gemäß § 43 II VwVfG durch Fristablauf oder auf andere Weise erledigen.

113 Davon zu unterscheiden ist die sog. äußere Wirksamkeit. Sie hängt - wie von § 43 I 1 VwVfG unmissverständlich verdeutlicht - untrennbar mit der individuellen Bekanntgabe (s. dazu noch Rn. 135ff.; indes zu den Besonderheiten der öffentlichen Bekanntgabe Rn. $154 \mathrm{ff}$.) gegenüber demjenigen, für den er bestimmt ist oder der von ihm betroffen wird, zusammen. Sie tritt daher auch nur gegenüber der Person ein, der der Verwaltungsakt wirksam bekanntgegeben wurde. Die rechtliche Existenz eines Verwaltungsakts ist damit absolut, seine (äußere) Wirksamkeit hingegen relativ (Grundsatz der relativen Wirksamkeit von Verwaltungsak-

342 Detterbeck, Allgemeines Verwaltungsrecht, 17. Aufl. 2019, Rn. 537; Ramsauer, in: Kopp/ Ramsauer, VwVfG, 20. Aufl. 2019, § 43 Rn. 4. Sie fällt dann zeitlich mit dem Eintritt der (mindestens) äußeren Wirksamkeit gegenüber dieser Person zusammen, s. dazu noch Rn. 113.

343 Leisner-Egensperger, in: Mann/Sennekamp/Uechtritz, VwVfG, 2. Aufl. 2019, § 43 Rn. 6.

344 OVG Magdeburg, Beschl. v. 27.5.2008, Az.: 2 M 72/08 = NVwZ-RR 2008, 747; Detterbeck, Allgemeines Verwaltungsrecht, 17. Aufl. 2019, Rn. 537; R. P. Schenke, in: Kopp/Schenke, VwGO, 25. Aufl. 2019, § 42 Rn. 56, 58. 
ten). ${ }^{345} \mathrm{Ab}$ dem Zeitpunkt der äußeren Wirksamkeit gilt: Es beginnt der Lauf der Rechtsbehelfsfristen, selbst dann wenn die innere Wirksamkeit (s. dazu sogleich Rn. 114) noch nicht eingetreten ist. ${ }^{346}$ Deren Beginn ist an die Bekanntgabe geknüpft (§§ 70 I, 74 VwGO, s. dazu genauer Rn. 353 ff.), sodass es im Falle zeitlich versetzter $^{347}$ Bekanntgaben an verschiedene Personen auch $\mathrm{zu}$ verschiedenen Fristläufen und einem entsprechend zeitversetzten Eintritt der (formellen) Bestandskraft (s. dazu sogleich Rn. 115) kommen kann. Wird ein Betroffener gänzlich übergangen, können Rechtsbehelfe gar für unbestimmte Zeit zulässig bleiben. ${ }^{348}$

Die innere Wirksamkeit eines Verwaltungsakts tritt erst dann ein, wenn die $\mathbf{1 1 4}$ in ihm enthaltene Regelung ihre Wirkung entfalten soll. Dies ergibt sich auch aus $\S 43$ I 2 VwVfG, wonach der Verwaltungsakt „mit dem Inhalt wirksam [wird], mit dem er bekannt gegeben wird“. Soweit sich aus dem Verwaltungsakt nichts anderes ergibt, fällt der Zeitpunkt des Eintritts der inneren mit dem der äußeren Wirksamkeit zusammen. ${ }^{349}$ Dies wird regelmäßig der Fall sein. Es kann jedoch auch zu Abweichungen der Zeitpunkte innerer und äußerer Wirksamkeit kommen $^{350}$ - so insbesondere durch die Verbindung des Verwaltungsakts mit aufschiebenden Befristungen oder Bedingungen (s. dazu Rn. $210 \mathrm{ff}$.) oder durch die (gesetzlich vorgesehene) Bestimmung der Rückwirkung eines Verwaltungsakts ${ }^{351}$. Ab dem Zeitpunkt der inneren Wirksamkeit gilt:

- Der Verwaltungsakt entfaltet seine Bindungswirkung vollständig: Der Begünstigte darf von einer Genehmigung Gebrauch machen, der Belastete muss sich einem Gebot oder Verbot fügen. Kehrseitig muss die Behörde die Betroffenen in ihrem Handeln gewähren oder ihnen gar bestimmte Leistungen zukommen lassen.

345 Stelkens, in: Stelkens/Bonk/Sachs, VwVfG, 9. Aufl. 2018, § 35 Rn. 20, § 41 Rn. 229; Sachs, a.a.O., § $43 \mathrm{Rn} .165$.

346 BVerwG, Urt. v. 1.2.1978, Az.: 6 C 9.77 = BVerwGE 55, 212 (215). So auch Ramsauer, in: Kopp/ Ramsauer, VwVfG, 20. Aufl. 2019, § 43 Rn. 5.

347 Oder unter abweichender Einhaltung der Vorgaben zur ordnungsgemäßen Rechtsbehelfsbelehrung, vgl. § 58 VwGO, s. dazu ausführlich Rn. $368 \mathrm{ff}$.

348 Eine zeitliche Grenze wird zumindest dann angenommen, wenn der Betroffene auf anderem Wege von dem Verwaltungsakt Kenntnis erlangt und untätig bleibt. In diesem Fall kann ein von ihm erhobener Rechtsbehelf wegen fehlenden Rechtsschutzbedürfnisses infolge von Verwirkung (als besonderer Form eines Verstoßes den den Rechtsgrundsatz von Treu und Glauben) unzulässig sein, s. dazu ausführlich Rn. 329, $399 \mathrm{ff}$.

349 BVerwG, Urt. v. 21.6.1961, Az.: VIII C 398.59 = BVerwGE 13, 1 (7).

350 BVerwG, Urt. v. 21.6.1961, Az.: VIII C 398.59 = BVerwGE 13, 1 (7); BVerwG, Urt. v. 1.2.1978, Az.: 6 C 9.77 = BVerwGE 55, 212 (215). S. auch Detterbeck, Allgemeines Verwaltungsrecht, 17. Aufl. 2019, Rn. $546 \mathrm{ff}$.

351 BVerwG, Urt. v. 21.6.1961, Az.: VIII C 398.59 = BVerwGE 13, 1 (7); Maurer/Waldhoff, Allgemeines Verwaltungsrecht, 19. Aufl. 2017, § 10 Rn. 11.

Tobias Brings-Wiesen 
- Soweit sein Regelungsinhalt dies ermöglicht (s. zum vollstreckbaren Verwaltungsakt Rn. 1331), wird der Verwaltungsakt grundsätzlich vollstreckbar. ${ }^{352}$ Die Vollziehbarkeit kann jedoch von der Erfüllung weiterer gesetzlicher Voraussetzungen abhängig gemacht werden. ${ }^{353}$ Sie wird durch Erhebung eines Widerspruchs bzw. einer Anfechtungsklage gegen den Verwaltungsakt im Regelfall gehemmt (sehr str.) ${ }^{354}$ (sog. „aufschiebende Wirkung“); ausnahmsweise kann ein Verwaltungsakt jedoch sofort vollziehbar sein, sodass es des Ersuchens nach vorläufigem Rechtsschutz gemäß $\S \S 80$ ff. bedarf (s. dazu ausführlich die $\S \S 8,9$ ). ${ }^{355}$ Die aufschiebende Wirkung hat zur Folge, dass zumindest die staatliche Seite aus dem betroffenen Verwaltungsakt weder rechtliche noch tatsächliche Folgen ableiten darf, bspw. gestützt auf eine Abrissverfügung einen Schwarzbau beseitigen. ${ }^{356}$

- Die innere Wirksamkeit des Verwaltungsakts tritt erst gar nicht ein oder endet, wenn er nichtig ist, zurückgenommen, widerrufen oder anderweitig aufgehoben wird oder sich durch Zeitablauf oder auf andere Weise erledigt.

115 Der (äußerlich) wirksame Verwaltungsakt kann sodann in Bestandskraft erwachsen. ${ }^{357}$ Dabei wird unterschieden zwischen formeller und materieller Be-

352 Peine/Siegel, Allgemeines Verwaltungsrecht, 12. Aufl. 2018, Rn. 459f.; Sachs, in: Stelkens/ Bonk/Sachs, VwVfG, 9. Aufl. 2018, § 43 Rn. 171; Schemmer, in: Bader/Ronellenfitsch, VwVfG, 44. Ed., Stand: 1.7.2019, § 43 Rn. 12.

353 So ist bspw. die Vollstreckung gegen Geldforderungen gemäß § 3 II lit. b), c) BVwVG erst nach Fälligkeit der Leistung und dem Ablauf einer (zusätzlichen) Wochenfrist möglich; die Erzwingung von Handlungen, Duldungen oder Unterlassungen verlangt gemäß § 6 I BVwVG im sog. gestreckten Verfahren die Unanfechtbarkeit des Verwaltungsakts. S. zur Verwaltungsvollstreckung ausführlich Rn. $1292 \mathrm{ff}$.

354 So zumindest nach der wohl h.M. in Rspr. und einem Teil der Lit., s. dazu ausführlich $\S 8$ Rn. 5 sowie Gersdorf, in: Posser/Wolff, VwGO, 50. Ed., Stand: 1.7.2018, § 80 Rn. 24 ff.

355 Verwaltungsakte, die den Antrag einer Person ablehnen (sog. Versagungsbescheide) und denen in der Hauptsache mit einer Verpflichtungsklage gemäß § 42 I Var. 2 VwGO (in Form der sog. Versagungsgegenklage) zu begegnen wäre, tragen keine vollziehbaren Regelungsinhalte mit sich. Besteht die Gefahr, dass sich die Verhältnisse in Folge der Ablehnung zulasten einer Person verändern, bevor diese ihr Klagebegehren in der Hauptsache durchsetzen kann, ist vorläufiger Rechtsschutz über § 123 VwGO zu erreichen, s. dazu ausführlich § 10.

356 Nach bereits benannter wohl h. M. in Rspr. und einem Teil der Lit. ist von einer Hemmung der Vollziehbarkeit nur die staatliche Seite betroffen; die sog. Wirksamkeitstheorien sowie die (vermittelnde) Position einer sog. „Verwirklichungshemmung“ kommen hingegen zu dem Ergebnis, dass auch die Folge- und Ausnutzungsmaßnahmen Privater untersagt sind, s. nur Gersdorf, in: Posser/Wolff, VwGO, 50. Ed., Stand: 1.7.2018, § 80 Rn. $24 \mathrm{ff.}$

357 S. zum verfassungsrechtlichen Hintergrund der Bestandskraft von Verwaltungsakten grundlegend BVerfG, Beschl. v. 20.4.1982, Az.: 2 BvL 26/81 = BVerfGE 60, 253 (269ff.). S. zur Bestandskraft auch Windoffer, JURA 2017, 1274.

Tobias Brings-Wiesen 
standskraft. Formell bestandskräftig ist ein Verwaltungsakt, soweit er von seinem Empfänger ${ }^{358}$ nicht mehr mit den ordentlichen Rechtsbehelfen (Widerspruch, Anfechtungs- oder Verpflichtungsklage) aufgehoben werden kann - entweder weil diese ausgeschöpft wurden oder weil die einschlägigen Rechtsbehelfsfristen abgelaufen sind. ${ }^{359}$ Als materiell bestandskräftig wird ein Verwaltungsakt bezeichnet, wenn seine Aufhebung auch nicht mehr im Wege des Wiederaufgreifens des Verfahrens gemäß $\S 51$ VwVfG (s. dazu noch $\S 3$ Rn. $98 \mathrm{ff}$.) oder über eine Rücknahme bzw. einen Widerruf gemäß $\S \S 48 f$. VwVfG (s. dazu noch Rn. 836 ff.) erreicht werden kann. ${ }^{360}$

Um den Lebenszyklus eines Verwaltungsakts umfassend und differenziert zu verstehen, bedarf 116 es eines - zugegebenermaßen komplexen - Beispiels:

Die in Nordrhein-Westfalen zuständige Ordnungsbehörde der Stadt Köln bringt am Freitag, den 22.3.2019, die nach \& 2 I 1 GastG erforderliche Erlaubnis zum Betrieb eines Gaststättengewerbes ab Mittwoch, den 1.5.2019, im Erdgeschoss des Hauses Zülpicher Straße 40 auf den Postweg zum A. Verbunden ist die Erlaubnis mit der Auflage, an der Decke des Gastraumes noch zusätzliche Schallschutzplatten anzubringen, um den Lärm des Betriebs für die darüber liegende Wohnung zu reduzieren, und einer ordnungsgemäßen Rechtsbehelfsbelehrung. Den A erreicht der Brief am Montag, den 25.3.2019. Als A drei Wochen später am Montag, den 8.4.2019, mit den Renovierungsarbeiten beginnt, werden Nachbar B und Nachbarin $C$ aus dem ersten und zweiten Obergeschoss darauf aufmerksam. Sie erkundigen sich noch am gleichen Tag via E-Mail bei der Ordnungsbehörde. Diese versendet am Freitag, den 12.4.2019, wiederum auf dem Postweg die Erlaubnis für den A auch an den B und die C. B erhält den Brief bereits am Montag, den 15.4.2019. Der Brief an C hingegen landet auf unglückliche Weise in einem Zwischenraum der Posttasche der Briefträgerin und wird von ihr erst am Freitag, den 19.4.2019, wiederentdeckt und bei C eingeworfen. Bei der Durchsicht des Dokuments fällt $C$ auf, dass ihm gar keine Rechtsbehelfsbelehrung beiliegt - dies war bei B anders. Der wird auch umgehend aktiv und erhebt am Freitag, den 26.4.2019, Anfechtungsklage gegen die Erlaubnis beim zuständigen Verwaltungsgericht. Als A die Klage am Montag, den 29.4. 2019, zugestellt wird ${ }^{361}$, ist er verärgert. Er erinnert sich aber bei dieser Gelegenheit auch daran, dass ihm die Auflage zu seiner Erlaubnis gar nicht passte und erhebt noch am gleichen Tag selbst Anfechtungsklage, um deren Aufhebung zu erwirken (zum Rechtsschutz gegen Neben-

358 Die formelle Bestandskraft eines Verwaltungsakts tritt wie seine äußere Wirksamkeit nicht absolut, sondern relativ ein.

359 S. nur Ramsauer, in: Kopp/Ramsauer, VwVfG, 20. Aufl. 2019, § 43 Rn. 29.

360 S. nur Maurer/Waldhoff, Allgemeines Verwaltungsrecht, 19. Aufl. 2017, § 10 Rn. 19; Schemmer, in: Bader/Ronellenfitsch, VwVfG, 44. Ed., Stand:1.7.2019, § 43 Rn. 23f., der überdies zu Recht darauf hinweist, dass der „materiellen Bestandskraft“ nach diesem Verständnis inhaltlich keine über die Bindungswirkung des Verwaltungsakts hinausgehende Bedeutung zukommt. Der Begriff beschreibt lediglich den Zustand der Bindungswirkung nach Eintritt der formellen Bestandskraft und hat somit in der Sache praktisch keinen Mehrwert.

361 Die Zustellung der Klage an den Beklagten erfolgt auf obligatorische Verfügung des Gerichts hin, § 85 S. 1 VwGO.

Tobias Brings-Wiesen 
bestimmungen ausführlich Rn. 204ff., 1388ff.). Die C kommt erst während eines Termins am Mittwoch, den 5.6.2019, dazu, mit ihrer Rechtsanwältin über den Fall zu sprechen, die für sie am Montag, den 10.6.2019, eine Anfechtungsklage erhebt. Bei Rückkehr von besagtem Termin trifft die $C$ auf den Nachbarn D aus dem dritten Obergeschoss, der von alldem bislang noch überhaupt nichts mitbekommen hatte. $C$ erzählt $D$ von den Klagen und rät ihm, sich anzuschließen. Der ist indes gerade mit anderen Dingen beschäftigt und verdrängt die Angelegenheit. Erst als anderthalb Jahre später im Rahmen der Verfahren eine Ortsbegehung erfolgt, wird er wieder darauf aufmerksam. Er erhebt am Mittwoch, den 9.12.2020, Anfechtungsklage.

- Der Verwaltungsakt der Gaststättenerlaubnis wurde am Freitag, den 22.3.2019, von der Ordnungsbehörde der Stadt Köln erlassen. Er wurde dem A gegenüber am Montag, den 25.3.2019, durch einfache Übermittlung mit der Post bekanntgegeben (§ 41 II 1 VwVfG ${ }^{362}$ ). Folglich wurde er A gegenüber äußerlich wirksam ( $\$ 43$ I 1 VwVfG) und somit zugleich universell rechtlich existent. Seine innere Wirksamkeit wird er jedoch wegen der aufschiebenden Befristung erst ab Mittwoch, den 1.5.2019, entfalten (§ 43 I 2 VwVfG). ${ }^{363}$ Wegen Entbehrlichkeit eines Widerspruchs- bzw. Vorverfahrens ${ }^{364}$ begann mit der Bekanntgabe auch die Frist für die Erhebung der Anfechtungsklage von einem Monat (\$ 74 I 2 VwGO), die gemäß der geltenden Berechnungsregeln (§ 57 II VwGO i.V.m. § 222 ZPO, §§ $187 f f$. BGB; zur Fristberechnung ausführlich Rn. 361 ff.) als Ereignismonatsfrist mit Ablauf des Donnerstags, den 25.4.2019, endete, sodass der Verwaltungsakt (inklusive der Auflage) an diesem Tag für den A auch in (formelle) Bestandskraft erwuchs. Die von A am Montag, den 29.4.2019, erhobene Anfechtungsklage war daher bereits aus diesem Grund unzulässig.

- B erhielt den Brief mit der Erlaubnis am Montag, den 15.4.2019. Mit dieser Bekanntgabe wurde der Verwaltungsakt B gegenüber äußerlich wirksam. Zu diesem Zeitpunkt war der Verwaltungsakt aber - wie dargestellt - bereits erlassen und rechtlich existent. Er hätte auch dem B gegenüber ab dem 1.5.2019 seine innere Wirksamkeit entfaltet. Allerdings erhob der B am Freitag, den 26.4.2019, Anfechtungsklage. Wie dargestellt war der Verwaltungsakt dem A gegenüber zu diesem Zeitpunkt bereits in (formelle) Bestandskraft erwachsen. Wegen der späteren Bekanntgabe an B begann der Lauf der einmonatigen Klagefrist ihm gegenüber jedoch auch erst später. Ihr Ende fiel auf Mittwoch, den 15.5.2019, sodass der Verwaltungsakt am Freitag, den 26.4.2019, dem B gegenüber noch nicht in (formelle) Bestandskraft erwachsen war. Durch die Klageerhebung wurde der Eintritt der Bestandskraft gegenüber B unterbunden. Darüber hinaus kam es bereits durch Erhebung dieser ersten

362 Hier geht die Erlaubnis dem A an dem Tage zu, an dem der Zugang gemäß § 41 II 1 VwVfG auch vermutet wird. S. aber noch ausführlich zur Wirkung dieser besonderen Regelung Rn. $136 \mathrm{ff}$. 363 Anders als die Befristung oder eine Bedingung hat die Auflage bewusst keinen Einfluss auf die Wirkung der Regelung eines Verwaltungsakts - hier die Erlaubnis, die Gaststätte ab dem 1.5. 2019 zu betreiben, s. zur Unterscheidung zwischen Bedingung und Auflage ausführlich Rn. $222 \mathrm{ff}$. 364 Dazu ein vorgreifender, aber notwendiger Hinweis: In vielen Bundesländern - darunter Nordrhein-Westfalen - wurde das Widerspruchsverfahren entsprechend § 68 (II i.V.m.) I 2 Hs. 1 VwGO weitgehend abgeschafft, s. dazu ausführlich Rn. $307 \mathrm{ff}$., dies gilt auch für Fragen des Gaststättenrechts in Nordrhein-Westfalen, vgl. § 68 I 2 VwGO i.V.m. § 110 I 1 JustG NRW.

Tobias Brings-Wiesen 
(zulässigen ${ }^{365}$ ) Anfechtungsklage zur sog. „aufschiebenden Wirkung“ (gemäß § 80 I 2 VwGO bei sog. Verwaltungsakten mit Doppel- bzw. Drittwirkung, s. dazu § 9 Rn. 6ff.), deren Effekt auf die Wirkungen des Verwaltungsakts - wie bereits erwähnt - stark umstritten sind.

- C erhielt den Brief mit der Erlaubnis am Freitag, den 19.4.2019. Mit dieser Bekanntgabe wurde der Verwaltungsakt $C$ gegenüber äußerlich wirksam. Sie kam durch ihre Rechtsanwältin aber leider erst am Montag, den 10.6.2019, dazu, selbst Anfechtungsklage zu erheben. Wegen der bereits von B am Freitag, den 26.4.2019, erhobenen Anfechtungsklage (und der mit ihr eingetretenen aufschiebenden Wirkung) wurde zwar - zumindest vorübergehend - mittelbar auch dem Interesse der C gedient. Zugleich kommt es mit der Klageerhebung durch einen Betroffen jedoch nicht zu einer Unterbrechung des Fristlaufs für die übrigen Betroffenen. Ihr Rechtsschutzbegehren ist grundsätzlich unabhängig zu verfolgen. Insofern könnte die von $C$ in anwaltlicher Vertretung erhobene Anfechtungsklage gemäß \& 74 I 2 VwGO bereits verfristet gewesen sein. Dies wäre jedoch nur der Fall, wenn die Frist zu laufen begonnen hätte. Dies erfolgt - bei Entbehrlichkeit eines Widerspruchs bzw. Vorverfahrens - grundsätzlich mit Bekanntgabe des Verwaltungsakts, es sei denn, diesem fehlt es an einer (hinreichenden) Rechtsbehelfsbelehrung gemäß \& 58 I VwGO. Ist eine Rechtsbehelfsbelehrung unterblieben oder unrichtig erteilt, so läuft ab Zustellung, Eröffnung oder Verkündung nur die einjährige Ausschlussfrist des §58 II 1 VwGO, die im Falle von C noch nicht abgelaufen war. (Dies wäre erst am Montag, den 20.4.2020, der Fall, da das Datum des eigentlichen Fristendes am 19.4.2020 auf einen Sonntag fällt, \&57 II VwGO i.V.m. § 222 II ZPO.) Sollte die Anfechtungsklage von C die übrigen Sachentscheidungsvoraussetzungen erfüllen, würde das zuständige Verwaltungsgericht die beiden anhängigen Verfahren über den gleichen Gegenstand qua Beschluss gemäß § 93 S. 1 VwGO miteinander verbinden.

- D erfuhr erst am Mittwoch, den 5.6.2019, von der Erlaubnis - allerdings nur aus einem persönlichen Gespräch mit der C. Ihm gegenüber erfolgte jedoch zu keinem Zeitpunkt eine Bekanntgabe seitens der Ordnungsbehörde der Stadt Köln (s. dazu ausführlich Rn. 122). Dies bedeutet, dass der Verwaltungsakt ihm gegenüber gemäß § 43 I 1 VwVfG auch nie äußerlich wirksam wurde. Mangels Bekanntgabe begann weder der Lauf der Klagefrist (§ 74 I 2 VwGO) noch der Lauf der Ausschlussfrist (\$ 58 II 1 VwGO), sodass D auch noch am Mittwoch, den 9.12.2020, gegen den am 25.3.2019 rechtlich entstandenen und seither existenten Verwaltungsakt Anfechtungsklage erheben konnte. Denkbar wäre nur eine Unzulässigkeit der Klage wegen fehlenden Rechtsschutzbedürfnisses infolge von Verwirkung (als besonderer Form eines Verstoßes den Rechtsgrundsatz von Treu und Glauben, s. dazu ausführlich Rn. 329, 399ff.).

365 S. zur Problematik des Eintritts der aufschiebenden Wirkung bei (offensichtlich) unzulässigen Rechtsbehelfen m.w. N. W.-R. Schenke, in: Kopp/Schenke, VwGO, 25. Aufl. 2019, § 80 Rn. 50 f. 


\section{Wirksamwerden von Verwaltungsakten, § 43 I VwVfG}

$117 \S 43$ I VwVfG knüpft den Eintritt der Wirksamkeit - das Wirksamwerden - eines Verwaltungsakts maßgeblich an den Akt der Bekanntgabe. ${ }^{366}$ Abgesehen von der Tatsache, dass sie auch im Interesse der Funktionsfähigkeit der Verwaltung erfolgt, ${ }^{367}$ dient die Bekanntgabe eines Verwaltungsakts insbesondere der Realisierung der verfassungsrechtlich geschützten Interessen der Betroffenen. Sie ist rechtsstaatlich geboten, denn erst die Kenntnisnahme des Inhalts eines Verwaltungsakts versetzt sie in den Stand, die Garantie effektiven Rechtsschutzes gemäß Art. 19 IV 1 GG $^{368}$ und ihren Anspruch auf rechtliches Gehör ${ }^{369} \mathrm{zu}$ verwirklichen und in der Folge effektiven Grundrechtsschutz ${ }^{370} \mathrm{zu}$ erlangen.

118 Soweit die Bekanntgabe nicht spezialgesetzlich geregelt ist, kommt es zentral auf die Vorgaben des $\mathbf{\$} \mathbf{4 1} \mathbf{V w V f G}^{371}$ an. Aus dieser Vorschrift ergeben sich insbesondere die allgemeinen Voraussetzungen der Bekanntgabe. Dabei ist der Wortlaut der Norm wenig ergiebig. Ihr ist weder eine Legaldefinition des Begriffs „Bekanntgabe“ zu entnehmen, noch enthält sie konkrete Merkmale. Die Bestimmung der Voraussetzungen erfolgt vielmehr unter Rückbesinnung auf die allgemeine Rechtsgeschäftslehre. Denn beim Verwaltungsakt handelt es sich der Sache nach um eine rechtliche Willenserklärung der Behörde (s. dazu Rn. 44 ff.). Aus diesem Grund wird - unter notwendiger Berücksichtigung etwaiger Besonderheiten im Staat-Bürger-Verhältnis - maßgeblich auf die aus dem Zivilrecht bekannten Grundsätze betreffend das Wirksamwerden von Willenserklärungen zurückgegriffen. ${ }^{372}$ Vor diesem Hintergrund ist auch für die Bekanntgabe des Verwaltungsakts zwischen zwei Verantwortungssphären zu unterscheiden: der der erklärenden Behörde und der des Empfängers (s. dazu Rn. 121ff.). Ist für einen Verwaltungsakt eine bestimmte Art der Bekanntgabe vorgesehen, sind darüber hinaus ergänzende bzw. abweichende besondere Vorgaben $\mathrm{zu}$ berücksichtigen (s. dazu Rn. $133 \mathrm{ff}$.).

366 S. zur Bekanntgabe ausführlich auch Erichsen/Hörster, JURA 1997, 659; Schoch, JURA 2011, 23; Beaucamp, JA 2016, 436.

367 Stelkens, in: Stelkens/Bonk/Sachs, VwVfG, 9. Aufl. 2018, § 41 Rn. 2.

368 BVerwG, Urt. v. 27.5.1983, Az.: 4 C 40.81 u. a. = BVerwGE 67, 206 (109); Stelkens, in: Stelkens/ Bonk/Sachs, VwVfG, 9. Aufl. 2018, § 41 Rn. 2; Couzinet/Fröhlich, in: Mann/Sennekamp/Uechtritz, VwVfG, 2. Aufl. 2019, § 41 Rn. 11.

369 BVerwG, Urt. v. 18.4.1997, Az.: 8 C 43.95 = BVerwGE 104, 301 (306); Stelkens, in: Stelkens/ Bonk/Sachs, VwVfG, 9. Aufl. 2018, § 41 Rn. 2.

370 Ramsauer/Tegethoff, in: Kopp/Ramsauer, VwVfG, 20. Aufl. 2019, § 41 Rn. 2; Couzinet/Fröhlich, in: Mann/Sennekamp/Uechtritz, VwVfG, 2. Aufl. 2019, § 41 Rn. 10.

371 Für einen Überblick über die Abweichungen in den entsprechenden Vorschriften des Landesrechts Stelkens, in: Stelkens/Bonk/Sachs, VwVfG, 9. Aufl. 2018, vor der Kommentierung zu § 41. 372 Stelkens, in: Stelkens/Bonk/Sachs, VwVfG, 9. Aufl. 2018, § 41 Rn. 7 f.

Tobias Brings-Wiesen 
In einer Prüfung ist die Bekanntgabe eines Verwaltungsakts überhaupt nur 119 dann zu thematisieren, wenn sich aus dem Sachverhalt diesbezüglich Zweifel ergeben. Sind hinsichtlich einer Bekanntgabe Unzulänglichkeiten erkennbar, stellt sich sodann jedoch die Frage, wie mit diesen umzugehen ist. Im Falle einer (im Rechtssinne) fehlenden Bekanntgabe besteht Einigkeit, dass es nicht zum Eintritt der (äußeren) Wirksamkeit gegenüber dem jeweiligen Empfänger kommt bzw. gegebenenfalls gar kein rechtlich existenter Verwaltungsakt vorliegt. ${ }^{373}$ Dies kann beispielsweise der Fall sein, wenn ein Verwaltungsakt ohne Bekanntgabewillen auf Seiten der Behörde den Empfänger erreicht oder wenn umgekehrt ein von der Behörde willentlich auf den Weg gebrachter Verwaltungsakt niemals in den Machtbereich des Empfängers gelangt (s. zu Einzelheiten noch unten Rn. $121 \mathrm{ff}$.). Umstritten ist hingegen der Umgang mit der fehlerhaften Bekanntgabe. ${ }^{374}$ Dies betrifft Konstellationen, in denen ein Verwaltungsakt willentlich die Verantwortungssphäre der Behörde verlassen hat und einem Empfänger zur Kenntnis gelangt ist - die allgemeinen Voraussetzungen also erfüllt sind -, dabei aber die für eine bestimmte Bekanntgabeart geltenden Voraussetzungen verfehlt wurden. Diesbezüglich werden diverse Grundpositionen verfochten: So wird vertreten, derartige Verstöße verhinderten nie das Wirksamwerden eines Verwaltungsakts; ${ }^{375}$ die Gegenmeinung verneint demgegenüber bei jedem Verstoß gegen zwingende Bekanntgabevorschriften die Wirksamkeit der Bekanntgabe; ${ }^{376}$ eine vermittelnde Auffassung unterscheidet nach dem Schweregrad des jeweiligen Fehlers und verneint bei weniger schweren Fehlern zumindest den Beginn des Laufs der Rechtsbehelfsfristen ${ }^{377}$. Hinzu kommt, dass darüber hinaus eine analoge Anwendung von $\S 8$ VwZG (s. dazu Rn. 172) auch auf Bekanntgabefehler

373 S. nur Detterbeck, Allgemeines Verwaltungsrecht, 17. Aufl. 2019, Rn. 553, 557; Maurer/ Waldhoff, Allgemeines Verwaltungsrecht, 19. Aufl. 2017, § 9 Rn. 71; Erichsen/Hörster, JURA 1997, 659 (663f.); Schoch, JURA 2011, 23 (29); Beaucamp, JA 2016, 436 (438).

374 S. auch die Darstellungen bei Detterbeck, Allgemeines Verwaltungsrecht, 17. Aufl. 2019, Rn. 556f.; Erichsen/Hörster, JURA 1997, 659 (664f.); Beaucamp, JA 2016, 436 (438f.).

375 Detterbeck, Allgemeines Verwaltungsrecht, 17. Aufl. 2019, Rn. 557, für den derartige Rechtsfehler maximal zur Nichtigkeit führen können, aber ansonsten als Frage der formellen Rechtmäßigkeit zu behandeln sind, a.a.O., Rn. 581ff.; wohl auch Erbguth/Guckelberger, Allgemeines Verwaltungsrecht, 9. Aufl. 2018, § 13 Rn. 13.

376 Stelkens, in: Stelkens/Bonk/Sachs, VwVfG, 9. Aufl. 2018, § 41 Rn. 222; Couzinet/Fröhlich, in: Mann/Sennekamp/Uechtritz, VwVfG, 2. Aufl. 2019, § 41 Rn. 145; Erichsen/Hörster, JURA 1997, 659 (664f.); Ehlers, Rechtsfragen der Existenz, der Wirksamkeit und der Bestandskraft von Verwaltungsakten, in: Krebs, Liber Amicorum Erichsen, 2004, S. 1 (6); Beaucamp, JA 2016, 436 (438f.); wohl auch Maurer/Waldhoff, Allgemeines Verwaltungsrecht, 19. Aufl. 2017, § 9 Rn. 73; Peine/ Siegel, Allgemeines Verwaltungsrecht, 12. Aufl. 2018, Rn. 451; Ruffert, in: Knack/Henneke, VwVfG, 10. Aufl. 2014, § 41 Rn. 69; Herrmann, ZJS 2011, 25 (27); Schoch, JURA 2011, 23 (29).

377 Ramsauer/Tegethoff, in: Kopp/Ramsauer, VwVfG, 20. Aufl. 2019, § 41 Rn. 23 ff.

Tobias Brings-Wiesen 
außerhalb des Zustellungsrechts starken Zuspruch findet. ${ }^{378}$ In der Rechtsprechung scheint sich - soweit ersichtlich - bislang keine kategorische Antwort auf diese Streitfrage herausgebildet zu haben. Dies ist jedoch nicht verwunderlich, da es - allen damit verbundenen Rechtsunsicherheiten zum Trotz ${ }^{379}$ - tatsächlich überzeugender ist, aufmerksam den einzelnen Bekanntgabefehler in den Fokus zu nehmen. Da nicht jede Bekanntgabevorschrift in gleicher Intensität zum Schutz der Interessen der Empfänger beiträgt, entspricht nur ein differenzierendes Fehlerfolgenregime den - auch der weitgehenden Entkopplung von Wirksamkeit und Rechtmäßigkeit von Verwaltungsakten zugrundeliegenden (s. dazu Rn. 105) - Interessen der Gewährleistung von Rechtssicherheit und der Funktionsfähigkeit der Verwaltung. ${ }^{380}$ Überdies werden die Unterschiede zwischen der Meinung, die für eine Unwirksamkeit bei Verletzung „Zwingender“ Bekanntgabevorschriften plädiert, und der, die nach dem Schweregrad des Fehlers urteilt, praktisch nur sehr gering sein. Abzulehnen ist indes die Auffassung, die nur bei Außerachtlassung der allgemeinen Voraussetzungen von einer Unwirksamkeit ausgeht. §43 I 1 VwVfG erhebt die Bekanntgabe allgemein zur Wirksamkeitsvoraussetzung. ${ }^{381}$ Differenzierungen zwischen den verschiedenen Arten der Bekanntgabe sind nur unter den besagten teleologischen Erwägungen geboten.

\section{a) Allgemeine Voraussetzungen der Bekanntgabe}

120 Wie bereits erwähnt sollte die Bekanntgabe eines Verwaltungsakts in einer Prüfung nur dann thematisiert werden, wenn diesbezügliche Probleme im Sachverhalt ersichtlich sind. Die folgenden Ausführungen sollen daher vorrangig eine Checkliste bieten, die im Rahmen der Auswertung eines Sachverhalts zuerst gedanklich durchgegangen werden kann. Die allgemeinen Voraussetzungen sind dabei stets, die besonderen Vorgaben nur bei gebotenem Anlass zu berücksichtigen. Sofern im Rahmen dieser Vorprüfung Zweifel an der Bekanntgabe auf-

378 Stelkens, in: Stelkens/Bonk/Sachs, VwVfG, 9. Aufl. 2018, § 41 Rn. 232; Couzinet/Fröhlich, in: Mann/Sennekamp/Uechtritz, VwVfG, 2. Aufl. 2019, § 41 Rn. 148; Ruffert, in: Knack/Henneke, VwVfG, 10. Aufl. 2014, § 41 Rn. 72; a. A. aber Schoch, JURA 2011, 23 (30); Beaucamp, JA 2016, 436 (439).

379 Dies als Argument gegen die vermittelnde Ansicht vorbringend Beaucamp, JA 2016, 436 (438).

380 Entsprechend differenzierend auch Stuhlfauth, in: Obermayer/Funke-Kaiser, VwVfG, 5. Aufl. 2018, § 41 Rn. 71 ff., wenngleich er zu einzelnen Fehlern sodann zu anderen Ergebnissen kommt. 381 Beaucamp, JA 2016, 436 (438).

Tobias Brings-Wiesen 
kommen, sollten diese in der Prüfung selbst auf die potentiellen Fehler konzentriert thematisiert werden.

\section{aa) Auf Seiten der erklärenden Behörde}

Der Gegenstand der Bekanntgabe ist laut § 41 I 1 VwVfG der „Verwaltungsakt“. 121 Dieser ist für die Zwecke der Bekanntgabe von seinen gesetzlich vorgesehenen Annexen zu unterscheiden, da sich eine fehlerhafte Bekanntgabe insofern unterschiedlich auswirkt. ${ }^{382}$ Die Wirksamkeit eines Verwaltungsakts ist nur von der ordnungsgemäßen Bekanntgabe seines verfügenden Teils - sprich seiner Regelung (s. dazu Rn. 63 ff.) - abhängig. ${ }^{383}$ Dazu gehören auch alle Nebenbestimmungen. ${ }^{384}$ Anders wirken indes Fehler hinsichtlich der Bekanntgabe einer dem Verwaltungsakt gegebenenfalls beizufügenden Begründung (§39 VwVfG) oder Rechtsbehelfsbelehrung ( $§ 37$ VI VwVfG): Bestehen Begründungsdefizite, ist ein Verwaltungsakt lediglich (formell) rechtswidrig und gar einer Heilung zugänglich (dazu speziell §45 I Nr. 2 VwVfG, s. dazu Rn. 662); Rechtsbelehrungsdefizite

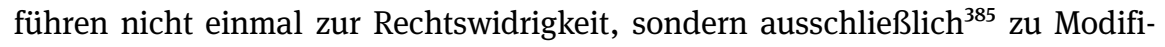
kationen der Rechtsbehelfsfristen nach $\S 58$ VwGO (s. dazu Rn. $368 \mathrm{ff}$.).

Der Verwaltungsakt muss mit Bekanntgabewillen der den Verwaltungsakt 122 erlassenden Behörde (in amtlicher Eigenschaft ${ }^{386}$ ) in Richtung eines bestimmten Empfängers auf den Weg gebracht werden. ${ }^{387}$ Fehlt dieser, kann ein Verwaltungsakt nicht i.S.v. § 43 I VwVfG wirksam werden. Die Bekanntgabe ist demnach von verschiedenen Möglichkeiten eines bloßen Bekanntwerdens des Verwaltungsakts zu unterscheiden. Die Erlassbehörde muss den Verwaltungsakt zwar

382 Differenzierend auch Stelkens, in: Stelkens/Bonk/Sachs, VwVfG, 9. Aufl. 2018, § 41 Rn. 15f.; Couzinet/Fröhlich, in: Mann/Sennekamp/Uechtritz, VwVfG, 2. Aufl. 2019, § 41 Rn. 24, dort auch zur (analogen) Anwendbarkeit auf Zusicherungen, Anordnungen der sofortigen Vollziehung und behördliche Verfahrensanordungen, a.a.O., Rn. $25 \mathrm{ff}$.

383 Tiedemann, in: Bader/Ronellenfitsch, VwVfG, 44. Ed., Stand: 1.7.2019, § 41 Rn. 6.

384 Sowie eine potentiell damit verbundene Anordnung der sofortigen Vollziehung, so Stelkens, in: Stelkens/Bonk/Sachs, VwVfG, 9. Aufl. 2018, § 41 Rn. $14 \mathrm{f}$.

385 Die verfahrensrechtlichen Folgen einer unrichtigen oder unterbliebenen Rechtsbehelfsbelehrung sind laut BVerwG in § 58 VwGO abschließend geregelt, Urt. v. 20.4.1994, Az.: 11 C $2.93=$ NVwZ-RR 1995, 50; Urt. v. 15.9.2010, Az.: 8 C 21.09 = BVerwGE 138, 1 (4, Rn. 19).

386 Bezüglich des beim nachbarschaftlichen Grillfest beiläufig mitgeteilten Verwaltungsakts wird es regelmäßig an einem Bekanntgabewillen fehlen.

387 S. nur das BVerwG - bereits vor Erlass des VwVfG - für die Bekanntgabe verallgemeinernd Urt. v. 29.4.1968, Az.: VIII C 19.64 = BVerwGE 29, 321 (323); so bereits konkret zur Zustellung BVerwG, Urt. v. 19.6.1963, Az.: V C 198.62 = BVerwGE 16, 165 (166f.); s. auch speziell zu § 74 VwGO BVerwG, Urt. v. 23.7.1965 - Az.: VII C 175.64 = BVerwGE 22, 14 (15).

Tobias Brings-Wiesen 
nicht selbst bekanntgeben, ${ }^{388}$ die Bekanntgabe aber zumindest willentlich veranlasst haben. ${ }^{389}$ Die ohne oder gar gegen den Willen der Erlassbehörde erfolgende Eröffnung des Verwaltungsakts gegenüber einem Betroffenen durch eine andere Behörde, ${ }^{390}$ einen anderen privaten Betroffenen ${ }^{391}$ oder gar jemand völlig Unbeteiligten ${ }^{392}$ führt nicht zu einer wirksamen Bekanntgabe. ${ }^{393}$ An einem Bekanntgabewillen kann es noch fehlen, wenn die Behörde eine Erklärung, die zwar ultimativ zum Verwaltungsakt werden soll, vorab bloß informatorisch übermittelt. Besonderer Berücksichtigung bedarf in diesem Zusammenhang die Genehmigungsfiktion gemäß § 42a VwVfG (s. zur Rechtsnatur der Genehmigungsfiktion Rn. 61). ${ }^{394}$ Deren Besonderheit liegt darin, dass ein das Verwaltungsverfahren abschließender Akt der Behörde ausbleibt. Gemäß § 42a I 1 VwVfG gilt eine beantragte Genehmigung jedoch unter bestimmten Voraussetzungen nach Ablauf

388 Vgl. nur das Auseinanderfallen der Zuständigkeit für eine Sachentscheidung und für deren Zustellung bei BVerwG, Beschl. v. 8.3.1984, Az.: 9 B 15204.82 = NVwZ 1984, 521.

389 Maurer/Waldhoff, Allgemeines Verwaltungsrecht, 19. Aufl. 2017, § 9 Rn. 74. Ist dies der Fall, ändert auch die Tatsache, dass eine für die Bekanntgabe unzuständige Behörde gehandelt hat, nichts an der Wirksamkeit des Verwaltungsakts, vgl. BVerwG, Beschl. v. 8.3.1984, Az.: 9 B 15204.82 = NVwZ 1984, 521. - Hier zeigt sich auch die Notwendigkeit eines differenzierten Verständnisses: Soweit eine Bekanntgabe durch die „zuständige Behörde“ gefordert wird, s. bspw. Detterbeck, Allgemeines Verwaltungsrecht, 17. Aufl. 2019, Rn. 552; Maurer/Waldhoff, a.a.O., kann damit nicht die Zuständigkeit für den Erlass des Verwaltungsakts (s. dazu ausführlich Rn. 580 ff.), sondern nur der Bekanntgabewille der Erlassbehörde gemeint sein. Erlässt folglich eine unzuständige Behörde einen Verwaltungsakt und gibt diesen sodann willentlich bekannt, kann dieser grundsätzlich Wirksamkeit erlangen. Er leidet indes wegen fehlender Zuständigkeit an einem formellen Fehler.

390 Bsp.: Die Eröffnung erfolgt durch eine Behörde, die verwaltungsintern vorzeitig über eine Sachentscheidung in Kenntnis gesetzt wurde, obwohl die die Sachentscheidung erlassende Behörde nicht bekanntgeben wollte, BVerwG, Urt. v. 29.4.1968, Az.: VIII C 19.64 = BVerwGE 29, 321 (323).

391 Bsp.: Der Bauherr übergibt seinem Nachbarn eine Kopie seiner Baugenehmigung, die die zuständige Behörde bisher nur ihm gegenüber bekanntgegeben hat.

392 Bsp.: Die Reinigungskraft findet nach Dienstschluss im Papierkorb einer Behördenmitarbeiterin mehrere verschlossene, adressierte Briefumschläge und gibt diese in der irrigen Annahme einer missverständlichen Entsorgung zur Poststelle der Behörde.

393 Nicht abschließend geklärt ist die Frage, wie bei Zweifeln am Bekanntgabewillen der Behörde zu verfahren ist. Zum Teil wird auf das Verständnis eines durchschnittlichen Empfängers abgestellt, Couzinet/Fröhlich, in; Mann/Sennekamp/Uechtritz, VwVfG, 2. Aufl. 2019, § 41 Rn. 18, zum Teil die Ersetzung des Bekanntgabewillens durch dem Zivilrecht entlehnte Rechtsscheinerwägungen gefordert, Stelkens, in: Stelkens/Bonk/Sachs, VwVfG, 9. Aufl. 2018, § 41 Rn. 57 ff., bezüglich derer jedoch angesichts der besonderen Wirkungen des Verwaltungsakts Vorsicht geboten ist.

394 S. rund um die Genehmigungsfiktion ausführlich Guckelberger, DÖV 2010, 109; Weidemann/ Barthel, JA 2011, 221; Kluth, JuS 2011, 1078; Ernst/Pinkl, JURA 2013, 685.

Tobias Brings-Wiesen 
einer für die Entscheidung festgelegten Frist (§ 42a II VwVfG: drei Monate ab Eingang der vollständigen Unterlagen, sofern spezialgesetzlich nichts anderes bestimmt ist) schlicht als erteilt - die Genehmigung wird fingiert ${ }^{395}$, ohne dass es auf einen Bekanntgabeakt oder auch nur einen darauf gerichteten Bekanntgabewillen gemäß $\S 41$ VwVfG ankäme. Insofern kommt es zu einer Modifikation des - gemäß §42a I 2 VwVfG zumindest entsprechend anwendbaren - § 43 I VwVfG. ${ }^{396}$ Mit Ablauf der Frist tritt die (äußere ${ }^{397}$ ) Wirksamkeit ein - allerdings nur gegenüber dem Antragssteller, nicht gegenüber anderen Betroffenen. ${ }^{398}$ Zentrale Voraussetzung des Wirksamwerdens einer solchen fingierten Genehmigung ist, dass sie gemäß § 42a I 1 VwVfG überhaupt durch Rechtsvorschrift angeordnet ist. ${ }^{399} \S 42 \mathrm{a}$ VwVfG selbst ist kein, sondern setzt einen anderweitig bestimmten ${ }^{400}$ Genehmigungstatbestand voraus. Soweit dieser Tatbestand selbst keine Voraussetzungen enthält, ${ }^{401}$ ergeben sich diese aus § 42a VwVfG: Danach bedarf es eines vollständigen wie hinreichend bestimmten Antrags ( $§ 42 \mathrm{a}$ I 1, II 2 VwVfG) an die zuständige Behörde ${ }^{402}$ sowie des Ablaufs der einschlägigen Frist vor Entscheidung der Behörde über den Antrag (§ 42a II VwVfG) ${ }^{403}$. Liegen diese Voraussetzungen vor, wird die fingierte Genehmigung gemäß § 42a I 2 i.V.m. § 43 II VwVfG wie ein regulär bekanntgegebener Verwaltungsakt ohne Rücksicht auf ihre Rechtmäßigkeit wirksam. ${ }^{404}$ Unwirksamkeit aufgrund von Nichtigkeit gemäß

395 Kurz und anschaulich zur Fiktion Kluth, JuS 2011, 1078 (1078f.); ausführlich zur Fiktion von Genehmigungen und zu Bekanntgabefiktionen im Verwaltungsverfahren m. zahlr. Bsp. Jachmann, Die Fiktion im öffentlichen Recht, 1998, S. $281 \mathrm{ff}$. und $442 \mathrm{ff}$.

396 Ramsauer, in: Kopp/Ramsauer, VwVfG, 20. Aufl. 2019, § 42a Rn. 2, 15.

397 Gemäß § 42a I 2 i.V.m. § 43 I 2 VwVfG wird die Genehmigung mit dem beantragten Inhalt wirksam, sodass die innere Wirksamkeit gleichsam erst zu einem späteren Zeitpunkt eintreten kann.

398 Ramsauer, in: Kopp/Ramsauer, VwVfG, 20. Aufl. 2019, § 42a Rn. 3; Kluth, JuS 2011, 1078 (1081); Ernst/Pinkl, JURA 2013, 685 (692). S. aber zu Ansprüchen auf Mitteilung gegenüber Dritten Ramsauer, a.a.O., § 42a Rn. 22, 30.

399 Ramsauer, in: Kopp/Ramsauer, VwVfG, 20. Aufl. 2019, § 42 Rn. 9 f.; Ernst/Pinkl, JURA 2013, 685 (686f.).

400 Für das Studium relevante Genehmigungstatbestände finden sich in §6a GewO, § 15 I 5 PBefG und insbesondere in einigen Landesbauordnungen im Hinblick auf das vereinfachte Baugenehmigungsverfahren, vgl. bspw. § 61 III HBauO. Für eine Übersicht über weitere Vorschriften s. Ramsauer, in: Kopp/Ramsauer, VwVfG, 20. Aufl. 2019, § 42a Rn. 10a.

401 S. mit Beispielen zu möglichen Abweichungen oder Ergänzungen Ernst/Pinkl, JURA 2013, 685 (689f.).

402 Ramsauer, in: Kopp/Ramsauer, VwVfG, 20. Aufl. 2019, § 42a Rn. 12a.

403 S. zur Funktionsweise der Fristenregelung in § 42a II VwVfG Ernst/Pinkl, JURA 2013, 685 (688f.).

404 Ramsauer, in: Kopp/Ramsauer, VwVfG, 20. Aufl. 2019, § 42a Rn. 16. 
§ 42a I 2 i.V.m. §§ 43 III, 44 VwVfG ist möglich, sofern der Grund für die Nichtigkeit nicht untrennbar mit Natur oder Verfahren der Genehmigungsfiktion verbunden ist. ${ }^{405}$ Sie kann gemäß $\S \S 48,49$ VwVfG oder aufgrund von spezialgesetzlichen Regelungen aufgehoben und mit den gegenüber Verwaltungsakten statthaften Rechtsbehelfen angegriffen werden. ${ }^{406}$

\section{bb) Auf Seiten des Empfängers}

124 Der Kreis der Empfänger von Verwaltungsakten ist gesetzlich bestimmt. Gemäß $\S 41 \mathrm{I} 1 \mathrm{VwVfG}$ ist ein Verwaltungsakt demjenigen Beteiligten bekannt zu geben, für den er bestimmt ist oder der von ihm betroffen wird. Damit ist der Grundsatz der individuellen Bekanntgabe eines Verwaltungsakts normiert, aus dem der Grundsatz der relativen Wirksamkeit von Verwaltungsakten gemäß § 43 I VwVfG (s. dazu Rn. 113) folgt.

Anders als § 43 I VwVfG knüpft die Vorschrift wörtlich an die Definition der „Beteiligten“ gemäß § 13 VwVfG an. Dabei erfasst sie jedoch in der Sache genauso zwei Gruppen Betroffener: Bestimmt ist der Verwaltungsakt für die Person ${ }^{407}$, die ihn für sich beantragt hat (§ 13 I Nr. 1 Var. 1 VwVfG) oder an die die Behörde den Verwaltungsakt (sonst) richtet (§ 13 I Nr. 1 Var. 2, Nr. 2 VwVfG). ${ }^{408}$ Die Bestimmung ergibt sich - wie bereits dargelegt (s. dazu Rn. 107) - maßgeblich aus dem Regelungsinhalt des Verwaltungsakts, wie die Behörde ihn festlegt. ${ }^{409}$ Von einem Verwaltungsakt sonst betroffen ist die Person, die vom Regelungsinhalt des Verwaltungsakts unter Berücksichtigung der aus dem einschlägigen materiellen Recht resultierenden Rechtsfolgewirkungen in ihren rechtlich geschützten Interessen berührt wird ${ }^{410}$ (§ 13 II VwVfG). Damit sind insbesondere die sog. Verwaltungsakte mit Doppel- bzw. Drittwirkung (vgl. dazu § 9 Rn. 6 f.) erfasst.

405 Ramsauer, in: Kopp/Ramsauer, VwVfG, 20. Aufl. 2019, § 42a Rn. 16; Ernst/Pinkl, JURA 2013, 685 (691). So sind mangels Schriftlichkeit bzw. Urkunde oder Erlass durch eine Behörde bereits die Anwendungsbereiche von $\S 44$ II Nr. 1 bis 3 VwVfG nicht eröffnet.

406 Ernst/Pinkl, JURA 2013, 685 (691f., 692f.).

407 Dabei ist auch eine Identitätstäuschung irrelevant, BVerwG, Urt. v. 9.9.2014, Az.: 1 C $10.14=$ NVwZ 2014, 1679 (1679f., Rn. 13).

408 Stelkens, in: Stelkens/Bonk/Sachs, VwVfG, 9. Aufl. 2018, § 41 Rn. 29.

409 Ob die Behörde den Verwaltungsakt an die richtige Person gerichtet hat, ist indes eine Frage der materiellen Rechtmäßigkeit, s. dazu allgemein Rn. 790 f., sowie insbesondere in den prüfungsrelevanten Konstellationen des Polizei- und Ordnungsrechts Rn. $1118 \mathrm{ff}$.

410 OVG Münster, Urt.v. 20.6.1991, Az.: 7 A 23/90 = NVwZ 1992, 991; Couzinet/Fröhlich, in: Mann/ Sennekamp/Uechtritz, VwVfG, 2. Aufl. 2019, § 41 Rn. 61; Ruffert, in: Knack/Henneke, VwVfG, 10. Aufl. 2014, § 41 Rn. 19. 
Der Rekurs auf die „Beteiligten“ i.S.v. § 13 VwVfG ist indes nicht überzubewerten. Unterbleibt eine Bekanntgabe gegenüber einem von mehreren gemäß § 41 I 1 VwVfG Betroffenen, ${ }^{411}$ ändert dies gemäß § 43 I VwVfG nichts an der Existenz und Wirksamkeit des Verwaltungsakts gegenüber den anderen, soweit er ihnen wirksam bekanntgegeben wurde. Dem sog. „übergangenen Betroffenen“ gegenüber wird der Verwaltungsakt zwar nicht rechtlich wirksam, er kann jedoch angesichts der gleichwohl drohenden (faktischen) Auswirkungen Rechtsbehelfe gegen einen bereits existenten Verwaltungsakt anstrengen (s. dazu Rn. 112). Mangels Bekanntgabe ist er dabei nicht fristgebunden (§§ 70 I 1, 74 I 2 VwGO); ${ }^{412}$ ein Rechtsbehelf kann jedoch gleichwohl wegen eines Verstoßes gegen die Grundsätze von Treu und Glauben (in Ausprägung der Verwirkung) verspätet sein, wenn der Betroffene von dem Verwaltungsakt Kenntnis erlangt hat oder zumindest hätte erlangen müssen. ${ }^{413}$ Gegenüber Beteiligten, die sich am Ende des Verwaltungsverfahrens doch nicht als Betroffene erweisen, muss keine Bekanntgabe erfolgen. ${ }^{414}$

Besonderheiten gilt es im Falle der Betroffenheit von Personenmehrheiten $^{415}$ und von juristischen Personen ${ }^{416} \mathrm{zu}$ beachten.

Um von dem Verwaltungsakt überhaupt Kenntnis nehmen zu können, muss der Betroffene auch handlungsfähig i.S.v. § 12 VwVfG (s. dazu Rn. 641) sein. ${ }^{417}$ Soweit er i.S.v. § 12 I Nr. 2 VwVfG nur beschränkt geschäftsfähig ist, ist innerhalb des geschäftsfähigen Rechtskreises noch eine persönliche Bekanntgabe mög-

411 Die Frage, ob nur am Verfahren Beteiligte, so Stelkens, in: Stelkens/Bonk/Sachs, VwVfG, 9. Aufl. 2018, § 41 Rn. 33, oder alle materiell Betroffenen, so Couzinet/Fröhlich, in: Mann/Sennekamp/Uechtritz, VwVfG, 2. Aufl. 2019, § 41 Rn. 61 m.w. N., gemeint sind, kann dahinstehen. 412 Vor diesem Hintergrund wird diskutiert, ob sowohl der übergangene Betroffene als auch der von einem Verwaltungsakt mit Drittwirkung Begünstigte gegen die Behörde einen Anspruch auf nachträgliche Bekanntgabe an sich bzw. den belasteten Dritten haben, bejahend Ramsauer/Tegethoff, in: Kopp/Ramsauer, VwVfG, 20. Aufl. 2019, § 41 Rn. 33; Tiedemann, in: Bader/Ronellenfitsch, VwVfG, 44. Ed., Stand: 1.7.2019, § 41 Rn. 58.

413 S. nur BVerwG, Urt. v. 25.1.1974, Az.: IV C 2.72 = BVerwGE 44, 294 (300f.); s. zu diesen Konstellationen ausführlich Rn. 329, $399 \mathrm{ff}$.

414 Stelkens, in: Stelkens/Bonk/Sachs, VwVfG, 9. Aufl. 2018, § 41 Rn. 32; Ruffert, in: Knack/ Henneke, VwVfG, 10. Aufl. 2014, § 41 Rn. 19.

415 S. zur Bekanntgabe an verschiedene Personenmehrheiten Ramsauer/Tegethoff, in: Kopp/ Ramsauer, VwVfG, 20. Aufl. 2019, § 41 Rn. 28 f., 30 ff.; Stelkens, in: Stelkens/Bonk/Sachs, VwVfG, 9. Aufl. 2018, § 44 Rn. 75 ff., 97; Ruffert, in: Knack/Henneke, VwVfG, 10. Aufl. 2014, § 41 Rn. 14 ff. 416 S. dazu Stelkens, in: Stelkens/Bonk/Sachs, VwVfG, 9. Aufl. 2018, § 41 Rn. 48 ff.; Couzinet/ Fröhlich, in: Mann/Sennekamp/Uechtritz, VwVfG, 2. Aufl. 2019, § 41 Rn. 60.

417 Stelkens, in: Stelkens/Bonk/Sachs, VwVfG, 9. Aufl. 2018, § 41 Rn. 50; Couzinet/Fröhlich, in: Mann/Sennekamp/Uechtritz, VwVfG, 2. Aufl. 2019, § 41 Rn. 69. 
lich. ${ }^{418}$ Soweit demgegenüber die Handlungsfähigkeit fehlt, muss die Bekanntgabe gegenüber dem gesetzlichen Vertreter erfolgen - so beispielsweise im Falle eines Minderjährigen ${ }^{419}$ regelmäßig gegenüber seinen Eltern, ${ }^{420}$ im Falle eines Volljährigen gegebenenfalls gegenüber seinem Betreuer. Eine gleichwohl gegenüber dem Handlungsunfähigen erfolgte Bekanntgabe ist unwirksam. ${ }^{421}$ Der gesetzliche Vertreter kann jedoch durch nachträgliche Genehmigung für eine Wirksamkeit sorgen; ebenso kann der Betroffene selbst bei späterer Wiedererlangung der Handlungsfähigkeit Kenntnis über den Verwaltungsakt erlangen. ${ }^{422}$

Gemäß § 41 I 2 VwVfG kann die Bekanntgabe auch einem Bevollmächtigten gegenüber vorgenommen werden. Der persönliche Anwendungsbereich der Vorschrift erstreckt sich nicht nur auf Bevollmächtigte i.S.v. § 14 VwVfG, sondern auch auf Empfangsbevollmächtigte i.S.v. $§ 15$ VwVfG. ${ }^{423}$ Ihnen gegenüber kann die Bekanntgabe indes nur dann wirksam erfolgen, wenn und solange (im Zeitpunkt des Zugangs) eine entsprechende Vollmacht vorliegt. ${ }^{424}$ Umstritten ist die Frage, ob es sich um einen Fehler handelt, wenn die Behörde den Verwaltungsakt einem Betroffenen persönlich bekanntgibt, obwohl dieser einen Bevollmächtigten mit der Wahrnehmung seiner Angelegenheit betraut hat und dies der Behörde auch bekannt ist. ${ }^{425}$ Dies wird von einer Mindermeinung unter Berufung auf $\S 14$ III 1 VwVfG, wonach sich die Behörde im Falle der Bestellung eines Bevoll-

418 Ramsauer/Tegethoff, in: Kopp/Ramsauer, VwVfG, 20. Aufl. 2019, § 44 Rn. 29; Stelkens, in: Stelkens/Bonk/Sachs, VwVfG, 9. Aufl. 2018, § 41 Rn. 50.

419 S. aber zum Sonderfall der Bekanntgabe eines Verwaltungsakts gegenüber minderjährigen Störern im Bereich des Polizei- und Ordnungsrechts Rn. 1121.

420 Die jedoch gemäß § 1629 I 2 Hs. 2 BGB bei Empfang der im Verwaltungsakt enthaltenen Willenserklärung ausnahmsweise jeweils alleinvertretungsberechtigt sind, Couzinet/Fröhlich, in: Mann/Sennekamp/Uechtritz, VwVfG, 2. Aufl. 2019, § 41 Rn. 70 m.w. N.

421 Ramsauer/Tegethoff, in: Kopp/Ramsauer, VwVfG, 20. Aufl. 2019, § 41 Rn. 29; Stelkens, in: Stelkens/Bonk/Sachs, VwVfG, 9. Aufl. 2018, § 41 Rn. 50.

422 Couzinet/Fröhlich, in: Mann/Sennekamp/Uechtritz, VwVfG, 2. Aufl. 2019, § 41 Rn. 71 m.w. N. 423 Die zu diesen Vorschriften geltenden Grundsätze sind entsprechend anzuwenden; insbesondere besteht auch die Möglichkeit einer Anscheins- bzw. Duldungsbevollmächtigung, BVerwG, Urt. v. 25.2.1994, Az.: 8 C 2.92 = NJW-RR 1995, 73 (75); BVerwG, Beschl. v. 20.1. 2017, Az.: 8 B 23.16 = NVwZ-RR 2017, 430 (430 f.); s. dazu auch m.w. N. Couzinet/Fröhlich, in: Mann/Sennekamp/Uechtritz, VwVfG, 2. Aufl. 2019, § 41 Rn. 65.

424 Stelkens, in: Stelkens/Bonk/Sachs, VwVfG, 9. Aufl. 2018, § 41 Rn. 36. Das BVerwG, Urt. v. 25. 2. 1994, Az.: 8 C 2.92 = NJW-RR 1995, 73 (75), hält demgegenüber in einer solchen Konstellation grds. eine Heilung entsprechend $\S 8$ VwZG (s. dazu noch Rn. 172) für möglich, wenn der Betroffene tatsächlich Kenntnis erlangt hat.

425 Davon ausdrücklich abzugrenzen sind Konstellationen der Zustellung an Bevollmächtigte gemäß § 7 VwZG, s. dazu noch Rn. 171. 
mächtigten an diesen wenden „soll“, grundsätzlich bejaht. ${ }^{426}$ Die h.M. sieht jedoch in § 41 I 2 VwVfG zu Recht eine Spezialregelung zu § 14 III VwVfG, die es in das Ermessen der Behörde stellt („kann“), wem gegenüber sie den Verwaltungsakt bekanntgibt. ${ }^{427}$ Dieses Auswahlermessen hat sie dann jedoch pflichtgemäß auszuüben, es dürfen ihr keine Ermessensfehler unterlaufen. ${ }^{428}$ Die Rechtsfolge eines Ermessensfehlers ist wiederum umstritten. ${ }^{429}$ Bei dualer Bekanntgabe an den Betroffenen und seinen Bevollmächtigten kommt es auf den zuerst bewirkten Zugang an. ${ }^{430}$

Der Akt der Bekanntgabe wird abgeschlossen mit dem „Zugang“ beim 130 Empfänger. Verlangt ist dafür keine tatsächliche Kenntnisnahme. ${ }^{431}$ Die Rechtsprechung ${ }^{432}$ und die ganz herrschende Meinung in der Literatur ${ }^{433}$ wenden für die Bestimmung des Zugangs der Willenserklärung Verwaltungsakt § 130 BGB analog an. ${ }^{434}$ Verlangt ist insofern die derartige Verbringung in den Machtbereich des jeweiligen Empfängers, dass „,bei gewöhnlichem Verlauf und normaler Gestaltung der Verhältnisse des Empfängers mit der Kenntnisnahme durch ihn zu rechnen ist““. ${ }^{435}$ Es geht demnach nur um die Kenntnisnahmemöglichkeit. Die Anforderungen an diese Kenntnisnahmemöglichkeit richten sich nach der Art der Bekanntgabe und den diesbezüglich existierenden Rechtsvorschriften

426 So noch das VGH Mannheim, Beschl.v. 7.10.1986, Az.: NC 9 S 550/86 = VBlBW 1987, 297; indes später aufgegeben in Urt. v. 19.7.2005, Az.: 9 S 2278/03 = NVwZ-RR 2006, 154.

427 BVerwG, Urt. v. 30.10.1997, Az.: 3 C 35.96 = BVerwGE 105, 288 (292ff.); so auch Ramsauer/ Tegethoff, in: Kopp/Ramsauer, VwVfG, 20. Aufl. 2019, § 41 Rn. 34; Couzinet/Fröhlich, in: Mann/ Sennekamp/Uechtritz, VwVfG, 2. Aufl. 2019, § 41 Rn. 66f. jeweils m.w. N.

428 S. für Beispiele potentieller Ermessensfehler Stelkens, in: Stelkens/Bonk/Sachs, VwVfG, 9. Aufl. 2018, § 41 Rn. 41; Couzinet/Fröhlich, in: Mann/Sennekamp/Uechtritz, VwVfG, 2. Aufl. 2019, $\S 41$ Rn. 67; vgl. auch BFH, Urt. v. 5.10.2000, Az.: VII R 96/99 = NVwZ 2001, 473 (474).

429 Für eine Unwirksamkeit der Bekanntgabe: Stelkens, in: Stelkens/Bonk/Sachs, VwVfG, 9. Aufl. 2018, § 41 Rn. 43; primär für ein Unterbleiben des Fristlaufs (subsidiär indes auch für eine Wiedereinsetzung): Ramsauer/Tegethoff, in: Kopp/Ramsauer, VwVfG, 20. Aufl. 2019, § 41 Rn. 35; für die Möglichkeit einer Wiedereinsetzung in den vorigen Stand: VGH Kassel, Urt. v. 10.8.1992, Az.: 12 UE 2254/89 = NVwZ-RR 1993, 432 (434f.); Couzinet/Fröhlich, in: Mann/Sennekamp/ Uechtritz, VwVfG, 2. Aufl. 2019, § 41 Rn. 68 m.w. N.

430 Couzinet/Fröhlich, in: Mann/Sennekamp/Uechtritz, VwVfG, 2. Aufl. 2019, § 41 Rn. 64.

431 Deswegen ist bspw. irrelevant, ob der Empfänger einen in seinen Machtbereich verbrachten Brief tatsächlich öffnet und liest.

432 S. nur BVerwG, Beschl.v. 22. 2.1994, Az.: 4 B 212.93 = BeckRS 1994, 31246579; Urt.v. 31.5. 2012, Az.: 3 C 12.11 = NVwZ-RR 2012, 628 (630, Rn. 18f.); Beschl.v. 21.12.2017, Az.: 6 B 43.17 = NVwZ 2018, 496 (498, Rn. 11).

433 Statt vieler Maurer/Waldhoff, Allgemeines Verwaltungsrecht, 19. Aufl. 2017, § 9 Rn. 75; Peine/ Siegel, Allgemeines Verwaltungsrecht, 12. Aufl. 2018, Rn. 443.

434 So bereits die Gesetzesmaterialien BT-Drucks. 7/910, S. $61 \mathrm{f}$.

435 S. nur BVerwG, Beschl. v. 21.12. 2017, Az.: 6 B 43.17 = NVwZ 2018, 496 (498, Rn. 11). 
und Verkehrsanschauungen. ${ }^{436}$ So kommt es beispielsweise im Falle der (fern-) mündlichen Bekanntgabe unter Anwesenden darauf an, dass die Erklärung sinnlich wahrnehmbar ist. ${ }^{437}$ Gemäß $§ 23$ I VwVfG wird sie grundsätzlich in deutscher Sprache erfolgen müssen. ${ }^{438}$ Erfolgt die Bekanntgabe in textlicher Verkörperung unter Abwesenden, wird es besonders auf die Bestimmung des „Machtbereichs“ ankommen: Dazu gehören beispielsweise im Falle des Einwurfs durch die Behörde oder der postalischen Übermittlung ein häuslicher Briefkasten oder ein Postschließfach, ${ }^{439}$ im Falle der Versendung per E-Mail der Posteingang (s. dazu Rn. 144ff.). Eine Verbringung in den Machtbereich des Empfängers ist auch durch Übermittlung an einen Empfangsboten denkbar, wenn dieser vom Betroffenen bestellt wurde oder nach der Verkehrsanschauung als solcher gewertet wird. ${ }^{440}$

131 Je nach Art der Bekanntgabe und Zugang beim Empfänger differiert auch der rechtlich relevante Zeitpunkt der Bekanntgabe. Dieser bestimmt sich wiederum in entsprechender Anwendung von $\S 130$ BGB - danach, wann bei gewöhnlichem Verlauf und normaler Gestaltung der Verhältnisse des Empfängers mit der Kenntnisnahme zu rechnen ist. ${ }^{441}$ Auch insofern kommt es maßgeblich auf die diesbezüglich existierenden Rechtsvorschriften und Verkehrsanschauungen an. Bereits im Studium sind besonders die Vorgaben in $\S 41 \mathrm{II} \mathrm{VwVfG} \mathrm{zu}$ beachten (s. dazu Rn. 136ff.).

132 Kommt es $\mathrm{zu}$ einem Zugangsproblem, ist nach dem Ursprung für dieses Problem innerhalb der getrennten Verantwortungssphären von Behörde und Empfänger zu suchen. Dabei ist zu berücksichtigen, dass für den Bürger keine allgemeine Pflicht besteht, Empfangsvorkehrungen $\mathrm{zu}$ treffen. ${ }^{442}$ Verschickt die Behörde beispielsweise einen Verwaltungsakt an eine im Melderegister falsch geführte Adresse, mag zwar ein Verstoß gegen Vorschriften des Melderechts

436 S. zu den verschiedenen Möglichkeiten des Zugangs je nach Art der Bekanntgabe ausführlich Stelkens, in: Stelkens/Bonk/Sachs, VwVfG, 9. Aufl. 2018, § 41 Rn. 69ff. m.w. N.

437 Ramsauer/Tegethoff, in: Kopp/Ramsauer, VwVfG, 20. Aufl. 2019, § 41 Rn. 7c.

$438 \mathrm{Zu}$ Recht differenzierend Tiedemann, in: Bader/Ronellenfitsch,VwVfG, 44. Ed., Stand: 1.7. 2019, § 41 Rn. 11f.; rigider Ramsauer/Tegethoff, in: Kopp/Ramsauer, VwVfG, 20. Aufl. 2019, § 41 Rn. 8a; Stelkens, in: Stelkens/Bonk/Sachs, VwVfG, 9. Aufl. 2018, § 41 Rn. 64. Vgl. auch zu anderen Kommunikationsproblemen Tiedemann, a.a.O., Rn. $15 \mathrm{f}$.

439 S. dazu ausführlich m.w. N. Stelkens, in: Stelkens/Bonk/Sachs, VwVfG, 9. Aufl. 2018, § 41 Rn. $69 \mathrm{ff}$.

440 S. dazu ausführlich m.w. N. Stelkens, in: Stelkens/Bonk/Sachs, VwVfG, 9. Aufl. 2018, § 41 Rn. $67 \mathrm{f}$.

441 BVerwG, Beschl. v. 22.2.1994, Az.: 4 B 212.93 = BeckRS 1994, 31246579; Urt. v. 31.5.2012, Az.: 3 C 12.11 = NVwZ-RR 2012, 628 (630, Rn. 18f.).

442 BVerwG, Urt. v. 29.6.1990, Az.: 8 C 22.89 = BVerwGE 85, 213 (216) m.w. N.

Tobias Brings-Wiesen 
vorliegen - dieser ändert aber nichts daran, dass es in der Risikosphäre der Behörde liegt, die richtige Adresse im Vorfeld sicher zu ermitteln. ${ }^{443}$ Etwas anderes kann sich jedoch daraus ergeben, ${ }^{444}$ dass den Empfänger besondere gesetzliche Pflichten treffen, ${ }^{445}$ er der Behörde eine bestimmte Empfangsmöglichkeit ausdrücklich kommuniziert hat oder es für ihn aus vorangegangenen Vorgängen erkenntlich war, dass er einen Verwaltungsakt erhalten wird. Kommt es in diesen Fällen zu Zugangsproblemen, kann darin eine schuldhafte treuwidrige Vereitelung durch den Empfänger liegen, sodass dieser sich nach den Grundsätzen von Treu und Glauben so behandeln lassen muss, als sei ihm die Erklärung wie im Falle seines pflichtgemäßen Verhaltens zugegangen. ${ }^{446}$

\section{b) Ergänzende bzw. abweichende besondere Vorgaben nach Art der Bekanntgabe}

Ob über die allgemeinen Voraussetzungen hinaus noch weitere bzw. abwei- 133 chende besondere Vorgaben bestehen, richtet sich nach der Art der Bekanntgabe. Wie für den Erlass des Verwaltungsakts (§ 37 II 1 VwVfG; s. dazu Rn. 681) gilt auch für seine Bekanntgabe der „Grundsatz der Formfreiheit“. ${ }^{447}$ Beide Anknüpfungspunkte dürfen jedoch nicht miteinander vermengt werden: Die Art der Bekanntgabe eines Verwaltungsakts ist zwingend von seiner Erlassform (s. dazu Rn. $681 \mathrm{ff}$.) zu unterscheiden, ${ }^{448}$ da diese unterschiedliche Fehlerfolgen nach sich ziehen. Auch wenn die Art $^{449}$ der Bekanntgabe in der Verwaltungspraxis oftmals der Erlassform folgen wird, ${ }^{450}$ hindert eine Verletzung von Formvorschriften nicht ${ }^{451}$ die wirksame Bekanntgabe des Verwaltungsakts. ${ }^{452}$

443 OVG Schleswig, Beschl. v. 28.3.2001, Az.: 1 M 24/00 = NVwZ 2002, 358 (359).

444 S. dazu ausführlich m.w. N. Stelkens, in: Stelkens/Bonk/Sachs, VwVfG, 9. Aufl. 2018, § 41 Rn. $103 \mathrm{ff}$.

445 Vgl. bspw. § 10 I AsylG; zu vergleichbaren Vorschriften des Wehrpflichtgesetzes instruktiv BVerwG, Urt. v. 29.6.1990, Az.: 8 C 22.89 = BVerwGE 85, 213 (215ff.).

446 S. nur BVerwG, Urt. v. 29.6.1990, Az.: 8 C 22.89 = BVerwGE 85, 213 (216). Demgegenüber in rechtsdogmatischer Hinsicht für die Annahme einer Zugangsfiktion Stelkens, in: Stelkens/Bonk/ Sachs, VwVfG, 9. Aufl. 2018, § 41 Rn. 102; dezidiert dagegen Tiedemann, in: Bader/Ronellenfitsch, VwVfG, 44. Ed., Stand: 1.7.2019, § 41 Rn. $32 \mathrm{ff}$.

447 Schwarz, in: Fehling/Kastner/Störmer, Verwaltungsrecht, 4. Aufl. 2016, § 41 VwVfG Rn. 9; Schoch, JURA 2011, 23 (25).

448 S. das Beispiel für die verschiedenen Arten der Bekanntgabe eines schriftlichen Verwaltungsakts bei Detterbeck, Allgemeines Verwaltungsrecht, 17. Aufl. 2019, Rn. 555.

449 Vor diesem Hintergrund ist es sinnvoller, wie hier von „Arten“ anstatt von „Formen“ der Bekanntgabe zu sprechen.

$450 \mathrm{Zu}$ weitgehend Ramsauer/Tegethoff, in: Kopp/Ramsauer, VwVfG, 20. Aufl. 2019, § 41 Rn. 6, die eine „Abhängigkeit“ der Art und Weise der Bekanntgabe von der Erlassform erkennen.

Tobias Brings-Wiesen 
Fehlen Bestimmungen darüber, auf welche Art und Weise ein Verwaltungsakt bekanntzugeben ist, steht die Entscheidung darüber grundsätzlich im Ermessen der Behörde. ${ }^{453}$ Dann bedarf es lediglich der Einhaltung der bereits dargelegten allgemeinen Voraussetzungen einer Bekanntgabe (s. dazu Rn. 120 f.).

\section{aa) Einfache individuelle Bekanntgabe}

135 Soweit gesetzlich keine besondere Art ${ }^{454}$ vorgesehen ist, handelt es sich um eine einfache individuelle Bekanntgabe. Diese kann mündlich in persona oder via Fernkommunikationsmitteln, schriftlich durch persönliche Übergabe, Einwurf eines Behördenmitarbeiters, Übermittlung durch die Post oder Versendung via $\mathrm{Fax}^{455}$ oder in völlig anderer Weise - beispielsweise durch Handzeichen oder Piktogramme (s. noch zu Verkehrszeichen Rn. 165) - erfolgen. Für die einfache Bekanntgabe sind zumindest im allgemeinen Verwaltungsrecht keine besonderen Voraussetzungen vorgesehen. Zu berücksichtigen ist jedoch § 41 II 1 und 3 VwVfG.

Entscheidet sich die Behörde für die Bekanntgabe eines schriftlichen Verwaltungsakts via Übermittlung durch die Post im Inland, gilt der Verwaltungsakt gemäß § 41 II 1 VwVfG als am dritten Tag nach der Aufgabe zur Post als bekannt gegeben. Der Anwendungsbereich der Vorschrift ist begrenzt ${ }^{456}:$ Sie gilt nur für schriftliche (s. dazu Rn. 685f.) Verwaltungsakte; wenn diese durch die „Post“, sprich irgendeinen Erbringer von Postdienstleistungen i.S.v. §4 Nr. 1 Post $\mathrm{G},{ }^{457}$ übermittelt werden; solange dies im Inland, sprich ausschließlich innerhalb des Staatsgebiets der Bundesrepublik Deutschland, geschieht. ${ }^{458}$

451 In Ausnahmefällen mag sie jedoch die Nichtigkeit des Verwaltungsakts begründen, s. dazu noch in $\S 6 \mathrm{Rn} .115 \mathrm{ff}$.

452 Maurer/Waldhoff, Allgemeines Verwaltungsrecht, 19. Aufl. 2017, § 9 Rn. 73; Couzinet/Fröhlich, in: Mann/Sennekamp/Uechtritz, VwVfG, 2. Aufl. 2019, § 41 Rn. 53. A.A. wohl OVG Münster, Beschl. v. 27.10.1995, Az.: 10 B 2720/95 = NWVBl 1996, 222.

453 BVerwG, Beschl. v. 21.12.2017, Az.: 6 B 43.17 = NVwZ 2018, 496 (498, Rn. 11); so auch mit Ausführungen zu entscheidungsleitenden Gesichtspunkten Stelkens, in: Stelkens/Bonk/Sachs, VwVfG, 9. Aufl. 2018, § 41 Rn. 18f.; Couzinet/Fröhlich, in: Mann/Sennekamp/Uechtritz, VwVfG, 2. Aufl. 2019, § 41 Rn. 31f. So auch bereits die Gesetzesmaterialien, BT-Drucks. 7/910, S. 62.

454 Ein davon abgzugrenzender Sonderfall einer „qualifizierten Bekanntgabe“ ist jedoch die Aushändigung sog. konstitutiver Urkunden, vgl. BVerwG, Urt. 1.2.1978, Az.: 6 C 9.77 = BVerwGE 55, 212 (213ff.). S. dazu auch noch die Ausführungen zu § 44 II Nr. 2 VwVfG in § 6 Rn. 125 f.

455 S. dazu ausführlich Stelkens, in: Stelkens/Bonk/Sachs, VwVfG, 9. Aufl. 2018, § 41 Rn. $82 \mathrm{ff}$. 456 Eine analoge Anwendung der Vorschrift auf andere Konstellationen der Bekanntgabe wird von der herrschenden Meinung abgelehnt, s. nur Schwarz, in: Fehling/Kastner/Störmer, Verwaltungsrecht, 4. Aufl. 2016, § 41 VwVfG Rn. 26.

457 Schoch, JURA 2011, 23 (28). Zentral ist nach dieser Definition insbesondere die Gewerbsmäßigkeit der Dienstleistung, sodass eine „Hauspost“ nicht in Frage kommt, vgl. OVG Koblenz, 
Auch wenn die rechtsdogmatische Einordnung der Vorschrift umstritten 137 ist, ${ }^{459}$ besteht weitgehend Einigkeit bezüglich ihrer Wirkungen: Die Vorschrift vermutet nicht nur die Bekanntgabe an sich, sondern insbesondere auch den u. a. ${ }^{460}$ - für die Fristberechnung relevanten Zeitpunkt dieser Bekanntgabe. Es handelt sich insofern um eine Spezialvorschrift, die den bereits dargelegten allgemeinen Regeln betreffend den Zugang eines Verwaltungsakts vorgeht.

Soll es tatsächlich zu einem Zugang vor Ablauf dieser Frist gekommen sein, 138 ist entsprechend des Sinn und Zwecks der Vermutung zu differenzieren: Die Vermutung bleibt maßgeblich, den Empfängern ist es jedoch in für sie günstigen Konstellationen möglich, sich unter Darlegung von Beweisen auf diesen früheren Zugang zu berufen. ${ }^{461}$ Der Behörde hingegen ist eine entsprechende Möglichkeit zum Gegenbeweis zulasten der Empfänger nicht eröffnet; insofern gilt die Vermutungswirkung uneingeschränkt. ${ }^{462}$

Soll es indes zu einem Zugang nach Ablauf dieser Frist gekommen oder dieser gar völlig unterblieben sein, greift § 41 II 3 VwVfG: Die Vermutung gilt als widerlegt (Hs. 1) und die Behörde hat den Zugang des Verwaltungsakts und den Zeitpunkt des Zugangs nachzuweisen (Hs. 2). Voraussetzung dessen ist, dass „Zweifel“ am (pünktlichen) Zugang bestehen. Bestehen diese Zweifel auch nach erneuter Sachverhaltsermittlung fort, trägt die Behörde das Risiko der Nichterweislichkeit, sodass letztlich gegebenenfalls der Vortrag des Empfängers zugrunde $\mathrm{zu}$ legen ist. ${ }^{463}$ Bis heute ist jedoch stark umstritten, welche Anforderungen an den Widerlegungsvortrag des Empfängers zu stellen sind, sprich wann

Urt.v. 28.6.2002, Az.: 2 A 10667/02 = NVwZ-RR 2003, 4. Kritischer zu bestimmten Postdienstleistern indes zuletzt der BFH, Urt. v. 14.6.2018, Az.: III R 27/17 = NJW 2018, 3606.

458 Ausführlich zu den Voraussetzungen Stelkens, in: Stelkens/Bonk/Sachs, VwVfG, 9. Aufl. 2018, § $41 \mathrm{Rn} .111 \mathrm{ff}$.

459 Das BVerwG sprach zu der vergleichbaren Vorschrift des $§ 4$ VwZG a. F. von einer „gesetzlichen Fiktion“ mit „Ausnahmevorschrift“, BVerwG, Urt. v. 23.7.1965, Az.: VII C 170/64 = BVerwGE 22, 11 (12f.); dem folgend Erichsen/Hörster, JURA 1997, 659 (661). Demgegenüber für eine „widerlegbare Vermutung“ m.w. N. Schoch, JURA 2011, 23 (28); für eine differenzierende Betrachtung Stelkens, in: Stelkens/Bonk/Sachs, VwVfG, 9. Aufl. 2018, § 41 Rn. 109.

460 S. für Beispiele zu anderen Bedeutungsdimensionen Stelkens, in: Stelkens/Bonk/Sachs, VwVfG, 9. Aufl. 2018, § 41 Rn. 122, 125.

461 OVG Lüneburg, Urt. v. 23.6.2009, Az.: 12 LC 136/07 = NVwZ-RR 2009, 866 (867); Stelkens, in: Stelkens/Bonk/Sachs, VwVfG, 9. Aufl. 2018, § 41 Rn. 125; a.A. wohl Tiedemann, in: Bader/Ronellenfitsch, VwVfG, 44. Ed., Stand: 1.7.2019, § 41 Rn. 71, der offenbar keinerlei Ausnahme außerhalb von Konstellationen des § 41 II 3 VwVfG zulassen will.

462 Ramsauer/Tegethoff, in: Kopp/Ramsauer, VwVfG, 20. Aufl. 2019, § 41 Rn. 40; Stelkens, in: Stelkens/Bonk/Sachs, VwVfG, 9. Aufl. 2018, § 41 Rn. 121. Vgl. bereits zu § 4 BVwZG a. F. BVerwG, Urt. v. 23.7.1965, Az.: VII C 170/64 = BVerwGE 22, 11 (13f.).

463 Stelkens, in: Stelkens/Bonk/Sachs, VwVfG, 9. Aufl. 2018, § 41 Rn. 127.

Tobias Brings-Wiesen 
dieser wirklich „Zweifel“ sät. Dabei lassen sich heute drei Hauptansätze ausmachen: Eine Ansicht lässt das schlichte Bestreiten des (pünktlichen) Zugangs genügen und verzichtet auf jegliche Substantiierung des Vortrags. ${ }^{464}$ Hingegen lässt die Gegenmeinung nur ein qualifiziertes Bestreiten ${ }^{465}$, sprich den Vortrag und die Glaubhaftmachung von Umständen, die bei objektiver Betrachtung geeignet sind, berechtigte Zweifel am Zugang des Verwaltungsakts zu begründen, ausreichen. ${ }^{466}$ Eine differenzierende Ansicht verlangt eine weitere Substantiierung je nach Lage des Einzelfalls und unterscheidet dabei insbesondere zwischen der Behauptung eines unterbliebenen (= keine weitere Substantiierung) und eines verspäteten Zugangs. ${ }^{467}$ Für ein schlichtes Bestreiten spricht bereits der Wortlaut von § 41 II 3 VwVfG, der gerade der Behörde in Zweifelsfällen (ohne weitere Differenzierung ${ }^{468}$ ) die objektive Beweislast und somit das Risiko der Nichterweislichkeit des Zugangs auferlegt. ${ }^{469}$ Weiterhin wird logisch argumentiert, dass von dem Empfänger nichts Unmögliches verlangt werden dürfe: „Negative Tatsachen“ - wie der unterbliebene oder verspätete Zugang - könnten nicht weiter substantiiert werden. ${ }^{470}$ Auch liegen die Ursachen für einen unterbliebenen oder verspäteten Zugang außerhalb des Einfluss- und Kenntnisbereichs des Empfängers. ${ }^{471}$ Umgekehrt habe es die Behörde selbst in der Hand, Nachweis-

464 Erbguth/Guckelberger, Allgemeines Verwaltungsrecht, 9. Aufl. 2018, § 13 Rn. 9; Stelkens, in: Stelkens/Bonk/Sachs, VwVfG, 9. Aufl. 2018, § 41 Rn. 127 f.; Couzinet/Fröhlich, in: Mann/Sennekamp/Uechtritz, VwVfG, 2. Aufl. 2019, § 41 Rn. 93.

465 Dabei werden an ein solches qualifiziertes Bestreiten überwiegend keine strengen Anforderungen gestellt, s. bspw. das OVG Bautzen, Urt. v. 12.5.2010, Az.: 5 A 203/08 = LKV 2010, 430 (431), das - zumindest im Falle der Behauptung des völligen Unterbleibens eines Zugangs - auch eine plausible schlichte Erklärung ausreichen lassen will.

466 OVG Koblenz, Urt. v. 10.10.1997, Az.: 2 A 13324/96 = juris, Rn. 23; OVG Lüneburg, Beschl.v. 3. 8. 2012, Az.: 12 LA 180/11 = juris, Rn. 6; OVG Bautzen, Urt. v. 12.5.2010, Az.: 5 A 203/08 = LKV 2010, 430 (431); OVG Münster, Beschl. v. 26.11.2014, Az.: 6 A 1784/12 = juris, Rn. 22.

467 Anschaulich Stuhlfauth, in: Obemayer/Funke-Kaiser, VwVfG, 5. Aufl. 2018, § 41 Rn. $37 \mathrm{ff}$. m.w. N. aus der Rspr. Vgl. zu § 122 II AO jüngst auch BVerwG, Urt. v. 15.6.2016, Az.: 9 C $19.15=$ BVerwGE 155, 241 (244f., Rn. 17f.).

468 Was somit auch gegen die differenzierende Ansicht spreche, Couzinet/Fröhlich, in: Mann/ Sennekamp/Uechtritz, VwVfG, 2. Aufl. 2019, § 41 Rn. 93; Ruffert, in: Knack/Henneke, VwVfG, 10. Aufl. 2014, § 41 Rn. 37.

469 Couzinet/Fröhlich, in: Mann/Sennekamp/Uechtritz, VwVfG, 2. Aufl. 2019, § 41 Rn. 91, 93; in die Richtung auch Stelkens, in: Stelkens/Bonk/Sachs, VwVfG, 9. Aufl. 2018, § 41 Rn. 127; Beaucamp, JA 2016, 436 (437).

470 Schoch, JURA 2011, 23 (29); Beaucamp, JA 2016, 436 (437).

471 Tiedemann, in: Bader/Ronellenfitsch, VwVfG, 44. Ed., Stand: 1.7.2019, § 41 Rn. 81.1; Schoch, JURA 2011, 23 (29); Beaucamp, JA 2016, 436 (437); Stelkens, in: Stelkens/Bonk/Sachs, VwVfG, 9. Aufl. 2018, § 41 Rn. 128, erkennt insofern ein Verwischen der Grenze zwischen der Prüfung der Substantiiertheit und der Beweiswürdigung.

Tobias Brings-Wiesen 
problemen durch die Entscheidung gegen eine einfache postalische Übermittlung und für eine Zustellung vorzubeugen. ${ }^{472}$ Für ein qualifiziertes Bestreiten spricht demgegenüber, dass das Ausreichenlassen eines schlichten Bestreitens praktisch zum Leerlauf der Zugangsvermutung § 41 II 1 VwVfG führte und somit dem Zweck der Vorschrift diametral entgegenstünde. ${ }^{473}$ Zwar sieht sich auch die differenzierende Ansicht der oben dargelegten Kritik ausgesetzt. Ihr ist indes zuzugestehen, dass sie vom Empfänger nur in den Fällen der Verspätung, wo der Verwaltungsakt zumindest zu einem gewissen Zeitpunkt in den Einfluss- und Kenntnisbereich gelangt, einen entsprechenden Vortrag und damit nicht etwas völlig Unmögliches verlangt. Zumindest in den Fällen verspäteten Zugangs gelingt ihr mithin ein zweckgerechterer Ausgleich.

Umstritten ist bis heute gleichsam die Bestimmung des „dritten Tages 140 nach“ der Aufgabe zur Post. Der Streit hat sich in der Praxis weit überwiegend an der Frage entladen, wie das Ende des Drei-Tages-Zeitraumes zu bestimmen ist, wenn der dritte Tag auf einen Sonntag, einen gesetzlichen Feiertag oder einen Sonnabend fällt. Käme in diesem Falle der $§ 31$ III $1 \mathrm{VwVfG}^{474}$ zur Anwendung, so wäre erst der nächstfolgende Werktag maßgeblich.

Die wohl herrschende Ansicht in Rechtsprechung ${ }^{475}$ und Literatur ${ }^{476}$ lehnt 141 die Anwendung der Vorschrift ${ }^{477}$ ab. Bei dem Drei-Tages-Zeitraum gemäß § 41 II 1 VwVfG handele es sich nicht um eine „Frist“ i.S.v. § 31 VwVfG, sondern lediglich um die Fiktion des Zeitpunktes der Bekanntgabe eines Verwaltungsakts ${ }^{478}$ und daher um einen „Termin“ i.S.v. $§ 31$ VwVfG. Die Bestimmung dieses Termins er-

472 Drescher, NVwZ 1987, 771 (772, 774); Hebeler, DÖV 2006, 112 (115f.); Schoch, JURA 2011, 23 (29); Beaucamp, JA 2016, 436 (437f.).

473 OVG Koblenz, Urt. v. 10.10.1997, Az.: 2 A 13324/96 = juris, Rn. 23; OVG Lüneburg, Beschl.v. 3. 8. 2012, Az.: 12 LA 180/11 = juris, Rn. 6; OVG Münster, Beschl.v. 26.11.2014, Az.: 6 A 1784/12 = juris, Rn. 22.

474 Oder eine seiner Parallelvorschriften in den VwVfG der Länder, im Abgaben- (§ 108 III AO) oder Sozialverwaltungsverfahrensrecht (§ 26 III 1 SGB X).

475 S. nur OVG Lüneburg, Beschl. v. 28.2.2011, Az.: 4 LA 44/10 = NJW 2011, 1529 (1530) m.w. N. Vgl. zur Parallelvorschrift im Sozialverwaltungsverfahrensrecht auch BSG, Urt. v. 6.5.2010, Az.: B 14 AS 12/09 R = NJW 2011, 1099 (1100, Rn. 11ff.) m.w. N.

476 S. nur Couzinet/Fröhlich, in: Mann/Sennekamp/Uechtritz, VwVfG, 2. Aufl. 2019, § 41 Rn. 90 m.w. N.

477 Das BSG, Urt. v. 6.5.2010, Az.: B 14 AS 12/09 R = NJW 2011, 1099 (1100, Rn. 11), hat zur Parallelvorschrift im Sozialverwaltungsverfahrensrecht zusätzlich klargestellt, dass sich eine entsprechende Einschränkung auch nicht aus der Vorschrift zur Bekanntgabevermutung selbst ergibt.

478 S. nur OVG Lüneburg, Beschl. v. 28.2.2011, Az.: 4 LA 44/10 = NJW 2011, 1529 (1530). 
folgt zwar in Orientierung am Ablauf eines pauschalierten Zeitraumes ${ }^{479}$, was auf den ersten Blick der Funktionsweise einer „Frist“ ähnelt. § 41 II 1 VwVfG hat jedoch nicht das Telos einer Fristenregelung. Eine „Frist“ sei eine abgegrenzte Zeitspanne, innerhalb der Leistungen erbracht oder Handlungen vorgenommen werden sollen oder können. Ein „Termin“ hingegen sei ein rechtserhebliches Datum, an dem etwas geschehen soll oder eine Rechtswirkung eintritt. ${ }^{480}$ Ein Termin kann auch mit Hilfe des Ablaufs eines Zeitraumes näher bestimmt werden. Der entscheidende Unterschied liegt in der Zweckrichtung der Vorschrift: Innerhalb des Drei-Tages-Zeitraums gemäß § 41 II 1 VwVfG wird von keinem Verfahrensbeteiligten ein Tätigwerden erwartet, die Vorschrift erfüllt allein den Zweck der pauschalierten Vermutung einer Bekanntgabe im Interesse von Rechtssicherheit, Verwaltungsvereinfachung und Sparsamkeit. ${ }^{481}$ Wie der Wortlaut und der systematische Vergleich mit Abs. 1 zeigten, gelte § $31 \mathrm{III} \mathrm{VwVfG} \mathrm{aber}$ nur für Fristen, nicht für Termine. ${ }^{482}$ Dieses Ergebnis wird auch teleologisch für überzeugend gehalten: Dem genannten Zweck diene am ehesten ein fester Maßstab, nicht aber eine Verschiebung des fingierten Zugangsdatums auf den nächsten Werktag, die gerade die Notwendigkeit einer genaueren Prüfung begründen würde. ${ }^{483}$ Dem sollen umgekehrt auch keine teleologischen Erwägungen im Interesse des Schutzes der Empfänger entgegenstehen, sodass zumindest mangels vergleichbarer Interessenlage ${ }^{484}$ auch keine analoge Anwendung von $\S 31$ III VwVfG in Frage komme. Der „Feiertagsregelung“ liege „,in erster Linie die Überlegung zu Grunde, dass die Abgabe einer Erklärung bzw. die Vornahme einer Handlung an diesen Tagen typischerweise Schwierigkeiten bereitet“. ${ }^{485}$ Entsprechende Schwierigkeiten treffen die Empfänger bei der bloßen Fiktion des Zugangs an einem solchen Tag indes nicht. Der allein nachteiligen Konstellation eines die Rechtsbehelfsfirsten verkürzenden Zugangs nach Ablauf des Drei-Tages-Zeitraums könnten die Betroffenen über die Ausnahmeregelung des § 41 II 3 VwVfG

479 OVG Lüneburg, Beschl. v. 26.10.2006, Az.: 7 PA 184/06 = NVwZ-RR 2077, 78; vgl. auch VGH München, Beschl. v. 23.7.1990, Az.: 19 B 88185 = NJW 1991, 1250 (1251).

480 Zu dieser Differenzierung VGH München, Beschl. v. 23.7.1990, Az.: Gr. S 1/90 - 19 B $88.185=$ NJW 1991, 1250 (1251).

481 Vgl. entsprechend BSG, Urt. v. 6.5.2010, Az.: B 14 AS 12/09 R = NJW 2011, 1099 (1100, Rn. 13); OVG Lüneburg, Beschl. v. 28.2.2011, Az.: 4 LA 44/10 = NJW 2011, 1529 (1530).

482 Vgl. entsprechend VGH München, Beschl. v. 23.7.1990, Az.: Gr. S 1/90 - 19 B $88.185=$ NJW 1991, 1250 (1251).

483 Vgl. entsprechend BSG, Urt. v. 6.5.2010, Az.: B 14 AS 12/09 R = NJW 2011, 1099 (1100, Rn. 13). 484 BSG, Urt. v. 6.5.2010, Az.: B 14 AS 12/09 R = NJW 2011, 1099 (1100, Rn. 13), und OVG Lüneburg, Beschl. v. 28.2.2011, Az.: 4 LA 44/10 = NJW 2011, 1529 (1530), verneinen im sozialverwaltungsverfahrensrechtlichen Kontext bereits das Vorliegen einer planwidrigen Regelungslücke.

485 BSG, Urt. v. 6.5.2010, Az.: B 14 AS 12/09 R = NJW 2011, 1099 (1100, Rn. 14).

Tobias Brings-Wiesen 
(s. dazu Rn. 139) begegnen. ${ }^{486}$ Im Ergebnis akzeptiert diese Ansicht mithin den Eintritt der Vermutung der Bekanntgabe auch an einem Sonntag, einem gesetzlichen Feiertag oder einem Sonnabend.

Die Gegenansicht plädiert hingegen für eine (analoge) Anwendung von 142 $\S 31$ III VwVfG und eine entsprechende Verschiebung des Eintritts der Bekanntgabefiktion auf den nächsten Werktag. ${ }^{487}$ Der Drei-Tages-Zeitraum gemäß § 41 II 1 VwVfG sei als „Frist“ i.S.v. § 31 VwVfG anzusehen. ${ }^{488}$ Der Begriff der „Frist“i.S.d. des BGB, dessen Sprachverständnis auch §31 VwVfG zugrunde liege, bedeute nur einen abgegrenzten Zeitraum. Es handele sich um einen weiten Fristbegriff, für den allein der Ablauf einer bestimmten Zeitspanne entscheidend sei. ${ }^{489}$ Auch regele § 41 II 1 VwVfG nicht allein den fiktiven Zeitpunkt der Bekanntgabe, sondern begründe darüber hinaus die Verpflichtung, bei verspätetem Zugang die Bekanntgabefiktion für den Drei-Tages-Zeitraums zu erschüttern. ${ }^{490}$ Auch die Zwecke der §§ 31 III und 41 II 1 VwVfG sprächen für eine Anwendbarkeit: Die mit der Verschiebung auf den nächsten Werktag erfolgende Berücksichtigung der in Wirtschaft und öffentlicher Verwaltung üblichen Fünf-Tage-Arbeitswoche ermögliche allen Verfahrensbeteiligten eine einfache, leicht nachprüfbare und rechtssichere Weise den vermuteten Bekanntgabetag zu errechnen und vermeide im Interesse des effektiven Rechtsschutzes (Art. 19 IV GG) und der Verwaltungsvereinfachung Schwierigkeiten hinsichtlich der Erschütterung der Bekanntgabevermutung. ${ }^{491}$

486 OVG Lüneburg, Beschl.v. 26.10.2006, Az.: 7 PA 184/06 = NVwZ-RR 2077, 78; vgl. entsprechend BSG, Urt. v. 6.5.2010, Az.: B 14 AS 12/09 R = NJW 2011, 1099 (1100, Rn. 14).

487 Stelkens, in: Stelkens/Bonk/Sachs, VwVfG, 9. Aufl. 2018, § 41 Rn. 133; Ruffert, in: Knack/ Henneke, VwVfG, 10. Aufl. 2014, § 41 Rn. 41. So mittlerweile auch für die abgabenverwaltungsverfahrensrechtliche Parallelvorschriften der $\S \S 108,122$ AO der BFH in st. Rspr. seit Urt. v. 14.10. 2003, Az.: IX R 68/98 = NJW 2004, 94.

488 Vgl. entsprechend BFH, Urt.v. 14.10.2003, Az.: IX R 68/98 = NJW 2004, 94. A.A. aber Stelkens, in: Stelkens/Bonk/Sachs, VwVfG, 9. Aufl. 2018, § 41 Rn. 133, der die Ablehnung einer „Frist“ für „formal korrekt“ hält.

489 Vgl. entsprechend BFH, Urt. v. 14.10.2003, Az.: IX R 68/98 = NJW 2004, 94. In Abgrenzug zu dem von der Gegenmeinung zugrundegelegten engen Fristbegriff, gemäß dem innerhalb eines Zeitraums Leistungen erbracht oder Handlungen vorgenommen werden sollen oder können.

490 Vgl. entsprechend BFH, Urt. v. 14.10.2003, Az.: IX R 68/98 = NJW 2004, 94 (94f.).

491 Vgl. in diesem Sinne BFH, Urt. v. 14.10. 2003, Az.: IX R 68/98 = NJW 2004, 94 (95); Stelkens, in: Stelkens/Bonk/Sachs, VwVfG, 9. Aufl. 2018, § 41 Rn. 133. Beachte aber auch das BSG, Urt. v. 6.5. 2010, Az.: B 14 AS 12/09 R = NJW 2011, 1099 (1100f., Rn. 15), das diese Argumentation des BFH, a.a.O., für den abgabenverwaltungsverfahrensrechtlichen Besonderheiten geschuldet hält. 
Für die Fristberechnung ist trotz allem gemäß $\S 31$ I VwVfG - mindestens in analoger Anwendung - auf die $\S \S 187 \mathrm{ff}$. BGB zurückzugreifen, sodass $\S 187$ I und $\S 188$ I BGB heranzuziehen sind.

\section{bb) Elektronische Bekanntgabe}

144 Besonderer Betrachtung bedarf die elektronische Bekanntgabe von Verwaltungsakten, die im Zuge einer sowohl praktischen als auch rechtlichen Hinwendung in Richtung einer Intensivierung des E-Governments ${ }^{492}$ in jüngerer Zeit zunehmend an Bedeutung gewonnen hat. Das allgemeine Verwaltungsrecht regelt heute zwei Arten elektronischer Bekanntgabe ausdrücklich: die elektronische Übermittlung und den Abruf über ein öffentlich zugängliches Netz.

145 Die Bekanntgabevermutung in $§ 41$ II 2 VwVfG setzt die Möglichkeit einer elektronischen Übermittlung voraus, schweigt indes zu deren Zulässigkeit. Diese richtet sich nach $\S 3 \mathrm{a} \mathrm{VwVfG}$, der allgemeine Vorgaben für die elektronische Kommunikation zwischen Behörde und Bürger trifft. Gemäß § 3a I VwVfG ist die Übermittlung von elektronischen Dokumenten - wie Verwaltungsakten zulässig, soweit der Empfänger hierfür einen Zugang eröffnet. Fehlt eine solche Zugangseröffnung, bleibt eine gleichwohl erfolgte elektronische Bekanntgabe unwirksam. ${ }^{493}$ Welche Anforderungen an eine Zugangseröffnung $\mathrm{zu}$ stellen sind, ist im Einzelnen umstritten. ${ }^{494} \mathrm{Zu}$ Recht wird jedoch angenommen, dass nicht schon dann von einer Zugangseröffnung auszugehen ist, wenn ein privater Empfänger über einen E-Mail-Account verfügt und die E-Mail-Adresse der Behörde bekannt ist. ${ }^{495}$ Die Verkehrsanschauung hinsichtlich der Kommunikation zwischen Bürger und Verwaltung hat sich noch nicht derart gewandelt, dass entsprechend dem Postweg jederzeit mit einer Kontaktaufnahme via E-Mail zu rechnen ist. ${ }^{496} \mathrm{Zu}$ fordern ist daher die ausdrückliche oder zumindest konkludente - beispielsweise durch vorangegangene Korrespondenz - Eröffnung dieses Kommunikationsweges. ${ }^{497}$ Im Falle der Kommunikation mit Geschäftspersonen

492 S. dazu im Überblick Prell, NVwZ 2018, 1255; zu weiteren jüngeren Änderungen des VwVfG Schmitz/Prell, NVwZ 2016, 1273.

493 Stelkens, in: Stelkens/Bonk/Sachs, VwVfG, 9. Aufl. 2018, § 41 Rn. 87; so auch Couzinet/ Fröhlich, in: Mann/Sennekamp/Uechtritz, VwVfG, 2. Aufl. 2019, § 41 Rn. 49, die in diesem Fall eine Heilung für unmöglich erachten.

494 Ausführlich dazu m.w. N. Stelkens, in: Stelkens/Bonk/Sachs, VwVfG, 9. Aufl. 2018, § 41 Rn. $88 \mathrm{ff}$.

495 OVG Münster, Beschl. v. 13.11.2014, Az.: 2 B 1111/14 = NVwZ-RR 2015, 172.

496 Stelkens, in: Stelkens/Bonk/Sachs, VwVfG, 9. Aufl. 2018, § 41 Rn. 88.

497 BVerwG, Urteile v. 7.12.2016, Az.: 6 C 12.15; 6 C 13.15 und 6 C 14.15 = juris, jeweils Rn. 19.

Tobias Brings-Wiesen 
oder Rechtsanwälten ist es grundsätzlich vertretbar, einen reduzierten Maßstab anzulegen. ${ }^{498}$ Hinsichtlich der Regelung in § 41 II 2 und 3 VwVfG gilt das zur Übermittlung des schriftlichen Verwaltungsakts per Post im Inland Gesagte (s. dazu Rn. 136 ff.) entsprechend. ${ }^{499}$

Seit Kurzem ${ }^{500}$ kann ein elektronischer Verwaltungsakt ${ }^{501}$ darüber hinaus 146 auch gemäß § 41 IIa 1 VwVfG dadurch bekannt gegeben werden, dass er vom Beteiligten oder von seinem Bevollmächtigten über ein öffentlich zugängliches Netz abgerufen wird. ${ }^{502}$ Die Besonderheit bei dieser Art der elektronischen Bekanntgabe besteht in der Rolle des Empfängers: Es wird erwartet, dass dieser sich (im Regelfall) den Verwaltungsakt in einem finalen Schritt selber bei der Verwaltung abholt. ${ }^{503} \mathrm{Da}$ also eine finale Verbringung des Verwaltungsakts in den Machtbereich des Empfängers fehlt, handelt es sich nicht um eine elektronische „Übermittlung“ i.S.v. §§ 3a I, 41 II 2 VwVfG. ${ }^{504}$ Die Wirksamkeit der Bekanntgabe gemäß § 41 IIa VwVfG wird an einige besondere Voraussetzungen geknüpft:

Wegen der Verschiebung der Verantwortlichkeit für den Zugang eines Verwaltungsakts zulasten der Empfänger setzt diese Art der Bekanntgabe tatbestandlich die Einwilligung des jeweiligen Beteiligten voraus, die jederzeit widerruflich ist ${ }^{505}$. Fehlt diese, kommt es nicht $\mathrm{zu}$ einer wirksamen Bekanntgabe des Verwaltungsakts. Teilweise werden auch an die Einwilligung erhöhte Anforderungen gestellt. ${ }^{506}$ Dem wird jedoch zu Recht das systematisch-teleologische Argument entgegengehalten, dass anders als im Rahmen der elektronischen Übermittlung gemäß § 3a I VwVfG (oder als gemäß der Parallelvorschrift im Ab-

$498 \mathrm{Zu}$ weitgehend aber OVG Münster, Beschl.v. 13.11.2014, Az.: 2 B 1111/14 = NVwZ-RR 2015, 172, wonach die bloße Angabe als Kontaktadresse auf der Internetseite ausreichen soll.

499 S. zu den wenigen Besonderheiten Couzinet/Fröhlich, in: Mann/Sennekamp/Uechtritz, VwVfG, 2. Aufl. 2019, § 41 Rn. $95 \mathrm{f}$.

500 Der Absatz wurde eingeführt durch Art. 20 Nr. 4 des Gesetzes zur Modernisierung des Besteuerungsverfahrens v. 18.7.2016, BGBl. I, S. 1679. Ausführlich dazu Schmitz/Prell, NVwZ 2016, 1273 (1277 ff.); Braun Binder, DÖV 2016, 891 (896ff.); Siegel, DVBl 2017, 24 (27 f.).

501 Die Frage, ob der Verwaltungsakt in elektronischer Form erlassen werden darf, ist davon abzugrenzen, Stelkens, in: Stelkens/Bonk/Sachs, VwVfG, 9. Aufl. 2018, § 41 Rn. 134c. S. dazu noch Rn. $687 \mathrm{f}$.

$502 \mathrm{Zu}$ den Hintergründen der Vorschrift Stelkens, in: Stelkens/Bonk/Sachs, VwVfG, 9. Aufl. 2018, § 41 Rn. $134 \mathrm{ff}$.

503 Schmitz/Prell, NVwZ 2016, 1273 (1278).

504 In diesem Sinne auch Stelkens, in: Stelkens/Bonk/Sachs, VwVfG, 9. Aufl. 2018, § 41 Rn. 134; Schmitz/Prell, NVwZ 2016, 1273 (1278, Fn. 23).

505 Ramsauer/Tegethoff, in: Kopp/Ramsauer, VwVfG, 20. Aufl. 2019, § 41 Rn. 43c; Tiedemann, in: Bader/Ronellenfitsch, VwVfG, 44. Ed., Stand: 1.7.2019, § 41 Rn. 82b.

506 Braun Binder, DÖV 2016, 891 (896); in diese Richtung bereits Braun Binder, NVwZ 2016, 342 $(345,347)$. 
gabenrecht, §122a AO) keine Bekanntgabevermutung nach drei Tagen eintritt (§ 41 II 2, 3 VwVfG; § 122a IV AO), sondern eine Bekanntgabe schlicht scheitert (§ 41 IIa 4, 5 VwVfG; s. dazu Rn. 149), sodass den Beteiligten in Folge der Annahme einer Einwilligung keine signifikanten Nachteile drohen. ${ }^{507}$ Angesichts dessen werden die Anforderungen an die Einwilligung mehrheitlich abgesenkt: Sie bedürfe keiner besonderen Form; ${ }^{508}$ es bedürfe keiner expliziten (vorherigen) $\mathrm{Zu}$ stimmung des Empfängers, vielmehr könne erst im Abruf eines gleichwohl bereitgestellten Verwaltungsakts die „Einwilligung“ gesehen werden; ${ }^{509}$ sollte gleichwohl eine vorherige Zustimmung eingeholt werden, könne diese - unter bestimmten Voraussetzungen - auch über die Bekanntgabe eines konkreten Verwaltungsakts als Ergebnis eines konkreten Verwaltungsverfahrens hinausgehen. ${ }^{510}$ Folgt man der letztgenannten Auffassung, hat die Einwilligung als Wirksamkeitsvoraussetzung praktisch kaum noch beschränkenden Charakter. Eine (höchst-)richterliche Klärung der Frage steht jedoch noch aus.

Wurde die Einwilligung erteilt, besteht keine Verpflichtung der Behörde, auch tatsächlich eine Bekanntgabe des Verwaltungsakts durch Abruf über ein öffentlich zugängliches Netz zu bewirken. ${ }^{511}$ Die Entscheidung für eine Bekanntgabe gemäß § 41 IIa VwVfG steht vielmehr im Ermessen der Behörde.

Die Bekanntgabe erfolgt erst mit dem tatsächlichen Abruf durch den Empfänger. ${ }^{512}$ Bis zu diesem Zeitpunkt steht es der Behörde daher auch - trotz willentlicher Einstellung und Benachrichtigung des Empfängers - uneingeschränkt frei, die Bereitstellung zu beenden und den bereitgestellten Verwaltungsakt damit

507 So - beschränkt auf § 122a AO - Stelkens, in: Stelkens/Bonk/Sachs, VwVfG, 9. Aufl. 2018, § 41 Rn. 134h; das Argument ist jedoch auf §§ 3a I, 41 II 2, 3 VwVfG ohne weiteres übertragbar.

508 Ramsauer/Tegethoff, in: Kopp/Ramsauer, VwVfG, 20. Aufl. 2019, § 41 Rn. 43c; so auch Tiedemann, in: Bader/Ronellenfitsch, VwVfG, 44. Ed., Stand:1.7.2019, § 41 Rn. 82b, der dies aus dem Grundsatz der Nichtförmlichkeit des Verwaltungsverfahrens ( $\$ 10 \mathrm{VwVfG})$ ableitet, aber aus Gründen der Rechtssicherheit einen irgendwie gearteten Nachweis empfiehlt.

509 Stelkens, in: Stelkens/Bonk/Sachs, VwVfG, 9. Aufl. 2018, § 41 Rn. 134 h; a. A. aber Ramsauer/ Tegethoff, in: Kopp/Ramsauer, VwVfG, 20. Aufl. 2019, § 41 Rn. 43c; Schmitz/Prell, NVwZ 2016, 1273 (1278); wohl auch Tiedemann, in: Bader/Ronellenfitsch, VwVfG, 44. Ed., Stand: 1.7.2019, § 41 Rn. 82b. Insofern für eine „Heilung“ Couzinet/Fröhlich, in: Mann/Sennekamp/Uechtritz, VwVfG, 2. Aufl. 2019, § 41 Rn. 113.

510 Unter Identifizierung einzelner Grenzen einer solchen generellen Einwilligung Stelkens, in: Stelkens/Bonk/Sachs, VwVfG, 9. Aufl. 2018, § 41 Rn. 134i; Schmitz/Prell, NVwZ 2016, 1273 (1278). 511 Stelkens, in: Stelkens/Bonk/Sachs, VwVfG, 9. Aufl. 2018, § 41 Rn. 134f, 134k; Tiedemann, in: Bader/Ronellenfitsch, VwVfG, 44. Ed., Stand: 1.7.2019, § 41 Rn. 82b.

512 Stelkens, in: Stelkens/Bonk/Sachs, VwVfG, 9. Aufl. 2018, § 41 Rn. 134q; Schmitz/Prell, NVwZ 2016, 1273 (1278). Demgegenüber kommt es im Abgabenrecht auf den Akt der Bereitstellung zum Abruf an, vgl. § 122 I und IV AO. Zu beachten ist, dass keine Pflicht zum Abruf besteht, sodass darin auch keine treuwidrige Vereitelung des Zugangs zu sehen ist.

Tobias Brings-Wiesen 
$\mathrm{zu}$ widerrufen. ${ }^{513}$ Darüber hinausgehend verpflichtet ${ }^{514} \S 41$ IIa 4 VwVfG die Behörde zur Beendigung der Bereitstellung, wenn der Verwaltungsakt nicht innerhalb von zehn Tagen nach Absendung einer Benachrichtigung abgerufen worden ist. Mit der Beendigung der Bereitstellung entfällt auch die Möglichkeit des Abrufs und somit der Bekanntgabe gemäß § 41 IIa 1 VwVfG.

Für Verwirrung sorgt vor diesem Hintergrund die Regelung des § 41 IIa 5 Hs. 1 VwVfG, nach der eine Bekanntgabe ,in diesem Fall [...] nicht bewirkt“ sein soll. Die Vorschrift könnte dahingehend missverstanden werden, dass eine mangels Beendigung der Bereitstellung nach Ablauf besagter zehn Tage gleichwohl durch Abruf erfolgte Bekanntgabe entgegen des Grundsatzes in § 41 IIa 1 VwVfG als rechtlich nicht erfolgt erachtet werden soll. Dem wird zu Recht bereits der Wortlaut entgegengehalten ${ }^{515}$ : „In diesem Fall“ bezieht sich auf Hs. 2 von $\S 41 \mathrm{IIa} 4 \mathrm{VwVfG}$ und somit auf die Beendigung der Bereitstellung, nicht auf den Hs. 1 und den Ablauf der zehn Tage - § 41 IIa 5 Hs. 1 VwVfG weist somit lediglich deklaratorisch auf die bereits mangels Abrufmöglichkeit eintretende Folge des Ausbleibens der Bekanntgabe hin. Auch Sinn und Zweck der Normen verlangen nicht danach. ${ }^{516}$ Folglich kann auch ein verspäteter Abruf noch zu einer wirksamen Bekanntgabe nach § 41 IIa 1 VwVfG führen. ${ }^{517}$ Zugleich bleibt gemäß § 41 IIa 5 Hs. 2 VwVfG die Möglichkeit einer erneuten Bereitstellung zum Abruf oder der Bekanntgabe auf andere Weise unberührt.

Damit dem Empfänger eine Weiterverwendung im Rechtsverkehr möglich ist, 150 ist über den bloßen Abruf hinaus auch die Speicherbarkeit des abgerufenen elektronischen Verwaltungsakts Wirksamkeitsvoraussetzung. ${ }^{518}$

Ohne Auswirkungen auf die Wirksamkeit der Bekanntgabe bleiben eine Verletzung der Verpflichtung zur Gewährleistung des Abrufs nur nach Authenti-

513 Stelkens, in: Stelkens/Bonk/Sachs, VwVfG, 9. Aufl. 2018, § 41 Rn. 134u; Schmitz/Prell, NVwZ 2016, 1273 (1279f.).

514 So wohl auch Ramsauer/Tegethoff, in: Kopp/Ramsauer, VwVfG, 20. Aufl. 2019, § 41 Rn. 43j. A. A. Tiedemann, in: Bader/Ronellenfitsch, VwVfG, 44. Ed., Stand:1.7.2019, § 41 Rn. 82e; Couzinet/ Fröhlich, in: Mann/Sennekamp/Uechtritz, VwVfG, 2. Aufl. 2019, § 41 Rn. 122, die sich demgegenüber für eine teleologische Reduktion auf die Möglichkeit einer Beendigung aussprechen.

515 Stelkens, in: Stelkens/Bonk/Sachs, VwVfG, 9. Aufl. 2018, § 41 Rn. 134v, jedoch ohne nähere Begründung.

516 S. dazu ausführlicher Stelkens, in: Stelkens/Bonk/Sachs, VwVfG, 9. Aufl. 2018, § 41 Rn. 134u; Tiedemann, in: Bader/Ronellenfitsch, VwVfG, 44. Ed., Stand: 1.7.2019, § 41 Rn. 82e.

517 Stelkens, in: Stelkens/Bonk/Sachs, VwVfG, 9. Aufl. 2018, § 41 Rn. 134u; Tiedemann, in: Bader/Ronellenfitsch, VwVfG, 44. Ed., Stand: 1.7.2019, § 41 Rn. 82e.

518 Ramsauer/Tegethoff, in: Kopp/Ramsauer, VwVfG, 20. Aufl. 2019, § 41 Rn. 43h; Couzinet/ Fröhlich, in: Mann/Sennekamp/Uechtritz, VwVfG, 2. Aufl. 2019, § 41 Rn. 115; Schmitz/Prell, NVwZ 2016, 1273 (1278). 
fizierung der berechtigten Person gemäß § 41 IIa 2 Hs. 2 VwVfG sowie das Ausbleiben bzw. die Fehlerhaftigkeit der in $\S 41$ IIa 4 VwVfG vorausgesetzten Benachrichtigung über die Bereitstellung. ${ }^{519}$

Der Zeitpunkt der Bekanntgabe richtet sich nach § 41 IIa 3 VwVfG: Der Verwaltungsakt gilt am Tag nach dem (erstmaligen) Abruf als bekannt gegeben. Die bereits dargestellte Problematik des Fristendes an einem Sonntag, einem gesetzlichen Feiertag oder einem Sonnabend wird bezüglich dieser Norm genauso diskutiert. ${ }^{520}$

153 Tatsächlich beschränkt sich die Möglichkeit der Bereitstellung von Verwaltungsakten über Internetportale jedoch nicht auf die in § 41 IIa VwVfG statuierte Art. Da im Falle des Fehlens von Bestimmungen darüber, auf welche Art und Weise ein Verwaltungsakt bekanntzugeben ist, die Entscheidung darüber grundsätzlich im Ermessen der Behörde steht (s. dazu Rn. 134), hat das Bundesverwaltungsgericht jüngst auch die Bereitstellung einer Klausurbenotung im Internetportal einer Hochschule als wirksame individuelle Bekanntgabe gewertet, da die Note über ein persönliches Konto ähnlich einem Briefkasten in den Machtbereich des Betroffenen gelange und aufgrund der dem Mitgliedschaftsverhältnis zugrundeliegenden Studienordnung, die eine Kommunikation über automatisierte Geschäftsprozesse und Verfahren vorsehe, mit einem regelmäßigen Besuch des Internetportals zu rechnen sei. ${ }^{521}$

\section{cc) Öffentliche Bekanntgabe}

154 „Öffentliche“ Bekanntgabe meint grundsätzlich die Bekanntgabe eines Verwaltungsakts ohne individuell identifizierten oder identifizierbaren Empfänger(-kreis). ${ }^{522}$ Sie ist mithin eine Ergänzung $\mathrm{zu}$ den bisher dargestellten verschiedenen Arten individueller Bekanntgabe. Sie verlangt keinen Zugang, dafür aber eine allgemeine Zugänglichkeit ${ }^{523}$ und insofern eine einhergehende Möglichkeit der Kenntnisnahme. Damit geht sie im Interesse der Funktionsfähigkeit

519 Ramsauer/Tegethoff, in: Kopp/Ramsauer, VwVfG, 20. Aufl. 2019, § 41 Rn. 43h.

520 Stelkens, in: Stelkens/Bonk/Sachs, VwVfG, 9. Aufl. 2018, § 41 Rn. 134s. S. auch Couzinet/ Fröhlich, in: Mann/Sennekamp/Uechtritz, VwVfG, 2. Aufl. 2019, § 41 Rn. $124 \mathrm{ff}$.

521 BVerwG, Beschl. v. 21.12.2017, Az.: 6 B 43.17 = NVwZ 2018, 496 (498, Rn. 12); so bereits in der Vorinstanz OVG Münster, Urt. v. 21.3.2017, Az.: 14 A 1689/16 = BeckRS 2017, 108275 (Rn. 37 ff.); zweifelnd noch VGH München, Beschl. v. 7.11.2012, Az.: 7 C 12.2143 = juris, Rn. 14.

522 Hierin liegt auch der zentrale Unterschied zur öffentlichen Zustellung gemäß § 10 VwZG: In ihrem Falle ist sehr wohl ein individuell identifizierter oder identifizierbarer Empfänger(-kreis) bekannt, eine individuelle Bekanntgabe jedoch aus anderen Gründen nicht möglich, s. dazu noch Rn. 173.

523 Detterbeck, Allgemeines Verwaltungsrecht, 17. Aufl. 2019, Rn. 555.

Tobias Brings-Wiesen 
der Verwaltung ${ }^{524}$ zulasten der mit der Bekanntgabe zu realisierenden verfassungsrechtlich geschützten Interessen der Betroffenen (s. dazu Rn. 117). Weil sie somit die Wahrscheinlichkeit der tatsächlichen Kenntnisnahme der durch einen Verwaltungsakt Betroffenen reduziert, bildet sie eine praktisch eng begrenzte Ausnahmeerscheinung. Sie ist nur in zwei Konstellationen zulässig: (1) wenn sie durch Rechtsvorschrift zugelassen wird (§ 41 III 1 VwVfG) oder (2) wenn es sich bei dem Verwaltungsakt um eine Allgemeinverfügung gemäß § 35 S. 2 VwVfG (s. dazu Rn. $77 \mathrm{ff}$.) handelt, deren Bekanntgabe an die Beteiligten untunlich ist (§ 41 III 2 VwVfG).

(1) § 41 III 1 VwVfG enthält selbst keine Ermächtigung der Behörden zur öffentlichen Bekanntgabe, sondern verweist insofern (deklaratorisch) auf andere Rechtsvorschriften. Im Umkehrschluss folgt damit aus der Norm jedoch der Grundsatz der Unzulässigkeit einer öffentlichen Bekanntgabe von Verwaltungsakten. ${ }^{525}$ Darin erschöpft sich indes auch ihr Regelungsgehalt; konkrete Vorgaben zur Zulässigkeit der öffentlichen Bekanntgabe sind den jeweiligen Spezialvorschriften $\mathrm{zu}$ entnehmen. Die zu einer öffentlichen Bekanntgabe ermächtigenden Vorschriften, die bereits im Studium bekannt sein sollten, sind insbesondere die $\S \S 36,37$ StVO betreffend die Verkehrszeichen (s. dazu Rn. 165) und Weisungen durch Polizeibeamte und Ampeln, die verschiedenen Vorschriften betreffend die Regelung von Eigenschaften und Nutzung von Straßen (vgl. beispielsweise $\S 2$ VI 4, 5 FStrG; §§ 5 II 2, III 3, 6 I 2, VIII 2, 7 I 3, VI 2, 8 I 2 StrWG NRW) sowie der § 41 III 2 VwVfG. Wird ein Verwaltungsakt öffentlich bekanntgegeben, obwohl eine entsprechende Ermächtigungsgrundlage fehlt, ist dieser unwirksam. ${ }^{526}$

(2) § 41 III 2 VwVfG ist selbst Ermächtigungsgrundlage. ${ }^{527}$ Die Vorschrift 156 ermöglicht es den Behörden, Allgemeinverfügungen i.S.v. §35 S. 2 VwVfG öffentlich bekanntzugeben, wenn eine individuelle Bekanntgabe an die Beteiligten untunlich ist. Dies verdeutlicht, dass auch für Allgemeinverfügungen eigentlich

524 Diesem Zweck dienen die § 41 III, IV VwVfG, Stelkens, in: Stelkens/Bonk/Sachs, VwVfG, 9. Aufl. 2018, § 41 Rn. 6. Zum verfassungsrechtlich anerkannten Prinzip der Verwaltungseffizienz m.w. N. BVerwG, Urt. v. 27.5.1983, Az.: 4 C 40, 44, 45.81 = BVerwGE 67, 206 (209f.), wo das Gericht überdies auch auf das damit zusammenhängende Interesse der Rechtssicherheit abstellt.

525 Stelkens, in: Stelkens/Bonk/Sachs, VwVfG, 9. Aufl. 2018, § 41 Rn. 148; Tiedemann, in: Bader/ Ronellenfitsch, VwVfG, 44. Ed., Stand: 1.7.2019, § 41 Rn. 100; ähnlich auch Couzinet/Fröhlich, in: Mann/Sennekamp/Uechtritz, VwVfG, 2. Aufl. 2019, § 41 Rn. 129.

526 Stelkens, in: Stelkens/Bonk/Sachs, VwVfG, 9. Aufl. 2018, § 41 Rn. 148; Couzinet/Fröhlich, in: Mann/Sennekamp/Uechtritz, VwVfG, 2. Aufl. 2019, § 41 Rn. 127. A. A. aber Detterbeck, Allgemeines Verwaltungsrecht, 17. Aufl. 2019, Rn. 557.

527 Stelkens, in: Stelkens/Bonk/Sachs, VwVfG, 9. Aufl. 2018, § 41 Rn. 152; Couzinet/Fröhlich, in: Mann/Sennekamp/Uechtritz, VwVfG, 2. Aufl. 2019, § 41 Rn. 128. 
der Grundsatz der individuellen Bekanntgabe gelten soll. Ihre besonderen Charakteristika (s. dazu Rn. 77 ff.) machen es indes unvermeidbar, weitreichendere Ausnahmekonstellationen zuzulassen. Zentrale Voraussetzung ist dabei die „Untunlichkeit“ der individuellen Bekanntgabe. Deren Vorliegen ist unter Berücksichtigung aller Umstände des Einzelfalls mit einer gebotenen Zurückhaltung $\mathrm{zu}$ bewerten. Dabei können verschiedene Faktoren einzeln oder kumulativ für eine Untunlichkeit sprechen. So kann die individuelle Bekanntgabe bereits wegen der Natur der Allgemeinverfügung unmöglich oder mit erheblichen Schwierigkeiten verbunden sein, ${ }^{528}$ beispielsweise weil der Kreis der betroffenen Personen überhaupt nicht abschließend bestimmbar oder zumindest nicht mit letzter Sicherheit ermittelbar ist ${ }^{529}$ - wie regelmäßig im Falle von sachbezogenen und benutzungsregelnden Allgemeinverfügungen gemäß $\S 35$ S. 2 Var. 2 und 3 $\mathrm{VwVfG}^{530}$ oder wie im Falle von personenbezogenen Allgemeinverfügungen gemäß § 35 S. 2 Var. 1 VwVfG, in deren Falle sich anhand allgemeiner Merkmale zwar ein Personenkreis, keineswegs aber jede individuelle Person identifizieren lassen mag, wie bei einem präventiven Versammlungsverbot, ${ }^{531}$ einem Aufenthaltsverbot für bestimmte Gemeindebereiche ${ }^{532}$ oder einem Verbot von Werbung für Sportwetten im Internet ${ }^{533}$. Eine große Anzahl Betroffener kann für die Beurteilung der Erheblichkeit des Verwaltungsaufwands entsprechend indizielle Bedeutung haben, sie wird jedoch mehrheitlich als allein nicht ausreichend erachtet. ${ }^{534}$ Auch personenunabhängige Erwägungen, wie eine besondere Eilbedürftigkeit der

528 S. dazu Ramsauer/Tegethoff, in: Kopp/Ramsauer, VwVfG, 20. Aufl. 2019, § 41 Rn. 46.

529 Vgl. bereits die Begründung zum Entwurf eines VwVfGes, BT-Drucks. 7/910, S. 62; Stelkens, in: Stelkens/Bonk/Sachs, VwVfG, 9. Aufl. 2018, § 41 Rn. 153; zu dinglichen Verwaltungsakten Niehues, DVBl 1982, 317 (317ff.).

530 Ramsauer/Tegethoff, in: Kopp/Ramsauer, VwVfG, 20. Aufl. 2019, § 41 Rn. 46; Stelkens, in: Stelkens/Bonk/Sachs, VwVfG, 9. Aufl. 2018, § 41 Rn. 153. Nicht aber im Falle einer sog. Schutzbereichsanordnung gemäß § 2 I 1 SchBerG, VGH Mannheim, Urt. v. 15.11.1988, Az.: 10 S 751/88 = NVwZ 1989, 978 (980), oder im Falle von (Ent-)Widmungen, die nur einzelne Personen betreffen, OVG Münster, Urt. v. 27.4.1998, Az.: 7 A 3814/96 = BeckRS 1999, 20219, Rn. 20 ff.

531 VGH Mannheim, Urt. v. 6.11.2013, Az.: 1 S 1640/12 = BeckRS 2013, 58560.

532 VG Darmstadt, Beschl. v. 28.4.2016, Az.: 3 L 642/16.DA = NVwZ 2016, 1344; vgl. auch VGH Mannheim, Beschl. v. 30.9.1996, Az.: 1 S 2531/96 = NVwZ-RR 1997, 225.

533 OVG Münster, Beschl. v. 19.1.2010, Az.: 13 A 841/09 = BeckRS 2010, 46385.

534 Ramsauer/Tegethoff, in: Kopp/Ramsauer, VwVfG, 20. Aufl. 2019, § 41 Rn. 46; so auch Stelkens, in: Stelkens/Bonk/Sachs, VwVfG, 9. Aufl. 2018, § 41 Rn. 154f., der für die Bestimmung der Erheblichkeit des Aufwands Orientierung in den (verworfenen) Vorschriften des VwVfG zu Sammelverfahren sucht; jedenfalls gegen eine schematische Übertragung Couzinet/Fröhlich, in: Mann/Sennekamp/Uechtritz, VwVfG, 2. Aufl. 2019, § 41 Rn. 133.

Tobias Brings-Wiesen 
Bekanntgabe, können - für sich ${ }^{535}$ oder in Kombination mit weiteren Erwägungen $^{536}$ - für eine Untunlichkeit sprechen.

Liegt eine dieser Konstellationen vor, steht es grundsätzlich im Ermessen 157 der zuständigen Behörde, den Verwaltungsakt öffentlichen bekanntzugeben. ${ }^{537}$ Insbesondere kann sie sich auch für eine „kombinierte Bekanntgabe“, sprich eine neben die öffentliche Bekanntgabe tretende individuelle Bekanntgabe an besonders Betroffene, entscheiden. ${ }^{538}$ Dies kann dazu führen, dass sich die Wirkungen eines Verwaltungsakts je nach Art der Bekanntgabe wieder (s. dazu Rn. 164) relativ entfalten.

Ist die öffentliche Bekanntgabe gemäß § 41 III VwVfG zulässig, bedarf es weiterhin der Beachtung ihrer Modalitäten. Für schriftliche und elektronische Verwaltungsakte $^{539}$ wurden in $\S 41$ IV VwVfG allgemeine Vorgaben normiert, die wie gewohnt durch spezialgesetzliche Vorschriften verdrängt oder ergänzt werden können. ${ }^{540}$

Zentral verlangt $\S 41 \mathrm{IV} 1 \mathrm{VwVfG}$ die ortsübliche Bekanntmachung des verfügenden Teils des Verwaltungsakts. Terminologisch wie systematisch zeigt sich, dass § 41 IV VwVfG zwischen öffentlicher Bekanntgabe und ortsüblicher Bekanntmachung unterscheidet: Die Bekanntmachung ist der formalisierte Hinweis auf einen andernorts zur Einsichtnahme bereitgehaltenen Verwaltungsakt ( $§ 41 \mathrm{IV} 2 \mathrm{VwVfG}){ }^{541}$ Dieser Hinweis muss vorab nur ${ }^{542}$ den verfügenden Teil ${ }^{543}$ des bekanntzugebenden Verwaltungsakts im Wortlaut ${ }^{544}$ sowie die

535 Stelkens, in: Stelkens/Bonk/Sachs, VwVfG, 9. Aufl. 2018, § 41 Rn. 153.

536 Couzinet/Fröhlich, in: Mann/Sennekamp/Uechtritz, VwVfG, 2. Aufl. 2019, § 41 Rn. 133.

537 Stelkens, in: Stelkens/Bonk/Sachs, VwVfG, 9. Aufl. 2018, § 41 Rn. 146; Tiedemann, in: Bader/ Ronellenfitsch, VwVfG, 44. Ed., Stand: 1.7.2019, § 41 Rn. 86.

538 Stelkens, in: Stelkens/Bonk/Sachs, VwVfG, 9. Aufl. 2018, § 41 Rn. 147 m.w. N.

539 S. zur öffentlichen Bekanntgabe mündlicher und in anderer Weise erlassener Verwaltungsakte Stelkens, in: Stelkens/Bonk/Sachs, VwVfG, 9. Aufl. 2018, § 41 Rn. $197 \mathrm{f}$.

540 Stelkens, in: Stelkens/Bonk/Sachs, VwVfG, 9. Aufl. 2018, § 41 Rn. 150.

541 Stelkens, in: Stelkens/Bonk/Sachs, VwVfG, 9. Aufl. 2018, § 41 Rn. 156.

542 Weitere Informationen, wie sie im Hinblick auf Bekanntmachungen von Verwaltungsentscheidungen im förmlichen oder im Planfeststellungsverfahren verlangt sind (§§ 69 II 4 bis 6, 74 IV 2 und 3, V 2 bis $4 \mathrm{VwVfG}$ ), wie beispielsweise der Zeitraum der Einsichtnahmemöglichkeit, sind bei der „verkürzten Bekanntgabe“ nicht erforderlich, Stelkens, in: Stelkens/Bonk/Sachs, VwVfG, 9. Aufl. 2018, § 41 Rn. 180 f.; a. A. aber zu den Geschäftszeiten Tiedemann, in: Bader/Ronellenfitsch, VwVfG, 44. Ed., Stand: 1.7.2019, § 41 Rn. 117.

$543 \mathrm{Zu}$ den verschiedenen denkbaren Bestandteilen dieses „verfügenden Teils“ vgl. nur Stelkens, in: Stelkens/Bonk/Sachs, VwVfG, 9. Aufl. 2018, § 41 Rn. 167 ff. S. dazu bereits Rn. 121.

544 Stelkens, in: Stelkens/Bonk/Sachs, VwVfG, 9. Aufl. 2018, § 41 Rn. 167; Tiedemann, in: Bader/ Ronellenfitsch, VwVfG, 44. Ed., Stand:1.7.2019, § 41 Rn. 111. Zur Frage einer möglichen Lockerung dieser Anforderung ausführlich m. zahlr. N. Stelkens, a.a.O., Rn. $168 \mathrm{ff}$.

Tobias Brings-Wiesen 
Angabe des Ortes ${ }^{545}$, wo der Verwaltungsakt und seine - gegebenenfalls erforderliche (s. dazu Rn. 690 ff.) - Begründung eingesehen werden können, beinhalten. Fehlt eine dieser Angaben, ist der Verwaltungsakt unwirksam. ${ }^{546}$

159 Examenswissen: Genauerer Betrachtung bedarf im Falle der öffentlichen Bekanntgabe der Umgang mit der Rechtsbehelfsbelehrung gemäß § 37 VI VwVfG, § 58 VwGO. Weitgehende Einigkeit besteht jedenfalls darüber, dass sie dem bekanntzugebenden Verwaltungsakt selbst beizufügen ist - entweder im Rahmen der Einsichtnahme gemäß § 41 IV 2 VwVfG ${ }^{547}$ oder bereits im Rahmen einer vollständigen öffentlichen Bekanntgabe ${ }^{548}$. Umstritten ist hingegen, ob sie im Falle einer „verkürzten“ öffentlichen Bekanntgabe (zusätzlich) bereits der ortsüblichen Bekanntmachung gemäß § 41 IV 1 VwVfG beizufügen ist. ${ }^{549}$ Dagegen sprächen der Wortlaut der Norm und der systematische Vergleich mit anderen Vorschriften zu Bekanntmachungen von Verwaltungsentscheidungen, die eine Bekanntmachung auch der Rechtsbehelfsbelehrung ausdrücklich verlangen (§§ 69 II 4, 74 V 2 VwVfG). ${ }^{550}$ Dafür werden Sinn und Zweck der Rechtsbehelfsbelehrung angeführt: Deren Signalwirkung bleibe aus, wenn sie nicht mit dem ersten öffentlich wahrnehmbaren Mitteilungsakt der Behörde, sondern erst bei einer späteren Einsichtnahme erfolgt. ${ }^{551}$ Verlangt man eine ortsübliche Bekanntmachung auch der Rechtsbehelfsbelehrung, führt deren Ausbleiben zur Modifikation des Laufs der Rechtsbehelfsfristen gemäß $§ 58$ VwGO (s. dazu Rn. 368f.).

160 Die „Ortsüblichkeit“ der Bekanntmachung ist abgestuft zu bestimmen: Fehlen vorrangige spezialgesetzliche Vorgaben ${ }^{552}$, verweist $\S 41 \mathrm{IV} 1 \mathrm{VwVfG}$ über den Terminus der Ortsüblichkeit auf das für den zuständigen Verwaltungsträger

545 Ein Ort wird regelmäßig ausreichend sein, Stelkens, in: Stelkens/Bonk/Sachs, VwVfG, 9. Aufl. 2018, § 41 Rn. 179.

546 Zu § 41 IV 2 VwVfG VGH München, Beschl.v. 9.7.2001, Az.: 6 B 98.2891 = BeckRS 2001, 25898, Rn. 5; Couzinet/Fröhlich, in: Mann/Sennekamp/Uechtritz, VwVfG, 2. Aufl. 2019, § 41 Rn. 136 m.w. N. Vgl. auch BVerwG, Urt. v. 21.11.1986, Az.: 8 C 127.84 = NVwZ 1987, 230.

547 Stelkens, in: Stelkens/Bonk/Sachs, VwVfG, 9. Aufl. 2018, § 41 Rn. 192; Couzinet/Fröhlich, in: Mann/Sennekamp/Uechtritz, VwVfG, 2. Aufl. 2019, § 41 Rn. 136, jeweils m.w. N.

548 Dafür ausdrücklich Tiedemann, in: Bader/Ronellenfitsch, VwVfG, 44. Ed., Stand: 1.7.2019, $\S 41 \mathrm{Rn} .116$.

549 Dafür Stelkens, in: Stelkens/Bonk/Sachs, VwVfG, 9. Aufl. 2018, § 41 Rn. 193 m.w. N. Dagegen Stuhlfauth, in: Obermayer/Funke-Kaiser, VwVfG, 5. Aufl. 2018, § 41 Rn. 56 m.w. N. Mit Vorsicht zu genießen ist der vielerorts erfolgende Verweis auf BVerwG, Beschl. v. 24.9.1987, Az.: 4 B $93.87=$ NVwZ 1988, 364, dessen Wertungen in einem völlig anderen gesetzessystematischen Zusammenhang erfolgten und nicht ohne weiteres auf § $41 \mathrm{IV}$ VwVfG übertragbar sind, so auch Stelkens, a. a.O., Fn. 462.

550 Tiedemann, in: Bader/Ronellenfitsch, VwVfG, 44. Ed., Stand:1.7.2019, § 41 Rn. 116; Couzinet/ Fröhlich, in: Mann/Sennekamp/Uechtritz, VwVfG, 2. Aufl. 2019, § 41 Rn. 136.

551 In diesem Sinne Stelkens, in: Stelkens/Bonk/Sachs, VwVfG, 9. Aufl. 2018, § 41 Rn. 193; Schwarz, in: Fehling/Kastner/Störmer, Verwaltungsrecht, 4. Aufl. 2016, § 41 VwVfG Rn. 39.

552 Vgl. bspw. die §§ 69 II 4, 74 V 2 VwVfG: „amtliche[s] Veröffentlichungsblatt“, „örtliche[n] Tageszeitungen“.

Tobias Brings-Wiesen 
geltende $\mathrm{e}^{553}$ Organisationsrecht. Dabei ist $\mathrm{zu}$ berücksichtigen, dass die Länder vereinzelt - insbesondere für die Gemeindebehörden - allgemeine gesetzliche Vorgaben für die öffentliche Bekanntmachung normiert haben. ${ }^{554}$ So gibt in Nordrhein-Westfalen §4 I 1 BekanntmVO ${ }^{555}$ für gesetzlich vorgeschriebene öffentliche Bekanntmachungen der Gemeinden vier Formen - via Amtsblatt, Zeitung, Aushang oder Internet - vor, aus denen die Gemeinden gemäß § 4 II 1 BekanntmVO die für sie geltende(n) Form(en) ${ }^{556}$ durch Festlegung in ihrer Hauptsatzung zu wählen haben. Fehlen demgegenüber jegliche gesetzliche Vorgaben, ist auf die ortsübliche Behördenpraxis ${ }^{557}$ abzustellen. ${ }^{558}$ Werden die einschlägigen Anforderungen verfehlt, erlangt der Verwaltungsakt keine Wirksamkeit. ${ }^{559}$

Darüber hinaus verlangt § 27a I 1 und 2 VwVfG seit Kurzem, dass die Behörde 161 den Inhalt einer gesetzlich angeordneten öffentlichen oder ortsüblichen Bekanntmachung zusätzlich ${ }^{560}$ im Internet veröffentlichen, sprich auf einer eigenen oder ihrem Verwaltungsträger zugeordneten Internetseite zugänglich machen soll. Entsprechend ist gemäß §27a II VwVfG in der öffentlichen oder ortsüblichen Bekanntmachung auf die jeweilige Internetseite hinzuweisen. An-

553 OVG Münster, Beschl. v. 19.1.2010, Az.: 13 A 841/09 = BeckRS 2010, 46385; Stelkens, in: Stelkens/Bonk/Sachs, VwVfG, 9. Aufl. 2018, § 41 Rn. 161; Niesler, in: Brandt/Domgörgen, Handbuch Verwaltungsverfahren und Verwaltungsprozess, 4. Aufl. 2018, Rn. 246f. Allgemein ist es hilfreicher, den Terminus „ortsüblich“ i.S.v. „für Veröffentlichungen dieser Behörde üblich“ zu verstehen, so ausdrücklich wie treffend Tiedemann, in: Bader/Ronellenfitsch, VwVfG, 44. Ed., Stand: 1.7.2019, § 41 Rn. 109.

554 S. für einen Überblick die Homepage des öffentlich-rechtlichen Online-Lernprojekts „Saarheim“ von Grupp und Stelkens, abrufbar unter: http://www.saarheim.de/Gesetze_Laender/be kanntmachg-laender.htm.

555 Verordnung über die öffentliche Bekanntmachung von kommunalem Ortsrecht (Bekanntmachungsverordnung - BekanntmVO) v. 26.8.1999 (GV. NRW. S. 516), zuletzt geändert durch Verordnung vom 5. November 2015 (GV. NRW. S. 741).

556 S. zu den Möglichkeiten der Selektion, Kumulation und Hierarchisierung der Formen Tiedemann, in: Bader/Ronellenfitsch, VwVfG, 44. Ed., Stand: 1.7.2019, § 41 Rn. $110 \mathrm{f}$.

557 OVG Münster, Beschl.v. 19.1.2010, Az.: 13 A 841/09 = BeckRS 2010, 46385; A. A. Tiedemann, in: Bader/Ronellenfitsch, VwVfG, 44. Ed., Stand: 1.7.2019, § 41 Rn. 109f., der die Festlegung der Form der öffentlichen Bekanntmachung durch Rechtssatz für zwingend hält.

558 Fehlt auch eine solche (in Verwaltungsgewohnheitsrecht mündende) Praxis, soll laut Stelkens, in: Stelkens/Bonk/Sachs, VwVfG, 9. Aufl. 2018, § 41 Rn. 160, die öffentliche Bekanntgabe ausgeschlossen sein.

559 Couzinet/Fröhlich, in: Mann/Sennekamp/Uechtritz, VwVfG, 2. Aufl. 2019, § 41 Rn. 134.

560 Damit wird eine allein im Internet erfolgende Bekanntmachung nicht ausgeschlossen, Tiedemann, in: Bader/Ronellenfitsch, VwVfG, 44. Ed., Stand: 1.7.2019, § 41 Rn. 110a; a. A. aber im Hinblick auf schriftliche Verwaltungsakte Stelkens, in: Stelkens/Bonk/Sachs, VwVfG, 9. Aufl. 2018, § 41 Rn. 164 ff. 
ders als der Hinweis auf die Einsichtnahmemöglichkeit gemäß § 41 IV 2 VwVfG handelt es sich nicht um eine Wirksamkeitsvoraussetzung. ${ }^{561}$

Dem Hinweis gemäß § 41 IV 2 VwVfG muss die reale Einsichtnahmemöglichkeit für Jedermann ${ }^{562}$ korrespondieren. ${ }^{563}$ Dem muss gerade der für die Einsichtnahme vorgesehene Zeitraum genügen: Dieser darf insgesamt nicht kürzer sein als die in $§ 41 \mathrm{IV} 3$ VwVfG vorgesehenen zwei Wochen; ${ }^{54}$ darüber hinaus müssen die (innerhalb der Geschäftszeiten einer Behörde) vorgesehenen einzelnen Zeitfenster für die Einsichtnahme angemessen zahlreich und lang sein ${ }^{565}$.

Werden die Wirksamkeitsvoraussetzungen eingehalten, ist eine öffentliche Bekanntgabe durch öffentliche Bekanntmachung gemäß $§ 41$ IV VwVfG erfolgreich. Daneben steht es der Behörde jedoch auch frei, sich - im Gegensatz zu dieser „verkürzten“ öffentliche Bekanntgabe - für eine vollständige öffentliche Bekanntgabe des in Rede stehenden Verwaltungsakts zu entscheiden. ${ }^{566}$ Tut sie dies, werden die Vorgaben des § 41 IV VwVfG zum Teil hinfällig. ${ }^{567}$

Sind die Voraussetzungen erfüllt, ist der jeweilige Verwaltungsakt mit Wirkung für und gegen jede Person bekanntgegeben und folglich wirksam i.S.v. § 43 I VwVfG. Es wird von einer „Ringsumwirkung“ gesprochen. ${ }^{568}$ Die öffentliche Bekanntgabe wirkt weltweit und zukunftsoffen. ${ }^{569}$ Dies gilt auch unabhängig von einer tatsächlichen Kenntnisnahme oder gar einer Betroffenheit (im Zeitpunkt der Bekanntgabe).$^{570}$ Gemäß § 41 IV 3 VwVfG gilt der Verwaltungsakt zwei Wochen nach der ortsüblichen Bekanntmachung als bekannt gegeben. Die Vorschrift ähnelt § 41 II 1, 2 VwVfG, verfolgt indes einen anderen Zweck: Den potentiell Betroffenen wird mehr Zeit für die Möglichkeit der Kenntnisnahme, insbesondere zur Einsichtnahme gemäß § 41 IV 3 VwVfG, eingeräumt, bevor die Wirksamkeit

561 Stelkens, in: Stelkens/Bonk/Sachs, VwVfG, 9. Aufl. 2018, § 27a Rn. 25f., 69; § 41 Rn. 183a. 562 Weil die Frage der individuellen Betroffenheit sich häufig erst durch Einsichtnahme klären lässt, s. BVerwG, Urt. v. 8.6.1995, Az.: 4 C 4.94 = BVerwGE 98, 339 (360f.).

563 Stelkens, in: Stelkens/Bonk/Sachs, VwVfG, 9. Aufl. 2018, § 41 Rn. 178; Tiedemann, in: Bader/ Ronellenfitsch, VwVfG, 44. Ed., Stand: 1.7.2019, § 41 Rn. 118.

564 Stelkens, in: Stelkens/Bonk/Sachs, VwVfG, 9. Aufl. 2018, § 41 Rn. 180; Tiedemann, in: Bader/ Ronellenfitsch, VwVfG, 44. Ed., Stand: 1.7.2019, § 41 Rn. 120.

565 S. m.w. N. zu verschiedenen Konstellationen nur Stelkens, in: Stelkens/Bonk/Sachs, VwVfG, 9. Aufl. 2018, § 41 Rn. 181.

566 S. dazu - auch terminologisch - Stelkens, in: Stelkens/Bonk/Sachs, VwVfG, 9. Aufl. 2018, § 41 Rn. 157 f.; Tiedemann, in: Bader/Ronellenfitsch, VwVfG, 44. Ed., Stand: 1.7.2019, § 41 Rn. 107.

567 Bspw. bedarf es keines Hinweises mehr auf die Einsichtnahmemöglichkeit, Stelkens, in: Stelkens/Bonk/Sachs, VwVfG, 9. Aufl. 2018, § 41 Rn. 177.

568 Stelkens, in: Stelkens/Bonk/Sachs, VwVfG, 9. Aufl. 2018, § 41 Rn. 137.

569 Stelkens, in: Stelkens/Bonk/Sachs, VwVfG, 9. Aufl. 2018, § 41 Rn. $138 \mathrm{f}$.

570 Stelkens, in: Stelkens/Bonk/Sachs, VwVfG, 9. Aufl. 2018, § 41 Rn. $136 \mathrm{ff}$.

Tobias Brings-Wiesen 
des Verwaltungsakts eintritt und der Lauf der Rechtsbehelfsfristen beginnt. ${ }^{571}$ Gemäß § 41 IV 4 VwVfG kann in einer Allgemeinverfügung selbst - im Interesse einer besonderen Eilbedürftigkeit - ein hiervon abweichender Tag, jedoch frühestens der auf die Bekanntmachung folgende Tag bestimmt werden.

Eine in der juristischen Ausbildung besonders relevante Sonderproblematik 165 offenbart sich im Zusammenhang mit der Bekanntgabe von Straßenverkehrszeichen. ${ }^{572}$ Bei diesen handelt es sich (s. dazu Rn. $85 \mathrm{f}$.) zumindest nach herrschender Ansicht um Allgemeinverfügungen i.S.v. § 35 S. 2 Var. 3 VwVfG. Das Bundesverwaltungsgericht vertritt $\mathrm{zu}$ den Fragen rund um ihre Bekanntgabe ${ }^{573}$ einen differenzierenden Ansatz: Die Bekanntgabe von Straßenverkehrszeichen als besondere Form der öffentlichen Bekanntgabe richtet sich ausschließ$\operatorname{lich}^{574}$ nach den (bundesrechtlichen) Spezialvorschriften der StraßenverkehrsOrdnung (StVO). Aus den §§ 39 I, 45 IV StVO ergibt sich, dass die Bekanntgabe von Verkehrszeichen grundsätzlich durch deren Aufstellung erfolgt. ${ }^{575}$ In diesem Moment werden sie für jeden Verkehrsteilnehmer wirksam, sofern sie entsprechend des sog. „Sichtbarkeitsgrundsatzes“ so aufgestellt sind, dass „sie ein durchschnittlicher Kraftfahrer bei Einhaltung der nach $\S 1$ StVO erforderlichen Sorgfalt schon ,mit einem raschen und beiläufigen Blick` erfassen kann [...], gleichgültig, ob er das Verkehrszeichen tatsächlich wahrnimmt oder nicht“. ${ }^{576}$ Die „Sichtbarkeit“ ist somit echte Wirksamkeitsvoraussetzung der Allgemeinverfügung Straßenverkehrszeichen. ${ }^{577}$ Die Anforderungen an den Sichtbarkeitsgrundsatz sind dabei stark verkehrssituationsbedingt ${ }^{578}$ : So soll grundsätzlich zwischen Zeichen zur Regelung des ruhenden und des fließenden Straßenverkehrs unterschieden werden; ${ }^{579}$ eine rasche und beiläufige Erkennbarkeit und Erfassbarkeit

571 Hinsichtlich der Fristberechnung gilt das zu § 41 II VwVfG Gesagte entsprechend, s. dazu bereits Rn. 143.

572 S. dazu ausführlich auch Milker, JURA 2017, 271 (274 ff.); Kümper, JuS 2017, 731 (733 ff.); ders., JuS 2017, 833.

573 Zur Entwicklung der Rspr. des BVerwG in dieser Frage m.w. N. Maurer/Waldhoff, Allgemeines Verwaltungsrecht, 19. Aufl. 2017, § 9 Rn. 37.

574 Zur Frage einer umfassenden Verdrängung von § 41 VwVfG BVerwG, Urt. v. 13.3.2008, Az.: 3 C 18.07 = BVerwGE 130, 383 (389f., Rn. 24f.); dazu bereits OVG Münster, Urt. v. 12.1.1996, Az.: 25 A 2475/93 = NJW 1996, 3024 (3025).

575 St. Rspr. des BVerwG, Urt. v. 11.12.1996, Az.: 11 C 15.95 = BVerwGE 102, 316 (318); zuletzt Urt.v. 24.5.2018, Az.: 3 C 25.16 = NJW 2018, 2910, Rn. 15.

576 Ausdrücklich seit BVerwG, Urt. v. 11.12.1996, Az.: 11 C 15.95 = BVerwGE 102, 316 (318); zuletzt Urt. v. 24.5.2018, Az.: 3 C 25.16 = NJW 2018, 2910, Rn. 15.

577 BVerwG, Urt. v. 6.4.2016, Az.: 3 C 10.15 = BVerwGE 154, 365 (373, Rn. 22).

578 S. dazu ausführlich Milker, JURA 2017, 271 (275f.); Kümper, JuS 2017, 733 (735f.).

579 BVerwG, Urt. v. 6.4.2016, Az.: 3 C 10.15 = BVerwGE 154, 365 (370 ff., Rn. 17 ff.).

Tobias Brings-Wiesen 
kann im Falle eines „Schilderwaldes“ $z u$ verneinen sein ${ }^{580}$. Die völlige Irrelevanz der tatsächlichen Kenntnisnahme zeigt sich in der Rechtsprechung des Bundesverwaltungsgerichts zu mobilen Straßenverkehrszeichen: Ein mobiles Halteverbotszeichen entfaltet gegenüber dem Halter eines Kraftfahrzeugs selbst dann Rechtswirkungen, wenn es erst nach dem Abstellen eines Fahrzeugs aufgestellt wird und der Halter wegen eines Krankenhausaufenthalts oder eines Urlaubs nicht einmal die Möglichkeit der Kenntnisnahme hatte. ${ }^{581}$ Vor dem Hintergrund des Sichtbarkeitsgrundsatzes ist sodann auch konsequent, dass die innere Wirksamkeit des Verkehrszeichens für den Zeitraum entfällt, während dessen sein Regelungsgehalt - beispielsweise wegen Vandalismus oder Witterungsbedingungen - nicht (mehr) erkennbar ist. ${ }^{582}$

Intensiv umstritten ist vor diesem Hintergrund die Frage des Rechtsschutzes im Hinblick auf die Rechtsbehelfsfristen. Diese beginnen gemäß $\S \S 70$ I 1 , 74 I VwGO grundsätzlich mit der Bekanntgabe des Verwaltungsakts (s. dazu Rn. 370 ff.). Nach dem Bundesverwaltungsgericht kann die Aufstellung als besondere Form der öffentlichen Bekanntgabe jedoch in ihrer Wirkung von der Wirkung anderer Formen der öffentlichen Bekanntgabe abweichen. ${ }^{583}$ Vor diesem Hintergrund ${ }^{584}$ entschied es, dass abweichend vom Eintritt der universellen Regelungswirkung (s. dazu Rn. 164) die Rechtsbehelfsfristen individuell erst dann zu laufen beginnen, „wenn sich der betreffende Verkehrsteilnehmer erstmals der Regelung des Verkehrszeichens gegenübersieht.“" ${ }^{585}$ Jedes andere Verständnis geriete in Konflikt mit der Garantie effektiven Rechtsschutzes gemäß Art. 19 IV 1 GG. ${ }^{586}$ Dies bedeutet, dass mangels Kenntnisnahme für eine Mehrheit an Ver-

580 S. BVerwG, Urt.v. 13.3.2008, Az.: 3 C 18.07 = BVerwGE 130, 383 (386ff., Rn. 13ff.), hinsichtlich eines Verkehrszeichens mit vier Zusatzzeichen.

581 BVerwG, Urt. v. 11.12.1996, Az.: 11 C 15.95 = BVerwGE 102, 316 (318); Urt. v. 24.5.2018, Az.: 3 C 25.16 = NJW 2018, 2910 (Rn. 15).

582 S. dazu nur Kümper, JuS 2017, 731 (736).

583 BVerwG, Urt. v. 23.9.2010, Az.: 3 C 37.09 = BVerwGE 138, 21 (25, Rn. 17).

584 Detterbeck, Allgemeines Verwaltungsrecht, 17. Aufl. 2019, Rn. 562, geht auf diese Differenzierung der Rechtswirkungen in der Rspr. des BVerwG nicht ein. De facto läuft sie nur auf ein differenziertes Verständnis des Aktes der Bekanntgabe in § 43 I VwVfG und §§ 58, 70 I 1, 74 I 2 VwGO hinaus.

585 BVerwG, Urt. v. 23.9.2010, Az.: 3 C 37.09 = BVerwGE 138, 21 (24, Rn. 16); so bereits ohne klarstellende Differenzierung BVerwG, Urt. v. 13.12.1979, Az.: 7 C 46.78 = BVerwGE 59, 221 (226). Krit. zu diesem Ansatz Stelkens, in: Stelkens/Bonk/Sachs, VwVfG, 9. Aufl. 2018, § 35 Rn. 333a m.w. Nw.

586 BVerwG, Urt. v. 23.9.2010, Az.: 3 C 37.09 = BVerwGE 138, 21 (24, Rn. 16). Zustimmend Maurer/ Waldhoff, Allgemeines Verwaltungsrecht, 19. Aufl. 2017, §9 Rn. 37. In dem vorausgehenden BVerfG(K), Beschl. v. 10.9.2009, Az.: 1 BvR 814/09 = NJW 2009, 3642 (3644), wurde auf die Notwendigkeit der Berücksichtigung von Art. 19 IV 1 GG bei der Bestimmung des Fristbeginns zwar

Tobias Brings-Wiesen 
kehrsteilnehmern nie eine Rechtsbehelfsfrist ausgelöst, der Verwaltungsakt Straßenverkehrszeichen mithin praktisch niemals in formelle Bestandskraft erwachsen wird. Um dem zu begegnen, vertritt eine Gegenansicht - gestützt auf eine konsequente Anwendung des Sichtbarkeitsgrundsatzes - die Meinung, dass auch die Rechtsbehelfsfristen ${ }^{587}$ im Zeitpunkt der Aufstellung ausgelöst werden. ${ }^{588}$ Gegen den Ansatz des Bundesverwaltungsgerichts werden der klare Wortlaut der einschlägigen Fristenregelungen, die ausdrücklich auf die Bekanntgabe abstellen, sowie das Argument fehlender Rechtssicherheit ins Feld geführt. ${ }^{589}$ Außerdem sei ausreichender Rechtsschutz über die Geltendmachung eines Anspruchs auf Wiederaufgreifen des Verfahrens nach $\S 51$ VwVfG oder eines Anspruchs auf ermessensfehlerfreie Entscheidung über eine Aufhebung des Verwaltungsakts nach $\S \S 48,49$ VwVfG zu erreichen. ${ }^{590}$

Obwohl durchaus Wertungsparallelen bestehen, sollte diese Sonderdogmatik der Bekanntgabe von Verkehrszeichen nicht ohne weiteres auf andere Konstellationen der öffentlichen Bekanntgabe, insbesondere von anderen Allgemeinverfügungen, übertragen werden. ${ }^{591}$

\section{dd) Die Bekanntgabe von Verwaltungsakten mittels Zustellung}

Die sog. „Zustellung“ ist eine besonders formalisierte Art der Bekanntgabe ei- 168 nes Verwaltungsakts (s. zum Zusammenhang von Zustellung und Klagefrist Rn. 373ff.). Ihre Existenz wird in $\S 41 \mathrm{~V} \mathrm{VwVfG}$ vorausgesetzt, wobei sich die Vorschrift in der Klarstellung erschöpft, dass die Vorschriften über die Bekanntgabe eines Verwaltungsakts mittels Zustellung unberührt bleiben. Sie verdeutlicht: Diese Vorschriften gehen $§ 41$ VwVfG schlicht vor, der weder subsidiär592

hingewiesen, jedoch keine Alternativlosigkeit postuliert; s. für einen Überblick über den diesbezüglichen Meinungsstand vor dem Urteil des BVerwG, a.a.O., BVerfG(K), ibid., 2642 (2643). 587 Wobei einhellige Meinung ist, dass mangels ordnungsgemäßer Rechtsbehelfsbelehrung praktisch immer die Ausschlussfrist von § 58 II VwGO relevant sein wird.

588 VGH Mannheim, Beschl. v. 2.3.2009, Az.: 5 S 3047/08 = juris, Rn. 5 ff.; Detterbeck, Allgemeines Verwaltungsrecht, 17. Aufl. 2019, Rn. 562; Stelkens, in: Stelkens/Bonk/Sachs, VwVfG, 9. Aufl. 2018, § 35 Rn. 333f. m.w. N.

589 Ehlers, JZ 2011, 155 (157); Milker, JURA 2017, 271 (278); Kümper, JuS 2017, 833 (835).

590 Detterbeck, Allgemeines Verwaltungsrecht, 17. Aufl. 2019, Rn. 562 m.w. N. Dagegen jedoch Maurer/Waldhoff, Allgemeines Verwaltungsrecht, 19. Aufl. 2017, § 9 Rn. 37.

591 Ausdrücklich ablehnend Stelkens, in: Stelkens/Bonk/Sachs, VwVfG, 9. Aufl. 2018, § 41 Rn. 136.

592 Stelkens, in: Stelkens/Bonk/Sachs, VwVfG, 9. Aufl. 2018, § 41 Rn. 199; Schwarz, in: Fehling/ Kastner/Störmer, Verwaltungsrecht, 4. Aufl. 2016, § 41 VwVfG Rn. 43; Stuhlfauth, in: Obermayer/ Funke-Kaiser, VwVfG, 5. Aufl. 2018, § 41 Rn. 69. 
noch analog ${ }^{593}$ auf Zustellungen anwendbar ist. Die für die Wirksamkeit einer Bekanntgabe dargelegten allgemeinen Voraussetzungen bestehen jedoch der Sache nach auch hinsichtlich der Zustellung. ${ }^{594}$ Besonderheiten ergeben sich vorrangig auf Seiten des Empfängers, insbesondere hinsichtlich des Zugangs. ${ }^{595}$

Die Vorgaben zur Zustellung finden sich allgemein im Verwaltungszustellungsgesetz des Bundes (VwZG) ${ }^{596}$, das indes unmittelbar nur für die Zustellungsverfahren der Bundesbehörden, der bundesunmittelbaren Körperschaften, Anstalten und Stiftungen des öffentlichen Rechts und der Landesfinanzbehörden gilt (§ 1 I VwZG). Darüber hinaus sind die Verwaltungszustellungsgesetze der Länder ${ }^{597} \mathrm{zu}$ berücksichtigen, die Vorgaben für die Zustellungsverfahren der übrigen staatlichen Behörden festlegen, ${ }^{598}$ dabei indes inhaltlich weitgehend den Vorgaben des VwZG entsprechen oder sich bisweilen gar in einer Verweisung darauf erschöpfen. Existieren besondere Zustellungsvorschriften, ist zu prüfen, ob und inwieweit diese gegenüber dem allgemeinen Zustellungsrecht Vorrang haben. ${ }^{599}$

Nach der Legaldefinition des $§ 2$ I VwZG ist eine Zustellung die Bekanntgabe eines schriftlichen oder elektronischen Dokuments ${ }^{600}$ in der im VwZG bestimmten Form. Sie erfolgt, soweit dies durch Rechtsvorschrift oder behördliche Anordnung bestimmt ist ( $§ 1$ II VwZG). Die behördliche Anordnung der Zustellung steht im Ermessen der Behörde. ${ }^{601}$ Wählt sie den Weg der Zustellung, muss

593 Ramsauer/Tegethoff, in: Kopp/Ramsauer, VwVfG, 20. Aufl. 2019, § 41 Rn. 56; Tiedemann, in: Bader/Ronellenfitsch, VwVfG, 44. Ed., Stand: 1.7.2019, § 41 Rn. 128.

594 Auf Seiten der Behörde muss jedoch ein spezifischer Zustellungswille bestehen, Schwarz, in: Fehling/Kastner/Störmer, Verwaltungsrecht, 4. Aufl. 2016, § 41 VwVfG Rn. 44.

595 Stelkens, in: Stelkens/Bonk/Sachs, VwVfG, 9. Aufl. 2018, § 41 Rn. 204.

596 Verwaltungszustellungsgesetz vom 12. August 2005 (BGBl. I S. 2354), zuletzt geändert durch Art. 11 Abs. 3 des aIDAS-Durchführungsgesetzes vom 18. Juli 2017 (BGBl. I S. 2745).

597 S. für eine kontinuierlich aktualisierte Auflistung die Homepage des öffentlich-rechtlichen Online-Lernprojekts „Saarheim“ von Grupp und Stelkens, abrufbar unter: http://www.saarheim. de/Gesetze_Laender/vwzg_laender.htm.

598 Selbst im Falle einer kraft Bundesrecht vorgeschriebenen Zustellung, BVerwG, Urt. v. 19.1. 1972, Az.: V C 54.70 = BVerwGE 39, 257 (259); Urt. v. 9.12.1988, Az.: 8 C 38.86 = NVwZ 1989, 648 (649).

599 Vgl. bspw. zum § 10 AsylG Bergmann, in: ders./Dienelt, Ausländerrecht, 12. Aufl. 2018, § 10 AsylG Rn. $10 \mathrm{ff}$.

600 Der Anwendungsbereich ist nicht auf die Bekanntgabe von Verwaltungsakten beschränkt, Stelkens, in: Stelkens/Bonk/Sachs, VwVfG, 9. Aufl. 2018, § 41 Rn. 206.

601 Ramsauer/Tegethoff, in: Kopp/Ramsauer, VwVfG, 20. Aufl. 2019, § 41 Rn. 58; Tiedemann, in: Bader/Ronellenfitsch, VwVfG, 44. Ed., Stand: 1.7.2019, § 41 Rn. 130. 
sie sich an dieser Entscheidung festhalten lassen und die Voraussetzungen des Zustellungsrechts erfüllen. ${ }^{602}$

Gemäß § 2 II 1 VwZG erfolgt die Zustellung durch einen Erbringer von 171 Postdienstleistungen (Post), einen nach $\S 17$ des De-Mail-Gesetzes akkreditierten Diensteanbieter oder durch die Behörde selbst. Davon abweichend können gemäß § 2 II 2 VwZG im Rahmen einer Zustellung im Ausland (§ 9 VwZG) oder einer öffentlichen Zustellung ( 10 VwZG) andere Akteure eingebunden werden. Sie erfolgt an den Empfänger ${ }^{603}$ selbst, seinen gesetzlichen Vertreter ( $§ 6$ VwZG) oder seinen Bevollmächtigten (§ 7 VwZG). Anders als nach § 41 I 2 VwVfG ist gemäß $\S 7$ I 2 BVwZG die Zustellung zwingend an den Bevollmächtigten zu richten, wenn dieser eine schriftliche Vollmacht vorgelegt hat, sodass die an eine andere Person erfolgte Zustellung unwirksam ist, ${ }^{604}$ jedoch gemäß $§ 8$ VwZG geheilt werden $\mathrm{kann}^{605}$.

Soweit nicht anders vorgesehen ${ }^{606}$ hat die Behörde gemäß $§ 2$ III 1 VwZG die Wahl zwischen den verschiedenen Arten der Zustellung. Für schriftliche Verwaltungsakte besteht die Wahl zwischen der Zustellung durch die Post mit Zustellungsurkunde ( $§ 3$ VwZG), mittels Einschreiben ( $\$ 4$ VwZG) $)^{607}$ oder gegen Empfangsbekenntnis ( $\S 5$ VwZG). Für elektronische Dokumente bietet sich die Möglichkeit der elektronischen Zustellung ( $\$ 5 \mathrm{~V}$ bis VII VwZG), insbesondere gegen Abholbestätigung über De-Mail-Dienste ( $§ 5 \mathrm{a} V w Z G){ }^{608}$ Für all diese Arten der Zustellung sind besondere Förmlichkeiten vorgesehen, deren Missachtung zur

602 OVG Lüneburg, Beschl.v. 13.3.2009, Az.:11 PA 157/09 = NJW 2009, 1834; Ramsauer/Tegethoff, in: Kopp/Ramsauer, VwVfG, 20. Aufl. 2019, § 41 Rn. 58.

603 Besonderheiten ergeben sich wiederum bei Personenmehrheiten Ramsauer/Tegethoff, in: Kopp/Ramsauer, VwVfG, 20. Aufl. 2019, § 41 Rn. 60.

604 BFH, Urt.v. 11.4.2017, Az.: IX R 50/15 = BeckRS 2017, 119902, Rn. 34; OVG Lüneburg, Beschl.v. 13.3.2009, Az.: 11 PA 157/09 = NJW 2009, 1834; Schlatmann, in: Engelhardt/App/Schlatmann, 11. Aufl. 2017, VwVG/VwZG, § 7 VwZG Rn. 8.

605 So bereits zu § 9 VwZG a.F. BVerwG, Urt. v. 15.1.1988, Az.: 8 C 8.86 = NJW 1988, 1612 (1613); Urt. v. 18.4.1997, Az.: 8 C 43.95 = BVerwGE 104, 301 (312ff.). Vgl. auch BFH, Urt. v. 11.4. 2017, Az.: IX R 50/15 = BeckRS 2017, 119902, Rn. 34.

606 So statuiert \& 2 III 2 VwZG unmittelbar eine Ausnahme von diesem Grundsatz: Die Behörde ist gemäß § 5 V 2 VwZG verpflichtet, elektronisch zuzustellen, wenn auf Grund einer Rechtsvorschrift ein Verfahren auf Verlangen des Empfängers in elektronischer Form abgewickelt wird.

$\mathbf{6 0 7}$ S. zu diesen beiden Formen noch näher Rn. $374 \mathrm{ff}$.

$608 \mathrm{Zu}$ den einzelnen Zustellungsarten Ramsauer/Tegethoff, in: Kopp/Ramsauer, VwVfG, 20. Aufl. 2019, § 41 Rn. 62ff.; Stelkens, in: Stelkens/Bonk/Sachs, VwVfG, 9. Aufl. 2018, § 41 Rn. 207 ff.; sowie die Kommentierungen zum BVwZG selbst.

Tobias Brings-Wiesen 
Unwirksamkeit der Zustellung führen kann. Dies wird jedoch insbesondere ${ }^{609}$ bei Vorliegen der Voraussetzungen des § 8 VwZG verneint: Danach gilt im Falle des Fehlens eines Nachweises der formgerechten Zustellung oder der Verletzung zwingender Zustellungsvorschriften ein Dokument als in dem Zeitpunkt zugestellt, in dem es dem Empfangsberechtigten tatsächlich zugegangen ist. ${ }^{610}$

Ein davon abzugrenzender Sonderfall ist die öffentliche Zustellung gemäß $\S 10$ VwZG. Mit ihr sollen die in § 10 I 1 VwZG als Voraussetzung ihrer Zulässigkeit $^{611}$ formulierten Hindernisse einer individuellen Zustellung, beispielsweise ein unbekannter Aufenthaltsort des Empfängers, überwunden werden. Die Wirksamkeit einer öffentlichen Zustellung setzt weiterhin die Einhaltung der in § 10 II VwZG vorgesehenen Vorgaben betreffend ihre Modalitäten voraus. Eine Heilung gemäß § 8 VwZG setzt ausdrücklich den Zugang des Dokuments voraus, von dessen Möglichkeit im Falle öffentlicher Zustellung regelmäßig nicht auszugehen ist. Sollte es gleichwohl dazu kommen oder der Empfänger anderweitig vom Inhalt des Verwaltungsakts Kenntnis erlangen ${ }^{612}$, kommt eine Heilung gemäß § 8 VwZG (analog) in Frage. ${ }^{613}$ Gelingt die öffentliche Zustellung wirkt sie anders als die öffentliche Bekanntgabe i.S.v. § 41 III, IV VwVfG (s. dazu Rn. 164) lediglich für die Person, die als Empfänger ausdrücklich identifiziert ist.

\section{c) Rechtsschutz bei Fehlern im Wirksamwerden eines Verwaltungsakts}

174 Wie bereits dargelegt (s. dazu Rn. 100) können sich Fragen des Wirksamkeit (und somit auch des Wirksamwerdens) eines Verwaltungsakts im Rahmen einer Prüfung inzident stellen. Genauso kann ein Verwaltungsakt, dessen Wirksamwerden in Zweifel steht, jedoch selbst Gegenstand eines Rechtsschutzbegehrens sein.

609 Darüber hinaus besteht die Möglichkeit der Unbeachtlichkeit eines Zustellungsfehlers in Konstellationen des „rügelosen Rechtsbehelfs“ und der Verwirkung, s. nur L. Ronellenfitsch, in: Bader/Ronellenfitsch, VwVfG, 44. Ed., Stand: 1.10.2018, § 8 VwZG Rn. $19 \mathrm{ff}$.

610 S. dazu ausführlich L. Ronellenfitsch, in: Bader/Ronellenfitsch, VwVfG, 44. Ed., Stand: 1.10. 2018, § 8 VwZG Rn. $1 \mathrm{ff}$.

611 S. noch zum alten Zustellungsrecht BVerwG, Urt. v. 18.4.1997, Az.: 8 C 43.95 = BVerwGE 104, 301 (306ff.).

612 Bspw. durch Übersendung als Aktenbestandteil an den bestellten Bevollmächtigten VGH Mannheim, Beschl. v. 7.12.1990, Az.: 10 S 2466/90 = NVwZ 1991, 1195 (1196).

613 Schlatmann, in: Engelhardt/App/Schlatmann, VwVG/VwZG, 11. Aufl. 2017, § 10 VwZG Rn. 19; L. Ronellenfitsch, in: Bader/Ronellenfitsch, VwVfG, 44. Ed., Stand: 1.10.2018, § 10 VwZG Rn. $37 \mathrm{f}$. Vgl. auch BFH, Urt. v. 5.3.1985, Az.: VII R 156/82 = BFHE 143, 220 (223). 
Aufgrund des Grundsatzes der relativen Wirksamkeit von Verwaltungsakten (s. dazu Rn. 113) ist zwischen zwei Grundkonstellationen zu unterscheiden: ${ }^{614}$

Ist der Verwaltungsakt nur einer Person wirksam bekanntgegeben wor- 175 den, ist er rechtlich existent, sodass er grundsätzlich von jeder Person im Wege des Widerspruchs gemäß § 68 I 1 VwGO bzw. der Anfechtungsklage gemäß § 42 I Var. 1 VwGO angegriffen und schließlich aufgehoben werden kann, wobei sich Unterschiede lediglich hinsichtlich des Laufs der Rechtsbehelfsfristen ergeben (s. Rn. 113, 116).

Ist der Verwaltungsakt niemandem gegenüber wirksam bekanntgegeben 176 worden, handelt es sich schlicht um einen „Nichtakt“615 (s. Rn. 20). Es stellt sich die Frage, ob gegen derartige Nichtakte gleichwohl ein Widerspruch gemäß $\S 68$ I 1 VwGO bzw. eine Anfechtungsklage gemäß § 42 I Var. 1 VwGO ${ }^{616}$ statthaft ist. Dies wird zum Teil ${ }^{617}$ schlicht mit dem Argument der fehlenden Existenz des Verwaltungsakts und dem Verweis auf die Möglichkeit der Beseitigung eines etwaigen Rechtsscheins im Wege der Feststellungsklage (s. Rn. 177) verneint. Auch begründe ein Nichtakt nicht mit gleicher Regelmäßigkeit wie ein nichtiger Verwaltungsakt den Rechtsschein seiner Wirksamkeit, sodass zwischen beiden zu unterscheiden sein soll. ${ }^{618}$ Die Gegenmeinung ${ }^{619}$ möchte demgegenüber eine Anfechtungsklage zulassen. Entsprechend der Argumentation für die Statthaftigkeit einer Anfechtungsklage gegen nichtige Verwaltungsakte (s. dazu noch in

614 So auch Couzinet/Fröhlich, in: Mann/Sennekamp/Uechtritz, VwVfG, 2. Aufl. 2019, § 41 Rn. $157 \mathrm{ff}$.

615 Das BVerwG bezeichnet die somit nicht bekanntgegebene Maßnahme als „Nichtakt“, Urt. v. 21.11.1986, Az.: 8 C 127.84 = NVwZ 1987, 330; Beschl. v. 19.5.2015, Az.: 3 B 6.14 = juris, Rn. 13. Im Falle des Fehlens der Merkmale nach § 35 VwVfG nennt es jedoch mittlerweile den in der Literatur gleichsam gebräuchlichen Begriff des „Scheinverwaltungsaktes“ mit, vgl. nur Urt. v. 22.3.2017, Az.: 5 C 4.16 = BVerwGE 158, 258 (261, Rn. 11).

616 Damit in engem Zusammenhang steht selbstredend die Frage, ob ein Antrag auf vorläufigen Rechtsschutz gemäß $\S 80 \mathrm{ff}$. VwGO statthaft wäre, s. dazu im Hinblick auf Nichtakte - wie die wohl h.M. - nur W.-R. Schenke, in: Kopp/Schenke, VwGO, 25. Aufl. 2019, § 80 Rn. 16 m.w. N. 617 Gegen die Statthaftigkeit einer Anfechtungsklage - insbesondere im Falle des klägerischen Vorbringens einer unwirksamen Bekanntgabe - VGH Mannheim, Beschl. v. 7.12.1990, Az.: 10 S 2466/90 = NVwZ 1991, 1195 (1195f.); OVG Greifswald, Urt.v. 24.3.2015, Az.: 1 L 313/11 = BeckRS 2015, 46844. So auch Hufen, Verwaltungsprozessrecht, 11. Aufl. 2019, § 14 Rn. 10; R. P. Schenke, in: Kopp/Schenke, VwGO, 25. Aufl. 2019, § 42 Rn. 4; von Albedyll, in: Bader/Funke-Kaiser/Stuhlfauth/ von Albedyll, VwGO, 7. Aufl. 2018, § 42 Rn. 13.

618 S. nur VGH Mannheim, Beschl. v. 7.12.1990, Az.: 10 S 2466/90 = NVwZ 1991, 1195 (1196). 619 Stelkens, in: Stelkens/Bonk/Sachs,VwVfG, 9. Aufl. 2018, § 41 Rn. 226f.; Pietzcker, in: Schoch/ Schneider/Bier, VwGO, 36. EL Februar 2019, § 42 I Rn. 20, jeweils m.w. N.

Tobias Brings-Wiesen 
$\S 6$ Rn. 197 ff. $^{620}$ ) wird maßgeblich auf das Rechtsschutzinteresse des Klägers abgestellt, den in zwischen ihm und der Behörde strittigen Konstellationen bestehenden Rechtsschein eines Verwaltungsakts zu beseitigen. ${ }^{621}$

Anstelle (oder eben neben ${ }^{622}$ ) der Anfechtungsklage kann eine Feststellungsklage gemäß $§ 43$ I Var. 2 VwGO auf Feststellung des Nichtbestehens eines Rechtsverhältnisses (sog. negative Feststellungsklage) ${ }^{623}$ statthaft sein. Das Klagebegehren ist auf die Feststellung gerichtet, dass der Verwaltungsakt nicht wirksam geworden ist und deshalb die mit ihm beabsichtigte Regelung nicht erreicht hat. ${ }^{624}$

\section{Das Ende der Wirksamkeit gemäß § 43 II VwVfG}

178 Neben der Unwirksamkeit auf Grund von Nichtigkeit gemäß § 43 III i.V.m. § 44 VwVfG, auf die noch gesondert einzugehen ist (s. dazu Rn. $189 \mathrm{ff}$. sowie ausführlich § 6 Rn. $115 \mathrm{ff}$.), sind § 43 II VwVfG Anknüpfungspunkte für die Beendigung der Wirksamkeit eines Verwaltungsakts zu entnehmen. Diese lassen sich in zwei Gruppen unterteilen: Das Ende der Wirksamkeit kann zum einen auf einen gezielten nachträglichen Akt, eine sog. Aufhebung, zurückzuführen sein. Sie kann sich zum anderen aber auch schlicht aus dem Verwaltungsakt und dem ihm zugrundeliegenden Recht selbst ergeben, sprich zu seiner Erledigung führen. ${ }^{625}$

620 Wegen der weitgehend vergleichbaren Interessenlage kann grundsätzlich entsprechend auf die umfassenderen Ausführungen zur Statthaftigkeit der Anfechtungsklage gegen nichtige Verwaltungsakte verwiesen werden. Diese sollen zur Vermeidung von Redundanzen an dieser Stelle nicht gespiegelt werden.

621 S. nur Stelkens, in: Stelkens/Bonk/Sachs, VwVfG, 9. Aufl. 2018, § 41 Rn. 227.

622 So zumindest Blunk/Schroeder, JuS 2005, 602 (605).

623 Wie im Zusammenhang mit der Frage der Nichtigkeit eines Verwaltungsakts, s. dazu noch $\S 6$ Rn. 75, kann auch hinsichtlich der übrigen Wirksamkeitsprobleme das Bedürfnis des Betroffenen bestehen, die Wirksamkeit eines Verwaltungsakts im Wege der sog. positiven Feststellungsklage gemäß § 43 I Var. 1 VwGO ausdrücklich bestätigen zu lassen.

624 So ausdrücklich BVerwG, Urt. v. 21.11.1986, Az.: 8 C 127.84 = NVwZ 1987, 330. S. zu den verschiedenen Begehren eines Feststellungsantrags Couzinet/Fröhlich, in: Mann/Sennekamp/ Uechtritz, VwVfG, 2. Aufl. 2019, § 41 Rn. 158. S. zur Feststellungsklage ausführlich noch § 6.

625 Vgl. zu § 43 II VwVfG ähnlich auch das BVerwG, Urt. v. 27.3.1998, Az.: 4 C 11.97 = NVwZ 1998, 729 (730); Urt. v. 19.4.2011, Az.: 1 C 2.10 = BVerwGE 139, 337 (340 f.). 


\section{a) Konstellationen der Aufhebung eines Verwaltungsakts}

Die für die Prüfung relevantesten Konstellationen sind die eines gezielten nach- 179 träglichen Aktes der Beendigung der Wirksamkeit - einer sog. Aufhebung. § 43 II VwVfG rekurriert ausdrücklich nur auf die Möglichkeiten der Rücknahme und des Widerrufs, belässt jedoch Raum für Optionen ,anderweitiger Aufhebung“. Um alle Konstellationen der Aufhebung zu erfassen, ist es hilfreich, in einem ersten Überblick zwischen behördlichen und gerichtlichen Entscheidungen zu differenzieren.

Zur gerichtlichen Aufhebung eines Verwaltungsakts kommt es insbeson- 180 dere im Falle der Begründetheit einer Anfechtungsklage, $\S \S 42$ I Var. 1, 113 I 1 VwGO. Nichts anderes gilt darüber hinaus im Falle der Begründetheit einer Verpflichtungsklage (§§ 42 I Var. 2, $113 \mathrm{~V}$ VwGO) in Form der sog. Versagungsgegenklage, da diese eine Klage gerichtet auf Aufhebung der ablehnenden Entscheidung rechtslogisch einschließt. ${ }^{626}$

Diesen beiden Klagearten vorausgehend kann es bereits im Vorverfahren gemäß §§ $68 \mathrm{ff}$. VwGO zu einer behördlichen Aufhebung eines Verwaltungsakts kommen. Hält die zuständige Behörde den Widerspruch für begründet, so hat sie ihm gemäß $\S 72$ VwGO abzuhelfen. Jederzeit kann die Behörde auch durch Rücknahme oder Widerruf (gemäß §§ $48 \mathrm{f}$. VwVfG oder spezialgesetzlichen Regelungen) die Aufhebung eines Verwaltungsakts ${ }^{627}$ erreichen (s. dazu Rn. $836 \mathrm{ff}$.). Auch der Antrag eines Betroffenen auf Wiederaufgreifen des Verfahrens gemäß $\S 51$ VwVfG kann zur Aufhebung führen (s. dazu § 3 Rn. 98 ff.).

\section{b) Konstellationen der Erledigung eines Verwaltungsakts (durch Zeitablauf oder auf andere Weise)}

Die Wirksamkeit eines Verwaltungsakts kann jedoch auch ohne gezielte nach- 182 trägliche Einwirkung auf eben diese Wirksamkeit enden. Das Gesetz fasst diese Konstellationen unter dem Begriff der „Erledigung“ zusammen. ${ }^{628}$ Das Bundesverwaltungsgericht versteht darunter allgemein, dass ein Verwaltungsakt „nicht

626 S. nur Schenke, Verwaltungsprozessrecht, 16. Aufl. 2019, Rn. 263, 851. S. auch das BVerwG, Urt.v. 17.11.1972, Az.: IV C 21.69 = BVerwGE 41, 178 (182); Urt.v. 21.5.1976, Az.: IV C 80.74 = BVerwGE 51,15 (21).

627 Der selbst Verwaltungsakt ist und somit Gegenstand einer Anfechtungsklage sein kann, sodass sich im Falle der „Aufhebung einer Aufhebung“ die Frage des Wiederauflebens des ursprünglichen Verwaltungsakts stellt, s. dazu ausführlich noch Rn. 839.

628 S. zur Erledigung instruktiv Reimer, Die Verwaltung 2015, 259; Schenke, Die Erledigung eines Verwaltungsakts im Sinne des § 43 II VwVfG, in: Festschrift Peine, 2016, S. 503.

Tobias Brings-Wiesen 
mehr geeignet ist, rechtliche Wirkungen zu erzeugen oder wenn die Steuerungsfunktion, die ihm ursprünglich innewohnte, nachträglich entfallen ist“629. Dieser Definitionsversuch ist nicht nur wegen seiner notwendigen Abstraktionshöhe für die (studentische) Praxis wenig hilfreich. Er ist überdies auch besonders voraussetzungsvoll, da er in seiner Kumulation denkbarer Möglichkeiten der Erledigung eine umfassende Kenntnis verwaltungsrechtlicher Methodik verlangt. Für Prüfungskonstellationen ist darüber hinaus stets zu erinnern, dass die Erledigungsbegriffe in $\S 43$ II VwVfG und $\S 113$ I 4 VwGO (s. dazu § 4 Rn. 11ff.) nicht deckungsgleich sind. ${ }^{630}$

Vergleichsweise leicht verständlich ist die bereits in der Norm ausdrücklich genannte Konstellation der Erledigung „durch Zeitablauf“. Mit ihr wird rekurriert auf eine durch die Verwaltung oder gar bereits den Gesetzgeber gewollte zeitliche Begrenzung der Regelungswirkung eines Verwaltungsakts. Der Verwaltung steht dafür insbesondere das Mittel der Nebenbestimmung (s. dazu Rn. 204 ff.) zur Verfügung. Auf Grundlage einer spezialgesetzlichen Befugnis oder des $§ 36$ VwVfG kann (oder gar muss ${ }^{631}$ ) sie einem Verwaltungsakt eine (einen Wirksamkeitszeitraum oder einen Endzeitpunkt bestimmende) Befristung (§ 36 II Nr. 1 VwVfG) beifügen. Der Gesetzgeber kann diese Entscheidung der Verwaltung durch Festsetzung von Mindest- und Höchstdauern vorprägen. Er kann sie gar durch Bestimmung genauer Wirksamkeitszeiträume vorwegnehmen. ${ }^{632}$ Eine häufig wiederkehrende Ausprägung der gesetzlich angeordneten Erledigung durch Zeitablauf stellt die Fallgruppe des „Erlöschens wegen Untätigkeit“ dar: Machen die Begünstigten eines genehmigenden Verwaltungsakts nicht innerhalb bestimmter Zeiträume von der Genehmigung Gebrauch, erlischt sie ipso iure ${ }^{633}$

Deutlich schwerer fassbar ist die Auffangkonstellation der Erledigung ,auf andere Weise“. ${ }^{634}$ Um nicht die grundlegende Systementscheidung des Gesetzgebers „in dubio pro“ Wirksamkeit in ihr Gegenteil zu verkehren, ist der Begriff tendenziell einschränkend auszulegen. ${ }^{635}$ Wichtig ist insbesondere, dass darunter

629 BVerwG, Urt. v. 25.9.2008, Az.: 7 C 5.08 = NVwZ 2009, 122; Urt. v. 19.4.2011, Az.: 1 C $2.10=$ BVerwGE 139, 337 (341); Urt. v. 22.8.2017, Az.: 1 A 3.17 = BVerwGE 159, 296 (299, Rn. 12).

630 S. dazu Reimer, Die Verwaltung 2015, 259.

631 S. dazu bspw. § 18 II 1 Var. 1 StrWG NRW, wonach die Erlaubnis zur Sondernutzung einer Straße nur auf Zeit (oder auf Widerruf) erteilt werden darf.

632 Ein exzellentes Beispiel für all die verschiedenen Optionen findet sich in § 26 I AufenthG. 633 S. bspw. § 75 I BauO NRW, § 75 IV 1 VwVfG, § 18 I BImSchG oder § 8 S. 1 GastG (dazu BVerwG, Beschl. v. 26.5.1987, Az.: 1 B 28.87 = NVwZ 1987, 1081).

634 S. dazu ausführlich Ruffert, BayVBl 2003, 33.

635 BVerwG, Urt.v. 9.5. 2012, Az.: 6 C 3.11 = BVerwGE 143, 87 (91, Rn. 19); Beschl.v. 6.10.2015, Az.: 3 B 9.15 = NVwZ-RR 2016, 128 (129). So auch Maurer/Waldhoff, Allgemeines Verwaltungsecht, 19. Aufl. 2017, § 10 Rn. 103; Ramsauer, in: Kopp/Ramsauer, VwVfG, 20. Aufl. 2019, § 43 Rn. 41. 
nicht behördliche Entscheidungen subsumiert werden, da es sonst $\mathrm{zu}$ einer Umgehung der Voraussetzungen der $\S \S 48,49$ VwVfG oder entsprechender spezialgesetzlicher Vorschriften käme. ${ }^{636}$ Für eine restriktive Handhabung spricht ebenso die § 51 I Nr. 1 VwVfG zugrundeliegende Wertung, dass eine nachträgliche Änderung der für den Verwaltungsakt maßgeblichen Sach- und Rechtslage grundsätzlich die Möglichkeit des Wiederaufgreifens des Verfahrens nach sich ziehen soll. ${ }^{637}$

Die verschiedenen Möglichkeiten der Erledigung können - sofern dies überhaupt möglich ist - an dieser Stelle nicht abschließend bestimmt werden. Rechtsprechung und Wissenschaft haben verschiedene wiederkehrende Fehlertypen in Fallgruppen zusammengefasst, die zwar Orientierungspunkte bieten, aber aufgrund fehlender Einheitlichkeit hinsichtlich Kategorienbildung und Sprachgebrauch mit einer gebotenen Vorsicht heranzuziehen sind. ${ }^{638}$ In der Prüfungssituation sollte daher der auch vom Bundesverwaltungsgericht fokussierte Grundgedanke des Entfalls der Steuerungsfunktion des Verwaltungsakts (unter besonderer Berücksichtigung des ihm zugrundeliegenden Rechts) Ausgangspunkt einer Prüfung sein. Vor diesem Hintergrund sind folgende Fallgruppen weitgehend akzeptiert:

- In Parallele zur Erledigung durch schlichten Zeitablauf kann die Erledigung auch Resultat des Eintritts ausdrücklich bestimmter Sachumstände sein. Die Verwaltung kann das Erlöschen durch Festsetzung einer auflösenden Bedingung (§ 36 II Nr. 1 VwVfG) zum Verwaltungsakt ermöglichen. ${ }^{639}$ Der Gesetzgeber kann auch gesetzliche Erlöschenstatbestände ${ }^{640}$ normieren. ${ }^{641}$

- Auch ohne deren ausdrückliche Bestimmung kann der Eintritt von Sachumständen zur Erledigung von Verwaltungsakten führen. Dies ist insbesondere

636 BVerwG, Urt. v. 9.5.2012, Az.: 6 C 3.11 = BVerwGE 143, 87 (91, Rn. 19). Kommt es zum Erlass eines Verwaltungsakts, der sich in inhaltlichen Widerspruch $\mathrm{zu}$ einem weiterhin wirksamen Verwaltungsakt setzt, kann darin ggf. eine konkludente Aufhebung gesehen werden, die jedoch sodann die einschlägigen Voraussetzungen erfüllen muss, s. BVerwG, a.a. O. (103ff., Rn. 37 ff.). Die Einzelheiten sind indes umstritten, s. nur Ramsauer, in: Kopp/Ramsauer, VwVfG, 20. Aufl. 2019, § 48 Rn. 29a f.

637 BVerwG, Urt. v. 9.5.2012, Az.: 6 C 3.11 = BVerwGE 143, 87 (94, Rn. 25).

638 S. für beispielshafte Auflistungen nur BVerwG, Urt. v. 9.5. 2012, Az.: 6 C 3.11 = BVerwGE 143, 87 (91ff., Rn. 19ff.); VGH Mannheim, Urt. v. 2.7.2014, Az.: 8 S 1071/13 = NVwZ 2014, 1597 (1598); Ramsauer, in: Kopp/Ramsauer, VwVfG, 20. Aufl. 2019, § 43 Rn. 41 ff.; Sachs, in: Stelkens/Bonk/ Sachs, VwVfG, 9. Aufl. 2018, § 43 Rn. $209 \mathrm{ff}$.

639 Stelkens, in: Stelkens/Bonk/Sachs, VwVfG, 9. Aufl. 2018, § 41 Rn. 207.

640 S. bspw. § 72 AsylG, § 51 I Hs. 1 Nr. 5 bis 8 AufenthG oder § 18 II BImSchG.

641 Ramsauer, in: Kopp/Ramsauer, VwVfG, 20. Aufl. 2019, § 43 Rn. 40d, erachtet diese Konstellation als Unterfall der „Erledigung durch Zeitablauf“. 
dann der Fall, wenn der personelle oder sachliche Bezugspunkt einer (avisierten) Regelung fehlt oder entfällt. Denkbar ist dies beispielsweise im Falle des Todes einer natürlichen oder der Auflösung einer juristischen Person als Berechtigte bzw. Verpflichtete, insbesondere wenn es sich um sog. höchstpersönliche Verwaltungsakte handelt, die an besondere subjektive Voraussetzungen anknüpfen und daher einer Rechtsnachfolge nicht zugänglich sind (s. dazu Rn. 107). ${ }^{642}$ Gleiches gilt, wenn ein Verwaltungsakt konkret auf einen Regelungsgegenstand bezogen gewesen ist, wie beispielsweise im Falle der Baugenehmigung, die mit der Zerstörung eines Gebäudes erlischt. ${ }^{643}$

- Auch darüber hinaus kann es zum Wegfall des Regelungsanlasses kommen. So kann in Ausnahmefällen auch eine nachfolgende behördliche Entscheidung die rechtlichen Voraussetzungen einer Erstentscheidung derart verändern, dass deren Steuerungsfunktion entfällt, so beispielsweise im Falle der Erteilung einer Aufenthaltserlaubnis, die die Ausreisepflicht des Betroffenen (§50 I AufenthG) und somit auch den Regelungsanlass einer Abschiebungsandrohung entfallen lässt, ${ }^{644}$ oder im Falle der Einbürgerung, die den Betroffenen zum deutschen Staatsangehörigen und somit einen Aufenthaltstitel (§4 I 1 AufenthG) überflüssig macht ${ }^{645}$. Eine Änderung der Rechtslage soll zwar - entsprechend der Wertung von § 51 I Nr. 1 VwVfG grundsätzlich nicht zur Erledigung des auf den geänderten Vorschriften beruhenden Verwaltungsakts führen. Etwas anderes soll jedoch dann gelten, wenn die geänderte Rechtslage dazu führt, dass der Verwaltungsakt gegenstandslos wird. Dies kann gesetzlich ausdrücklich bestimmt sein. Zumeist ist es jedoch unter Auslegung von Inhalt und Zweck des Verwaltungsakts, gegebenenfalls im Zusammenhang mit den Vorschriften, auf denen dieser beruht, $\mathrm{zu}$ bestimmen. ${ }^{646} \mathrm{Zu}$ bejahen ist eine Gegenstandslosigkeit jedenfalls dann, wenn eine gesetzliche Genehmigungspflicht vollständig entfällt. ${ }^{647}$

642 So bspw. durch Auslegung der Vorschriften betr. die Bewilligung von Wohngeld BVerwG, Urt. v. 23.1.1990, Az.: 8 C 37.88 = BVerwGE 84, 274 (277); betr. den Aufnahmebescheid für Spätaussiedler, BVerwG, Urt. v. 25.11.2004, Az.: 5 C 47.03 = NVwZ 2005, 818 (819); oder betr. ein an besondere subjektive Voraussetzungen geknüpftes Wegerecht, BVerwG, Urt. v. 29.4.2015, Az.: 6 C 39.13 = NVwZ 2015, 1578 (1579ff., Rn. 14 ff.).

643 OVG Münster, Urt. v. 6.2.2015, Az.: 2 A 1394/13 = BeckRS 2015, 42849.

644 Vgl. zur Erledigung eines Rechtsstreits in der Hauptsache BVerwG, Urt. v. 21.9.1999, Az.: 9 C 12.99 = BVerwGE 109, 305 (313f.)

645 BVerwG, Urt. v. 9.4.2011, Az.: 1 C 2.10 = BVerwGE 139, 337 (341, Rn. 15).

646 BVerwG, Urt. v. 9.5.2012, Az.: 6 C 3.11 = BVerwGE 143, 87 (94, Rn. 25); Ramsauer, in: Kopp/ Ramsauer, VwVfG, 20. Aufl. 2019, § 43 Rn. 42. 
- Denkbar ist auch, dass eine Erledigung auf den Willen der Personen zurückgeht, für die die Regelungswirkung des Verwaltungsakts von Relevanz ist. So kann der Antragssteller vor Unanfechtbarkeit des Verwaltungsakts seinen Antrag zurücknehmen ${ }^{648}$ oder auch später noch auf einen Verwaltungsakt verzichten ${ }^{649}$. Das Bundesverwaltungsgericht hat eine Erledigung auch für den Fall bejaht, dass die an einem Verwaltungsakt Beteiligten durch übereinstimmendes Verhalten dem ursprünglichen Verwaltungsakt keinerlei tatsächliche oder rechtliche Bedeutung mehr beimessen und ihn mithin als erledigt ansehen. ${ }^{650}$ An ein derartiges Verhalten wird man im Einzelfall jedoch hohe Anforderungen stellen müssen. ${ }^{651}$

- Situationen des Gebrauchmachens, der Erfüllung oder der Vollstreckung sind differenziert zu beurteilen. Die Baugenehmigung legalisiert auch nach Abschluss der Bauarbeiten weiterhin das Bauwerk, der Abgabenbescheid bildet auch nach Zahlung des geforderten Betrages deren Rechtsgrund ${ }^{652}$. Vor diesem Hintergrund können auch Konstellationen der Vollstreckung eines Verwaltungsakts nicht anders bewertet werden. Selbst wenn durch einen Vollzug selbst irreversible Tatsachen geschaffen werden, ist vorrangig relevant, ob sich ein Grundverwaltungsakt noch rechtlich auswirkt. ${ }^{653}$ Dies wird beispielsweise mehrheitlich für den Fall bejaht, dass ein Grundverwaltungsakt zugleich die Grundlage für einen Kostenbescheid bildet. ${ }^{654}$

- Die Konsequenzen der sog. ,aufschiebende Wirkung“ gemäß § 80 I VwGO (s. dazu $\S 8$ Rn. 5) für die Wirksamkeit eines Verwaltungsakts sind zwar umstritten, ${ }^{655}$ jedenfalls führt sie nicht zu dessen Erledigung.

647 S. für Beispiele die Nachweise bei Stelkens, in: Stelkens/Bonk/Sachs, VwVfG, 9. Aufl. 2018, $\S 41 \mathrm{Rn} .212 \mathrm{a}$.

648 Ramsauer, in: Kopp/Ramsauer, VwVfG, 20. Aufl. 2019, § 41 Rn. 45.

649 BVerwG, Urt. v. 15.12.1989, Az.: 4 C 36.86 = BVerwGE 84, 209 (211f.); VGH Mannheim, Urt. v. 10.11.1993, Az.: 3 S 1120/92 = NVwZ 1995, 280 (280f.); Maurer/Waldhoff, Allgemeines Verwaltungsrecht, 19. Aufl. 2017, § 10 Rn. 104.

650 BVerwG, Urt. v. 27.3.1998, Az.: 4 C 11.97 = NVwZ 1998, 729 (730).

651 S. zum unmissverständlichen Ausdruck des Verzichtswillens VGH Mannheim, Urt. v. 10.11. 1993, Az.: 3 S 1120/92 = NVwZ 1995, 280 (280 f.); zum konsensualen Verhalten BVerwG, Urt. v. 27.3. 1998, Az.: 4 C 11.97 = NVwZ 1998, 729 (730).

652 BVerwG, Urt. v. 3.6.1983, Az.: 8 C 43.81 = NVwZ 1984, 168.

653 BVerwG, Urt. v. 25.9.2008, Az.: 7 C 5.08 = NVwZ 2009, 122.

654 BVerwG, Urt. v. 25.9.2008, Az.: 7 C 5.08 = NVwZ 2009, 122; kritisch dazu Jäckel, NVwZ 2014, 1625, m.w. N. zu den verschiedenen Positionen.

655 S. dazu auch Detterbeck, Allgemeines Verwaltungsrecht, 17. Aufl. 2019, Rn. 1477 f.; Stelkens, in: Stelkens/Bonk/Sachs, VwVfG, 9. Aufl. 2018, § 43 Rn. 227 ff.

Tobias Brings-Wiesen 


\section{c) Rechtsschutz bei Beendigung der Wirksamkeit}

186 Auch im Falle der Beendigung der Wirksamkeit eines Verwaltungsakts können Betroffene unter bestimmten Umständen ein Rechtsschutzinteresse haben.

187 Hebt eine Behörde den Verwaltungsakt gemäß $\S \S 48$, 49 oder 51 VwVfG (oder entsprechender spezialgesetzlicher Regelungen) auf, handelt es sich bei ihrer Entscheidung um einen neuen Verwaltungsakt, der wiederum im Wege des Widerspruchs gemäß § 68 I 1 VwGO bzw. der Anfechtungsklage gemäß § 42 I Var. 1 VwGO durch das Verwaltungsgericht aufgehoben werden kann.

188 Erledigt sich ein Verwaltungsakt durch Zeitablauf oder auf andere Weise können Betroffene gleichwohl ein fortbestehendes Interesse an der Klärung seiner Rechtswidrigkeit haben, die sie mit Hilfe der (verlängerten) Fortsetzungsfeststellungsklage gemäß $§ 113$ I 4 VwGO (analog) erreichen können (s. dazu ausführlich § 4).

\section{Unwirksamkeit aufgrund von Nichtigkeit, § 43 III VwVfG}

189 Gemäß § 43 III VwVfG ist ein nichtiger Verwaltungsakt unwirksam. Die Vorschrift verweist somit auf die Regelung in \$ 44 VwVfG und spezialgesetzliche Nichtigkeitsvorschriften.

190 Mit § 43 III VwVfG hat der Gesetzgeber in Umsetzung des Grundsatzes der Gesetzmäßigkeit der Verwaltung (als Element des verfassungsrechtlichen Rechtsstaatsprinzip) ${ }^{656}$ die Wertentscheidung getroffen, bestimmte Rechtsfehler als so relevant zu erachten, dass ihr Vorliegen bereits ipso iure die Wirksamkeit eines Verwaltungsakts zerstört. Der Grundsatz der Gesetzmäßigkeit der Verwaltung überwiegt insofern ausnahmsweise den ebenfalls dem Rechtsstaatsprinzip entspringenden Grundsatz der Rechtssicherheit, der der grundsätzlichen Differenzierung von Wirksamkeit und Rechtmäßigkeit von Verwaltungsakten zugrunde liegt.

191 Zur Erinnerung: Nichtige Verwaltungsakte sind von sog. „Nichtakten“ zu unterscheiden. Während im Falle von Nichtakten bereits das Entstehen eines Verwaltungsakts scheitert, folgt aus $\S 43$ III VwVfG (zumeist bereits) in der juristischen Sekunde ihres Entstehens ihre Unwirksamkeit auf Grund von Nichtigkeit. Auch „gegenstands- oder funktionslose Verwaltungsakte“ sind von nichtigen Verwaltungsakten abzugrenzen. ${ }^{657}$ Bei diesen Verwaltungsakten fehlt oder entfällt der sachliche Bezugspunkt der avisierten Regelung und es tritt „Erledigung auf andere Weise“ gemäß § 43 II VwVfG (s. dazu Rn. 185) ein.

656 S. dazu ausführlich Detterbeck, Allgemeines Verwaltungsrecht, 17. Aufl. 2019, Rn. $256 \mathrm{ff}$. 657 Ramsauer, in: Kopp/Ramsauer, VwVfG, 20. Aufl. 2019, § 44, Rn. 2a. 
Ein Verwaltungsakt kann je nach der Natur seines Fehlers von Beginn an 192 nichtig sein oder erst $\mathrm{zu}$ einem späteren Zeitpunkt nichtig werden. ${ }^{658}$ Liegen mehrere Fehler vor, sind diese - selbst im Falle der Nichtigkeit aufgrund eines Fehlers - vollständig nebeneinander zu prüfen. Liegt ein Nichtigkeitsgrund vor, sind sowohl eine Heilung als auch eine Unbeachtlichkeit von Verfahrens- und Formfehlern nicht mehr möglich (vgl. §§ 45 I, 46 VwVfG).

Nach den vorangehenden Ausführungen erscheint die Diskussion um einen

Rechtsschutz gegen nichtige Verwaltungsakte - wie im Falle von Nichtakten (s. dazu Rn. 174ff.) - auf den ersten Blick überflüssig: Soweit die Unwirksamkeit eines Verwaltungsakts auf Grund von Nichtigkeit gemäß § 44 i.V.m. § 43 III VwVfG ipso iure eintritt, entfaltet dieser ohne weiteres Zutun weder für die Betroffenen noch für den Staat rechtliche Wirkung. Ziel der vom Gesetzgeber speziell geschaffenen Rechtsbehelfe der behördlichen Feststellung der Nichtigkeit gemäß $\S 44$ V VwVfG und der Nichtigkeitsfeststellungsklage gemäß § 43 I Var. 3 VwGO (s. zu beiden näher $\S 6 \mathrm{Rn}$. $73 \mathrm{ff}$. und 166ff.) ist sodann auch nicht die durch Widerspruch und Anfechtungsklage begehrte rechtsgestaltende Aufhebung eines Verwaltungsakts i.S.v. § 43 II VwVfG, sondern die Zerstörung des Rechtsscheins seiner Wirksamkeit durch die verbindliche Feststellung der (teilweisen ${ }^{659}$ ) Nichtigkeit. ${ }^{660}$

Gleichwohl sind die Rechtsschutzmöglichkeiten nicht auf diese beiden Optionen beschränkt. Es bieten sich sowohl auf behördlicher als auch auf gerichtlicher Ebene mehrere Wege, einem nichtigen Verwaltungsakt $\mathrm{zu}$ begegnen. Entsprechend vielgestaltig können auch Prüfungskonstellationen sein, in denen die Nichtigkeit eines Verwaltungsakts eine Rolle spielt.

Auf gerichtlicher Ebene kommt der Frage zentrale Bedeutung zu, ob auch die Anfechtungsklage gemäß § 42 I Var. 1 VwGO gegen nichtige Verwaltungsakte statthaft oder aber ein Kläger ausschließlich auf die Nichtigkeitsfeststellungsklage gemäß § 43 I Var. 3 VwGO zu verweisen ist (s. dazu Rn. 197). Hat die Behörde einen Antrag auf Feststellung der Nichtigkeit gemäß § 44 V VwVfG negativ beschieden, kann sich darüber hinaus die Frage stellen, ob dem Betroffenen die Möglichkeit einer Verpflichtungsklage gemäß § 42 I Var. 2 VwGO zur Durchsetzung

658 Ramsauer, in: Kopp/Ramsauer, VwVfG, 20. Aufl. 2019, § 43 Rn. 47; Schenke, DÖV 1990, 489 (496).

659 So wie ein Verwaltungsakt gerichtlich (s. dazu Rn. 259) und behördlich (s. dazu ausführlich Rn. 841) nur teilweise aufhebbar ist, kann sich sowohl die (behördliche wie gerichtliche) Feststellung der Nichtigkeit entsprechend § 44 IV VwVfG auch nur auf einen Teil des Verwaltungsakts beziehen. Diese Möglichkeit wird im Folgenden nicht wiederholt erwähnt, sondern ist mitzudenken.

660 Will/Rathgeber, JuS 2012, 1057 (1062); Schenke, JuS 2016, 97. 
der behördlichen Nichtigkeitsfeststellung nach §44 V VwVfG zustehen soll (s. dazu unter $\S 3$ Rn. $23 \mathrm{ff}$.).

Auf behördlicher Ebene bietet sich neben der behördlichen Feststellung der Nichtigkeit gemäß § 44 V VwVfG der Weg der Aufhebung des Verwaltungsakts qua Abhilfebescheid im Widerspruchsverfahren gemäß §§ 68 I 1, 72 VwGO (s. dazu Rn. 202) sowie die Aufhebung gemäß §§ $48 \mathrm{f}$. VwVfG (s. dazu Rn. 862).

\section{a) Statthaftigkeit der Anfechtungsklage nach § 42 I Var. 1 VwGO bei nichtigen Verwaltungsakten?}

197 Eine heute ganz herrschende Meinung bejaht die Statthaftigkeit der Anfechtungsklage gemäß $\S 42$ I Var. 1 VwGO auch für den Fall, dass sie gegen einen potentiell nichtigen Verwaltungsakt erhoben wird. ${ }^{661}$

198 Dem könnte man bei streng dogmatischer Betrachtung entgegenhalten, dass das mit der Anfechtungsklage begehrte Ziel der Aufhebung eines Verwaltungsakts (§§ 42 I Var. 1, 113 I 1 VwGO; § 43 II VwVfG) im Falle eines bereits auf Grund von Nichtigkeit ipso iure eingetretener Unwirksamkeit (§ 43 III VwVfG) unerreichbar ist. ${ }^{662}$ Die herrschende Meinung legt den prozessrechtlichen Begriff des Verwaltungsakts in $\S 42$ I VwGO jedoch weit aus und fasst im Interesse eines umfassenden Rechtsschutzes auch nichtige Verwaltungsakte darunter. ${ }^{663}$ Dies wird konkret damit begründet, dass die Unterscheidung eines bloß rechtswidrigen und somit aufhebbaren von einem bereits nichtigen Verwaltungsakt schwierig ist und oft erst durch eine gerichtliche Entscheidung beantwortet werden kann. Der Kläger solle aber nicht das Risiko einer unstatthaften Anfechtungsklage tragen. ${ }^{664}$ Bestätigt wird dieses Ergebnis in systematischer Hinsicht: Die in § 43 II 2 VwGO normierte Ausnahme vom Grundsatz der Subsidiarität der Feststellungsklage gegenüber Gestaltungs- und Leistungsklagen setzt deren grundsätzliche Statthaftigkeit denklogisch voraus. ${ }^{665}$ Die Parallelität war vom Gesetzgeber überdies ausdrücklich so beabsichtigt. ${ }^{666}$

661 BVerwG, Urt.v. 20.3.1964, Az.: VII C 10.61 = BVerwGE 18, 154 (155); Maurer/Waldhoff, Allgemeines Verwaltungsrecht, 19. Aufl. 2017, § 10 Rn. 93; Schenke, Verwaltungsprozessrecht, 16. Aufl. 2019, Rn. 183; Sodan, in: Sodan/Ziekow, VwGO, 5. Aufl. 2018, § 42 Rn. 23; § 43 Rn. 68, m.w. N. 662 Hufen, Verwaltungsprozessrecht, 11. Aufl. 2019, § 14 Rn. 11.

663 S. nur BVerwG, Urt. v. 20.3.1964, Az.: VII C 10.61 = BVerwGE 18, 154 (155); Schenke, JuS 2016, 97 (99).

664 S. nur Sodan, in: Sodan/Ziekow, VwGO, 5. Aufl. 2018, § 42 Rn. 23.

665 S. nur Schenke, JuS 2016, 97 (99f.).

666 BT-Drucks. 3/55, S. 32.

Tobias Brings-Wiesen 
Examenswissen: Umstritten ist indes die - davon abzugrenzende - Folgefrage von Inhalt und 199

Tenorierung des Urteils durch das Verwaltungsgericht (§ 113 I VwGO) im Falle der Nichtigkeit eines angefochtenen Verwaltungsakts. Diese ist auch insofern von Interesse, als sie das Prüfprogramm in einer Klausur determinieren kann. Je nach Positionierung kann eine Prüfung der Nichtigkeit durch das Gericht dahinstehen und können Ausführungen entsprechend auf die bloße Rechtswidrigkeit konzentriert erfolgen.

So wird einerseits vertreten, das Gericht habe auch im Rahmen der Anfechtungsklage als ein im Anfechtungsbegehren enthaltenes „Minus“, ${ }^{667}$ nach entsprechender Umdeutung (von Amts wegen) ${ }^{668}$ oder nach Umstellung des Klageantrags (auf Hinweis des Gerichts) ${ }^{669}$ - nur die Nichtigkeit des angegriffenen Verwaltungsakts festzustellen. Dafür spreche das - in § 43 II VwVfG auch eine systematische Bestärkung findende - dogmatische Argument, die Aufhebung eines Verwaltungsakts setze dessen Wirksamkeit voraus. ${ }^{670}$

Demgegenüber vertritt die Gegenmeinung, dass auch ein nichtiger Verwaltungsakt vom Gericht aufzuheben sei. ${ }^{671}$ Dafür spreche in systematisch-dogmatischer Hinsicht bereits der allgemeine Charakter der Anfechtungs- als Gestaltungsklage (vgl. §§ 42 I Var. 1, 113 I 1 VwGO). ${ }^{672}$ Wäre eine Aufhebung nicht möglich, hätte das Gericht gemäß § 86 III VwGO gar strenggenommen auf eine Umstellung des Aufhebungs- in einen Feststellungsantrag hinzuwirken, was jedoch aufgrund der damit einhergehenden zeitlichen Verzögerung aus prozessökonomischen Gründen und insofern teleologisch unbefriedigend wäre. ${ }^{673}$ Darüber hinaus gebiete dies eine am Gleichheitssatz des Art. 3 I GG orientierte verfassungskonforme Auslegung: Ein auf die bloße Feststellung der Nichtigkeit beschränktes Urteil hätte - wie alle Feststellungsurteile - lediglich inter partes-Wirkung und bliebe somit in seiner Rechtsschutzintensität hinter der erga omnes-Wirkung eines Gestaltungsurteils, mit dem es zur Aufhebung eines Verwaltungsakts käme, zurück, obwohl im Interesse der Gesetzmäßigkeit der Verwaltung mit der ipso iure eintretenden Unwirksamkeit eines Verwaltungsakts aufgrund von Nichtigkeit ( $\$ 3$ III VwVfG) gerade besonders schweren Rechtsfehlern begegnet werden solle (s. dazu Rn. 190). ${ }^{674}$

667 VGH München, Urt. v. 15.9.1983, Az.: 23 B 80 A.861 = NJW 1984, 626; Maurer/Waldhoff, Allgemeines Verwaltungsrecht, 19. Aufl. 2017, § 10 Rn. 93; auch Möstl, in: Posser/Wolff, VwGO, 50. Ed., Stand: 1.4.2019, § 43 Rn. 38, und Pietzcker, in: Schoch/Schneider/Bier, VwGO, 36. EL Februar 2019, § 42 I Rn. 18; § 43 Rn. 27.

668 Vgl. BSG, Urt. v. 21.6.1960, Az.: 3 RK 72/55 = NJW 1960, 2308 (2309).

669 Schmitt Glaeser/Horn, Verwaltungsprozessrecht, 15. Aufl. 2000, Rn. 139; Sodan, in: Sodan/ Ziekow, VwGO, 5. Aufl. 2018, § 42 Rn. 23, § 43 Rn. 68; letztlich auch Hufen, Verwaltungsprozessrecht, 11. Aufl. 2019, § 14 Rn. 11, § 29 Rn. 11.

670 Hufen, Verwaltungsprozessrecht, 11. Aufl. 2019, § 14 Rn. 11. Dies wird indes zu Recht mit dem grundsätzlichen Einwand gekontert, dass es dem Gesetzgeber konstruktiv freistehe, neben der in $\S 43$ III VwVfG formulierten Rechtsfolge der Unwirksamkeit weitere Rechtsfolgen zu normieren, Ipsen, Allgemeines Verwaltungsrecht, 11. Aufl. 2019, Rn. 696; Schenke, JuS 2016, 97 (101).

671 Schenke, Verwaltungsprozessrecht, 16. Aufl. 2019, Rn. 183; Schmidt-Kötters, in: Posser/Wolff, VwGO, 50. Ed., Stand: 1.7.2017, § 42 Rn. 21, jeweils m.w. N.

672 Schenke, JuS 2016, 97 (100). Unergiebig hinsichtlich des gesetzgeberischen Willens sind demgegenüber - entgegen der Auffassung von Schenke, a.a.O. (100, Fn. 25) - die Gesetzesmaterialien, vgl. BT-Drucks. 3/55, S. 32.

673 Schenke, JuS 2016, 97 (100).

674 Schenke, JuS 2016, 97 (100).

Tobias Brings-Wiesen 
200 Akzeptiert man die Statthaftigkeit der Anfechtungsklage, müssen im Folgenden uneingeschränkt deren Sachentscheidungsvoraussetzungen erfüllt sein. Dies bedeutet insbesondere, dass ein potentiell erforderliches Widerspruchs- bzw. Vorverfahren ( $\S 68 \mathrm{ff}$. VwGO) erfolglos durchgeführt und die Klagefristen ( 74 VwGO) eingehalten ${ }^{675}$ worden sein müssen.

201 Entsprechend umstritten ist auch die Frage einer Anwendbarkeit der Vorschriften über den vorläufigen Rechtsschutz gegenüber Verwaltungsakten ( $\S 80$ ff. VwGO, s. dazu ausführlich die $\S \S 8$ und 9). Insofern bestehen in argumentativer Hinsicht weitgehende Parallelen zum Streit um die Statthaftigkeit der Anfechtungsklage. Gegen eine Anwendung auf nichtige Verwaltungsakte ${ }^{676}$ wird vorgebracht, dass diese gemäß § 43 III VwVfG keine Wirkung entfalteten und sich daher die Frage der aufschiebenden Wirkung nicht stelle. Der vorläufige Rechtsschutz richte sich vielmehr nach $\S 123$ I VwGO. ${ }^{677}$ Die Gegenmeinung ${ }^{678}$ wendet demgegenüber jedoch ein, dass auch vom nichtigen Verwaltungsakt der Rechtsschein einer hoheitlichen Regelung ausgehe und insbesondere in den schwierigen Fällen der Differenzierung von bloßer Rechtswidrigkeit und Nichtigkeit die Schutzfunktion der ,aufschiebenden Wirkung“ als Interimslösung auch bei einem nichtigen Verwaltungsakt ausgelöst werde. ${ }^{679}$

\section{b) Erhebung eines Widerspruchs gegen den nichtigen Verwaltungsakt gemäß $\S \S 68 \mathrm{ff}$. VwGO}

202 Sofern die Statthaftigkeit der Anfechtungsklage gemäß § 42 I Var. 1 VwGO gegen einen nichtigen Verwaltungsakt bejaht wird, ist konsequenterweise auch die Erhebung eines - soweit gesetzlich vorgesehenen ${ }^{680}$ - Widerspruchs gemäß § 68 I 1 VwGO gegen einen nichtigen Verwaltungsakt zu akzeptieren. Wie hinsichtlich des

675 Hält man die behördliche Rücknahme eines nichtigen Verwaltungsakts gemäß § 48 VwVfG für zulässig, besteht im Falle der Verfristung auch die Möglichkeit einer darauf gerichteten Verpflichtungsklage, Schenke, JuS 2016, 97 (100).

676 Gegen eine Anwendung OVG Münster, Beschl.v. 27.2.1992, Az.: 7 B 2686/92 = NVwZ-RR 1993, 234; Puttler, in: Sodan/Ziekow, VwGO, 5. Aufl. 2018, § 80 Rn. 20; Gersdorf, in: Posser/Wolff, VwGO, 50. Ed., Stand: 1.7.2018, § 80 Rn. 8.

677 OVG Münster, Beschl. v. 27.2.1992, Az.: 7 B 2686/92 = NVwZ-RR 1993, 234.

678 W.-R. Schenke, in: Kopp/Schenke, 25. Aufl. 2019, § 80 Rn. 5, 16; Schoch, in: Schoch/ Schneider/Bier, VwGO, 36. EL Februar 2019, § 80 Rn. 37; Bostedt, in: Fehling/Kastner/Störmer, Verwaltungsrecht, 4. Aufl. 2016, §80 VwGO Rn. 18; Funke-Kaiser, in: Bader/Funke-Kaiser/ Stuhlfauth/von Albedyll, VwGO, 7. Aufl. 2018, § 80 Rn. 8; tendenziell auch VGH Mannheim, Beschl. v. 7.12.1990, Az.: 10 S 2466/90 = NVwZ 1991, 1195 (1195f.).

679 So insbesondere Schoch, in: Schoch/Schneider/Bier, VwGO, 36. EL Februar 2019, § 80 Rn. 37. $680 \mathrm{Zu}$ den in § $68 \mathrm{I} 2 \mathrm{VwGO}$ vorgesehenen Abweichungsbefugnissen ausführlich Rn. $308 \mathrm{ff}$.

Tobias Brings-Wiesen 
Urteils des Verwaltungsgerichts (s. dazu Rn. 199) ist jedoch auch im Hinblick auf den Abhilfebescheid der Widerspruchsbehörde ( $\$ 72$ VwGO) umstritten, ob diese auf die bloße Feststellung der Nichtigkeit beschränkt ist ${ }^{681}$ oder den angegriffenen nichtigen Verwaltungsakt aufhebt ${ }^{682}$.

\section{Literaturhinweise}

Lehrbeiträge: Beaucamp, Rechtsfragen der Bekanntgabe nach §41 VwVfG, JA 203 2016, 436; Blunk/Schröder, Rechtsschutz gegen Scheinverwaltungsakte, JuS 2005, 602; Erichsen/Hörster, Die Bekanntgabe von Verwaltungsakten, JURA 1997, 659; Ernst/Pinkl, Genehmigungsfiktion und Fiktionsbescheinigung nach § 42a VwVfG, JURA 2013, 685; Herrmann, Aus dem Leben eines Verwaltungsaktes, ZJS 2011, 25; Korte, in: Wolff/Bachof/Stober/Kluth, Verwaltungsrecht I, 13. Aufl. 2017, § 48, passim; Kümper, Das Verkehrszeichen als Quelle klassischer Probleme des Verwaltungs- und Verwaltungsprozessrechts, JuS 2017, 731 und 833; Milker, Die Bekanntgabe von Verkehrszeichen, JURA 2017, 271; Reimer, Die Erledigung des Verwaltungsakts, Die Verwaltung 2015, 259; Schoch, Die Bekanntgabe des Verwaltungsakts, JURA 2011, 23; Weber, Die Bedeutung der Bekanntgabe des schriftlichen Verwaltungsaktes, VR 2016, 299; Wolff, in: Wolff/Decker, VwGO/ VwVfG, 3. Aufl. 2012, § 43 VwVfG

Fallbearbeitungen: Grupp/Stelkens, Abgeschleppt und abgezockt?, abrufbar unter http://www.saarheim.de/Faelle/abgeschleppt-fall.htm (Bearbeitungsstand: 2.10.2018); Hong, Altes und Neues zum Abschleppen und zur Bekanntgabe und Anfechtung von Verkehrszeichen, JURA 2012, 473

\section{Die Anfechtung von Nebenbestimmungen (Christian Kaerkes)}

Verwaltungsakte (§35 VwVfG) erlauben der Behörde, bestimmte Rechtsfolgen 204 gegenüber dem Bürger herbeizuführen. Die Behörde kann im Rahmen der Gesetze eine Vielzahl von Handlungen mittels Verwaltungsakts (s. zum Verwaltungsakt Rn. $38 \mathrm{ff}$.) erlauben oder verbieten.

Beispiele: Erlaubnis zur Errichtung eines Gebäudes (Baugenehmigung); Aufstellen von Verkehrszeichen (z.B. Parkverbot); Genehmigung des Verkaufs von alkoholischen Getränken

681 So Hufen, Verwaltungsprozessrecht, 11. Aufl. 2019, § 9 Rn. 9; Schmitt Glaeser/Horn, Verwaltungsprozessrecht, 15. Aufl. 2000, Rn. 218; Geis, in: Sodan/Ziekow, VwGO, 5. Aufl. 2018, § 73 Rn. 36 (Fn. 90).

682 So Schenke, Verwaltungsprozessrecht, 16. Aufl. 2019, Rn. 686; Schenke, JuS 2016, 97 (101). 
(„Schanklizenz“); Einwilligung zur Platzierung von Tischen und Stühlen auf dem Gehweg vor einem Restaurant (Sondernutzungserlaubnis)

205 Diese Verwaltungsakte sind für sich genommen aber reichlich unflexibel. Die Behörde kann die Baugenehmigung erteilen oder nicht. Der Verkauf von alkoholischen Getränken kann nur erlaubt oder abgelehnt werden. Es ist aber einsichtig, dass zumindest im realen Leben eine gewisse Flexibilität notwendig ist. Wenn nur Nebensächlichkeiten an dem Bauvorhaben des Bürgers problematisch sind, dann sollte nicht deswegen die Baugenehmigung abgelehnt werden. Das Gesetz kennt aus diesem Grund die sogenannten Nebenbestimmungen. ${ }^{683}$

206 Nebenbestimmungen sind nach gängiger Definition „einem Verwaltungsakt beigefügte Regelungen, die dessen Inhalt einschränken oder ergänzen“ “. ${ }^{684}$ Das Gesetz enthält und definiert bestimmte Nebenbestimmungen in § $36 \mathrm{II} \mathrm{VwVfG} \mathrm{(und}$ den inhaltsgleichen Länderregelungen ${ }^{685}$ ):

- Befristung,

- Bedingung,

- Widerrufsvorbehalt,

- Auflage und

- Auflagenvorbehalt.

207 Nebenbestimmungen sind Zusätze, die zu einem sogenannten „Hauptverwaltungsakt“" hinzugefügt werden können. Ein kleineres Problem an dem Bauantrag eines Bürgers (z. B. eine fehlende Feuertreppe) muss der Baugenehmigung (als Hauptverwaltungsakt) dann nicht mehr entgegenstehen. Stattdessen ist es der Behörde möglich, die Genehmigung mit dem Zusatz (einer Nebenbestimmung) zu erteilen, noch eine Feuertreppe zu errichten. Nebenbestimmungen ermöglichen Flexibilität. Die Behörde muss nicht mehr „Nein!“ zu dem Antrag des Bürgers sagen, sondern kann mit „Ja, aber!“ antworten. Das liegt regelmäßig auch im Interesse des Antragsstellers:

„Einen begünstigenden Verwaltungsakt unter Beifügung einer Nebenbestimmung zu erteilen, ist vielfach das mildere Mittel gegenüber einer sonst erforderli-

683 Vgl. Brenner, JuS 1996, 281.

684 Statt vieler Axer, Jura 2001, 748.

685 § 36 II LVwVfG BW; Art. 36 II BayVwVfG; § 1 I BlnVwVfG i.V. m. § 36 II VwVfG; § 1 II VwVfGBbg i.V.m. § 36 I VwVfG; § 36 II BremVwVfG; § 36 II HmbVwVfG; § 36 II HVwVfG; § 36 II VwVfG M-V; § 1 I NVwVfG i.V.m. § 36 II VwVfG; § 36 II VwVfG NRW; § 1 I LVwVfG RLP i.V.m. § 36 II VwVfG; § 36 II SVwVfG; § 1 SächsVwVfZG i.V.m. § 36 II VwVfG; § 1 I VwVfG LSA i.V.m. § 36 II VwVfG; § 107 II LVwG SH; § 36 II ThürVwVfG.

\section{Christian Kaerkes}


chen Ablehnung. “686 Die Formulierung des Bundesverwaltungsgerichts bringt klar zum Ausdruck, dass der Bürger ein Interesse an dem Erlass von Nebenbestimmungen hat: Lieber eine Genehmigung mit Nebenbestimmungen, als überhaupt keine Genehmigung. Das gilt natürlich nicht nur für die Baugenehmigung (dem Beispiel, das besonders relevant ist), sondern für alle begünstigenden Verwaltungsakte, die dem Bürger einen Vorteil bieten.

Allerdings stellen Nebenbestimmungen zugleich eine Belastung dar, weil 208 sie den Hauptverwaltungsakt einschränken. Möchte ein Gastwirt dauerhaft Sitzplätze vor seiner Gaststätte anbieten, dann ist die Einschränkung dieser Genehmigung auf einen Monat für ihn ein Problem und unerwünscht. In diesen Fällen muss für den Bürger die Möglichkeit bestehen, sich gegen die Einschränkung seiner Genehmigung zur Wehr zu setzen. Der Rechtsschutz gegen Nebenbestimmungen ist nicht nur der Klausurklassiker, sondern auch in Literatur und Rechtsprechung seit langem umstritten (s. dazu Rn. $249 \mathrm{ff}$.).

\section{Die Nebenbestimmungen im Einzelnen}

Im Folgenden werden die verschiedenen Nebenbestimmungen genauer darge- 209 stellt. Es ist wichtig, dass Nebenbestimmungen im Gutachten erkannt und richtig eingeordnet werden, weil sich die Wirkungen der einzelnen Nebenbestimmungen zum Teil wesentlich voneinander unterscheiden.

\section{a) Befristung}

Die Befristung ist die wohl „einfachste“ Nebenbestimmung, die der Behörde zur 210 Verfügung steht. Gem. § 36 II Nr. 1 VwVfG ist die Befristung eine „Bestimmung, nach der eine Vergünstigung oder Belastung zu einem bestimmten Zeitpunkt beginnt, endet oder für einen bestimmten Zeitraum gilt““ ${ }^{687}$ Der Verwaltungsakt wird demnach in seiner Geltung zeitlich begrenzt, nicht aber inhaltlich verändert.

Beispiele: Gewährung der Sondernutzungserlaubnis bis zum Ende des Jahres; Erteilung der Baugenehmigung ab Beginn des neuen Monats; Parkverbot an einer Straße für die Dauer einer Baustelle

Das Kennzeichen der Befristung ist, dass der Eintritt des angegebenen Zeitpunktes 211 sicher ist. Wenn der Zeitpunkt durch ein Datum festgelegt wird, ist das offen-

686 BVerwG, Urt. v. 9.12.2015, Az.: 6 C 37.14 = BVerwGE 153, 301 = JuS 2016, 959 (m. Anm. Waldhoff) = JA 2016, 799 (m. Anm. Hebeler).

687 Vgl. Wagner, JA 2008, 866. 
sichtlich der Fall. Ausreichend ist aber auch, dass das Datum nur bestimmbar ist. ${ }^{688}$ Die Erlaubnis, die Parkplätze einer Schule nur während der Ferien nutzen zu dürfen, wäre folglich eine zulässige Befristung des Hauptverwaltungsakts. Schließlich kann die Dauer der Ferien kalendermäßig bestimmt werden.

Beispiele: ${ }^{689}$ Erlaubnis zum Aufstellen von Stühlen auf dem Gehweg für die Monate Mai bis Oktober; Erster Prüfungstermin des Jahres; Aufstellung des Imbissstandes nach Ende des Handwerkermarktes

In allen diesen Fällen steht mit Sicherheit fest, dass das „Ereignis“ eintritt. Der Handwerkermarkt wird enden und irgendwann die erste Prüfung stattfinden. In diesen Fällen kann sogar das Datum genauer bestimmt werden. Das ist aber nicht zwingend erforderlich, wenn der Eintritt des Ereignisses zumindest sicher ist.

Beispiel: Monatliche Auszahlung einer Geldsumme bis zum Tod des Leistungsempfängers

Hier ist der Hauptverwaltungsakt auch wirksam befristet, obwohl noch nicht bekannt ist, wann genau der Empfänger der Leistung verstirbt. Der Tod wird aber mit Sicherheit eintreten, weshalb es sich um eine zulässige Befristung handelt. ${ }^{690}$

\section{b) Bedingung}

212 Die Bedingung ist eine „Bestimmung, nach der der Eintritt oder Wegfall einer Vergünstigung oder einer Belastung von dem ungewissen Eintritt eines zukünftigen Ereignisses abhängt“, vgl. § 36 II Nr. 2 VwVfG. Die Bedingung unterscheidet sich von der Befristung dadurch, dass der Eintritt des Ereignisses noch im Ungewissen liegt.

Beispiele: Genehmigung zum Betrieb einer Anlage, wenn vorher die Luftfilter erneuert werden; Aufenthaltsgenehmigung für den Fall einer beruflichen Anstellung; Erteilung einer Baugenehmigung, wobei weitere Stellplätze zu schaffen sind

Diese Ereignisse sind noch ungewiss und können deshalb als Bedingung qualifiziert werden. Die Filter können erneuert werden, müssen es aber nicht. Der Arbeitgeber kann die berufliche Anstellung durch eine Kündigung beenden, ist dazu aber nicht gezwungen. Es ist möglich, zusätzliche Stellplätze zu schaffen,

688 Brenner, JuS 1996, 281 (283).

689 Voßkuhle/Kaiser, JuS 2012, 699 (700); Brenner, JuS 1996, 281 (283); Axer, Jura 2001, 748. 690 Erichsen, Jura, 1990, 214 (215). 
aber keine Pflicht. Diese Zusätze können daher als Bedingung verstanden werden (s. zur Abgrenzung von der Auflage Rn. 222ff.).

Weiterhin unterscheidet man drei verschiedene Arten von Bedingungen: ${ }^{691}$

- Aufschiebende Bedingung,

- Auflösende Bedingung und

- Potestativbedingung.

Eine aufschiebende Bedingung liegt dann vor, wenn die Wirksamkeit des 214 Hauptverwaltungsaktes von dem Eintritt des ungewissen Ereignisses abhängig sein soll. Erst mit Eintritt des Ereignisses kann von der Genehmigung Gebrauch gemacht werden. Vorher sind die Wirkungen des Hauptverwaltungsaktes in die Zukunft verschoben.

Beispiel: In dem Beispiel in Rn. 212 darf das Gebäude errichtet werden, sobald die Stellplätze geschaffen worden sind, aber nicht davor.

Um eine auflösende Bedingung handelt es sich hingegen, wenn die rechtlichen Wirkungen des Hauptverwaltungsaktes mit dem Eintritt des ungewissen Ereignisses ihr Ende finden sollen. Dann würde sich die Genehmigung gewissermaßen „,in Luft auflösen“ und der Begünstigte kann von dieser Erlaubnis keinen Gebrauch mehr machen.

Beispiel: Erfolgt in dem anderen Beispiel in Rn. 212 die Kündigung des Arbeitnehmers, erlischt die Aufenthaltsgenehmigung.

Die Potestativbedingung zeichnet sich dadurch aus, dass der Eintritt des un- 216 gewissen Ereignisses vom Willen (meist des Begünstigten) abhängt. Weil Menschen handeln können, aber nicht müssen, ist das Ereignis als ungewiss anzusehen. Potestativbedingungen werden deshalb verwendet, weil sie einen Anreiz zu dem in der Bedingung vorgegebenen Verhalten schaffen.

Beispiel: Möchte der Bauherr (in dem Beispiel in Rn. 212) etwa sein Gebäude errichten, dann wird er auch dazu bereit sein, weitere Stellplätze zu schaffen.

Examenswissen: Zum Thema Bedingungen ist unlängst eine Entscheidung des Bundesverwal- 217 tungsgerichts ergangen. ${ }^{692}$ Das Urteil hat zwei Punkte deutlich gemacht:

Ereignisse müssen äußerlich wahrnehmbar sein: Das Gericht hat sich dabei zunächst von

691 Vgl. Detterbeck, Allgemeines Verwaltungsrecht, 17. Aufl. 2019, § 10 Rn. 647 ff. 692 BVerwG, Urt. v. 16.6.2015, Az.: 10 C 15.14 = BVerwGE 152, 211 = ZJS 2015, 532 (m. Anm. Wißmann) $=$ JuS 2016, 187 (m. Anm. Waldhoff). 
dem Prinzip der Rechtssicherheit leiten lassen. Es dürfe nicht sein, dass das Ereignis nur in der „Gedankenwelt“ vorkomme. Die Behörde könne den Hauptverwaltungsakt nicht unter den Vorbehalt einer nur internen Neubewertung stellen. Da mit dem Eintritt des Ereignisses Rechtswirkungen verbunden sind, ist es notwendig, dass das Ereignis durch alle Beteiligten wahrgenommen werden können muss.

„Überprüfungsvorbehalte“ sind keine Bedingungen: Überprüfungsvorbehalte würden es der Behörde erlauben, den Hauptverwaltungsakt einfach zu beseitigen. Durch einen solchen Vorbehalt drohten die Regelungen über den Widerruf und die Rücknahme unterlaufen zu werden. $\S \S 48,49$ VwVfG erfordern immerhin die Einhaltung von Fristen und die Berücksichtigung des schutzwürdigen Vertrauens des Bürgers. An diese Voraussetzungen sollte die Behörde weiterhin gebunden sein.

\section{c) Auflage, Abgrenzung und „modifizierende Auflage“}

218 Eine bedeutsame Nebenbestimmung ist die Auflage. Diese Nebenbestimmung wird immer wieder in Klausuren relevant und muss daher unbedingt beherrscht werden. Schwierigkeiten bereitet dabei vor allem die Abgrenzung zur Bedingung und zur „modifizierenden Auflage“.

\section{aa) Auflage}

219 Die Auflage ist gem. §36 II Nr. 4 VwVfG eine „Bestimmung, durch die dem Begünstigten ein Tun, Dulden oder Unterlassen vorgeschrieben wird“. Kennzeichen der Auflage ist, dass durch sie eine zusätzliche Verpflichtung geschaffen wird, die neben den Hauptverwaltungsakt tritt.

Beispiele: Genehmigung für eine Gaststätte mit der Maßgabe, Maßnahmen zum Lärmschutz zu ergreifen; Fahrerlaubnis mit dem Zusatz, regelmäßig die Abstinenz von Drogen/Alkohol nachzuweisen; Erlaubnis zum Fällen von Bäumen, sofern an anderer Stelle neue Bäume gepflanzt werden

Der Antragssteller erhält in allen diesen Fällen seine Genehmigung, wenn auch mit einer weiteren Verpflichtung. Diese Verpflichtung ist aber akzessorisch, das bedeutet, dass die Verpflichtung vom Hauptverwaltungsakt abhängig ist. ${ }^{693}$ Die Maßnahmen zum Lärmschutz müssen nur dann ergriffen werden, wenn die Genehmigung wirksam ist und genutzt wird. Ohne den Hauptverwaltungsakt hat die Auflage folglich keinerlei Bedeutung.

Beispiele: Wird die Fahrerlaubnis aufgehoben, dann entfällt gleichzeitig auch die Verpflichtung der Auflage, regelmäßig an Drogen- und Alkoholtests teilzunehmen; Beschließt der Begüns-

693 Brenner, JuS 1996, 281 (284). 
tigte, die Bäume doch nicht zu fällen, dann entfaltet die Auflage keine Wirkung und er muss folglich keine neuen Bäume pflanzen.

Die Auflage ist aber in gewisser Weise doch selbstständig und unterscheidet sich 220 damit insbesondere von der Bedingung. ${ }^{694}$ Was geschieht, wenn die Verpflichtung nicht erfüllt wird? Im Fall einer auflösenden Bedingung erlischt die bisherige Genehmigung. Würde es sich hingegen um eine Auflage handeln, dann bliebe die Genehmigung bestehen, die Verpflichtung könnte aber durch die Behörde erzwungen werden.

Beispiel: Werden keine Maßnahmen zum Lärmschutz ergriffen, dann wird die Genehmigung entweder unwirksam (Bedingung) oder die Genehmigung bleibt wirksam, wobei der Lärmschutz durch die Behörde erzwungen werden kann (Auflage).

Es macht daher für den Bürger einen großen Unterschied, ob es sich um eine Auflage oder Bedingung handelt. Diesen Unterschied hat von Savigny mit seiner bekannten Formulierung „Die Bedingung suspendiert, zwingt aber nicht; der Modus [die Auflage] zwingt, suspendiert aber nicht." auf den Punkt gebracht. ${ }^{695}$ In dem einen Fall handelt der Bürger ohne Genehmigung, in dem anderen Fall mit einer Genehmigung, wobei die Auflage durch die Behörde erzwungen werden kann.

Die Auflage kann Gebote oder Verbote enthalten, die nach allgemeinen Re- 221 geln durchsetzbar sind. Die Behörde kann von den Mitteln der Verwaltungsvollstreckung Gebrauch machen und die Einhaltung der Auflage erzwingen (s. zur Verwaltungsvollstreckung Rn. 1292ff.). Grundsätzlich kommen etwa das Zwangsgeld oder die Ersatzvornahme in Betracht. Erweist sich die Verwaltungsvollstreckung einmal nicht als ausreichend, kann die Behörde auch die Genehmigung gem. § 49 II Nr. 2 VwVfG widerrufen und damit den Hauptverwaltungsakt beseitigen.

Beispiel: Sind die Bäume gefällt worden, ohne dass vorher neue Bäume gepflanzt worden sind, kann die Behörde ein Zwangsgeld festsetzen, damit die Auflage doch noch erfüllt wird.

\section{bb) Abgrenzung von Bedingung und Auflage}

Bedingung und Auflage unterscheiden sich in ihren rechtlichen Wirkungen. Die 222 Auflage kann nur durch die Behörde durchgesetzt werden, wohingegen die Bedingung ihre Wirkung automatisch entfaltet und nicht auf das Tätigwerden der

694 Maurer/Waldhoff, Allgemeines Verwaltungsrecht, 19. Aufl. 2017, § 12 Rn. $10 \mathrm{ff}$. 695 V. Savigny, System des heutigen römischen Rechts, Band III, 1840, S. 231.

Christian Kaerkes 
Behörde angewiesen ist. Weil sich Auflage und Bedingung überschneiden können, ist eine Abgrenzung unumgänglich.

Beispiel: Dürfen die Bäume erst gefällt werden, wenn an anderer Stelle neue Bäume gepflanzt wurden (aufschiebende Bedingung), oder schon zuvor, aber mit der späteren Möglichkeit der zwangsweisen Durchsetzung (Auflage)?

223 Es sind grundsätzlich folgende Abgrenzungskriterien anerkannt: ${ }^{696}$

- Wortlaut der Nebenbestimmung,

- Wichtigkeit des Gebots oder Verbots,

- Rechtmäßigkeit des Zusatzes und

- Im Zweifel: Auflage.

224 Zunächst ist von der Formulierung der Nebenbestimmung auszugehen. Spricht diese ausdrücklich von einer Auflage oder Bedingung, ist anzunehmen, dass die Behörde die Nebenbestimmung mit Bedacht gewählt hat. Allerdings kommt dem Wortlaut wohl nur eine Indizwirkung zu. Es ist nicht ausgeschlossen, dass sich die Behörde geirrt oder schlicht nur allgemein von „Nebenbestimmungen“ gesprochen hat. ${ }^{697}$

225 Wichtiger ist daher die Bedeutung der Erfüllung des Gebots oder Verbots (für die Behörde). Es muss danach gefragt werden, ob die Genehmigung mit der Nebenbestimmung „stehen oder fallen“ soll. ${ }^{698}$ Je bedeutsamer die Erfüllung des Gebots oder Verbots ist, desto eher handelt es sich um eine Bedingung und nicht um eine Auflage. Bei der Auflage ist deshalb Vorsicht geboten, weil der Begünstigte von der Genehmigung Gebrauch machen kann.

Beispiel: Baugenehmigung mit dem Zusatz der Behörde, noch ein Gutachten über die Standsicherheit des geplanten Gebäudes vorzulegen

Hier wäre von einer aufschiebenden Bedingung auszugehen. Da das Gutachten dazu dient, Gefahren für Menschen auszuschließen, wäre es verfehlt, wenn mit dem Bau begonnen werden dürfte, obwohl das Gutachten noch nicht vorliegt. Die Genehmigung soll deshalb mit der Verpflichtung „stehen oder fallen“. Das erreicht aber nur die (aufschiebende) Bedingung, weil die Auflage die Wirksamkeit des Hauptverwaltungsaktes unberührt lässt.

696 Voßkuhle/Kaiser, JuS 2012, 699 (701).

697 Brenner, JuS 1996, 281 (282).

698 Wagner, JA 2008, 866 (867).

Christian Kaerkes 
Ein weiteres Kriterium ist schließlich die Zulässigkeit der Nebenbestimmung. 226 Ist zum Beispiel nur die Auflage, nicht aber die Bedingung rechtmäßig, dann spricht dies für eine Auflage. Da die Behörde an das Gesetz gebunden ist, kann davon ausgegangen werden, dass die Behörde auch rechtmäßig handeln wollte.

Verbleiben am Ende noch Zweifel, ob es sich um eine Bedingung oder Auf- 227 lage handelt, ist von einer Auflage auszugehen. Die Auflage ist im Verhältnis zur Bedingung das mildere Mittel, immerhin kann von der Genehmigung schon Gebrauch gemacht werden. ${ }^{69}$ Im Zweifel kann deshalb von einer Auflage ausgegangen werden, weil die durch die Behörde verursachten Unklarheiten nicht zu Lasten des Bürgers gehen sollten.

\section{cc) „Modifizierende Auflage“ und Inhaltsbestimmung}

Die sogenannte modifizierende Auflage ist keine Nebenbestimmung, insbeson- 228 dere keine Auflage im Sinne des § 36 II Nr. 4 VwVfG. Der Begriff „modifizierende Auflage“ ist von Weyreuther geprägt worden ${ }^{700}$ und beschreibt vor allem „eine qualitative Änderung der Gewährung in bezug auf den Antragsgegenstand“. ${ }^{701}$ Diese komplizierte Formulierung beschreibt eine Situation, in der die erteilte Genehmigung von dem Antrag des Bürgers inhaltlich abweicht (,Inhaltsbestimmung“).

Beispiele: Baugenehmigung mit einem Flachdach, anstatt des beantragten Giebeldachs; Baugenehmigung für ein einstöckiges, aber kein mehrstöckiges Gebäude; Sondernutzungserlaubnis für ein religiöses Straßenfest an einem anderen Tag

In diesen Fällen erhält der Bürger zwar eine Genehmigung, allerdings mit einem Inhalt, der in dieser Form nicht von ihm beantragt wurde. De facto ist der ursprüngliche Antrag erst abgelehnt und dann ein veränderter Verwaltungsakt erlassen worden. Ein eingeschossiges Gebäude ist inhaltlich etwas anderes als ein mehrgeschossiges Gebäude. Ein Flachdach kann nicht mit einem Giebeldach verglichen werden. Im Zivilrecht könnte die „modifizierende Auflage“ als ein „Aliud“ verstanden werden. ${ }^{702}$

In der Vergangenheit sind diese inhaltlichen Veränderungen als Auflage be- 229 zeichnet worden. Diese falsche Bezeichnung ändert aber auch nichts daran,

699 Brenner, JuS 1996, 281 (285).

700 Weyreuther, DVBl. 1969, 295 und deutlicher in DVBl. 1984, 365.

701 BVerwG, Urt. v. 8.2.1974, Az.: IV C 73.72 = BVerwG, DÖV 1974, 380 (381).

702 Axer, Jura 2001, 748 (750). 
dass es sich in Wirklichkeit nicht um eine Nebenbestimmung handelt. ${ }^{703}$ Der Bürger erhält keine Baugenehmigung für ein mehrstöckiges Haus mit der Auflage, nur einen Stock zu bauen, sondern die Genehmigung ist von vornherein beschränkt und nur in diesem Umfang erlassen worden.

Das hat erhebliche Bedeutung für den Begünstigten: Errichtet er dennoch ein mehrgeschossiges Gebäude, dann handelt er ohne die erforderliche Genehmigung und sein Bau ist rechtswidrig. Möchte er das Haus in seiner gewünschten Art und Weise errichten, muss zwingend Rechtsschutz vor den Gerichten begehrt werden (Verpflichtungsklage auf Erlass der erweiterten Baugenehmigung).

Die Abgrenzung der „modifizierenden Auflage“ bzw. der Inhaltsbestimmung von einer regulären Auflage ist im Einzelfall schwierig. Es muss sich um eine wesentliche, inhaltliche Abweichung vom Antrag handeln. Dabei kann u.a. auf die folgenden Kriterien abgestellt werden:

- Durchsetzbarkeit der vermeintlichen Auflage,

- Umfang der Abweichung vom Antrag und

- Bedeutung des Elements für das Vorhaben.

231 Grundsätzlich gilt: Desto mehr die Gewährung von dem Antrag abweicht, desto eher handelt es sich um eine Inhaltsbestimmung. Vorhaben werden nämlich durch bestimmte konstitutive Merkmale bestimmt. ${ }^{704}$ Ein Haus ohne Dach ist nicht mehr sinnvoll als Haus zu bezeichnen. Verändert die Behörde das beantragte Dach, spricht dies für eine Inhaltsbestimmung und gegen eine echte Auflage.

232 Schließlich kann auch danach gefragt werden, ob die vermeintliche Auflage zumindest selbstständig durchsetzbar wäre. ${ }^{705}$ Würde das Gebäude mit einem Giebeldach erbaut, wie sollte die Behörde sinnvoll ein Flachdach im Wege der Verwaltungsvollstreckung durchsetzen? Es ist ein Kennzeichen der Auflage, dass diese rechtlich durchsetzbar ist. Ist das nicht möglich, handelt es sich mithin um eine Inhaltsbestimmung und keine Nebenbestimmung.

\section{d) Widerrufs- und Auflagenvorbehalt}

233 Der Vorbehalt des Widerrufs ( $§ 36 \mathrm{II}$ Nr. 3 VwVfG) ergibt nur im Zusammenspiel mit § 49 II Nr. 1 VwVfG einen Sinn. Danach ist der Widerruf eines rechtmäßigen Verwaltungsakts möglich, wenn dieser „im Verwaltungsakt vorbehalten ist“. Die Ankündigung in der Nebenbestimmung, dass der Verwaltungsakt widerrufen

703 Erichsen, Jura 1990, 214 (216).

704 Vgl. Bumke, in: Festschrift für Battis, 2014, 177 (184).

705 Detterbeck, Allgemeines Verwaltungsrecht, 17. Aufl. 2019, § 10 Rn. 657.

Christian Kaerkes 
werden kann, verhindert die Entstehung schutzwürdigen Vertrauens. ${ }^{706}$ Der Bürger wird gewarnt, dass er seine Genehmigung wieder verlieren könnte.

Beispiele: Baugenehmigung für die Aufstellung von Werbeanlagen mit Widerrufsvorbehalt; Erhalt einer Subvention unter Widerrufsvorbehalt

Konsequenz eines Widerrufsvorbehalts ist auch, dass keine Entschädigung im Falle der Aufhebung des Verwaltungsakts zu zahlen ist, vgl. § 49 VI 1 VwVfG.

Allerdings ist ein Widerruf nicht willkürlich möglich, sondern erfordert 234 die Ausübung pflichtgemäßen Ermessens. ${ }^{707}$ Insbesondere hat sich die Behörde an dem Sinn und Zweck des Gesetzes zu orientieren. Der Widerruf für die Baugenehmigung zur Aufstellung von Werbeanlagen darf nicht deshalb erfolgen, weil der Begünstigte zu schnell mit seinem Auto gefahren ist. Hier besteht kein Zusammenhang zwischen dem vermeintlichen Anlass und dem Baurecht. Die Subvention könnte aber widerrufen werden, wenn Anzeichen dafür bestehen, dass die Gelder nicht wirtschaftlich verwendet werden.

Der Auflagenvorbehalt meint den „,Vorbehalt der nachträglichen Aufnahme, 235 Änderung oder Ergänzung einer Auflage“, vgl. § 36 II Nr. 5 VwVfG. Er hat mit dem Widerrufsvorbehalt gemeinsam, dass die Entstehung von schutzwürdigem Vertrauen grundsätzlich verhindert wird. Auflagenvorbehalt und Widerrufsvorbehalt unterscheiden sich aber dadurch, dass der Auflagenvorbehalt im Vergleich das mildere Mittel darstellt. ${ }^{708}$ Anstatt den Hauptverwaltungsakt vollständig durch einen Widerruf aufzuheben, wird nur eine nachträgliche Auflage erlassen.

Verwendung findet der Auflagenvorbehalt insbesondere bei Unsicherheiten 236 über die zukünftige Entwicklung bestimmter Umstände.

Beispiele: Unklare Lärmbelästigung durch eine neue Gaststätte; Unsicherheit über den Grad der Luftverschmutzung durch eine neue Fabrik

Die Behörde kann in diesen Situationen noch nicht genau wissen, welche Auflagen später im Einzelnen erforderlich sein könnten. Trotzdem sollte es auch unter diesen Umständen im Interesse des Bürgers möglich sein, die entsprechenden Genehmigungen zu erteilen. Der Auflagenvorbehalt erlaubt es nun der Behörde, nachträglich die notwendigen Auflagen zu erlassen. Stellt sich heraus, dass von der Fabrik eine erhebliche Luftverschmutzung ausgeht, könnte der Einbau einer Filteranlage angeordnet werden.

706 Maurer/Waldhoff, Allgemeines Verwaltungsrecht, 19. Aufl. 2017, § 12 Rn. 9.

707 Erichsen, Jura 1990, 214 (216f.).

708 Vgl. Tiedemann, in: Bader/Ronellenfitsch, VwVfG, 44. Ed., Stand: 1.7.2019, § 36 Rn. 68. 


\section{e) Keine Nebenbestimmungen}

237 Es existieren noch zwei weitere scheinbare Nebenbestimmungen, die aber in Wirklichkeit gar keine Nebenbestimmungen darstellen:

- „Hinweise“ auf die Rechtslage und

- „Auflagen“ ohne Hauptverwaltungsakt.

In beiden Fällen handelt es sich selbst dann nicht um Nebenbestimmungen, wenn sie als „Auflagen“ bezeichnet werden: ${ }^{709}$ Hinweise auf die Rechtslage sind deshalb keine Auflagen, weil ihnen keine neue Regelungswirkung zukommt. Das entsprechende Gebot oder Verbot besteht schon kraft Gesetzes, sodass es überhaupt keiner Nebenbestimmung bedarf.

Beispiele: Hinweis, dass die Genehmigung nicht verändert werden darf (Urkundenfälschung); Verpflichtung zur Einhaltung von ohnehin geltenden Sicherheitsvorschriften in einer erteilten Baugenehmigung

238 Nebenbestimmungen sind schließlich nur dann möglich, wenn ein Hauptverwaltungsakt existiert. Relevant ist das im Versammlungsrecht (s. hierzu näher Rn. 1141). Hier erlässt die zuständige Behörde „Auflagen“.

Beispiele: Begrenzung der Teilnehmer auf eine bestimmte Anzahl; Versammlung an einem Ort, anstatt einer Route

Da alle Versammlungen genehmigungsfrei sind (vgl. ausdrücklich Art. 8 I GG) bedarf es offensichtlich keiner Genehmigung. Ohne eine solche Genehmigung gibt es aber auch keinen Hauptverwaltungsakt, zu dem die Nebenbestimmung hinzugefügt werden könnte. Wird die Teilnehmerzahl begrenzt oder die Versammlung anderweitig beschränkt, liegt daher schlicht keine Auflage vor. Es handelt sich vielmehr um einen eigenständigen Verwaltungsakt nach dem Versammlungsgesetz (§ 15 VersG).

\section{Zulässigkeit von Nebenbestimmungen}

239 Rechtsgrundlage für Nebenbestimmungen können entweder das (vorrangige) Fachrecht oder die allgemeine Vorschrift des § 36 VwVfG sein. In einzelnen Fällen sind Nebenbestimmungen aber von vornherein unzulässig (,nebenbestimmungsfeindliche Verwaltungsakte“). Es handelt sich dabei um „Statusentscheidungen“.

709 Hufen/Bickenback, JuS 2004, 867 (869).

Christian Kaerkes 
Beispiele: Einbürgerung; Ärztliche Approbation; Abitur

Darüber hinaus sind Nebenbestimmungen nach $\S 36$ VwVfG möglich. Die Vor- 240 schrift unterscheidet danach, ob der Hauptverwaltungsakt im Ermessen (s. dazu Rn. 729 ff.) der Behörde steht oder nicht.

§ 36 I VwVfG betrifft Verwaltungsakte, auf deren Erlass der Bürger einen Anspruch hat. Eine Nebenbestimmung ist „nur“ zulässig, „wenn sie durch Rechtsvorschrift zugelassen ist oder wenn sie sicherstellen soll, dass die gesetzlichen Voraussetzungen des Verwaltungsakts erfüllt werden“. Aus der Formulierung der Vorschrift („nur“) wird bereits deutlich, dass es sich um eine Ausnahme handelt. Nebenbestimmungen sind grundsätzlich unzulässig, weil der Anspruch des Bürgers beschränkt wird..$^{710}$

Nebenbestimmungen zu gebundenen Entscheidungen sind bürgerfreundlich, weil sie der Behörde erlauben, eine Genehmigung zu erteilen, obwohl eigentlich nicht alle Tatbestandsvoraussetzungen erfüllt sind..$^{711}$

Beispiele: Erteilung einer Baugenehmigung mit dem Zusatz, eine Brandmeldeanlage einzubauen; Leistungen für Eheleute an Verlobte unter der Bedingung eines späteren Heiratsnachweises

Anstatt die Anträge abzulehnen, kann die Behörde als milderes Mittel den Hauptverwaltungsakt mit Nebenbestimmungen erlassen, die sicherstellen, dass die Voraussetzungen erfüllt werden.

Examenswissen: Das Bundesverwaltungsgericht hat unlängst entschieden, dass Nebenbestimmungen unzulässig sind, wenn sichergestellt werden soll, dass die gesetzlichen Voraussetzungen erfüllt bleiben. ${ }^{712}$ Liegen die Voraussetzungen für den Erlass des Verwaltungsakts gegenwärtig vor, ist dieser auch zu erlassen. Dafür spricht vor allem der Wortlaut (,erfüllt werden“) des §36 I VwVfG.

Grundsätzlich zulässig sind Nebenbestimmungen hingegen dann, wenn der 242 Hauptverwaltungsakt im Ermessen der Behörde steht, vgl. § 36 II VwVfG. Kann die Behörde den Antrag auch ablehnen, so muss es ihr auch möglich sein, den Verwaltungsakt mit Nebenbestimmungen zu erlassen. Genau dieser Fall liegt vor, wenn der Erlass des Hauptverwaltungsaktes im Ermessen der Behörde steht. Allerdings können die Nebenbestimmungen nicht nach Gutdünken der Behörde

710 Axer, Jura 2001, 748 (751).

711 Brenner, JuS 1996, 281 (282).

712 BVerwG, Urt. v. 9.12.2015, Az.: 6 C 37.14 = BVerwGE 153, 301 = JuS 2016, 959 (m. Anm. Waldhoff) = JA 2016, 799 (m. Anm. Hebeler). 
erlassen werden. Die Behörde ist nämlich gehalten, ihr Ermessen ordnungsgemäß auszuüben und insbesondere den Grundsatz der Verhältnismäßigkeit (hierzu Rn. 767 ff.) zu beachten. ${ }^{713}$

243 Gem. § 36 III VwVfG „darf [eine Nebenbestimmung] dem Zweck des Verwaltungsakts nicht zuwiderlaufen". Diese Vorschrift ist weithin unter dem Begriff „Kopplungsverbot“ bekannt. ${ }^{714}$ Das Kopplungsverbot verlangt, dass zwischen der Nebenbestimmung und dem Hauptverwaltungsakt ein sachlicher Zusammenhang besteht. Ein solcher Zusammenhang besteht insbesondere dann nicht, wenn:

- Verwaltungsakte, auf die ein Anspruch besteht, von der Zahlung einer Geldsumme abhängig gemacht werden oder

- „Ressortfremde“ Interessen verfolgt werden.

244 „Ressortfremde“ Interessen sind Ziele, für deren Verwirklichung die handelnde Behörde nicht zuständig ist. Die Straßenbaubehörde darf bei einem Antrag auf Sondernutzung nicht berücksichtigen, dass es möglicherweise ein Problem mit dem Jugendschutz gibt. Für den Jugendschutz ist schlicht eine andere Behörde zuständig. Deshalb darf die Sondernutzungserlaubnis nicht mit Nebenbestimmungen erlassen werden, die den Jugendschutz betreffen. ${ }^{715}$

245 Unzulässig ist es auch, Verwaltungsakte von der Zahlung einer Geldsumme abhängig zu machen.

Beispiele: Baugenehmigung mit der aufschiebenden Bedingung, noch ausstehende Steuern zu bezahlen; Baugenehmigung mit der Auflage, einen Betrag für das städtische Schwimmbad zu „spenden“

In diesen Fällen besteht kein Zusammenhang zwischen der Baugenehmigung und der Forderung. Zulässig wären Nebenbestimmungen, die baurechtliche Zwecke verfolgen. Das ist hier aber gerade nicht der Fall. Die Behörde soll Genehmigungen nicht ,verkaufen“.

246 Schließlich gibt es noch weitere Konstellationen, in denen schlicht ein $\mathbf{Z u}$ sammenhang zwischen Nebenbestimmung und Hauptverwaltungsakt fehlt und daher ein Verstoß gegen das Kopplungsverbot gegeben ist.

Beispiele: Erlaubnis zum Fällen von Bäumen nur gegen Abtretung eines anderen Grundstückes; Gaststättenerlaubnis nur gegen Ermäßigungen für Mitarbeiter der Verwaltung

713 Schachel, Jura 1981, 449 (458f.).

714 Vgl. Breuer, NVwZ 2017, 112 (114).

715 Axer, Jura 2001, 748 (751).

Christian Kaerkes 
Grundsätzlich sind rechtswidrige (d.h. unzulässige) Nebenbestimmungen trotz247 dem wirksam und können wie alle übrigen Verwaltungsakte bestandskräftig (s. dazu Rn. 115ff.) werden. Wenn sie nicht rechtzeitig angefochten werden, müssen unzulässige Nebenbestimmungen beachtet werden. ${ }^{716}$ Aus diesem Grund ist der Rechtsschutz gegen Nebenbestimmungen von besonderer Bedeutung.

Examenswissen: Ausnahmsweise kann eine Nebenbestimmung nichtig sein, vgl. §44 VwVfG (s. dazu $\S 6$ Rn. 115ff.). In einem solchen seltenen Ausnahmefall kann entweder die Aufhebung der nichtigen Nebenbestimmung (Anfechtungsklage) oder die Feststellung der Nichtigkeit der Nebenbestimmung (Nichtigkeitsfeststellungsklage) begehrt werden. ${ }^{717}$

Beispiel: ${ }^{718}$ Willkürliche Auflage, ein Grundstück verkaufen zu müssen

\section{Rechtsschutz gegen Nebenbestimmungen}

Nebenbestimmungen sind oftmals Belastungen zu einem für den Bürger günsti- 249 gen Verwaltungsakt (einer Genehmigung). In diesen Situationen möchte der Bürger zwar die Begünstigung behalten, aber gleichzeitig die Belastung nach Möglichkeit beseitigen.

Beispiele: Baugenehmigung unter der Bedingung zusätzlicher Stellplätze; Gaststättenerlaubnis mit Lärmschutzauflagen

Dabei ist zu beachten, dass Nebenbestimmungen bestandskräftig werden können und dann beachtet werden müssten, selbst wenn sie sich als rechtswidrig erweisen würden. ${ }^{719}$ Der Bürger wird daher gezwungen, rechtzeitig Rechtsschutz vor den Verwaltungsgerichten zu suchen. Dabei bestehen zwei Möglichkeiten:

- Anfechtungsklage gerichtet gegen die Nebenbestimmung oder

- Verpflichtungsklage auf Erlass eines Verwaltungsakts ohne Nebenbestimmung.

Es liegt aber nicht im Interesse des Bürgers, den Hauptverwaltungsakt anzugreifen, weil er im Regelfall den begünstigenden Verwaltungsakt behalten möchte. Er möchte nicht die Baugenehmigung verlieren, sondern nur die Nebenbestimmung beseitigen. Diesem Ziel entspricht allerdings nur die Anfechtungsklage, nicht aber die Verpflichtungsklage. Mit der Verpflichtungsklage kann regelmäßig nur

716 Schwerdtfeger/Schwerdtfeger, Öffentliches Recht, 14. Aufl. 2012, Rn. 168.

717 Vgl. Schenke, JuS 2016, 97 (99f.).

718 Hufen/Bickenbach, JuS 2004, 966 (968).

719 Detterbeck, Allgemeines Verwaltungsrecht, 17. Aufl. 2019, § 10 Rn. 563 ff., 656. 
eine von Grund auf neue Entscheidung über den gesamten Verwaltungsakt herbeigeführt werden.

251 Die Anfechtungsklage (s. zur Anfechtungsklage Rn. 2ff.) ist noch aus weiteren Gründen für den Bürger vorteilhafter: ${ }^{720}$

- Aufschiebende Wirkung der Anfechtungsklage

- Einstweiliger Rechtsschutz über $§ 80$ V VwGO

- Ggf. kostengünstiger als die Verpflichtungsklage

252 Der Streit über den Rechtsschutz gegen Nebenbestimmungen ist ein Streit um die richtige Klageart: Kann und darf der Bürger Anfechtungsklage ausschließlich gegen die belastende Nebenbestimmung erheben (,isolierte Anfechtung“) oder muss er stattdessen Verpflichtungsklage erheben? Diese Frage ist in der Statthaftigkeit der Klageart zu erörtern und ist heftig umstritten.

\section{a) Sonderfall - „Modifizierende Auflage“}

253 Unstrittig ist aber der Rechtsschutz gegen die „modifizierende Auflage“. Gegen diese Bestimmung des Inhalts des Hauptverwaltungsaktes kann nur mit der Verpflichtungsklage vorgegangen werden. ${ }^{721}$ Dafür wird angeführt, dass ein untrennbarer Zusammenhang zwischen der „modifizierenden Auflage“ und dem Hauptverwaltungsakt bestehe. Besser verständlich ist allerdings der Grund, dass mit der Anfechtungsklage kein sinnvolles Ergebnis erzielt werden könnte.

Beispiel: Baugenehmigung mit einem Flachdach statt des beantragten Giebeldachs

254 Würde in diesem Fall die „modifizierende Auflage“ angefochten und durch das Gericht aufgehoben, so bliebe eine Baugenehmigung ohne Dach übrig. ${ }^{722}$ Mit der Anfechtungsklage kann das Rechtsschutzziel des Bürgers (Giebeldach) gar nicht erreicht werden. Die inhaltliche Veränderung der Genehmigung ist nur mit der Verpflichtungsklage möglich.

255 Für den Sonderfall der „modifizierenden Auflage“ - die zwar keine echte Nebenbestimmung ist (s. Rn. 228ff.), aber hier im Zusammenhang behandelt wird - besteht daher weitgehend Einigkeit, dass nur die Verpflichtungsklage statthaft ist.

720 Fricke, DÖV 2019, $48 \mathrm{f}$.

721 BVerwG, Urt. v. 8.2.1974, Az.: IV C 73.72 = BVerwG, DÖV 1974, 380 (381).

722 Schmidt, VBlBW 2004, 81 (83).

Christian Kaerkes 


\section{b) Echte Nebenbestimmungen}

Heftig umstritten ist hingegen der Rechtsschutz gegen die echten Nebenbestim- 256 mungen. Im Laufe der Zeit haben sich dabei vier unterschiedliche Positionen herausgebildet:

- Grundsätzlich immer Anfechtungsklage,

- Grundsätzlich immer Verpflichtungsklage,

- Unterscheidung nach der Art des Hauptverwaltungsaktes oder

- Unterscheidung zwischen den Nebenbestimmungen.

\section{aa) h.M.: Anfechtungsklage}

Die Position, dass gegen alle Nebenbestimmungen gleichermaßen Anfechtungs- 257 klage erhoben werden kann, entspricht der mittlerweile herrschenden Meinung. Das Bundesverwaltungsgericht hat sich sehr deutlich für diese überzeugende Ansicht ausgesprochen: „Gegen belastende Nebenbestimmungen ist die Anfechtungsklage gegeben. “723

Hierfür sprechen vor allem zwei Überlegungen:

- $\S 113$ I 1 VwGO kennt die Teilaufhebung und

- Teilbarkeit betrifft die Begründetheit.

Gem. § 113 I 1 VwGO ist es möglich, dass der Verwaltungsakt nur teilweise auf- 259 gehoben wird (,soweit der Verwaltungsakt rechtswidrig ist“). ${ }^{724}$ Wird der gesamte Verwaltungsakt angegriffen, kann es demnach sein, dass nur ein Teil des Verwaltungsakts aufgehoben wird. Einen solchen Teil stellt die Nebenbestimmung dar. Das Gesetz selbst sieht demnach die Teilaufhebung vor und erfasst an sich die Aufhebung von rechtswidrigen Nebenbestimmungen.

Entscheidend ist daher, ob Nebenbestimmung und Hauptverwaltungsakt 260 teilbar sind. Wenn beide untrennbar wären, könnte nicht nur ein Teil davon aufgehoben werden. Das ist nach der herrschenden Meinung aber keine Frage der statthaften Klageart, sondern betrifft die Begründetheit der Klage. Weil aber Zulässigkeit und Begründetheit zu unterscheiden sind, ist die Anfechtungsklage selbst dann statthaft, wenn sich Nebenbestimmung und Hauptverwaltungsakt als unteilbar erweisen würden.

723 BVerwG, Urt. v. 10.7.1980, Az.: 3 C 136.79 = BVerwGE 60, 269 (274); bestätigt durch BVerwG, Urt. v. 22.11.2000, Az.: 11 C 2.00 = BVerwGE 112, 221 (224).

724 Schenke, JuS 1983, 182 (184). 
261 Examenswissen: Hiervon wird nur dann eine Ausnahme gemacht, wenn die ,isolierte Aufhebbarkeit offenkundig von vornherein ausscheidet “ ${ }^{725}$ Für die Anfechtungsklage soll in diesen Fällen bereits das Rechtsschutzbedürfnis fehlen (s. dazu Rn. 477 ff.). Welche Fallgruppen davon genau erfasst sein sollen, ist jedoch noch nicht eindeutig geklärt. In der Literatur wird vor allem die Inhaltsbestimmung bzw. die „modifizierende Auflage“ als Beispiel angeführt. ${ }^{726}$ Hierbei handelt es sich jedoch schon um keine Nebenbestimmungen (s. bereits Rn. $228 \mathrm{ff}$.).

\section{bb) a. A.: Verpflichtungsklage}

262 Seltener vertreten und gelegentlich unterschätzt wird die Position, dass für den Rechtsschutz gegen Nebenbestimmungen grundsätzlich nur die Verpflichtungsklage in Betracht kommt. ${ }^{727}$ Dafür werden insbesondere zwei Gründe angeführt:

- Aufschiebende Wirkung der Anfechtungsklage und

- Vergleich mit der „klassischen“ Verpflichtungssituation.

263 Gem. §80 I 1 VwGO hat die Anfechtungsklage aufschiebende Wirkung. Rechtsfolge der aufschiebenden Wirkung ist, dass die angegriffene Regelung nicht mehr vollziehbar ist und deshalb nicht beachtet werden muss. ${ }^{728}$ Es sei aber problematisch, wenn sich die aufschiebende Wirkung nur gegen die Nebenbestimmung richten würde. Der Bürger könnte nämlich von dem Hauptverwaltungsakt weiter Gebrauch machen, ohne sich für die Nebenbestimmung interessieren zu müssen. ${ }^{729}$

Beispiel: Anfechtungsklage gegen eine Baugenehmigung mit Lärmschutzauflage führt (vorläufig) zu einer nebenbestimmungsfreien Baugenehmigung

Allerdings kann die Behörde gem. § 80 II Nr. 4 VwGO die sofortige Vollziehung anordnen, mit der Folge, dass der Anfechtungsklage keine aufschiebende Wirkung mehr zukommt. Das „Problem“ lässt sich demnach durch die Behörde beseitigen. Außerdem sollte die aufschiebende Wirkung nicht zu kritisch gesehen werden, weil der Bürger sonst während der (langen) Dauer des Prozesses nicht von der Genehmigung in der von ihm gewünschten Weise profitieren könnte. ${ }^{730}$

Das zweite Argument läuft vor allem darauf hinaus, dass die Gewährung einer Genehmigung mit Nebenbestimmung de facto eine (Teil-)Ablehnung des Antrags

725 BVerwG, Urt. v. 22.11.2000, Az.: 11 C 2.00 = BVerwGE 112, 221 (224).

726 Sproll, NJW 2002, 3221 (3223).

727 Stadie, DVBl. 1991, 613 (614).

728 Hufen, Verwaltungsprozessrecht, 11. Aufl. 2019, § 32 Rn. $1 \mathrm{ff}$.

729 Stadie, DVBl. 1991, 613 (615).

730 Schmidt, VBlBW 2004, 81 (83).

Christian Kaerkes 
auf eine nebenbestimmungsfreie Genehmigung sei. Der Rechtsschutz müsse nach allgemeinen Regeln durch die Verpflichtungsklage erfolgen. ${ }^{731}$ Hier läge eine „klassische“ Verpflichtungssituation vor, vgl. § 42 I Alt. 2VwGO („Erlaß eines abgelehnten [...] Verwaltungsakts“).

Die Verpflichtungsklage ist für den Bürger aber durchaus problematisch, 265 weil regelmäßig nur ein „Bescheidungsurteil“ ergehen wird. Die Behörde muss dann erneut (und ermessensfehlerfrei) über den Antrag entscheiden. Die Verpflichtungsklage kann daher nicht mit der gleichen Effektivität rechtswidrige Nebenbestimmungen beseitigen. ${ }^{732}$ Der Verpflichtungsklage kommt außerdem keine aufschiebende Wirkung zu.

Die Bürger werden durch eine grundsätzliche Verpflichtungsklage im Er- 266 gebnis ohne ausreichende Rechtfertigung schlechter gestellt, weshalb diese Auffassung abzulehnen ist. Gegen diese Position spricht demnach:

- Vorteile der aufschiebenden Wirkung,

- Möglichkeit der Verwaltung, die sofortige Vollziehung anzuordnen und

- Benachteiligung des Bürgers durch die Verpflichtungsklage.

\section{cc) a.A.: Unterscheidung nach der Art des Hauptverwaltungsaktes}

Eine weitere Position unterscheidet danach, ob der Erlass des Verwaltungsakts

im Ermessen der Behörde steht oder nicht. Habe der Bürger einen Anspruch auf den Verwaltungsakt, sei die Anfechtungsklage gegeben, stehe der Verwaltungsakt aber im Ermessen der Behörde, sei die Verpflichtungsklage statthaft. Das entsprach zumindest einer Zeit lang der Rechtsprechung des Bundesverwaltungsgerichts. ${ }^{733}$ Für die Ansicht sprechen zwei Gründe:

- Einheitliche Ermessensentscheidung (,Gewaltenteilung“) und

- Bürger erhielten ansonsten mehr als ihnen zustünde.

Der erste Grund beruht auf der Annahme, dass die Behörde ihr Ermessen nur 268 einheitlich ausübt. Die Behörde würde den Hauptverwaltungsakt (der in ihrem Ermessen steht) nicht ohne die ergänzenden Nebenbestimmungen erlassen haben.

Beispiel: Sondernutzungserlaubnis zum Aufstellen von Stühlen auf dem Gehweg nur mit Befristung, hingegen keinesfalls ohne Befristung

731 Vgl. Labrenz, NVwZ 2007, 161 (164f.).

732 Detterbeck, Allgemeines Verwaltungsrecht, 17. Aufl. 2019, § 10 Rn. 671.

733 BVerwG, Urt. v. 7.7.1978, Az.: 4 C 79.76 = BVerwGE 56, 254 (256). 
269 Würde in einem solchen Fall die Nebenbestimmung aufgehoben, dann würde der Behörde ein Verwaltungsakt „aufgedrängt“, den sie in dieser Form niemals erlassen hätte. Das wäre mit Blick auf die Gewaltenteilung (Abgrenzung von Exekutive und Judikative) tatsächlich nicht unproblematisch. ${ }^{734}$ Die Verpflichtungsklage würde einen „Übergriff“ in die alleinige Kompetenz der Behörde verhindern. Die Nebenbestimmung würde nicht aufgehoben, sondern die Behörde nur zur erneuten Entscheidung verpflichtet.

Indes wird der Behörde kein Verwaltungsakt aufgedrängt, und zwar deshalb, weil die Behörde den Verwaltungsakt beseitigen kann. Ihr stehen die Instrumente des Widerrufs und der Rücknahme zur Verfügung, vgl. §§ 48, 49 VwVfG (näher dazu Rn. 836ff.). ${ }^{735}$ Das Bundesverwaltungsgericht erlaubt zudem auch eine Analogie zu § 49 II Nr. 2 VwVfG. ${ }^{736}$ Die Behörde muss aus diesem Grund nicht durch die Verpflichtungsklage geschützt werden, weil sie sich selbst vor einem „aufgedrängten“ Verwaltungsakt schützen kann.

Der zweite Grund bezieht sich darauf, dass die Anfechtungsklage die Stellung des Bürgers über seinen materiellen Anspruch ausweiten würde. Der Bürger habe keinen Anspruch auf einen Verwaltungsakt ohne Nebenbestimmungen, sondern nur auf eine ermessensfehlerfreie Entscheidung. ${ }^{737}$ Daher solle die Nebenbestimmung auch nicht durch eine Anfechtungsklage aufgehoben werden können. Statthaft sei die Verpflichtungsklage.

272 Allerdings spricht diese Überlegung noch nicht gegen die Anfechtungsklage als solche. Den Bedenken kann nämlich im Rahmen der Begründetheit durchaus Rechnung getragen werden und die Behörde hat immer noch die Möglichkeit, den missliebigen Verwaltungsakt einfach selbst aufzuheben. Daher ist dieser Meinung aus den folgenden Gründen nicht $\mathrm{zu}$ folgen:

- „Selbstschutz“ der Behörde durch Widerruf und Rücknahme und

- Bedenken können in der Begründetheit berücksichtigt werden.

\section{dd) a.A.: Unterscheidung zwischen den Nebenbestimmungen}

273 Nach einer weiteren Ansicht kommt es auf die jeweilige Art der Nebenbestimmung an. Auflage und Auflagenvorbehalt seien zwar mit der Anfechtungsklage angreifbar; im Übrigen bleibe aber nur die Verpflichtungsklage. Auch diese Un-

734 Schenke, JuS 1983, 182 (185).

735 Vgl. Hufen/Bickenbach, JuS 2004, 966 (967).

736 BVerwG, Urt. v. 12.3.1982, Az.: 8 C 23.80 = BVerwGE 65, 139 (141).

737 Jahndorf, JA 1999, 676 (677).

Christian Kaerkes 
terscheidung findet sich in der älteren Rechtsprechung des Bundesverwaltungsgerichts wieder. ${ }^{738}$ Dafür wird vor allem ein Grund angeführt:

- Selbstständigkeit bzw. Unselbstständigkeit der Nebenbestimmungen.

Diese Auffassung betrachtet Auflage und Auflagenvorbehalt als „selbstständig“ und Befristung, Bedingung sowie Widerrufsvorbehalt als „unselbstständig“. Unselbstständige Nebenbestimmungen könnten nur als „untrennbare Einheit“ bzw. „integrale Bestandteile“ des Hauptverwaltungsaktes begriffen werden. ${ }^{739}$ Anhaltspunkt für diese Position sei der Wortlaut des $\S 36$ II VwVfG, weil dort zwischen den einzelnen Nebenbestimmungen unterschieden werde (,erlassen mit“ einerseits, „verbunden mit“ andererseits). Letztlich geht es wieder um die Frage, ob Nebenbestimmung und Hauptverwaltungsakt voneinander zu trennen sind.

Indes erscheint die Anknüpfung an den Wortlaut des $\S 36$ II VwVfG als un- 275 zureichend. ${ }^{740}$ Aus diesen sprachlichen Unterschieden folgt nicht zwingend, dass in einem Fall die Anfechtungs- im anderen Fall die Verpflichtungsklage zulässig wäre. Eine solche Unterscheidung überzeugt aber auch deshalb nicht, weil ein sachlicher Grund fehlt, der eine differenzierte Behandlung rechtfertigen würde. Das gilt insbesondere deshalb, weil damit weitere Konsequenzen verbunden sind:

- Aufschiebende Wirkung,

- Einstweiliger Rechtsschutz und

- Anforderungen an die Begründetheit.

Sollte eine Klage gegen die Bedingung keinerlei aufschiebende Wirkung haben, wohl aber gegen eine inhaltsgleiche Auflage? Hierfür dürfte es an einer inhaltlichen Rechtfertigung fehlen. ${ }^{741}$ Vielmehr sollten die Nebenbestimmungen in dieser Hinsicht gleichbehandelt werden.

Daher sprechen zumindest die folgenden Gründe gegen den Vorschlag, zwi- 276 schen den verschiedenen Nebenbestimmungen zu unterscheiden:

- Folgerung aus sprachlichen Unterschieden nicht stichhaltig und

- Fehlende sachliche Rechtfertigung für die unterschiedliche Behandlung.

738 BVerwG, Urt. v. 21.10.1970, Az.: IV C 165.65 = BVerwGE 36, 145 (154).

739 Axer, Jura 2001, 748 (752f.).

740 Bumke, in: Festschrift für Battis, 2014, 177 (185).

741 Vgl. Schmidt, VBlBW 2004, 81 (83). 


\section{ee) Ergebnis}

277 Die besseren Gründe dürften insgesamt für die herrschende Meinung sprechen. Danach sind alle Nebenbestimmungen grundsätzlich mit der Anfechtungsklage angreifbar. Die Teilaufhebung durch die Anfechtungsklage ist in der VwGO vorgesehen. Gleichzeitig können viele Bedenken entkräftet oder in der Begründetheit der Anfechtungsklage berücksichtigt werden. Es besteht danach kein Grund, die Nachteile der Verpflichtungsklage für den Bürger in Kauf zu nehmen.

278 Klausurrelevant: Die herrschende Meinung muss aber die Teilbarkeit von Hauptverwaltungsakt und Nebenbestimmung in der Begründetheit der Anfechtungsklage berücksichtigen. Das führt zu einem besonderen Aufbau der Prüfung (dazu ausführlich Rn. $1388 \mathrm{ff}$.), der in der Klausur unbedingt bekannt sein muss.

\section{Literaturhinweise}

279 Aufsätze: Voßkuhle/Kaiser, Grundwissen - Öffentliches Recht: Nebenbestimmungen, Jus 2012, 699; Brenner, Der Verwaltungsakt mit Nebenbestimmungen, JuS 1996, 281; Hufen/Bickenbach, Der Rechtsschutz gegen Nebenbestimmungen zum Verwaltungsakt, JuS 2004, 867

Lehrbücher: Detterbeck, Allgemeines Verwaltungsrecht, 17. Aufl. 2019, § 10 Rn. 643 ff.; Maurer/Waldhoff, Allgemeines Verwaltungsrecht, 19. Aufl. 2017, § 12 Rn. $1 \mathrm{ff}$.

Übungsfälle: Fall 2 in: Eisentraut, Fälle zum Verwaltungsrecht, 2020; Ernst/ Kämmerer, Fälle zum Allgemeinen Verwaltungsrecht, 3. Aufl. 2016, Fall 9: „Baustelle ohne Verkehr“; Payandeh, „Übungsfall: Der fragwürdige Widerrufsvorbehalt“, ZJS 2017, 544; Tschentscher, „Zur Übung - Öffentliches Recht: Die religiöse Sondernutzung“, JuS 2003, 345

Lehrvideo: Dobiasch/Schwarz/Schuster, Peer2Peer Lehrvideo Anfechtung von Nebenbestimmungen, abrufbar unter https://youtu.be/2LNM6WkmG0I

\section{B. Weitere Zulässigkeitsvoraussetzungen der Anfechtungsklage}

280 Nach der Prüfung der Eröffnung des Verwaltungsrechtswegs und der Prüfung der statthaften Klageart sind im Falle der Anfechtungsklage regelmäßig die folgenden weiteren Zulässigkeitsvoraussetzungen anzusprechen, wobei es auch hierbei auf problembewusstes Arbeiten ankommt (dazu § 1 Rn. 52, 123). 


\section{Die Klagebefugnis (Hendrik Burbach)}

Die Klagebefugnis nach $\S 42$ II VwGO ist eine der zentralen Voraussetzungen für $\mathbf{2 8 1}$ die Zulässigkeit verwaltungsgerichtlicher Klagen und Anträge. Nach § 42 II VwGO sind Anfechtungs- und Verpflichtungsklagen, soweit gesetzlich nichts anderes bestimmt ist, nur zulässig, wenn der Kläger geltend macht, durch den Verwaltungsakt oder seine Ablehnung oder Unterlassung in seinen Rechten verletzt zu sein. Obgleich der Wortlaut des § 42 II VwGO ausdrücklich nur die Anfechtungsund Verpflichtungsklagen umfasst, ist auch für die übrigen Klagearten die Klagebefugnis des Klägers erforderlich (s. im Einzelnen $\S 3$ Rn. 28, §4 Rn. 33, § 5 Rn. 31, § 6 Rn. 78, § 7 Rn. 36., § 8 Rn. 30, § 9 Rn. 34, § 10 Rn. 11).

Durch das Merkmal der Klagebefugnis soll gewährleistet werden, dass nur Klage erheben kann, wer auch die Verletzung seiner subjektiven Rechte geltend machen kann. Die Verwaltungsgerichtsbarkeit soll hiermit von einer Vielzahl ungerechtfertigter Inanspruchnahmen durch Popularklagen entlastet werden. ${ }^{742}$ Bei diesen erhebt sich der Kläger zum Sachwalter öffentlicher Interessen oder rechtlich geschützter Interessen Dritter. ${ }^{73}$

Examenswissen: Die Klagebefugnis ist dabei nicht mit der Sachlegitimation des Klägers zu verwechseln. Die Sachlegitimation ist die subjektive Seite der Anspruchsberechtigung oder -verpflichtung, die ausschließlich nach dem materiellen Recht zu bestimmen und daher eine Frage der Begründetheit der Klage ist.

Im Rahmen des § 42 II VwGO muss der Kläger substantiiert vortragen, dass er in 284 subjektiven Rechten verletzt ist. Dabei werden an die Voraussetzungen des die Klagebefugnis begründenden Rechts keine hohen Anforderungen gestellt. Ob dieses Recht besteht ist schließlich eine Frage der Begründetheit der Klage. ${ }^{744}$

Examenswissen: Demgegenüber hat der Gesetzgeber gerade im Umwelt- und Naturschutzrecht zur effektiven Durchsetzung des Rechts auch Verbandsklagen zugelassen. Hierbei wird - europarechtlich geprägt ${ }^{745}$ - eine Ausnahme von dem Erfordernis der Verletzung eigener Rechte gemacht. ${ }^{746}$ Insofern spricht man hinlänglich von Interessentenklagen. Diese können Personen erheben, die ein gesetzlich anerkanntes Interesse am Klageausgang haben. ${ }^{77}$ Ist der Anwendungsbereich des $\S 1$ UmwRG eröffnet, sind nach $\S 3$ UmwRG anerkannte Vereinigungen grund-

742 Hufen, Verwaltungsprozessrecht, 11. Aufl. 2019, § 14 Rn. 53.

743 Schenke, Verwaltungsprozessrecht, 16. Aufl. 2019, § 14 I Rn. 490.

744 R. P. Schenke, in: Kopp/Schenke, VwGO, 25. Aufl. 2019, § 42 Rn. 65; Kintz, Öffentliches Recht im Assessorexamen, 10. Aufl., 2018, Rn. 227.

745 Vgl. EuGH, Urt. v. 12.5.2011, Az.: C-115/09 = NVwZ 2011, 801 (mit Anmerkung von Schlacke). 746 Schenke, Verwaltungsprozessrecht, 16. Aufl. 2019, § 14 I Rn. 490a.

747 Peine, Klausurenkurs im Verwaltungsrecht, 6. Aufl. 2016, 1. Teil Rn. 131.

Hendrik Burbach 
sätzlich klagebefugt, ohne dass es einer Darlegung der Verletzung eigener Rechte bedarf, § 2 I 1 UmwRG. ${ }^{748}$ Dies gilt dagegen nicht, wenn die Vereinigung einen Rechtsbehelf gegen eine Entscheidung nach § 1 I Nr. 2a-6 UmwRG einlegt. In diesen Konstellationen sieht § 2 I 2 UmwRG vor, dass die Vereinigung „die Verletzung umweltbezogener Vorschriften geltend machen“ kann. ${ }^{749}$

\section{Voraussetzungen des $\$ 42$ II VwGO}

286 Der Kläger muss nach § 42 II VwGO die Möglichkeit einer Rechtsverletzung geltend machen können. Unzulässig ist die Klage nur, wenn unter Zugrundelegung des Klägervortrags offensichtlich und eindeutig nach keiner Betrachtungsweise subjektive Rechte des Klägers verletzt sein können. ${ }^{750}$

287 Im Rahmen der Fallbearbeitung ist die Möglichkeit der Rechtsverletzung näher zu begründen. Dabei darf allerdings nicht geprüft werden, ob der Kläger durch den Verwaltungsakt tatsächlich in seinen Rechten verletzt ist. Dies ist erst im Rahmen der Begründetheit zu erörtern, § 113 I 1 VwGO. ${ }^{71}$ Zur Begründung der Klagebefugnis genügt daher die Möglichkeit einer Rechtsverletzung. ${ }^{752}$ Diese sollte im Rahmen der Klausur auch kurz dargelegt werden.

288 Die Klagebefugnis folgt bei einer Anfechtungsklage nach § 42 I 1. Alt VwGO zumeist bereits aus der Adressatentheorie. Nach dieser ist der Adressat eines belastenden Verwaltungsakts stets klagebefugt. Dies gilt jedoch nur für den Inhaltsadressat, nicht aber für den Bekanntgabeadressaten. ${ }^{753}$

Bei Drittanfechtungs- oder Nachbarschutzfällen bedarf die Darlegung der Klagebefugnis hingegen einer tiefergehenden Untersuchung. In der Klausur sollte das subjektiv-öffentliche Recht sauber herausgearbeitet werden. Hierbei ist vor allem auch auf den notwendigen Drittschutz der Norm zu achten (vgl. hierzu näher Rn. 296f.).

\section{a) Möglichkeitstheorie}

290 Nach der herrschenden Möglichkeitstheorie genügt zur Begründung der Klagebefugnis, dass die Möglichkeit der vom Kläger behaupteten Rechtsverletzung besteht. ${ }^{754}$ Diese Prüfung folgt dabei einem dreistufigen Aufbau: Es bedarf zunächst

748 Erbguth/Guckelberger, Allgemeines Verwaltungsrecht, 9. Aufl. 2018, §20 Rn. 20.

749 Vertiefend Erbguth/Guckelberger, Allgemeines Verwaltungsrecht, 9. Aufl. 2018, §20 Rn. 20; Schlacke, NVwZ 2017, 905.

750 Kintz, Öffentliches Recht im Assessorexamen, 10. Aufl., 2018, Rn. 227.

751 Detterbeck, Allgemeines Verwaltungsrecht, 17. Aufl. 2019, § 31 Rn. 1351.

752 R. P. Schenke, in: Kopp/Schenke, VwGO, 25. Aufl. 2019, § 42 Rn. 59.

753 Happ, in: Eyermann, VwGO, 15. Aufl. 2019, § 42 Rn. 91.

754 Exemplarisch: R. P. Schenke, in: Kopp/Schenke, VwGO, 25. Aufl. 2019, § 42 Rn. 66.

Hendrik Burbach 
eines Rechts, dieses muss dem Kläger subjektiv zuzuordnen und schließlich auch verletzt sein.

Der Kläger muss zunächst die Verletzung eines Rechts geltend machen. Ein solches liegt insbesondere dann nicht vor, wenn lediglich bloße Interessen, Erwerbschancen, Situationsvorteile oder sonstige Chancen bestehen, die nicht bereits in einer Rechtsposition resultiert sind. ${ }^{755}$ Gleiches gilt für den Fall, dass der Kläger bloß eine obligatorische Rechtsposition innehat. ${ }^{756}$

Beispiel: Dies ist etwa dann der Fall, wenn in einer baurechtlichen Streitigkeit der Mieter eines Objektes klagen möchte. Insoweit gilt der Grundsatz, dass das Grundstück nur einmal gerichtlich repräsentiert werden darf, nämlich durch den Eigentümer; Der Mieter ist insoweit nach ständiger Rechtsprechung des BVerwG nicht klagebefugt. ${ }^{757}$

Weiterhin ist $\mathrm{zu}$ untersuchen, ob dem Kläger das geltend gemachte Recht auch subjektiv zugeordnet werden kann. Dies ist nach der sog. Schutznormtheorie insbesondere dann der Fall, wenn die Norm zumindest auch den Individualinteressen des Klägers $\mathrm{zu}$ dienen bestimmt ist. ${ }^{758}$ Nach dieser genügt zur Begründung der Klagebefugnis jedes von der Rechtsordnung als schutzwürdig anerkannte Individualinteresse. ${ }^{759}$ Hierunter fallen alle geschriebenen oder ungeschriebenen Rechtsnormen des öffentlichen Rechts. Relevant ist dies vor allem in Fällen der Drittanfechtung.

Als subjektive Rechte des Klägers kommen dabei nicht nur materielle Rechte, 293 sondern auch Verfahrensrechte in Betracht. ${ }^{760}$

\section{b) Adressatentheorie}

In vielen Fällen kann im Rahmen einer Anfechtungsklage die Adressatentheorie 294 herangezogen werden. Nach dieser ist der Adressat eines belastenden Verwaltungsakts, der ihm ein Handeln, Dulden oder Unterlassen gebietet, stets möglicherweise in seinen eigenen Rechten verletzt. ${ }^{761}$ Der belastende Verwaltungsakt

755 Gersdorf, Verwaltungsprozessrecht, 6. Aufl. 2019, Rn. 30; Hufen, Verwaltungsprozessrecht, 11. Aufl. 2019, § 14 Rn. $61 \mathrm{ff}$.

756 Hufen, Verwaltungsprozessrecht, 11. Aufl. 2019, § 14 Rn. 67.

757 BVerwG, Urt. v. 18.11.1985, Az. 8 C 43.83 = BVerwGE 72, 226; BVerwG, Urt. v. 06.03.1987, Az. 8 C 1.85 = NJW 1987, 2829; BVerwG, Urt. v. 05.04.1993, Az. 4 NB 3.91 = NJW 1994, 1233; s. auch Schmidt-Preuß, NJW 1995, 27 (28).

758 Schaks/Friedrich, JuS 2018, 860 (864).

759 R. P. Schenke, in: Kopp/Schenke, VwGO, 25. Aufl. 2019, § 42 Rn. 78.

760 Schenke, Verwaltungsprozessrecht, 16. Aufl. 2019, § 14 I Rn. 489.

761 Detterbeck, Allgemeines Verwaltungsrecht, 17. Aufl. 2019, § 31 Rn. 1352.

Hendrik Burbach 
beeinträchtigt den Kläger zumindest in dem ihm von Art. 2 I GG gewährten Schutz seiner Freiheitssphäre. ${ }^{762}$

295 Die Adressatentheorie kann also grundsätzlich immer dann in der Klausur angewendet werden, wenn der Kläger gegen einen ihn belastenden Verwaltungsakt vorgehen möchte. An dieser Stelle sollte aber nicht nur pauschal auf die Adressatentheorie verwiesen werden, sondern gleichfalls unter Rückgriff auf Art. 2 I GG eine kurze Begründung für die Rechtsverletzung gegeben werden.

\section{c) Drittanfechtungsklagen}

296 Geht der Kläger gegen einen Verwaltungsakt vor, der einen Dritten begünstigt und ihn belastet, liegt ein sog. begünstigender Verwaltungsakt mit belastender Drittwirkung vor. In diesem Fall kann der Kläger seine Klagebefugnis nicht mit der Adressatentheorie begründen. Hauptanwendungsfälle für diese Konstellation folgen aus Nachbarklagen im Bau- und Umweltrecht, bei beamtenrechtlichen und wirtschaftsverfassungsrechtlichen Konkurrentenklagen sowie bei Konkurrentenklagen im Subventionsbereich. ${ }^{763}$ Auch im In diesen Konstellationen führt der Kläger zwar den Prozess gegen die Verwaltung, in der Sache geht es allerdings um eine Entscheidung über konkurrierenden Privatinteressen. ${ }^{764}$

297 Auch in diesen Fällen muss der Kläger die Verletzung eigener subjektiver Rechte geltend machen können. Er muss daher zur Begründung seiner Klagebefugnis vortragen, dass der angegriffene, einen anderen begünstigende und ihn belastende Verwaltungsakt eine Norm verletzt, die zumindest auch seinem Schutz dient. ${ }^{765}$ Dies ist stets dann der Fall, wenn der Norm drittschützende Wirkung zukommt. Ob dies der Fall ist, bestimmt sich u. a. durch die Schutznormtheorie. Nach der Schutznormtheorie ist ein Recht drittschützend, wenn es nicht nur ausschließlich dem Interesse der Allgemeinheit dient, sondern vielmehr auch dem Schutz individueller Rechte dient, die einem abgrenzbaren Kreis von Begünstigten zustehen (s. dazu auch Rn. 828 und beispielhaft Fall 3 in: Eisentraut, Fälle zum Verwaltungsrecht, 2020).

762 R. P. Schenke, in: Kopp/Schenke, VwGO, 25. Aufl. 2019, § 42 Rn. 69.

763 Württemberger/Heckmann, Verwaltungsprozessrecht, 4. Aufl. 2018, § 21 Rn. 334.

764 Schmidt-Preuß, Kollidierende Privatinteressen im Verwaltungsrecht, 2. Auflage 2005, S. 17 ff.; s. auch Schmidt-Aßmann/Schenk in: Schoch/Schneider/Bier, VwGO, 36. EL Februar 2019, Einleitung Rn. $192 \mathrm{ff}$.

765 Württemberger/Heckmann, Verwaltungsprozessrecht, 4. Aufl. 2018, § 21 Rn. 334.

Hendrik Burbach 
Beispiele für drittschützende Normen: ${ }^{766}$

- Ordnungsrechtliche Generalklauseln (Polizei- und Ordnungsrecht)

- Baurechtliche Gebot der Rücksichtnahme, hergeleitet u. a. aus § 15 I BauNVO, § 31 II BauGB, § 34 I BauGB, § 34 II BauGB, § 35I, II i.V.m. § 35 III BauGB (s. dazu beispielhaft Fall 3 in: Eisentraut, Fälle zum Verwaltungsrecht, 2020)

- Festsetzungen des Bebauungsplans zur Art der baulichen Nutzung

- Im Rahmen der wirtschaftlichen Konkurrentenklage kann aus dem Besonderen Verwaltungsrecht (z.B. GewO) möglicherweise Drittschutz vermittelt werden. ${ }^{767}$ In Ausnahmefällen kann auch Art. 12 GG drittschützend wirken, wenn der Wettbewerb empfindlich beeinflusst wurde.

- Vorschriften des BImSchG (z.B. \& 5 I Nr. 1 BImSchG)

\section{Formulierungsvorschlag}

In klassischen Adressatenanfechtungskonstellationen kann wie folgt formu- 298 liert werden: „Der Kläger müsste nach $\S 42$ II VwGO klagebefugt sein. Er ist Adressat eines ihn belastenden Verwaltungsakts und kann mithin geltend machen, im Sinne der Adressatentheorie zumindest in seinem Grundrecht der Allgemeinen Handlungsfreiheit nach Art. 2 I GG verletzt zu sein. Folglich ist der Kläger klagebefugt."

In Drittanfechtungskonstellationen kann hingegen wie folgt die Prüfung eingeleitet werden: „Der Kläger müsste klagebefugt sein. Dies ist bei einer Anfechtungsklage nach $\S 42$ II VwGO der Fall, wenn der Kläger geltend machen kann, durch den Verwaltungsakt in seinen Rechten verletzt zu sein. Diesbezüglich genügt es, wenn die Möglichkeit der Verletzung in eigenen Rechten durch den Verwaltungsakt besteht. Allerdings wurde der vorliegend angegriffene Verwaltungsakt nicht dem Kläger persönlich, sondern (...) erteilt. Die Adressatentheorie ist in diesem Fall unanwendbar. Vielmehr ist anhand der Schutznormtheorie zu untersuchen, ob durch den erteilten Verwaltungsakt eine Verletzung gerade dem Schutz des Klägers dienender Rechtspositionen möglich erscheint. Nach der Schutznormtheorie ist ein Recht drittschützend, wenn es nicht nur ausschließlich dem Interesse der Allgemeinheit dient, sondern vielmehr auch dem Schutz individueller Rechte, die einem abgrenzbaren Kreis von Begünstigten zusteht.“

\section{Literaturhinweise}

Detterbeck, Allgemeines Verwaltungsrecht, 17. Aufl. 2019, § 31 Rn. 1351-1353 und 300 Rn. 1382-1383; Gersdorf, Verwaltungsprozessrecht, 6. Aufl. 2019, Rn. 27 ff; Hufen,

766 Vgl. weiterführend Gersdorf, Verwaltungsprozessrecht, 6. Aufl. 2019, Rn. 31. 767 Gersdorf, Verwaltungsprozessrecht, 6. Aufl. 2019, Rn. 31. 
Verwaltungsprozessrecht, 11. Aufl. 2019, § 14 Rn. 53ff.; Schaks/Friedrich, Verwaltungsaktbezogener Rechtsschutz: Die Zulässigkeitsprüfung, JuS 2018, 860

\section{Das Vorverfahren (Renana Braun)}

301 Das Widerspruchsverfahren (auch: Vorverfahren) eröffnet der Verwaltung die Möglichkeit, nach dem Erlass eines Verwaltungsakts die von der Ausgangsbehörde in der Sache getroffene Entscheidung verwaltungsintern zu überdenken. Im Rechtsstreit um die Rechtmäßigkeit von Verwaltungsakten stellt es eine Sachentscheidungsvoraussetzung für die Klageerhebung dar.

302 Das Vorverfahren bezweckt auf der einen Seite die Stärkung der Selbstkontrolle der Verwaltung verbunden mit einer Filterfunktion zur Entlastung der Verwaltungsgerichte. ${ }^{768}$ Auf der anderen Seite erweitert es den Rechtsschutz der Adressaten von Verwaltungsakten um eine kostengünstige und aus diesem Grunde risikoarme Form, die die Ausübung des Ermessens insgesamt in den Blick nimmt und nicht nur auf Ermessensfehler überprüft. ${ }^{769}$ Damit steht das Vorverfahren als Zwitter zwischen Verwaltungs- und Gerichtsverfahren.

Besondere Bedeutung entfaltet der Widerspruch im Hinblick auf die formelle Bestandskraft, bei deren Eintritt die Anfechtbarkeit durch den Betroffenen entfällt und der Verwaltungsakt nur noch unter den engmaschigen Voraussetzungen einer Wiederaufnahme des Verfahrens nach $\S 51$ VwVfG (näher dazu $\S 3$ Rn. 108 ff.) bzw. durch Rücknahme oder Widerruf nach §§ $48 \mathrm{ff}$. VwVfG (näher dazu Rn. 844 ff. und 941 ff.) behördlich aufgehoben werden kann: Nach § 80 I VwGO entfaltet die Einlegung eines Widerspruchs aufschiebende Wirkung (Suspensiveffekt). Diese hält so lange an, bis im Rahmen eines Widerspruchsbescheides über den Widerspruch entschieden wird. Die Hemmung des Eintritts der formellen Bestandskraft des Verwaltungsakts sperrt die Vollstreckbarkeit des Verwaltungsakts, sofern nicht dessen sofortige Vollziehung gesetzlich oder behördlich angeordnet worden ist (vgl. § 6 I VwVG, § 80 II 1 VwGO).

304 Das Vorverfahren richtet sich in erster Linie nach $\S \S 68-73$ VwGO und den Ausführungsgesetzen der Bundesländer. Es beginnt mit der Einlegung des außergerichtlichen Rechtsbehelfs und endet mit dem Abhilfe- oder Widerspruchs-

768 Vgl. Schenke, Verwaltungsprozessrecht, 15. Aufl. 2017, Rn. 646.

769 Vgl. Erbguth/Guckelberger, Allgemeines Verwaltungsrecht mit Verwaltungsprozessrecht und Staatshaftungsrecht, 9. Aufl. 2018, § 20 Rn. 2; Maurer/Waldhoff, Allgemeines Verwaltungsrecht, 19. Aufl. 2017, Teil 3 Rn. 75; Brühl, Verwaltungsrecht für die Fallbearbeitung - Anleitungen zum Erwerb prüfungs- und praxisrelevanter Kenntnisse und Fertigkeiten, 9. Aufl. 2018, Rn. 602; Würtenberger/Heckmann, Verwaltungsprozessrecht - Ein Studienbuch, 4. Aufl. 2018, Rn. $410 \mathrm{ff}$. 
bescheid. Da dieser selbst in Form eines Verwaltungsakts im Sinne des $§ 35$ VwVfG ergeht, sind nachrangig (vgl. § 79 VwVfG) die Vorschriften des VwVfG einschlägig.

Abhilfeverfahren

Hält die Ausgangsbehörde den Widerspruch für zulässig und begründet, hilft sie ihm ab (§ 72 VwGO), indem sie den Verwaltungsakt aufhebt oder ändert.
Widerspruchsverfahren (i.e.S.)

305

Hält die Ausgangsbehörde den Widerspruch für unzulässig oder unbegründet, hilft sie nicht ab und legt ihn stattdessen der Widerspruchsbehörde vor (§ 73 I 1 VwGO). Diese erlässt einen Widerspruchsbescheid, in dem sie den Widerspruch als unzulässig verwirft, als unbegründet zurückweist oder diesem stattgibt.

Als Zulässigkeitsvoraussetzung der Anfechtungsklage muss der Kläger in der 306 Regel vor Klageerhebung form- und fristgerecht, aber erfolglos Widerspruch eingelegt haben.

\section{Erforderlichkeit des Vorverfahrens}

Das Vorverfahren ist als Sachentscheidungsvoraussetzung im Rahmen eines Klageverfahrens erforderlich, wenn der Widerspruch statthaft und nicht entbehrlich ist.

Statthaft ist der Widerspruch für die Erhebung der Anfechtungsklage gemäß $\S 68$ I 1 VwGO.

Nach § 68 I 2 Hs. 1 VwGO ist das Vorverfahren entbehrlich, wenn ein Ge- 308 setz dies bestimmt. Entsprechende Ausschlüsse des Vorverfahrens sind sowohl in Bundes-, als auch in Landesgesetzen vorgesehen. In einigen Bundesländern wie Niedersachsen und Nordrhein-Westfalen wurde das Vorverfahren grundsätzlich, in anderen für bestimmte Bereiche oder Behörden abgeschafft. Als Gründe hierfür werden Vereinfachungsbestrebungen, die Ersparnis von Verwaltungskosten, die Beschleunigung des Rechtsschutzes und die geringe Erfolgsquote des Widerspruchsverfahrens genannt. ${ }^{770}$

770 Vgl. Erbguth/Guckelberger, Allgemeines Verwaltungsrecht mit Verwaltungsprozessrecht und Staatshaftungsrecht, 9. Aufl. 2018, § 20 Rn. 2; Maurer/Waldhoff, Allgemeines Verwaltungsrecht, 19. Aufl. 2017, Teil 3 Rn. 75; krit. Würtenberger/Heckmann, Verwaltungsprozessrecht - Ein Studienbuch, 4. Aufl. 2018, Rn. 408. 
309 Examenswissen: Ausnahmen auf Bundesebene finden sich beispielsweise in §§ 74 I 2, 70 VwVfG, $\S 74$ VI 3 VwVfG, § 17b I FStrG, § 11 AsylG, § 83 II AufenthG, § 25 IV 2 JuSchG, § 54 II 3 BeamtStG und $\S 20$ VI BDSG.

Beispiele für Sondervorschriften auf Länderebene liefern § 15 BWAGVwGO, § 15 II BayAGVwGO, § 4 II AGVwGO Bln, § 93 I LBG Bln, \& 6 II HbgAGVwGO, § 16a I HessAGVwGO, § 13b AGGStrG $M-V, \S 13 a$ GerStrukGAG M-V, \& 8a I NdsAGVwGO, §110 JustG NRW und §8a SachsAnhAGVwGO.

310 Darüber hinaus ist das Vorverfahren gegen Entscheidungen einer obersten Bundes- oder Landesbehörde entbehrlich (\$ 68 I 2 Nr. 1 VwG0). ${ }^{771}$ Da es in diesen Fällen an einer nächsthöheren Behörde fehlt und die Ministerialebene von Widerspruchsverfahren freigehalten werden soll, ${ }^{772}$ kann das Verwaltungsgericht hier unmittelbar angerufen werden.

311 Schließlich ist das Vorverfahren auch dann entbehrlich, wenn der Abhilfeoder Widerspruchsbescheid erstmalig eine Beschwer enthält (§ 68 I 2 Nr. 2 VwGO). Von der „erstmaligen“ Beschwer ist auch die „zusätzliche“ Beschwer i.S.d. § 79 II VwGO erfasst.

Über die gesetzlich normierten Ausnahmen hinaus erkennt die Rechtsprechung auch dann die Entbehrlichkeit des Widerspruchsverfahrens an, wenn seine Zwecke bereits auf andere Weise erreicht worden sind oder nicht länger erreicht werden können. ${ }^{773}$ Angenommen wird dies zum Beispiel, wenn sich die Widerpruchsbehörde vorgerichtlich endgültig auf die Ablehnung des Rechtsschutzbegehrens festgelegt hat und dies zu erkennen gibt ${ }^{774}$ oder den anzugreifenden Verwaltungsakt selbst aufgrund bindender Weisung der Aufsichtsbehörde erlassen hat ${ }^{775}$. Dazu zählt auch der Fall, dass sich die Widerspruchsbehörde unter Verzicht auf die Durchführung des Vorverfahrens auf die Klage einlässt; anders ist indes der Fall zu beurteilen, in dem sich die Widerspruchsbehörde nur „hilfsweise“ zur Sache einlässt. ${ }^{776}$

771 Beachte die Sonderregelungen nach $\S 126$ III BBG und § 54 III BeamtStG.

772 Vgl. Uerpmann-Wittzack, Examens-Repetitorium - Allgemeines Verwaltungsrecht mit Verwaltungsprozessrecht, 5. Aufl. 2018, § 5 Rn. 87a.

773 BVerwG, Urt. v. 15.9.2010, Az.: 8 C 21.09 = BVerwGE 138, 1 mit ausführlicher Begründung. 774 BVerwG, Urt. v. 30.10.2013, Az.: 2 C 23.12 = BVerwGE 148, 217.

775 BVerwG, Urt. v. 15.9.2010, Az.: 8 C 21.09 = BVerwGE 138, 1.

776 Hüttenbrink, in: Posser/Wolff, VwGO, 49. Ed., (Stand: 1.4. 2018), § 68 Rn. 23; VGH BW, Urt. v. 23.9.1991, Az.: 1 S 1746/91 Rn. 17 = NVwZ-RR 1992, 184; OVG NRW, Urt. v. 18.4.2013, Az.: 1 A 155/11 Rn. 66 = BeckRS 2013, 50411. 


\section{Ordnungsgemäße Einlegung}

Der Widerspruch muss nicht als solcher bezeichnet werden. ${ }^{777}$ Vielmehr genügt 313 es, wenn die Willenserklärung des Klägers nach § 133 BGB analog erkennen lässt, dass dieser gegen einen erlassenen Verwaltungsakt bzw. die Nichtvornahme eines Verwaltungsakts vorgehen möchte. ${ }^{778}$

\section{a) Handlungsfähigkeit (§§ 79, 11ff. VwVfG)}

Der Widerspruchsführer muss handlungsfähig i.S.d. $\S \S 79,11 \mathrm{ff}$. VwVfG sein. Die 314 an die Handlungsfähigkeit nach $\S 12$ VwVfG gestellten Anforderungen entsprechen im Wesentlichen denjenigen der Prozessfähigkeit nach § 62 VwGO (näher dazu Rn. $433 \mathrm{ff}$.). ${ }^{779}$ Bei gewillkürter Vertretung muss wie im Rahmen des $§ 67$ VwGO eine entsprechende Vollmacht vorliegen (§§ 14, 79 VwVfG).

\section{b) Einhaltung der Widerspruchsform ( $\$ 70$ I 1 VwG0)}

$\S 70$ I 1 VwGO sieht vor, dass der Widerspruch schriftlich, in elektronischer Form 315 nach § 3a II VwVfG oder zur Niederschrift zu erheben ist.

Grundsätzlich verlangt die schriftliche Einlegung des Widerspruchs eine 316 eigenständige Unterschrift des Widerspruchsführers oder seines Bevollmächtigten. ${ }^{780}$ Das Schriftformerfordernis ist allerdings nicht streng i.S. d. § $126 \mathrm{BGB} z \mathrm{zu}$ verstehen. Vielmehr genügt es, wenn aus dem Widerspruchsschreiben klar hervorgeht, wer dessen Urheber ist und dass es zur Erhebung des Widerspruchs willentlich in Verkehr gebracht wurde. ${ }^{781}$

Die elektronische Einlegung setzt voraus, dass die Behörde hierzu den $\mathrm{Zu}-317$ gang eröffnet (§ 3a I VwVfG). Sie ist auf die in § 3a II VwVfG genannten Verfahren beschränkt. Die Versendung einer einfachen E-Mail ohne Signatur erfüllt diese Voraussetzungen nicht. $^{782}$

777 Schenke, Verwaltungsprozessrecht, 16. Aufl. 2019, Rn. 653.

778 Brühl, Verwaltungsrecht für die Fallbearbeitung - Anleitungen zum Erwerb prüfungs- und praxisrelevanter Kenntnisse und Fertigkeiten, 9. Aufl. 2018, Rn. 607.

779 Detterbeck, Allgemeines Verwaltungsrecht mit Verwaltungsprozessrecht, 17. Aufl. 2019, Rn.1366; Erbguth/Guckelberger, Allgemeines Verwaltungsrecht mit Verwaltungsprozessrecht und Staatshaftungsrecht, 9. Aufl. 2018, § 20 Rn. 9.

780 Würtenberger/Heckmann, Verwaltungsprozessrecht - Ein Studienbuch, 4. Aufl. 2018, Rn. 355.

781 BVerwG, Urt.v. 17.10.1968, Az.: II C 112.65 = BVerwGE 30, 274; Brühl, Verwaltungsrecht für die Fallbearbeitung - Anleitungen zum Erwerb prüfungs- und praxisrelevanter Kenntnisse und Fertigkeiten, 9. Aufl. 2018, Rn. 627 m.w. N.

782 Vgl. Hufen, Verwaltungsprozessrecht, 11. Aufl. 2019, § 6 Rn. 23. 
Die Einlegung des Widerspruchs zur Niederschrift verlangt demgegenüber die mündliche Abgabe der Widerspruchserklärung gegenüber einem zuständigen Behördenmitarbeiter, der hierüber eine Niederschrift anfertigt. Hierzu muss der Widerspruchsführer persönlich anwesend sein. ${ }^{783}$ Ein Telefonat genügt insoweit nicht.

\section{c) Einhaltung der Widerspruchsfrist ( $\$ 70$ I 1 VwG0)}

319 Neben den Vorgaben für die Form regelt $\S 70$ I 1 VwGO auch die Frist, innerhalb derer der Widerspruch einzulegen ist.

\section{aa) Monatsfrist}

320 Die Frist zur Einlegung des Widerspruchs beträgt nach $\S 70$ I 1 VwGO einen Monat ab Bekanntgabe des Ausgangsbescheides. Bekanntgabe ist die amtlich veranlasste Kenntnisnahme eines Verwaltungsakts i.S.d. § 41 VwVfG. ${ }^{784}$

Für den Zeitpunkt der Bekanntgabe des Verwaltungsakts kann § 41 II VwVfG heranzuziehen sein, wonach ein im Inland durch die Post übermittelter schriftlicher Verwaltungsakt am dritten Tag nach der Aufgabe zur Post und ein elektronisch übermittelter Verwaltungsakt am dritten Tag nach der Absendung als bekannt gegeben gelten, wenn der Verwaltungsakt nicht überhaupt nicht oder zu einem späteren Zeitpunkt zugeht. Hierbei handelt es sich um eine unwiderlegbare Fiktion. ${ }^{785}$ Ein tatsächlich früher erfolgender Zugang ist folglich unschädlich, auch wenn dieser nachweisbar ist. Da mit der Vorschrift nicht das Ende einer Frist bestimmt wird, ist $§ 193$ BGB nicht anwendbar. ${ }^{786}$ Eine entsprechende Regelung für die förmliche Bekanntgabe von Verwaltungsakten im Wege der Zustellung trifft § 4 II 2 VwZG. Ein elektronischer Verwaltungsakt, der durch den Abruf über öffentlich zugängliche Netze bekanntgegeben wird, gilt am Tag nach dem Abruf als bekannt gegeben (\$ 41 IIa VwVfG). Als zugestellt gilt ein elektronisches Dokument gemäß § 5 VII 2 und $\mathbf{3}$ VwZG am dritten Tag nach der Absendung an den vom Empfänger hierfür eröffneten Zugang, wenn der Empfänger nicht nachweist, dass ihm das Dokument nicht oder zu einem späteren Zeitpunkt zugegangen ist.

783 Brühl, Verwaltungsrecht für die Fallbearbeitung - Anleitungen zum Erwerb prüfungs- und praxisrelevanter Kenntnisse und Fertigkeiten, 9. Aufl. 2018, Rn. 629.

784 Würtenberger/Heckmann, Verwaltungsprozessrecht - Ein Studienbuch, 4. Aufl. 2018, Rn. 356.

785 Eine abweichende Regelung trifft $\S 7$ VwVfGBbg.

786 Hierzu ausführlich Brühl, Verwaltungsrecht für die Fallbearbeitung - Anleitungen zum Erwerb prüfungs- und praxisrelevanter Kenntnisse und Fertigkeiten, 9. Aufl. 2018, Rn. 636.

Renana Braun 
Für die Berechnung der Monatsfrist stehen sich die verwaltungsprozessuale 321 Lösung über § 57 II VwGO i.V.m. § 222 I ZPO i.V.m. §§ $187 \mathrm{ff}$. BGB und die verwaltungsverfahrensrechtliche Lösung ${ }^{787}$ über $\S 79$ i.V.m. $\S 31$ I VwVfG i.V.m. $\S \S 187 \mathrm{ff}$. BGB gegenüber. In einer Klausur braucht der Streit nicht entschieden zu werden, da letztlich beide Lösungen zur Anwendung der zivilrechtlichen Vorschriften zur Fristberechnung führen und § 222 II ZPO und § 31 III VwVfG inhaltsgleiche Regelungen enthalten, sodass die unterschiedlichen Lösungswege insofern keine Auswirkung auf das Ergebnis nehmen. ${ }^{788}$

Hausarbeitswissen: Als Argumente für die verwaltungsprozessuale Lösung können der in $\S 79$ VwVfG verankerte Vorrang der VwGO, die Regelung des Widerspruchs innerhalb der VwGO sowie seine Rechtsnatur als Rechtsbehelf angeführt werden. Für die verwaltungsverfahrensrechtliche Lösung spricht demgegenüber zum einen, dass das Vorverfahren der Selbstkontrolle der Behörde dient und in erster Linie als internes Verwaltungs- und nicht als gerichtliches Verfahren konzipiert ist. Zum anderen markieren die §§ 68ff. VwGO für das Widerspruchsverfahren erkennbar Ausnahmebestimmungen, weshalb beispielsweise $\S 70$ II VwGO auf andere Vorschriften der VwGO verweist. Dieser Verweis erstreckt sich aber nicht auch auf \& 57 II VwGO.

Insofern ist für den Fristbeginn $\S 187$ I BGB maßgeblich. Danach beginnt die Widerspruchsfrist mit dem Tag, der auf die Bekanntgabe der Frist folgt, zu laufen. Für das Fristende gelten $\S 188$ BGB und $\S 222$ II ZPO nach verwaltungsprozessualer Lösung bzw. § 31 III VwVfG nach verwaltungsverfahrensrechtlicher Lösung. Im Grundsatz endet die Widerspruchsfrist damit mit Ablauf desjenigen Tages des Folgemonats, der in seiner Ziffer dem Tag der Bekanntgabe entspricht. Ausnahmen bestehen, wenn im Folgemonat der für den Ablauf maßgebende Tag fehlt (vgl. § 188 BGB) oder das Fristende auf einen Samstag, Sonntag oder Feiertag fällt (vgl. § 222 II ZPO bzw. § 31 III VwVfG). Im ersten Fall endet die Frist mit dem Ablauf des letzten Tages des Monats, im zweiten Fall mit dem nächsten Werktag.

Da für die Sachentscheidungsvoraussetzungen der Anfechtungsklage auf 323 den Zeitpunkt der letzten mündlichen Verhandlung des Verwaltungsgerichts abzustellen ist, ist $\mathrm{zu}$ berücksichtigen, dass ein fehlendes, aber erforderliches Vorverfahren nach Klageerhebung nachgeholt werden kann, sofern die Widerspruchsfrist noch nicht abgelaufen ist. ${ }^{789}$

787 Erbguth/Guckelberger, Allgemeines Verwaltungsrecht mit Verwaltungsprozessrecht und Staatshaftungsrecht, 9. Aufl. 2018, § 20 Rn. 9.

788 Vgl. Detterbeck, Allgemeines Verwaltungsrecht mit Verwaltungsprozessrecht, 17. Aufl. 2019, Rn. 1356.

789 Detterbeck, Allgemeines Verwaltungsrecht mit Verwaltungsprozessrecht, 17. Aufl. 2019, Rn. 1354 m.w. N.; Schenke, Verwaltungsprozessrecht, 16. Aufl. 2019, Rn. 642 m.w. N.

Renana Braun 


\section{bb) Jahresfrist}

324 Bei unterbliebener oder unrichtiger Rechtsbehelfsbelehrung beträgt die Widerspruchsfrist gemäß $\S 70$ II i.V.m. § 58 II VwGO statt einem Monat ein Jahr. Für die Berechnung der Jahresfrist gelten dieselben Vorschriften wie für die Monatsfrist. Eine ordnungsgemäße Rechtsbehelfsbelehrung setzt Angaben über den Rechtsbehelf, die Behörde, an die der Widerspruch zu richten ist, deren Sitz und die einzuhaltende Frist voraus (vgl. §37 VI 1 VwVfG). Zur Unrichtigkeit der Rechtsbehelfsbelehrung führen sämtliche Angaben, die geeignet sind, den Betroffenen durch einen hervorgerufenen Irrtum von einer ordnungsgemäßen Widerspruchseinlegung abzuhalten. ${ }^{790}$ Hierzu genügen beispielsweise die Angabe einer Frist von vier Wochen anstelle der gesetzlichen Monatsfrist, eine fehlerhafte Behördenanschrift oder die Angabe, die Widerspruchsfrist beginne mit dem Zugang statt mit der Bekanntmachung zu laufen. Angaben zur Form der Widerspruchseinlegung bedarf es nicht. Verlangt die Rechtsbehelfsbelehrung allerdings die schriftliche Einlegung, macht der fehlende Hinweis auf die Alternativen zur schriftlichen Einlegung in Form der elektronischen Einlegung und der Einlegung zur Niederschrift diese unrichtig. ${ }^{791}$

\section{cc) Verstreichen der Widerspruchsfrist}

325 Bei verstrichener Widerspruchsfrist kann dem Widerspruchsführer Wiedereinsetzung in den vorigen Stand zu gewähren sein. Dies bestimmt sich nach $\S 70$ II i.V.m. §60 I bis IV VwGO und setzt voraus, dass der Widerspruchsführer ohne Verschulden daran gehindert war, die Widerspruchsfrist einzuhalten. Der Antrag auf Wiedereinsetzung ist binnen zwei Wochen ab Wegfall des Hindernisses und innerhalb eines Jahres nach Ende der versäumten Frist zu stellen und die Tatsachen zu seiner Begründung vom Antragsteller glaubhaft zu machen (§ 173 VwGO i.V.m. § 294 ZPO). Die Einlegung des Widerspruchs ist innerhalb der zweiwöchigen Antragsfrist nachzuholen. Ist dies geschehen, kann die Wiedereinsetzung auch ohne Antrag gewährt werden. „Ohne Verschulden“ wird die Frist versäumt, wenn der Widerspruchsführer die erforderliche Sorgfalt walten lässt, die in seiner Situation für einen gewissenhaften Beteiligten geboten und zumutbar erscheint. ${ }^{792}$

790 Brühl, Verwaltungsrecht für die Fallbearbeitung - Anleitungen zum Erwerb prüfungs- und praxisrelevanter Kenntnisse und Fertigkeiten, 9. Aufl. 2018, Rn. 659.

791 Brühl, Verwaltungsrecht für die Fallbearbeitung - Anleitungen zum Erwerb prüfungs- und praxisrelevanter Kenntnisse und Fertigkeiten, 9. Aufl. 2018, Rn. 659f.

792 Erbguth/Guckelberger, Allgemeines Verwaltungsrecht mit Verwaltungsprozessrecht und Staatshaftungsrecht, 9. Aufl. 2018, § 20 Rn. 9.

Renana Braun 
Nach der Rechtsprechung des Bundesverwaltungsgerichts ${ }^{793}$ kann auch ein 326 verfristeter Widerspruch sachlich beschieden werden. Für die Zulässigkeitsprüfung im Rahmen der Anfechtungsklage bedeutet dies, dass auch dann vom Vorliegen der Sachentscheidungsvoraussetzung eines erfolglos durchgeführten Vorverfahrens auszugehen ist, wenn ein Widerspruchsbescheid ergeht, gleichwohl die Widerspruchsfrist versäumt worden ist. Dies ist Ausfluss der ständigen Rechtsprechung, wonach eine sachliche Bescheidung des Widerspruchs die Klagemöglichkeit unabhängig davon eröffnet, ob die Widerspruchsbehörde zu seiner Bescheidung verpflichtet war oder nicht. ${ }^{794}$ Damit kommt der Widerspruchsbehörde die Dispositionsfreiheit $\mathrm{zu}$, die behördlichen und gerichtlichen Rechtsschutzmöglichkeiten des Widerspruchsführers nach Ablauf der Widerspruchsfrist wiederherzustellen.

Examenswissen: Ein Teil der Literatur kritisiert die Rspr. zur Heilung der Verfristung eines Widerspruchs mittels einer in der Sache ergehenden Entscheidung der Widerspruchsbehörde, weil sie im Widerspruch zu Rechtssicherheit und Bestandsschutz steht, die u. a. die Inanspruchnahme der Verwaltungsgerichte begrenzen. ${ }^{795}$ Denn mit der behördlichen Heilung der Verfristung des Widerspruchs wird auch die Befassung der Verwaltungsgerichtsbarkeit in das Ermessen der Widerspruchsbehörde gestellt. Weder die Argumentation, wonach die Widerspruchsbehörde die Sachherrschaft behalten und „Herrin des Streitstoffs“ bleiben solle, ${ }^{796}$ noch ein Abstellen darauf, dass die Widerspruchsfrist in erster Linie den Schutz des Rechtsträgers der Ausgangs- bzw. Widerspruchsbehörde bezwecke, ${ }^{797}$ vermögen diese Bedenken auszuräumen. Schließlich beschränkt sich die Sachherrschaft bei fristgemäßer Einlegung eines Widerspruchs darauf, über den Widerspruch zu entscheiden, und erstreckt sich nicht auch auf die Frage der Zulässigkeit einer Klage, soweit für den Fall einer ausbleibenden Entscheidung § 75 VwGO den Klageweg ebnet. Bei $\S 70$ I 1 VwGO handelt es sich auch nicht um eine verfahrensrechtliche Schutzvorschrift allein zugunsten des Rechtsträgers der Ausgangs- bzw. Widerspruchsbehörde, auf deren Schutz diese verzichten kann. Dies gilt zum einen mit Blick auf etwaig betroffene Dritte (etwa beim Nachbarwiderspruch) und zum anderen bei einer reformatio in peius für den Widerspruchsführer selbst. Die Norm ist vielmehr als Teil des Geflechts von Verfahrensvorschriften zu betrachten, das die Bestandskraft von Verwaltungsakten regelt. Hierin ist eine Durchbrechung der Bestandskraft in den Ausnahmefällen der Wiedereinsetzung in den vorigen Stand, des Wiederaufgreifens des Verfahrens nach $\S 51$ VwVfG sowie der Aufhebung von Verwaltungsakten nach $§ \S 48 \mathrm{ff}$. VwVfG

793 BVerwG, Urt. v. 28.10.1982, Az.: 2 C 4.80 = NVwZ 1983, 608; BVerwG, Urt. v. 18.11.2010, Az.: 3 C 42.09 = BVerwGE 138, 159 (Rn. 13).

794 Vgl. BVerwG, Urt. v. 21.3.1979, Az.: 6 C 10.78 = BVerwGE 57, 342 (344f.) m.w. N.; BVerwG, Urt.v. 28.10.1982, Az.: 2 C 4.80 = NVwZ 1983, 608.

795 Brühl, Verwaltungsrecht für die Fallbearbeitung - Anleitungen zum Erwerb prüfungs- und praxisrelevanter Kenntnisse und Fertigkeiten, 9. Aufl. 2018, Rn. 663.

796 Würtenberger/Heckmann, Verwaltungsprozessrecht - Ein Studienbuch, 4. Aufl. 2018, Rn. 361 m.w. N.

797 Jäde, Verwaltungsverfahren Widerspruchsverfahren Verwaltungsprozess - Problemschwerpunkte zur Vorbereitung auf die Zweite Juristische Staatsprüfung, 6. Aufl. 2011, Rn. 142f.

Renana Braun 
vorgesehen. Gemein ist diesen Ausnahmen, dass sie die betroffenen Interessen in der jeweiligen Konstellation gegeneinander abwiegen und der Behörde nicht gemeinhin ohne weitere Voraussetzungen ermöglichen, die Bestandskraft des Verwaltungsakts anzurühren. Insofern steht die verwaltungsprozessuale Ausgestaltung der Bestandskraft zum Zwecke der Rechtssicherheit einer Ausweitung der behördlichen Gestaltungsmacht, wonach die Widerspruchsbehörde den nach dem Prozessrecht bereits geschlossenen Zugang zum gerichtlichen Rechtsschutz nach eigenem Ermessen erneut eröffnen könnte, entgegen.

In einer Klausur ist der Streit nur zu diskutieren, wenn zu einem verfristeten Widerspruch eine Sachentscheidung der Behörde ergeht. Wer sich gegen die Rspr. entscheidet, muss hilfsgutachterlich weiterprüfen (dazu § 1 Rn. 139).

Abweichend begründet die Verfristung des Widerspruchs ungeachtet einer sachlichen Bescheidung durch die Widerspruchsbehörde unstrittig die Unzulässigkeit einer sich anschließenden Klage, wenn der Widerspruchsbescheid die Interessen eines Dritten berührt, der durch die mit Fristablauf eingetretene Bestandskraft des Verwaltungsakts bereits eine gesicherte Rechtsposition erlangt hatte. ${ }^{798}$ Denn auch die von der herrschenden Meinung angenommene behördliche Sachherrschaft geht nicht so weit, als dass die Widerspruchsbehörde über geschützte Interessen Dritter disponieren dürfte. ${ }^{799}$

\section{dd) Verwirkung}

329 Hat die Widerspruchsfrist in Ermangelung einer Bekanntgabe (beispielsweise im Falle des Nachbarwiderspruchs gegen einen Verwaltungsakt, der nur dem Adressaten, nicht aber dem Widerspruch einlegenden Nachbarn bekannt gegeben wurde $)^{800}$ nicht zu laufen begonnen, kann im Rahmen des allgemeinen Rechtsschutzbedürfnisses zu prüfen sein, ob der Widerspruchsführer den Rechtsbehelf möglicherweise verwirkt hat. Denn auch die Ausübung des Widerspruchsrechts unterliegt dem allgemeinen Rechtsgrundsatz von Treu und Glauben (§ 242 BGB analog). Hiernach kann sich der Widerspruchsführer nicht darauf berufen, dass ihm der Verwaltungsakt nicht bekanntgegeben worden sei,

798 Detterbeck, Allgemeines Verwaltungsrecht mit Verwaltungsprozessrecht, 17. Aufl. 2019, Rn. 1357; Schenke in: Kopp/Schenke, VwGO, 25. Aufl. 2019, § 70 Rn. 9.

799 BVerwG, Urt. v. 29.10.1968, Az.: IV B 7.68G = DÖV 1969, 142 (142f.); Würtenberger/Heckmann, Verwaltungsprozessrecht - Ein Studienbuch, 4. Aufl. 2018, Rn. 361 m.w. N.

800 S. hierzu Erbguth/Guckelberger, Allgemeines Verwaltungsrecht mit Verwaltungsprozessrecht und Staatshaftungsrecht, 9. Aufl. 2018, § 20 Rn. 9 m.w. N. 
wenn er sichere Kenntnis von diesem erhalten hat ${ }^{801}$ und $\mathrm{zu}$ dem Zeitmoment ein Umstandsmoment hinzutritt (s. zur Verwirkung auch Rn. 399f.). ${ }^{802}$

\section{d) Richtige Behörde}

Die Widerspruchsfrist wird nur bei Einlegung des Widerspruchs bei der richti- 330 gen Behörde gewahrt. Dies ist nach $\S 70$ I 1 VwGO grundsätzlich die Ausgangsbehörde. Nach $\S 70$ I 2 VwGO wird die Frist aber auch dann eingehalten, wenn der Widerspruch bei der Behörde, die den Widerspruchsbescheid zu erlassen hat, eingelegt wird.

Widerspruchsbehörde ist gemäß $§ 73$ I 2 Nr. 1 VwGO die nächsthöhere Be- 331 hörde, wenn nicht aufgrund sondergesetzlicher Bestimmung die Behörde, die den Verwaltungsakt erlassen hat, auch für die Entscheidung über den Widerspruch zuständig ist (§ 73 I 3 VwGO). Ist die nächsthöhere Behörde eine oberste Bundesoder oberste Landesbehörde, ist die Behörde, die den Verwaltungsakt erlassen hat, auch Widerspruchsbehörde (§ 73 I 2 Nr. 2 VwGO). Dies dient - wie $§ 68$ I 2 Nr. 1 VwGO - der Entlastung der Ministerialebene. ${ }^{803}$ In Selbstverwaltungsangelegenheiten ist die Selbstverwaltungsbehörde für die Entscheidung über den Widerspruch zuständig, soweit nicht durch Gesetz etwas anderes bestimmt ist (§ 73 I 2 Nr. 3 VwGO).

Examenswissen: Wird ein Widerspruch bei einer unzuständigen Behörde eingelegt, ist diese grundsätzlich verpflichtet, den Widerspruch weiterzuleiten. ${ }^{804}$ Unterlässt sie dies, kann das Konstrukt der Einheit der Verwaltung bewirken, dass der Widerspruch als rechtzeitig erhoben angesehen werden muss. Gelangt der Widerspruch allerdings trotz unverzüglicher Weiterleitung zu spät an die zuständige Behörde, bewirkt die Einlegung bei der falschen Behörde nicht etwa eine Fristwahrung kraft Einheit der Verwaltung. Dasselbe gilt, wenn die Verfristung auch bei einer unverzüglichen Weiterleitung eingetreten wäre. Die Zulässigkeit des Widerspruchs hängt demnach bei Einlegung bei einer falschen Behörde davon ab, ob diese den Widerspruch noch rechtzeitig innerhalb der Widerspruchsfrist an die zuständige Behörde weiterleiten kann.

801 Würtenberger/Heckmann, Verwaltungsprozessrecht - Ein Studienbuch, 4. Aufl. 2018, Rn. 362.

802 Näher zur Verwirkung Detterbeck, Allgemeines Verwaltungsrecht mit Verwaltungsprozessrecht, 17. Aufl. 2019, Rn. 561.

803 Vgl. Uerpmann-Wittzack, Examens-Repetitorium - Allgemeines Verwaltungsrecht mit Verwaltungsprozessrecht, 5. Aufl. 2018, §5 Rn. 87a.

804 Detterbeck, Allgemeines Verwaltungsrecht mit Verwaltungsprozessrecht, 17. Aufl. 2019, Rn. 1367. 


\section{Erfolglosigkeit des Widerspruchs}

333 Erfolglos ist der Widerspruch, soweit dem Begehren des Widerspruchsführers nicht im Rahmen eines Abhilfebescheides vollumfänglich abgeholfen wird.

334 Wird über den Widerspruch ohne zureichenden Grund nicht innerhalb einer angemessenen Frist entschieden, ist die Anfechtungsklage nach §75 1 VwGO auch ohne Beendigung des Vorverfahrens durch einen Widerspruchsbescheid als sogenannte Untätigkeitsklage zulässig (s. hierzu Rn. 384 ff.). Die Angemessenheit der Frist ist je nach den Umständen des Einzelfalls zu bestimmen, deckt sich aber regelmäßig mit der Sperrfrist von drei Monaten aus § 752 VwGO. Ein nach Ablauf der Frist ergehender versagender Bescheid lässt das Erfordernis eines Vorverfahrens nicht wieder aufleben, da eine einmal zulässige Klage nicht durch einseitiges Handeln der Verwaltung unzulässig werden darf. Da der Ablauf der Frist erst zum Zeitpunkt der Entscheidung des Gerichts eingetreten sein muss, kann die Untätigkeitsklage auch schon vor deren Ablauf erhoben werden. In diesem Fall ist sie im Zeitpunkt der Erhebung unzulässig, wird aber mit Ablauf der Frist (Heilung des Mangels) zulässig. Ein der Untätigkeitsklage entgegenstehender besonderer Grund kann sich beispielsweise aus den besonderen Schwierigkeiten des Falles oder der Notwendigkeit der Beteiligung Dritter ergeben, nicht aber allein aus Gründen der Arbeitsüberlastung oder aus einer fehlenden Vorauszahlung von Gebühren.

\section{Prüfungsschema Erfolgsaussichten eines Widerspruchs}

335 In einigen Klausurkonstellationen wird nicht nach den Erfolgsaussichten einer Klage, sondern nach denen eines Widerspruchs gefragt. Das Prüfungsschema richtet sich dann nach Zulässigkeit und Begründetheit des Widerspruchs: ${ }^{805}$

\section{A. Zulässigkeit}

I. Verwaltungsrechtsweg (\$ 40 I 1 VwGO analog): Die Eröffnung des Verwaltungsrechtswegs ist ausführlich in $\S 1 \mathrm{Rn} .162 \mathrm{ff}$. dargestellt.

II. Statthaftigkeit des Widerspruchs: Statthaft ist der Widerspruch nur für Situationen, für die das Widerspruchsverfahren ausdrücklich angeordnet

805 Ausführlich bei Brühl, Verwaltungsrecht für die Fallbearbeitung - Anleitungen zum Erwerb prüfungs- und praxisrelevanter Kenntnisse und Fertigkeiten, 9. Aufl. 2018, Rn. 606 ff.; Detterbeck, Allgemeines Verwaltungsrecht mit Verwaltungsprozessrecht, 17. Aufl. 2019, Rn. 1360 ff.; Erbguth/ Guckelberger, Allgemeines Verwaltungsrecht mit Verwaltungsprozessrecht und Staatshaftungsrecht, 9. Aufl. 2018, § 20 Rn. 6 ff.; Würtenberger/Heckmann, Verwaltungsprozessrecht - Ein Studienbuch, 4. Aufl. 2018, Rn. 421 ff.; s. auch Schenke, Verwaltungsprozessrecht, 16. Aufl. 2019, Rn. $648 \mathrm{ff}$. 
ist, so bei Anfechtungs- (§ 68 I 1 i.V.m. § 42 I Alt. 1 VwGO) und Verpflichtungskonstellationen (in der Variante der Versagungsgegenklage gemäß § 68 II i.V.m. § 42 I Alt. 2 VwGO), soweit es nicht durch abweichende Vorschriften ausdrücklich ausgeschlossen ist, und in bestimmten Fällen, in denen die allgemeine Leistungs- oder Feststellungsklage statthafte Klageart ist (vgl. § 54 II 1 BeamtStG, § 126 II 1 BBG).

III. Widerspruchsbefugnis (\$ 42 II VwGO analog): Der Widerspruchsführer muss die Verletzung eigener subjektiv-öffentlicher Rechte geltend machen. Dies ergibt sich aus $\S 70$ I VwGO, nach dem nur „der Beschwerte“ Widerspruch einlegen kann.

Besonderheit: Es genügt, dass der Betroffene geltend macht, der beeinträchtigende Verwaltungsakt sei nicht zweckmäßig (vgl. § 68 I 1 VwGO). Im Falle des Anfechtungswiderspruchs kann auf die Adressatentheorie (s. Rn. 294f.) zurückgegriffen werden.

IV. Ordnungsgemäße Einlegung (insbes. Wahrung Form und Frist): Dazu 339 bereits Rn. $315 \mathrm{ff}$.

V. Allgemeines Rechtsschutzbedürfnis: Der Widerspruch muss Vorteile $\mathbf{3 4 0}$ bezwecken, die nicht allein darin bestehen, anderen $\mathrm{zu}$ schaden, und darf auch nicht auf sonstige Weise offensichtlich rechtsmissbräuchlich sein. ${ }^{806}$ Bei einem Verpflichtungswiderspruch muss außerdem zuvor ein Antrag auf Vornahme des begehrten Verwaltungsakts von der zuständigen Behörde abgelehnt worden sein.

\section{B. Begründetheit}

Ein Anfechtungswiderspruch (§ 68 I VwGO) ist begründet, soweit der angegriffene 341 Verwaltungsakt rechtswidrig und der Widerspruchsführer dadurch in seinen Rechten verletzt ist oder der Verwaltungsakt zweckwidrig und der Widerspruchsführer dadurch in seinen Rechten beeinträchtigt ist (§ 68 I i.V.m. § 113 I 1 VwGO analog).

Ein Verpflichtungswiderspruch (§ 68 II VwGO) ist begründet, soweit die Ab- 342 lehnung des Verwaltungsakts rechtswidrig und der Widerspruchsführer dadurch in seinen Rechten verletzt ist oder die Ablehnung zweckwidrig und der Widerspruchsführer dadurch in seinen Rechten beeinträchtigt ist (§ 68 II i.V.m. § $113 \mathrm{~V} 1$ VwGO analog).

806 Erbguth/Guckelberger, Allgemeines Verwaltungsrecht mit Verwaltungsprozessrecht und Staatshaftungsrecht, 9. Aufl. 2018, § 20 Rn. 10. 
343 Examenswissen: Spezialgesetzliche Regelungen können die Widerspruchsbehörde darauf begrenzen, den Widerspruch nur auf seine Rechtmäßigkeit, nicht aber auf seine Zweckmäßigkeit zu überprüfen. Dies ist der Fall, wenn entgegen § 73 I Nr. 3 VwGO in Selbstverwaltungsangelegenheiten nicht die Selbstverwaltungsbehörde, sondern aufgrund von Landesrecht eine andere Behörde über den Widerspruch entscheidet (vgl. § 8 I BWAGVwGO). ${ }^{807}$ Hebt die Widerspruchsbehörde den Bescheid dennoch wegen Zweckwidrigkeit auf, verletzt sie damit das Selbstverwaltungsrecht der Ausgangsbehörde. Die betroffene Selbstverwaltungskörperschaft kann in diesem Fall als erstmalig beschwerter Dritter i.S.d. § 79 I Nr. 2 VwGO Klage gegen den Widerspruchsbescheid erheben.

\section{Reformatio in peius (,Veränderung ins Schlechte“)}

344 Im Rahmen der Entscheidung über einen Widerspruch kann sich unter dem Stichwort der reformatio in peius die Frage stellen, ob die Widerspruchsbehörde den Verwaltungsakt zu Lasten des Widerspruchsführers ändern kann. In einer Klausur zeitigt eine solche Verböserung im Widerspruchsverfahren Auswirkungen auf verschiedenen Ebenen des Prüfungsschemas, die im Folgenden besprochen werden.

345 Gänzlich von der Konstellation einer reformatio in peius zu unterscheiden ist der Fall, dass ein begünstigender Verwaltungsakt auf den Widerspruch eines belasteten Dritten zu Lasten des Begünstigten verschärft wird. ${ }^{808}$

\section{a) Besonderheiten bei der Prüfung der Zulässigkeit der Klage}

346 Da der Widerspruchsführer im Umfang der Verböserung durch den Widerspruchsbescheid zusätzlich beschwert ist, kann er den Klagegegenstand gemäß $\S 79$ II 1 VwGO hierauf beschränken. Richtiger Klagegegner ist dann die Widerspruchsbehörde bzw. deren Träger (§ 78 II VwGO). ${ }^{809}$

\section{b) Besonderheiten bei der Prüfung der Begründetheit der Klage}

347 Im Rahmen der Begründetheit zeitigt die reformatio in peius auf den Ebenen der Ermächtigungsgrundlage, der formellen sowie der materiellen Rechtmäßigkeit Diskussionsbedarf.

807 Vgl. Detterbeck, Allgemeines Verwaltungsrecht mit Verwaltungsprozessrecht, 17. Aufl. 2019, Rn. 1371.

$808 \mathrm{Zu}$ weiteren Abgrenzungen s. Hufen, Verwaltungsprozessrecht, 11. Aufl. 2019, § 9 Rn. 15. 809 Vgl. Hufen, Verwaltungsprozessrecht, 11. Aufl. 2019, § 9 Rn. 22. 


\section{aa) Ermächtigungsgrundlage}

Es ist umstritten, ob eine reformatio in peius überhaupt zulässig ist. ${ }^{810}$ Die 348 grundsätzliche Möglichkeit zur Verböserung im Laufe des Widerspruchsverfahrens wird durch die VwGO zwar vorausgesetzt. Die Vorschriften der $\S \S 68$ I 2 Nr. 2, 78 II und 79 I Nr. 2, II 1 VwGO lassen jedoch auch eine Lesart zu, der zufolge eine Verschlechterung im Widerspruchsverfahren möglich, aber nicht zwangsläufig auch rechtmäßig sein kann. ${ }^{811}$ Die besseren Gründe sprechen jedoch für die Zulässigkeit der reformatio in peius: Dafür spricht zunächst $§ 71 \mathrm{VwGO}$, der eine Anhörung verlangt, wenn die Aufhebung oder Änderung eines Verwaltungsakts im Widerspruchsverfahren erstmalig mit einer Beschwer verbunden ist. Denn anderenfalls liefe der Schutzzweck der erforderlichen Anhörung ins Leere und wäre die formelle Rechtmäßigkeitsanforderung nicht sachgerecht. Für eine Gestattung der reformatio in peius im Allgemeinen spricht außerdem die Verpflichtung der Widerspruchsbehörde zu einer umfassenden Rechts- und Zweckmäßigkeitskontrolle im Rahmen des Vorverfahrens. ${ }^{812}$ Weiterhin wird der Grundsatz der Gesetzmäßigkeit der Verwaltung zur Begründung ihrer Zulässigkeit ins Feld geführt. ${ }^{813}$

Neben der generellen Gestattung, einen angegriffenen Verwaltungsakt im Widerspruchsverfahren $\mathrm{zu}$ Lasten des Widerspruchsführers abzuändern, verlangt der Vorbehalt des Gesetzes (Art. 20 III GG) eine materiell-rechtliche Ermächtigung der Verwaltung, die belastende Regelung zu erlassen. ${ }^{814}$ Hierfür lassen sich die $\S \S 48 \mathrm{ff}$. VwVfG sowie die Ermächtigungsgrundlage fruchtbar machen, die dem Ausgangsbescheid zugrunde lag. ${ }^{815}$ Damit die im Widerspruchsbescheid getroffene Entscheidung auf diese Rechtsgrundlagen gestützt werden kann, muss sie zum einen für die Beseitigung der im Ausgangsbescheid getroffenen Regelung die Grundsätze über die Aufhebung von Verwaltungsakten beachten und zum anderen die Anwendungsgrenzen der ursprünglichen Rechtsgrundlage einhalten. ${ }^{816}$ Dies ist wiederum im Rahmen der formellen und materiellen Rechtmäßigkeit zu prüfen.

810 Kritisch Hufen, Verwaltungsprozessrecht, 11. Aufl. 2019, § 9 Rn. $15 \mathrm{ff}$.

811 Vgl. Detterbeck, Allgemeines Verwaltungsrecht mit Verwaltungsprozessrecht, 17. Aufl. 2019, Rn. 1373; Ipsen, Allgemeines Verwaltungsrecht, 11. Aufl. 2019, Rn. 1080b.

812 Vgl. Würtenberger/Heckmann, Verwaltungsprozessrecht - Ein Studienbuch, 4. Aufl. 2018, Rn. 435.

813 Detterbeck, Allgemeines Verwaltungsrecht mit Verwaltungsprozessrecht, 17. Aufl. 2019, Rn. 1373.

814 Vgl. Hufen, Verwaltungsprozessrecht, 11. Aufl. 2019, § 9 Rn. 18.

815 S. hierzu Schenke, Verwaltungsprozessrecht, 16. Aufl. 2019, Rn. $693 \mathrm{f}$.

816 Weber in Brandt/Domgörgen, Handbuch Verwaltungsverfahren und Verwaltungsprozess, 4. Aufl. 2018, S. 316f. Rn. 164. 


\section{bb) Formelle Rechtmäßigkeit}

349 Die Widerspruchsbehörde muss außerdem als Teil ihrer sachlichen Zuständigkeit selbst über die erforderliche Kompetenz für die verbösernde Regelung verfügen. Unproblematisch der Fall ist dies, wenn Ausgangs- und Widerspruchsbehörde identisch sind. Außerdem ist die Widerspruchsbehörde verfahrensrechtlich zur Verböserung befugt, wenn sie im Rahmen ihres Rechts zum Selbsteintritt im Widerspruchsverfahren vollumfänglich an die Stelle der Ausgangsbehörde tritt oder sie die Fachaufsicht über die Ausgangsbehörde innehat. ${ }^{817}$

$\S 71$ VwGO verlangt darüber hinaus die Anhörung des Widerpruchsführers zu der behördlich geplanten Änderung. ${ }^{818}$

\section{cc) Materielle Rechtmäßigkeit}

351 Nach ständiger Rechtsprechung des BVerwG sind im Rahmen der materiellen Rechtmäßigkeit die in \$\$ 48 ff. VwVfG niedergelegten Grundsätze über den Vertrauensschutz bei Rücknahme und Widerruf von Verwaltungsakten zu beachten. ${ }^{819}$ Denn der Austausch des belastenden Ausgangsbescheides gegen einen noch stärker belastenden Widerspruchsbescheid ist aus Sicht des Adressaten der Aufhebung eines begünstigenden Verwaltungsakts vergleichbar. ${ }^{820}$ Dabei ist zu berücksichtigen, dass der Widerspruchsführer mit Einlegung des Widerspruchs grundsätzlich mit der Verschlechterung seiner Position zu rechnen hat, da der angegriffene Verwaltungsakt nicht länger Grundlage für ein zu schützendes Vertrauen sein kann. ${ }^{821}$ Für die Annahme eines entsprechenden Vertrauens müssen insoweit besondere Umstände hinzutreten. ${ }^{822}$ Eine Ausnahme ist nach

817 Vgl. Erbguth/Guckelberger, Allgemeines Verwaltungsrecht mit Verwaltungsprozessrecht und Staatshaftungsrecht, 9. Aufl. 2018, § 20 Rn. 15; Groscurth, Examenskurs VwGO für Studenten und Referendare, 2014, Rn. 316; Würtenberger/Heckmann, Verwaltungsprozessrecht - Ein Studienbuch, 4. Aufl. 2018, Rn. 436 m.w. N.

818 Hierzu Hufen, Verwaltungsprozessrecht, 11. Aufl. 2019, § 9 Rn. 20; Weber in Brandt/Domgörgen, Handbuch Verwaltungsverfahren und Verwaltungsprozess, 4. Aufl. 2018, S. 317 f. Rn. 168. 819 S. bspw. BVerwG, Urt. v. 13.9.2006, Az.: 6 C 10.06 = NVwZ-RR 2007, 192 m.w. N.; krit. Groscurth, Examenskurs VwGO für Studenten und Referendare, 2014, Rn. 316.

820 Vgl. Detterbeck, Allgemeines Verwaltungsrecht mit Verwaltungsprozessrecht, 17. Aufl. 2019, Rn. 1374; Erbguth/Guckelberger, Allgemeines Verwaltungsrecht mit Verwaltungsprozessrecht und Staatshaftungsrecht, 9. Aufl. 2018, § 20 Rn. 15.

821 Brühl, Verwaltungsrecht für die Fallbearbeitung - Anleitungen zum Erwerb prüfungs- und praxisrelevanter Kenntnisse und Fertigkeiten, 9. Aufl. 2018, Rn. 685; krit. hierzu Ipsen, Allgemeines Verwaltungsrecht, 11. Aufl. 2019, Rn. 1080c.

822 BVerwG, Urt. v. 15.4.1983, Az.: 8 C 170.81 = BVerwGE 67, 129. 
der Rechtsprechung dann anzunehmen, wenn die Verböserung anderenfalls zu „untragbaren Zuständen“ führte. ${ }^{823}$

\section{Literaturhinweise}

Zum Widerspruch im Allgemeinen: Brandt in Brandt/Domgörgen, Handbuch 352 Verwaltungsverfahren und Verwaltungsprozess, 4. Aufl. 2018, S. 319-354; Brühl, Verwaltungsrecht für die Fallbearbeitung - Anleitungen zum Erwerb prüfungsund praxisrelevanter Kenntnisse und Fertigkeiten, 9. Aufl. 2018, Rn. 602-729; Detterbeck, Allgemeines Verwaltungsrecht mit Verwaltungsprozessrecht, 17. Aufl. 2019, Rn. 1359-1375; Erbguth/Guckelberger, Allgemeines Verwaltungsrecht mit Verwaltungsprozessrecht und Staatshaftungsrecht, 9. Aufl. 2018, § 20 Rn. 1-16; Groscurth, Examenskurs VwGO für Studenten und Referendare, 2014, Rn. 276333; Hufen, Verwaltungsprozessrecht, 11. Aufl. 2019, Teil 2 Das Widerspruchsverfahren; Schenke, Verwaltungsprozessrecht, 16. Aufl. 2019, Rn. 639-696; Weber, in: Brandt/Domgörgen, Handbuch Verwaltungsverfahren und Verwaltungsprozess, 4. Aufl. 2018, S. 276ff.; Würtenberger/Heckmann, Verwaltungsprozessrecht - Ein Studienbuch, 4. Aufl. 2018, Rn. 407-437

Zum Widerspruch im Rahmen der Anfechtungsklage: Brühl, Verwaltungsrecht für die Fallbearbeitung - Anleitungen zum Erwerb prüfungs- und praxisrelevanter Kenntnisse und Fertigkeiten, 9. Aufl. 2018, Rn. 759f.; Detterbeck, Allgemeines Verwaltungsrecht mit Verwaltungsprozessrecht, 17. Aufl. 2019, Rn. 1354-1358; Ipsen, Allgemeines Verwaltungsrecht, 11. Aufl. 2019, Rn. 1061-1080; Sauer, Klausurtraining - Allgemeines Verwaltungsrecht und Verwaltungsprozessrecht, 2018, Rn. 80 - 82; Würtenberger/Heckmann, Verwaltungsprozessrecht - Ein Studienbuch, 4. Aufl. 2018, Rn. 353-363

Übungsfälle: Saarheimer Fälle: „Ausgehöhlt!“, „Dr. Eisenbart“, „Feuer und Flamme“, „Nicht ohne meine Hose“, „Sammy im Saarheimer See“, abrufbar unter http://saarheim.de/; Kurzfälle bei Uerpmann-Wittzack, Examens-Repetitorium Allgemeines Verwaltungsrecht mit Verwaltungsprozessrecht, 5. Aufl. 2018, Fälle $35-37$

Lehrvideo: Brink/Kölle/Weigel, Peer2Peer Lehrvideo Reformatio in peius, abrufbar unter https://youtu.be/04 h4nPGxqT0

823 S. bspw. BVerwG, Urt. v. 13.9.2006, Az.: 6 C 10.06 = NVwZ-RR 2007, 192 m.w. N. 


\section{Die Klagefrist (Patrick Stockebrandt)}

353 Die Einhaltung der Klagefrist des $\S 74$ VwGO gehört zu den zwingenden Sachentscheidungsvoraussetzungen ${ }^{824}$ und ist eine der Prozessvoraussetzungen sowohl für die Anfechtungs- und Verpflichtungsklage als auch für weitere Klagebzw. Antragsarten. ${ }^{825}$ Dies hat zur Folge, dass der gerichtliche Rechtsschutz, der dem Einzelnen gemäß Artikel 19 IV GG verfassungsrechtlich gewährt wird, auch von der Einhaltung der Fristbestimmungen abhängig ist. Es bestehen jedoch keine Zweifel an der Verfassungsmäßigkeit solcher Fristen, da auch im Rechtsstaat ein legitimes, erhebliches Interesse daran besteht, einen Rechtsstreit in angemessener Zeit klären zu können und damit Rechtssicherheit und vor allem auch Rechtsfrieden zu ermöglichen. ${ }^{826}$

354 Die Fristenproblematik ist in der öffentlich-rechtlichen Klausur häufig vorzufinden und es wird erwartet, dass die Klagefrist berechnet werden kann. ${ }^{827}$ Jedoch ist nur auf solche Aspekte einzugehen, die im Sachverhalt auch problematisiert werden. Schweigt der Sachverhalt zu einzelnen Aspekten, ist davon auszugehen, dass die entsprechenden Voraussetzungen im vorliegenden Fall eingehalten wurden.

355 Nachfolgend werden zunächst die Funktion der Klagefrist und die Bestandskraft eines Verwaltungsakts (1.) und sodann die grundlegende Systematik und der Bezug zum Vorverfahren (2.) erläutert. Daran anschließend wird die eigentliche Berechnung beschrieben (3.) und typische Problemfelder im Einzelnen besprochen (4. -7 .).

\section{Funktion der Klagefrist und Bestandskraft eines Verwaltungsakts}

356 Die zentrale Funktion der Klagefrist ist die Sicherung der Bestandskraft eines Verwaltungsakts. ${ }^{828}$ Dieser hat dann Bestandskraft, wenn er mit ordentlichen Rechtsbehelfen (z. B. Widerspruch und Anfechtungsklage) nicht mehr angefochten werden kann. ${ }^{829}$

824 Kintz, Öffentliches Recht im Assessorexamen, 10. Aufl. 2018, Rn. 271; Schenke, in: Kopp/ Schenke, VwGO, 25. Aufl. 2019, Vor § 40 Rn. 17.

825 Schenke, in: Kopp/Schenke, VwGO, 25. Aufl. 2019, § 74 Rn. 1 sowie Rn. 4.

826 Schenke, in: Kopp/Schenke, VwGO, 25. Aufl. 2019, § 74 Rn. 1.

827 Kintz, Öffentliches Recht im Assessorexamen, 10. Aufl. 2018, Rn. 271.

828 Schenke, in: Kopp/Schenke, VwGO, 25. Aufl. 2019, § 74 Rn. 2.

829 Maurer/Waldhoff, Allgemeines Verwaltungsrecht, 19. Aufl. 2017, § 10 Rn. 16; Ramsauer, in: Kopp/Ramsauer, VwVfG, 19. Aufl. 2018, § 43 Rn. 29. Dies wird auch „formelle“ Bestandskraft ge- 
Die „Bestandskraft“ eines Verwaltungsakts ist klar von seiner „Wirksam- 357 keit“ und der möglichen „Rechtswidrigkeit“ zu trennen. Ein Verwaltungsakt wird gemäß § 43 I 1 VwVfG gegenüber demjenigen, für den er bestimmt ist oder der von ihm betroffen wird, in dem Zeitpunkt wirksam, in dem er ihm bekannt gegeben wird. ${ }^{830} \S 43$ II VwVfG nennt die Fälle, in denen die Wirksamkeit eines Verwaltungsakts endet. ${ }^{831}$ Der Umstand, dass ein Verwaltungsakt rechtswidrig ist, ändert zunächst nichts an seiner Wirksamkeit. ${ }^{832}$ Dies hat zur Konsequenz, dass ein rechtswidriger, aber wirksamer Verwaltungsakt grundsätzlich beachtet werden muss. ${ }^{833}$

Der Betroffene kann sich gegen einen rechtswidrigen Verwaltungsakt jedoch mit den dafür vorgesehenen Rechtsbehelfen - z.B. mit Widerspruch und Anfechtungsklage - wehren. Wenn er dies allerdings unterlässt oder z.B. die entsprechenden Fristen nicht einhält, tritt die Bestandskraft - trotz der Rechtswidrigkeit - des Verwaltungsakts ein. ${ }^{834}$ Ein etwaiger Rechtsbehelf hätte dann keine Aussicht auf Erfolg.

Soweit ein Verwaltungsakt bestandskräftig geworden ist, sind vor allem $\mathbf{3 5 8}$ noch zwei Wege der Aufhebung denkbar: über das Wiederaufgreifen des Verfahrens gemäß $\S 51$ VwVfG und vor allem über Rücknahme und Widerruf des Verwaltungsakts gemäß §§ 48, 49 VwVfG (s. dazu Rn. 836ff.). ${ }^{835}$ Im Hinblick auf den äußerst seltenen Fall eines nichtigen Verwaltungsakts gemäß §44 VwVfG (s. dazu $\S 6$ Rn. 115ff.) ist zu beachten, dass ein solcher Verwaltungsakt unwirksam ist ${ }^{836}$ und insofern auch keine Bestandskraft eintreten kann. Auf die Möglichkeit der Wiedereinsetzung in den vorigen Stand wird später einzugehen sein (s. sogleich Rn. 394 ff.).

nannt; s. hierzu insgesamt Maurer/Waldhoff, Allgemeines Verwaltungsrecht, 19. Aufl. 2017, § 10 Rn. 12ff., insbesondere Rn. 16-19.

830 S. auch Maurer/Waldhoff, Allgemeines Verwaltungsrecht, 19. Aufl. 2017, § 9 Rn. 40 sowie $§ 10$ Rn. 7.

831 S. auch Maurer/Waldhoff, Allgemeines Verwaltungsrecht, 19. Aufl. 2017, §10 Rn. 8.

832 Maurer/Waldhoff, Allgemeines Verwaltungsrecht, 19. Aufl. 2017, § 9 Rn. 40 sowie $§ 10$ Rn. 6. 833 Ramsauer, in: Kopp/Ramsauer, VwVfG, 19. Aufl. 2018, § 43 Rn. $14 \mathrm{f}$.

834 Maurer/Waldhoff, Allgemeines Verwaltungsrecht, 19. Aufl. 2017, § 9 Rn. 40; Kopp, in: Kopp/ Ramsauer, VwVfG, 19. Aufl. 2018, § 43 Rn. 8.

835 Ramsauer, in: Kopp/Ramsauer, VwVfG, 19. Aufl. 2018, § 43 Rn. 31.

836 Maurer/Waldhoff, Allgemeines Verwaltungsrecht, 19. Aufl. 2017, § 10 Rn. 7. S. hierzu auch Maurer/Waldhoff, Allgemeines Verwaltungsrecht, 19. Aufl. 2017, § 10 Rn. $85 \mathrm{ff}$.

Patrick Stockebrandt 


\section{Systematik und Bezug zum Vorverfahren}

359 Die Klagefrist des $\S 74$ VwGO gehört zum 8. Abschnitt und damit zu den besonderen Vorschriften für die Anfechtungs- und Verpflichtungsklage. Die Vorschrift knüpft dabei grundsätzlich an das Vorverfahren gemäß §§ $68 \mathrm{ff}$. VwGO (s. hierzu Rn. $301 \mathrm{ff}$.$) an, denn die „Grundregel“ des § 74$ I 1 VwGO bezieht sich auf den Widerspruchsbescheid und damit auf den Abschluss des Vorverfahrens. Insoweit ein Widerspruchsbescheid nach $\S 68$ VwGO nicht erforderlich ist (s. hierzu Rn. 308f.), bezieht sich die Klagefrist gemäß § 74 I 2 VwGO auf den „Ausgangsverwaltungsakt“; also den Verwaltungsakt, der den Einzelnen ursprünglich zu einem Handeln im weitesten Sinne veranlasst hat.

360 Gemäß der Systematik des § 74 I VwGO muss zunächst das fristauslösende Ereignis identifiziert werden. Denn $\S 74$ VwGO knüpft an unterschiedliche Bezugspunkte an: Soweit ein Widerspruchsbescheid erforderlich ist, muss die Anfechtungsklage innerhalb eines Monats nach dessen „Zustellung“ (§ 74 I 1 VwGO) und nur soweit kein Widerspruchsbescheid erforderlich ist, innerhalb eines Monats nach „Bekanntgabe“ des Ausgangsverwaltungsakts (§ 74 I 2 VwGO) erhoben werden.

\section{Fristberechnung}

361 Im Hinblick auf die konkrete Fristberechnung sind gemäß $§ 57$ II VwGO ${ }^{837}$ i.V.m. $\S 222$ ZPO die entsprechenden Regeln des BGB (§§ 187ff. BGB) heranzuziehen. ${ }^{838}$ Die zentralen Vorschriften zur Berechnung sind § 187 BGB und § 188 BGB. Besonderheiten ergeben sich aus § 222 II ZPO und § 58 II VwGO.

362 Die Anfechtungsklage muss innerhalb eines Monats nach ordnungsgemäßer Zustellung des Widerspruchsbescheids (§ 74 I 1 VwGO) bzw. innerhalb eines Monats nach ordnungsgemäßer Bekanntgabe des Ausgangsverwaltungsakts (§ 74 I 2 VwGO) erhoben werden. Der Umstand, dass beispielsweise die Zustellung „ordnungsgemäß“ erfolgt sein muss, kann durchaus relevant sein, da bei einer unwirksamen Zustellung die Klagefrist nicht zu laufen beginnt. ${ }^{839}$

363 Bei der Fristberechnung wird gemäß § 187 I BGB der Tag der Zustellung bzw. der Bekanntgabe nicht mitgerechnet. ${ }^{840}$ Insofern ist der auf dieses „Ereignis“

837 Schenke, in: Kopp/Schenke, VwGO, 25. Aufl. 2019, § 57 Rn. 1.

838 Schenke, in: Kopp/Schenke, VwGO, 25. Aufl. 2019, § 57 Rn. 1 sowie Rn. 10a.

839 Kintz, Öffentliches Recht im Assessorexamen, 10. Aufl. 2018, Rn. 280; Schenke, in: Kopp/ Schenke, VwGO, 25. Aufl. 2019, § 57 Rn. 16f.

840 Schenke, in: Kopp/Schenke, VwGO, 25. Aufl. 2019, § 57 Rn. 10 sowie Rn. 10a; Schenke, Verwaltungsprozessrecht, 16. Aufl. 2019, Rn. 711.

Patrick Stockebrandt 
(die Zustellung oder die Bekanntgabe) folgende Tag maßgebend, auch wenn dieser ein Samstag, Sonn- oder Feiertag ist. ${ }^{841}$

Beispiel: Der Widerspruchsbescheid wurde am 16.07. zugestellt. Die Klagefrist beginnt sodann am Folgetag, den 17.07., um 00:00 Uhr.

Im Hinblick auf das Fristende bestimmt $§ 188$ II BGB: „Eine Frist, die (...) nach 364 Monaten (...) bestimmt ist, endigt im Falle des $\S 187$ I mit dem Ablauf desjenigen Tages (...) des letzten Monats, welcher durch (...) seine Zahl dem Tage entspricht, in den das Ereignis (...) fällt (...).“

Insofern endet die Klagefrist mit Ablauf desjenigen Tages des Folgemonats, der durch seine Zahl dem Tag entspricht, in dem das „Ereignis“, also die Zustellung oder die Bekanntgabe, fällt. ${ }^{842}$

Beispiel (Fortführung aus Rn. 363): Die Zustellung (das „Ereignis“) ist am 16.07. erfolgt und die Frist beträgt einen Monat. Folglich endet die Frist mit Ablauf des Monatstages „16“ im Folgemonat, also am 16.08. um 24:00 $\mathrm{Uhr}^{843}$

Insbesondere wenn der Folgemonat der Februar ist, ist $\mathrm{zu}$ beachten, dass es $\mathbf{3 6 5}$ vorkommen kann, dass es den entsprechenden Monatstag (z. B. den „31.“) nicht gibt. Gemäß $§ 188$ III BGB ist sodann der letzte Tag dieses Monats maßgebend. ${ }^{844}$

Beispiel: Die Zustellung erfolgt am 31.01. eines Jahres, so dass die Frist mit Ablauf des 28.02. ${ }^{845}$ endet.

\section{a) Fristende fällt auf einen Sonnabend, Sonn- oder Feiertag - § 222 II ZPO}

Soweit das Fristende auf einen Sonnabend (d.h. einen Samstag), einen Sonntag 366 oder einen allgemeinen Feiertag fällt, ist die Vorschrift des $\S 222$ II ZPO zu beachten. Demnach endet die Klagefrist dann nämlich nicht an dem entsprechenden Samstag, Sonntag oder Feiertag, sondern erst mit Ablauf des nächsten Werktages. ${ }^{846}$

841 Schenke, in: Kopp/Schenke, VwGO, 25. Aufl. 2019, § 57 Rn. 10a.

842 Schenke, in: Kopp/Schenke, VwGO, 25. Aufl. 2019, § 57 Rn. 10a.

843 S. hierzu auch Schenke, in: Kopp/Schenke, VwGO, 25. Aufl. 2019, § 57 Rn. 10a.

844 Schenke, in: Kopp/Schenke, VwGO, 25. Aufl. 2019, § 57 Rn. 10a; Schenke, Verwaltungsprozessrecht, 16. Aufl. 2019, Rn. 712.

845 Bzw. 29.02. in Schaltjahren.

846 Schenke, in: Kopp/Schenke, VwGO, 25. Aufl. 2019, § 57 Rn. 10a. 
Beispiel: Die Klagefrist endet nach § 188 II BGB rechnerisch am Samstag, den 31.05. eines Jahres und fällt damit auf einen Sonnabend. Gemäß § 222 II ZPO ist Fristende sodann Montag, der 02.06., um 24:00 Uhr.

367 Allgemeine Feiertage i. S.d. § 222 II ZPO sind nur gesetzlich bestimmte Feiertage, d. h. vor allem auch, dass der 24.12. und der 31.12. keine Feiertage i. S. d. Vorschrift sind. ${ }^{847}$ Soweit ein Tag nur in einzelnen Bundesländern gesetzlich zum Feiertag erklärt worden ist, kommt es auf das Recht am Ort des Gerichtes an, bei dem die Frist zu wahren ist. ${ }^{848}$

\section{b) Unterbliebene oder fehlerhafte Rechtsbehelfsbelehrung - §58 II VwGO}

368 Soweit in einer Klausur keine Angaben gemacht werden, ist davon auszugehen, dass die Rechtsbehelfsbelehrung ordnungsgemäß erfolgt ist. Sollte sie aber erwähnt oder sogar abgedruckt sein, ist zu prüfen, ob sie fehlerhaft ist. Denn soweit die Belehrung unterblieben ist oder unrichtig erteilt wurde, ${ }^{849}$ ist die Einlegung des Rechtsbehelfs, vorliegend relevant vor allem der Widerspruch und die Klage, ${ }^{850}$ gemäß $§ 58$ II VwGO grundsätzlich innerhalb eines Jahres möglich. Dies ist als Ausschlussfrist zu verstehen. ${ }^{851}$ Bitte hier einen Absatz ergänzen, um die „Anmerkungen zur Falllösung“ graphisch besser abzusetzen.

\section{Anmerkungen zur Falllösung:}

- Der Obersatz zur Fristberechnung könnte demnach lauten: „Die Klage ist fristgerecht zu erheben. Fraglich ist, ob die Klagefrist des $\& 74$ I VwGO eingehalten wurde."

- Ein „Klausurklassiker“ ist der fehlerhafte Hinweis in der Rechtsbehelfsbelehrung, dass die Klagefrist 4 Wochen (und nicht 1 Monat) betrage. Vom Klausurbearbeiter wird sodann erwartet, $\S 58$ II VwGO zu kennen und anzuwenden.

847 Schenke, in: Kopp/Schenke, VwGO, 25. Aufl. 2019, § 57 Rn. 10a.

848 Schenke, in: Kopp/Schenke, VwGO, 25. Aufl. 2019, § 57 Rn. 10a.

849 S. zu den obligatorischen Bestandteilen der Rechtsbehelfsbelehrung: Kintz, Öffentliches Recht im Assessorexamen, 10. Aufl. 2018, Rn. $281 \mathrm{ff}$. sowie Schenke, in: Kopp/Schenke, VwGO, 25. Aufl. 2019, § 58 Rn. $10 \mathrm{ff}$.

850 Schenke, in: Kopp/Schenke, VwGO, 25. Aufl. 2019, § 58 Rn. 4.

851 Schenke, in: Kopp/Schenke, VwGO, 25. Aufl. 2019, § 58 Rn. 16.

Patrick Stockebrandt 


\section{Bekanntgabe als fristauslösendes Ereignis und die sog. „Drei-Tages-Fiktion“}

Soweit kein Widerspruchsbescheid nach § 68 VwGO erforderlich ist, knüpft § 74 I 2370 VwGO an die Bekanntgabe des Ausgangsverwaltungsakts als fristauslösendes Ereignis an. Grundsätzlich ist ein Verwaltungsakt dann „bekanntgegeben“, wenn die zuständige Behörde wissentlich und willentlich den Inhalt des Verwaltungsakts gegenüber dem Betroffenen eröffnet (s. zur Bekanntgabe ausführlich Rn. 117 ff.). ${ }^{852}$ Dabei ist der Verwaltungsakt gemäß § 41 I 1 VwVfG demjenigen Beteiligten bekannt zu geben, für den er bestimmt ist oder der von ihm betroffen ist. Sofern gesetzlich keine besonderen Anforderungen an die Bekanntgabe eines Verwaltungsakts bestehen, kann diese auf jede geeignete Weise erfolgen. ${ }^{853}$

Ein mündlicher Verwaltungsakt kann nur unter Anwesenden bekannt 371 gegeben werden, da er eine empfangsbedürftige Willenserklärung darstellt. ${ }^{854}$ Ein schriftlicher Verwaltungsakt muss in den Machtbereich des Adressaten gelangt sein, z. B. durch Einwurf in den Briefkasten. ${ }^{855}$ Soweit beispielsweise demnach ein schriftlicher Verwaltungsakt durch einen behördlichen Boten in den Briefkasten des Adressaten gelangt, ist die Bekanntgabe dann erfolgt, wenn bei gewöhnlichem Verlauf mit der Kenntnisnahme durch den Empfänger zu rechnen ist und zwar grundsätzlich unabhängig von der tatsächlichen Kenntnisnahme. ${ }^{856}$

Soweit ein schriftlicher Verwaltungsakt durch die Post übermittelt wird, 372 ist die sog. Drei-Tages-Fiktion des § $41 \mathrm{II}$ VwVfG zu beachten: Demnach gilt ein solcher Verwaltungsakt am dritten Tag nach Aufgabe zur Post als bekannt gegeben, es sei denn, er ist nicht oder zu einem späteren Zeitpunkt zugegangen. Soweit der einfache Brief dem Empfänger tatsächlich früher zugegangen ist, gilt die DreiTages-Fiktion. ${ }^{857}$

Dies gilt ausnahmsweise dann nicht, wenn der Verwaltungsakt nicht oder später zugegangen ist, denn dann kommt es auf den, insoweit späteren, tatsächlichen Zugangszeitpunkt an. ${ }^{858}$

852 Sodan/Ziekow, Grundkurs Öffentliches Recht, 8. Aufl. 2018, § 79 Rn. 13.

853 Sodan/Ziekow, Grundkurs Öffentliches Recht, 8. Aufl. 2018, § 70 Rn. 14.

854 Sodan/Ziekow, Grundkurs Öffentliches Recht, 8. Aufl. 2018, § 79 Rn. 14.

855 Sodan/Ziekow, Grundkurs Öffentliches Recht, 8. Aufl. 2018, § 79 Rn. 14.

856 Sodan/Ziekow, Grundkurs Öffentliches Recht, 8. Aufl. 2018, § 79 Rn. 14; Ramsauer, in: Kopp/ Ramsauer, VwVfG, 19. Aufl. 2018, § 41 Rn. 7c.

857 Sodan/Ziekow, Grundkurs Öffentliches Recht, 8. Aufl. 2018, § 79 Rn. 14. 858 Sodan/Ziekow, Grundkurs Öffentliches Recht, 8. Aufl. 2018, § 79 Rn. 14.

Patrick Stockebrandt 
Beispiel: Ein einfacher Brief wird per Post am 5. des Monats versendet. Die Bekanntgabe erfolgt nach der Drei-Tages-Fiktion sodann am 8. des Monats - also drei Tage nach Aufgabe zur Post.

\section{Zustellung als fristauslösendes Ereignis und verschiedene Zustellungsarten}

Soweit ein Widerspruchsbescheid nach $\S 68 \mathrm{VwGO}$ erforderlich ist, knüpft $\S 74$ I 1 VwGO an die (ordnungsgemäße) ${ }^{859}$ Zustellung des Widerspruchsbescheids als fristauslösendes Ereignis an (zur Zustellung von Verwaltungsakten s. auch Rn. 168 ff.). Der Widerspruchsbescheid ist aufgrund der Regelungen in $\S 73$ III 1 VwGO und § 73 III 2 VwGO von Amts wegen nach den Vorschriften des VwZG des Bundes zuzustellen. ${ }^{860}$

„Zustellung“ ist demnach eine besondere Form der Bekanntgabe ${ }^{861}$, die sodann nach § 2 I VwZG durch ein schriftliches oder elektronisches Dokument in der im VwZG bestimmten Form erfolgt. Dabei liegt die Auswahl der Zustellungsart im Ermessen der Behörde. ${ }^{862}$ Relevante Zustellungsarten (s. §§ 3-5a VwZG) sind vor allem die Zustellung durch die Post mittels Zustellungsurkunde ( 3 VwZG) und die Zustellung durch die Post mittels Einschreiben ( 4 VwZG). ${ }^{863}$ Die Zustellung ist dann notwendig, wenn dies durch eine Rechtsvorschrift oder eine behördliche Anordnung vorgesehen ist (§ $1 \mathrm{II}$ VwZG). Für den Widerspruchsbescheid ordnet dies $\S 73$ III 1 VwGO an. Zustellungsmängel können im Rahmen des $\S 8$ VwZG geheilt werden. ${ }^{864}$

\section{a) Zustellung durch die Post mittels Zustellungsurkunde}

375 Die praktisch meistgenutzte Zustellungsart ist die Zustellung durch die Post mit Zustellungsurkunde (§ 3 VwZG) ${ }^{865}$ Mit „Post“ ist dabei ein Erbringer von Postdienstleistungen i.S.d. § 2 II 1 VwZG und § 5 PostG gemeint. ${ }^{866}$

Bei dieser Form der Zustellung übergibt die Behörde gemäß § 3 I VwZG der Post den Zustellungsauftrag, das zuzustellende Dokument in einem verschlosse-

859 Bei einer unwirksamen Zustellung beginnt die Klagefrist nicht zu laufen; Kintz, Öffentliches Recht im Assessorexamen, 10. Aufl. 2018, Rn. 280; Schenke, in: Kopp/Schenke, VwGO, 25. Aufl. 2019, § 57 Rn. 16f.

860 Schenke, in: Kopp/Schenke, VwGO, 25. Aufl. 2019, § 73 Rn. 22a.

861 Sodan/Ziekow, Grundkurs Öffentliches Recht, 8. Aufl. 2018, § 79 Rn. 15.

862 Schenke, in: Kopp/Schenke, VwGO, 25. Aufl. 2019, § 73 Rn. 22b.

863 Sodan/Ziekow, Grundkurs Öffentliches Recht, 8. Aufl. 2018, § 79 Rn. 15.

864 Dieser wird im Rahmen der Rechtsprechung über den Wortlaut hinaus ausgelegt, s. dazu Schenke, in: Kopp/Schenke, VwGO, 25. Aufl. 2019, § 73 Rn. 23a.

865 Schenke, in: Kopp/Schenke, VwGO, 25. Aufl. 2019, § 73 Rn. 22b.

866 Schenke, in: Kopp/Schenke, VwGO, 25. Aufl. 2019, § 73 Rn. 22b, s. dort Fn. 36. 
nen Umschlag und den Vordruck einer Zustellungsurkunde. Im Regelfall wird der Postbedienstete das Schriftstück vor Ort übergeben, die Zustellung beurkunden und die Urkunde an die Behörde zurückschicken. ${ }^{867}$

Der Vorteil dieser Zustellungsart gegenüber dem Einschreiben ist, dass die $\mathbf{3 7 7}$ Möglichkeit der Ersatzzustellung nach § 3 II 1 VwZG i.V.m. §§ 177-182 ZPO besteht. ${ }^{868}$ Das bedeutet, dass eine Zustellung insbesondere auch in den Fällen der unberechtigten verweigerten Annahme $(\S 179 \mathrm{ZPO})^{869}$ und durch das Einlegen in den Briefkasten (§ $180 \mathrm{ZPO})^{870}$ erfolgen kann.

\section{b) Zustellung durch die Post mittels Einschreiben}

Der Widerspruchsbescheid kann nach $\S 4$ VwZG durch die Post mittels Ein- 378 schreiben zugestellt werden. Zu beachten ist zunächst, dass gemäß § 4 I VwZG nur das Übergabe-Einschreiben sowie das Einschreiben mit Rückschein zulässig sind. Das einfache Einwurf-Einschreiben durch die Post reicht mangels Übergabe nicht aus. ${ }^{871}$

Hat die Verwaltung in einer Klausur per Einschreiben zugestellt, so handelt 379 es sich grundsätzlich um ein Übergabe-Einschreiben, da ein Einschreiben mit Rückschein nur vorliegt, wenn es ausdrücklich im Sachverhalt erwähnt wird. ${ }^{872}$

Beim Übergabe-Einschreiben wird das Dokument, sofern nicht das Merk- 380 mal „eigenhändig“ ausgewählt wurde ${ }^{873}$, dem Zustellungsadressaten oder dem Ersatzempfänger ausgehändigt. Soweit dies nicht möglich ist, wird der Adressat mittels Benachrichtigungszettel aufgefordert, das Dokument selbst abzuholen. ${ }^{874}$ Dabei erfolgt die Zustellung nicht schon durch Zugang des Benachrichtigungszettels, sondern erst, wenn die Sendung abgeholt wird. ${ }^{875}$ Im Übrigen gilt die Zugangsvermutung des § 4 II 2 VwZG. Nur soweit diese Vermutung substantiiert bestritten wird, ist der Zugang und dessen Zeitpunkt gemäß § 4 II 3 VwZG von der Behörde $\mathrm{zu}$ beweisen. ${ }^{876}$

867 Pietzner/Ronellenfitsch, Das Assessorexamen im Öffentlichen Recht, 14. Aufl. 2019, Rn. 1358. 868 Kues/Schildheuer, Verwaltungsprozessrecht, 4. Aufl. 2018, 66.

869 Schenke, in: Kopp/Schenke, VwGO, 25. Aufl. 2019, § 73 Rn. 22b sowie § 56 Rn. 33.

870 Schenke, in: Kopp/Schenke, VwGO, 25. Aufl. 2019, § 73 Rn. 22b sowie § 56 Rn. 34.

871 Schenke, in: Kopp/Schenke, VwGO, 25. Aufl. 2019, §73 Rn. 22b; Sodan/Ziekow, Grundkurs Öffentliches Recht, 8. Aufl. 2018, § 79 Rn. 15.

872 Kues/Schildheuer, Verwaltungsprozessrecht, 4. Aufl. 2018, 68.

873 Die Auswahl der Zustellungsart liegt im Ermessen der Behörde, s. Schenke, in: Kopp/ Schenke, VwGO, 25. Aufl. 2019, § 73 Rn. 22b.

874 Schenke, in: Kopp/Schenke, VwGO, 25. Aufl. 2019, § 73 Rn. 22b.

875 Schenke, in: Kopp/Schenke, VwGO, 25. Aufl. 2019, § 73 Rn. 22b.

876 Schenke, in: Kopp/Schenke, VwGO, 25. Aufl. 2019, § 73 Rn. 22b.

Patrick Stockebrandt 
Beim Einschreiben mit Rückschein genügt gemäß § 4 II 1 VwZG der Rückschein als Nachweis der Zustellung. Insofern gilt das Datum auf dem Rückschein als Tag der Zustellung und die Zugangsvermutung des § 4 II 2 VwZG ist nur noch heranzuziehen, wenn der Rückschein verloren gegangen oder unbrauchbar ist. ${ }^{877}$ Auch eine Zustellung an ein vom Empfänger unterhaltenes Postfach ist möglich. $^{878}$

\section{aa) Ersatzempfänger beim Einschreiben}

382 Die Frage der Möglichkeit der Übergabe an einen Ersatzempfänger, z. B. einen Familienangehörigen, richtet sich bei der Zustellung mittels Einschreiben nicht nach den gesetzlichen Vorschriften, sondern nach den allgemeinen Geschäftsbedingungen des Postdienstleisters. ${ }^{879}$ Ersatzempfänger sind z.B. der Ehepartner, der Lebenspartner oder ein Familienmitglied des Empfängers. ${ }^{880}$ Wenn das Dokument nur dem Adressaten ausgehändigt werden darf, muss insoweit das Merkmal „eigenhändig“ ausgewählt werden. ${ }^{881}$

\section{bb) Zugang im Falle der Notwendigkeit der Abholung eines Einschreibens bei der Post}

383 Soweit der Adressat das Dokument selbst abholen muss, hat dies zur Konsequenz, dass der Zugang grundsätzlich erst dann erfolgt, wenn der Empfänger es tatsächlich abholt, selbst wenn er dies bewusst verzögert. ${ }^{882}$ Insoweit das Dokument nicht abgeholt wird, ist es auch nicht zugegangen. ${ }^{883}$ Die Grenze ist hier in den seltenen Fällen zu sehen, in denen der Empfänger die Zustellung gegen Treu und Glauben verzögert oder vereitelt, in dem er beispielsweise den Namen an seinem Briefkasten entfernt. ${ }^{884}$ Sodann muss er sich behandeln lassen, als sei die $\mathbf{Z u}$ stellung in dem Zeitpunkt erfolgt, in dem er bei pflichtgemäßen Verhalten das Dokument erhalten hätte. ${ }^{885}$

877 BT-Drucks. 15/5216, 12; Schenke, in: Kopp/Schenke, VwGO, 25. Aufl. 2019, § 73 Rn. 22b.

878 Schenke, in: Kopp/Schenke, VwGO, 25. Aufl. 2019, § 73 Rn. 22b.

879 Schenke, in: Kopp/Schenke, VwGO, 25. Aufl. 2019, § 73 Rn. 22b.

880 Ramsauer, in: Kopp/Ramsauer, VwVfG, 19. Aufl. 2018, § 41 Rn. 72; Pietzner/Ronellenfitsch, Das Assessorexamen im Öffentlichen Recht, 14. Aufl. 2019, Rn. 1362.

881 Schenke, in: Kopp/Schenke, VwGO, 25. Aufl. 2019, § 73 Rn. 22b; Kues/Schildheuer, Verwaltungsprozessrecht, 4. Aufl. 2018, 67.

882 Pietzner/Ronellenfitsch, Das Assessorexamen im Öffentlichen Recht, 14. Aufl. 2019, Rn. 1363.

883 Kues/Schildheuer, Verwaltungsprozessrecht, 4. Aufl. 2018, 67.

884 Ramsauer, in: Kopp/Ramsauer, VwVfG, 19. Aufl. 2018, § 41 Rn. 72 sowie Rn. 19.

885 S. Kues/Schildheuer, Verwaltungsprozessrecht, 4. Aufl. 2018, 67.

Patrick Stockebrandt 


\section{Untätigkeit der Behörde - $\$ 75$ VwGO}

Soweit eine Behörde über einen Widerspruch oder über einen Antrag auf Vor- 384 nahme eines Verwaltungsakts ohne zureichenden Grund in angemessener Frist sachlich nicht entscheidet, ordnet $\S 751 \mathrm{VwGO}$ an, dass die Klage abweichend von $\S 68$ VwGO zulässig ist. Durch diese Vorschrift wird auch der Grundsatz aus Art. 19 IV GG geschützt, da die Verwaltung nicht durch ihre Untätigkeit einen Betroffenen von der Möglichkeit der Klage abhalten können soll. ${ }^{886}$

Die Vorschrift des $\S 75$ VwGO hat zur Konsequenz, dass der Klageweg ab- 385 weichend von den Vorschriften der $\S 68 \mathrm{ff}$. und $\S 74 \mathrm{VwGO}$ unmittelbar begangen werden kann und die Klage in einem solchen Fall ohne vorherigen Abschluss bzw. ohne vorherige Durchführung eines Vorverfahrens - unter Beachtung der dreimonatigen Sperrfrist des $\S 752$ VwGO - zulässig ist. ${ }^{887}$

\section{a) Zureichender Grund für die Verzögerung}

Ob und inwieweit ein zureichender Grund besteht, ist nach objektiven Gesichts- 386 punkten zu beurteilen. ${ }^{888}$ Die Rechtsprechung hat hierzu eine Fülle an Entscheidungen in unterschiedlichen Bereichen erlassen. ${ }^{889}$

Im Hinblick auf das in gewisser Regelmäßigkeit vorgetragene Argument der 387 „Überlastung“ muss unterschieden werden: Die vorübergehende Überlastung einer Behörde infolge einer Gesetzesänderung oder die vorübergehende besondere Geschäftsbelastung der Behörde aus anderen Gründen, soweit nicht ein strukturelles Defizit vorliegt, kann ein zureichender Grund für eine Verzögerung sein. ${ }^{890}$ Bei länger andauernder Überlastung muss die Verwaltung jedoch für Ausgleich sorgen. ${ }^{891}$ Kein zureichender Grund ist dagegen Urlaub, Krankheit oder Arbeitsüberlastung einzelner Sachbearbeiter, da die Verwaltung in solchen Fällen für ausreichende Vertretung sorgen muss. ${ }^{892}$

Liegt ein zureichender Grund für die Verzögerung vor, so setzt das Gericht 388 das Verfahren gemäß $\S 753$ VwGO bis zum Ablauf einer von ihm bestimmten Frist aus. ${ }^{893}$

886 Schenke, in: Kopp/Schenke, VwGO, 25. Aufl. 2019, § 75 Rn. 1.

887 Schenke, in: Kopp/Schenke, VwGO, 25. Aufl. 2019, § 75 Rn. 1; Schenke, Verwaltungsprozessrecht, 16. Aufl. 2019, Rn. 715.

888 Schenke, in: Kopp/Schenke, VwGO, 25. Aufl. 2019, § 75 Rn. 13.

889 S. hierzu Schenke, in: Kopp/Schenke, VwGO, 25. Aufl. 2019, § 75 Rn. 13 ff.

890 Schenke, in: Kopp/Schenke, VwGO, 25. Aufl. 2019, § 75 Rn. 13.

891 Schenke, in: Kopp/Schenke, VwGO, 25. Aufl. 2019, § 75 Rn. 13, dort Fn. 16.

892 Schenke, in: Kopp/Schenke, VwGO, 25. Aufl. 2019, § 75 Rn. 13.

893 S. hierzu Brink, in: Posser/Wolff, VwGO, 49. Ed., Stand: 1.4. 2019, § 75 Rn. 14 ff. 


\section{b) Angemessene Frist \& dreimonatige „Sperrfrist“}

389 Die Verwaltung ist grundsätzlich dazu verpflichtet, über Antrag und Widerspruch so rasch wie möglich zu entscheiden. ${ }^{894} \mathrm{Zu}$ beachten ist jedoch, dass die Klage gemäß $§ 752$ VwGO grundsätzlich nicht vor Ablauf von drei Monaten (sog. „Sperrfrist“) seit der Einlegung des Widerspruchs oder dem Antrag auf Vornahme des Verwaltungsakts erhoben werden kann und eine Klage insoweit - im Regelfall - unzulässig ist. ${ }^{895}$

390 Nur soweit besondere Umstände vorliegen, kann eine kürzere Frist geboten sein. ${ }^{896}$ Dies ist beispielsweise dann der Fall, wenn der Kläger ohne eine alsbaldige Entscheidung einen schweren und irreparablen Nachteil erleiden würde. ${ }^{897}$

\section{c) Zeitliche Begrenzung der Klage}

391 Die Vorschrift des $\S 75$ VwGO regelt nicht, wie lange eine Klage in einer solchen Situation erhoben werden kann. Da die frühere gesetzliche Regelung in $\S 76 \mathrm{VwGO}$ aufgehoben wurde, die im Regelfall eine Jahresfrist vorgesehen hatte, kann die Klage grundsätzlich ohne zeitliche Befristung erhoben werden. ${ }^{898}$

392 Jedoch kann sich aus dem Grundsatz der Verwirkung etwas Anderes ergeben, sodass das prozessuale Recht zur Klage nach den allgemeinen Grundsätzen verwirkt (s. näher Rn. 399 ff.) wird. ${ }^{899}$ Allerdings kann aufgrund der Aufhebung des $\S 76$ VwGO nicht davon ausgegangen werden, dass die Verwirkung regelmäßig nach Ablauf eines Jahres eintritt, da dies dem gesetzgeberischen Willen zuwiderlaufen würde. ${ }^{900}$

\section{Weitere Bereiche}

393 Über die bereits genannten Bereiche hinaus können im Rahmen einer Klausur weitere Fragen aufgeworfen werden. Hierzu zählen die Möglichkeit der Wiedereinsetzung in den vorigen Stand und der Aspekt der Verwirkung.

894 Schenke, in: Kopp/Schenke, VwGO, 25. Aufl. 2019, § 75 Rn. 8.

895 Schenke, in: Kopp/Schenke, VwGO, 25. Aufl. 2019, § 75 Rn. 8.

896 S. hierzu Schenke, in: Kopp/Schenke, VwGO, 25. Aufl. 2019, § 75 Rn. 12.

897 Schenke, Verwaltungsprozessrecht, 16. Aufl. 2019, Rn. 715.

898 Schenke, Verwaltungsprozessrecht, 16. Aufl. 2019, Rn. 720.

899 Schenke, in: Kopp/Schenke, VwGO, 25. Aufl. 2019, § 76 Rn. 2.

900 Schenke, Verwaltungsprozessrecht, 16. Aufl. 2019, Rn. 721; Schenke, in: Kopp/Schenke, VwGO, 25. Aufl. 2019, § 76 Rn. 2. 


\section{a) Wiedereinsetzung in den vorigen Stand - $\$ 60$ VwGO}

Soweit der Kläger die Monatsfrist des § 74 VwGO nicht eingehalten und es auch 394 keine fehlerhafte Rechtsbehelfsbelehrung gegeben hat, kommt die Wiedereinsetzung in den vorigen Stand gemäß $\S 60 \mathrm{VwGO}$ in Betracht.

Die Wiedereinsetzung ist eine gerichtliche Entscheidung und stellt eine 395 Wiederherstellung der Zulässigkeit für eine versäumte Prozesshandlung dar. ${ }^{901}$ Dies kann u. a. zur Folge haben, dass beispielsweise die eingetretene Bestandskraft eines Verwaltungsakts nachträglich wieder entfällt und somit auch der Weg zur Sachentscheidung hierüber wieder eröffnet ist. ${ }^{902}$

Voraussetzung für die Wiedereinsetzung gemäß §60 I VwGO ist, dass eine 396 gesetzliche Frist schuldlos versäumt wurde. ${ }^{903}$ Eine gesetzliche Frist ist die Frist, deren Dauer durch das Gesetz bestimmt ist und die ohne besondere Festsetzung - sondern kraft Gesetzes - aufgrund eines bestimmten Ereignisses, z. B. die Zustellung, zu laufen beginnt. ${ }^{904}$ So ist beispielsweise auch die Klagefrist des $\S 74$ VwGO eine gesetzliche Frist. ${ }^{905}$ Ausgeschlossen ist die Anwendbarkeit des $\S 60$ VwGO hingegen auf sogenannte Ausschlussfristen, wie sie beispielsweise in $\S 60$ III VwGO und § 47 II 1 VwGO vorzufinden sind. ${ }^{906}$ Lediglich bei höherer Gewalt $^{907}$ gewährt $§ 60$ III 2. Hs. VwGO hiervon eine Ausnahme.

Insoweit der Betroffene eine gesetzliche Frist versäumt hat, ist die Frage des Verschuldens $\mathrm{zu}$ erörtern. Ein Verschulden im Sinne der Vorschrift liegt vor, wenn der Betroffene hinsichtlich der Wahrung der Frist diejenige Sorgfalt außer Acht gelassen hat, die für einen gewissenhaften, sachgemäß agierenden Prozessführenden geboten ist und ihm die Fristwahrung in der Gesamtschau des Einzelfalls auch zuzumuten war. ${ }^{908}$

Bei der Betrachtung der Anforderungen an die Sorgfaltspflicht muss auf die 398 Verhältnisse des Betroffenen abgestellt werden. ${ }^{909}$ So sind bei einem Rechtsanwalt beispielsweise grundsätzlich höhere Anforderungen zu stellen, als bei einem juristischen Laien. ${ }^{910}$ Darüber hinaus kommt es im Wesentlichen auch auf die konkreten Umstände des Einzelfalles an. ${ }^{911}$

901 Schenke, in: Kopp/Schenke, VwGO, 25. Aufl. 2019, § 60 Rn. 1.

902 Schenke, in: Kopp/Schenke, VwGO, 25. Aufl. 2019, § 60 Rn. 1.

903 Schenke, in: Kopp/Schenke, VwGO, 25. Aufl. 2019, § 60 Rn. 6.

904 Schenke, in: Kopp/Schenke, VwGO, 25. Aufl. 2019, § 57 Rn. 3.

905 Schenke, in: Kopp/Schenke, VwGO, 25. Aufl. 2019, §60 Rn. 3. Davon abzugrenzen sind richterliche Fristen, s. Schenke, in: Kopp/Schenke, VwGO, 25. Aufl. 2019, § 60 Rn. 3.

906 Schenke, in: Kopp/Schenke, VwGO, 25. Aufl. 2019, § 60 Rn. 4.

907 Zum Begriff s. Schenke, in: Kopp/Schenke, VwGO, 25. Aufl. 2019, § 58 Rn. 20.

908 Schenke, in: Kopp/Schenke, VwGO, 25. Aufl. 2019, § 60 Rn. 9.

909 Schenke, in: Kopp/Schenke, VwGO, 25. Aufl. 2019, § 60 Rn. 9.

910 Schenke, in: Kopp/Schenke, VwGO, 25. Aufl. 2019, § 60 Rn. 9.

Patrick Stockebrandt 


\section{b) Klageverwirkung}

399 In seltenen Fällen besteht die Möglichkeit, dass ein Kläger sein Klagerecht dadurch verwirkt hat, dass er die Klageerhebung unredlich verzögert hat und seine Klage damit dann nicht mehr zulässig ist. ${ }^{912}$ Voraussetzung ist, dass die späte Klageerhebung gegen Treu und Glauben verstößt. ${ }^{913}$

400 Dies kann insbesondere dann angenommen werden, wenn der Kläger bereits seit längerer Zeit Kenntnis vom Klagegrund hat oder hätte haben müssen und die Klage trotzdem erst zu einem Zeitpunkt erhebt, in dem der Beklagte oder sonstige Beteiligte nach den Umständen des Falles nicht mehr mit einer Klage rechnen mussten. ${ }^{914}$

401 Eine Klageverwirkung kann kaum vor der in der VwGO mehrfach erwähnten Jahresfrist ${ }^{915}$ eintreten, die insofern als allgemeiner Rechtsgedanke angesehen werden muss. ${ }^{916}$ Maßgeblich sind jedoch die Umstände des konkreten Einzelfalls. ${ }^{917}$

\section{Literaturhinweise}

402 Hufen, Verwaltungsprozessrecht, 11. Aufl. 2019, § 14 Rn. 114 ff.; Kintz, Öffentliches Recht im Assessorexamen, 10. Aufl. 2018, S. 118ff.; Kues/Schildheuer, Verwaltungsprozessrecht, 4. Aufl. 2018, S. 65 ff.; Schenke, Wolf-Rüdiger, Verwaltungsprozessrecht, 16. Aufl. 2019, Rn. 700 ff.; Schmitz, Klagefrist und Fristversäumnis bei der Anfechtungsklage, JuS 2015, 895

\section{Die Beteiligten (Carola Creemers)}

403 Ein verwaltungsgerichtlicher Rechtsstreit kann nur zwischen tauglichen Beteiligten geführt werden. Obwohl die Prüfung der Beteiligten in der verwaltungsrechtlichen Klausur meist unproblematisch ist, wird stets erwartet, dass die ent-

911 Schenke, in: Kopp/Schenke, VwGO, 25. Aufl. 2019, § 60 Rn. 9. Eine Betrachtung von Einzelfällen ist zu finden bei Schenke, in: Kopp/Schenke, VwGO, 25. Aufl. 2019, § 60 Rn. $10 \mathrm{ff}$.

912 Schenke, in: Kopp/Schenke, VwGO, 25. Aufl. 2019, § 74 Rn. 18.

913 Schenke, in: Kopp/Schenke, VwGO, 25. Aufl. 2019, § 74 Rn. 19.

914 Schenke, Verwaltungsprozessrecht, 16. Aufl. 2019, Rn. 590; Schenke, in: Kopp/Schenke, VwGO, 25. Aufl. 2019, § 74 Rn. 19. Insofern ist insbesondere auch zu beachten, ob es sich um einen Verwaltungsakt mit Drittwirkung handelt, s. hierzu Schenke, in: Kopp/Schenke, VwGO, 25. Aufl. 2019, § 74 Rn. 19.

915 S. z.B. § 58 II VwGO und § 60 III VwGO.

916 Schenke, in: Kopp/Schenke, VwGO, 25. Aufl. 2019, § 74 Rn. 20.

917 Schenke, in: Kopp/Schenke, VwGO, 25. Aufl. 2019, § 74 Rn. 20.

Patrick Stockebrandt/Carola Creemers 
sprechenden Normen bekannt sind und sauber geprüft und angewendet werden können. Zudem treten bestimmte Probleme im Rahmen der Beteiligten in verwaltungsrechtlichen Klausuren immer wieder auf, die jedoch nur bei entsprechenden Anhaltspunkten im Sachverhalt anzusprechen sind.

Die VwGO verwendet den Begriff der Beteiligten in den $\S \S 61,63$ VwGO als Teil 404 der allgemeinen Verfahrensvorschriften des 7. Abschnitts.

\section{Beteiligte, $\$ 63 \mathrm{VwGO}$}

$\S 63$ VwGO regelt abschließend wer zu den Prozessbeteiligten zählt: Der Klä- 405 ger (Nr. 1), der Beklagte (Nr. 2), der Beigeladene nach § 65 VwGO (Nr. 3) und der Vertreter des Bundesinteresses beim Bundesverwaltungsgericht ( $\$ 35 \mathrm{VwGO}$ ) oder der Vertreter des öffentlichen Interesses ( $\$ 36$ VwGO), falls er von seiner Beteiligungsbefugnis Gebrauch macht (Nr. 4). Kläger und Beklagter (bzw. Antragssteller und Antragsgegner im Normenkontrollverfahren sowie im einstweiligen Rechtsschutz) sind die Hauptbeteiligten im Verwaltungsprozess. Nebenbeteiligte können der Beigeladene sowie der Vertreter des Bundesinteresses beim BVerwG oder der Vertreter des öffentlichen Interesses sein, wobei die Nebenbeteiligten nicht automatisch am Verfahren beteiligt sind. ${ }^{918}$ Der Beigeladene erlangt die Stellung eines Beteiligten durch Zustellung des Beiladungsbeschlusses und der Vertreter des Bundesinteresses beim BVerwG oder der Vertreter des öffentlichen Interesses durch einseitige Erklärung, dass sie sich beteiligen. ${ }^{919}$

Nur die nach $\S 63$ VwGO am verwaltungsgerichtlichen Verfahren Beteilig- 406 ten haben eigene Verfahrensrechte und können wirksame Prozesshandlungen vornehmen. ${ }^{920}$ Zudem bindet ein rechtskräftiges Urteil gem. $§ 121$ Nr. 1 VwGO die Beteiligten. Folglich erstreckt sich die Rechtskraft des Urteils auf die Beteiligten i.S.d. § 63 VwGO und es tritt für sie eine Bindungswirkung im Umfang des Streitgegenstandes ein. ${ }^{921}$ Insbesondere ist eine erneute Klage über den gleichen Streitgegenstand zwischen denselben Beteiligten unzulässig. ${ }^{922}$ Daher ist bei entsprechenden Anhaltspunkten im Sachverhalt neben der Prüfung der Hauptbeteiligten insbesondere an die Beiladung zu denken (s. zur Beiladung Rn. 445 ff.).

918 Schenke, Verwaltungsprozessrecht, 16. Aufl. 2019, Rn. 453-454.

919 Kintz, in: Posser/Wolff, VwGO, 50. Ed., Stand: 1.4.2019, § 63 Rn. 5, 6.

920 Hoppe, in: Eyermann, VwGO, 15. Aufl. 2019, § 63 Rn. 4; Schenke, in: Kopp/Schenke, VwGO, 25. Aufl. 2019, § 63 Rn. 1.

921 Clausing, in: Schoch/Schneider/Bier, VwGO, 36. EL Februar 2019, §121 Rn. 95; Schenke, Verwaltungsprozessrecht, 16. Aufl. 2019, Rn. 619, 631.

922 Lindner, in: Posser/Wolff, VwGO, 50. Ed., Stand: 1.7.2019, § 121 Rn. 16. 
Die formelle Beteiligteneigenschaft des $\S 63$ VwGO ist von der Beteiligungsfähigkeit des $\S 61 \mathrm{VwGO}$ zu unterscheiden. Denn zulässig sind verwaltungsrechtliche Klagen nur, wenn die Prozessbeteiligten auch beteiligungsfähig i. S.d. § $61 \mathrm{VwGO}$ und prozessfähig i.S.d. § $62 \mathrm{VwGO}$ sind.

Anmerkung zur Falllösung: Die Nennung der Beteiligten i.S.d. § 63 VwGO ist zwar nicht Teil der Zulässigkeitsprüfung, ${ }^{923}$ jedoch kann $\S 63 \mathrm{VwGO}$ als Ausgangspunkt der Ausführungen zu den Beteiligten genommen werden, indem festgestellt wird, wer am Verfahren beteiligt ist und ob diese Personen auch beteiligungs- und prozessfähig sind. Zulässigkeitsvoraussetzung sind die Beteiligungs- und die Prozessfähigkeit (s. ausführlich Rn. $419 \mathrm{ff.}, 430 \mathrm{ff}$. .).

\section{Passive Prozessführungsbefugnis, $\S 78$ VwGo}

$409 \S 78$ VwGO bestimmt gegen wen Anfechtungs- und Verpflichtungsklagen zu richten sind, d.h. wer richtiger Beklagter ist.

410 Anmerkung zur Falllösung: Der Beklagte zählt nach § 63 Nr. 2 VwGO zu den Prozessbeteiligten. Es empfiehlt sich bereits vor der Prüfung der Beteiligungs- und der Prozessfähigkeit, den richtigen Beklagten zu bestimmen, da auch der richtige Beklagte beteiligungs- und prozessfähig sein muss.

411 Formulierungsvorschlag: „Die Anfechtungsklage muss gegen den richtigen Beklagten gerichtet werden. Gem. \& 78 I Nr. 1 VwGO ist die Anfechtungsklage grundsätzlich gegen die Körperschaft zu richten, deren Behörde den angefochtenen Verwaltungsakt erlassen hat." ${ }^{\text {"924 }}$

\section{a) Richtiger Beklagter nach § 78 I VwGO}

412 Nach $\S 78$ I Nr. 1 VwGO ist die Klage gegen den Bund, das Land oder die Körperschaft, deren Behörde den angefochtenen Verwaltungsakt erlassen oder den beantragten Verwaltungsakt unterlassen hat, zu richten, d.h. richtiger Klagegegner ist der Rechtsträger der handelnden Behörde (Rechtsträgerprinzip). Wer Rechtsträger der handelnden Behörde ist, bestimmt sich nach dem insoweit maßgeblichen Bundes- oder Landesorganisationsrecht. ${ }^{925}$

413 Abweichend vom Rechtsträgerprinzip ermächtigt §78 I Nr. 2 VwGO den Landesgesetzgeber zu bestimmen, dass die Anfechtungs- oder Verpflichtungs-

923 Hufen, Verwaltungsprozessrecht, 11. Aufl. 2019, § 12 Rn. 1.

924 Vgl. Darstellung verschiedener Einzelprobleme bei der Anwendung von $\S 78$ VwGO bei Hufen, Verwaltungsprozessrecht, 11. Aufl. 2019, § 12 Rn. $33 \mathrm{ff}$.

925 Kintz, in: Posser/Wolff, VwGO, 50. Ed., Stand: 1.4.2019, § 78 Rn. 17. 
klage gegen die Behörde selbst $\mathrm{zu}$ richten ist (Behördenprinzip) ${ }^{926}$ Besteht eine solche landesrechtliche Regelung, geht diese $\S 78$ I Nr. 1 VwGO vor. $\S 78$ I Nr. 2 VwGO ist damit eine gesetzliche Ausnahme vom Rechtsträgerprinzip und ein Fall einer gesetzlich geregelten Prozessstandschaft. ${ }^{927}$

\section{b) Sonderfall: Widerspruchsbescheid als Klagegegenstand}

Nach $§ 79$ I Nr. 1 VwGO ist Gegenstand der Anfechtungsklage der ursprüngliche 414 Verwaltungsakt in der Gestalt, die er durch den Widerspruchsbescheid gefunden hat, sodass die Klage grundsätzlich gegen den Rechtsträger der Ausgangsbehörde (§ 78 I Nr. 1 VwGO) oder gegen die Ausgangsbehörde selbst (§ 78 I Nr. 2 VwGO i.V.m. Landesrecht) $\mathrm{zu}$ richten ist.

Bei isolierter Anfechtung des Widerspruchsbescheids, wenn dieser erstmalig 415 oder eine zusätzliche selbständige Beschwer erhält, ist die Klage ausnahmsweise gegen den Rechtsträger der Widerspruchsbehörde zu richten (§ 78 II VwGO bzw. $\S 79$ II i.V.m. § 78 II VwGO) bzw. falls § 78 I Nr. 2 VwGO Anwendung findet gegen die Widerspruchsbehörde selbst. ${ }^{928}$

\section{c) Aufbauproblem: Prüfungsstandort des $\S 78$ VwGO}

$\S 78$ VwGO regelt die passive Prozessführungsbefugnis. ${ }^{929}$ Die passive Pro- 416 zessführungsbefugnis ist die Befugnis des Beklagten, über die vom Kläger behauptete Verpflichtung im eigenen Namen den Prozess zu führen. ${ }^{930}$ Sie wird innerhalb der Zulässigkeit geprüft.

926 Von der Ermächtigung Gebrauch gemacht haben Brandenburg (§ 8 II VwGG), MecklenburgVorpommern (§14 II AGGerStrG) und das Saarland (§ 19 II AGVwGO) für Behörden allgemein sowie Niedersachsen (§ 8 II AGVwGO), Schleswig-Holstein (§ 6 AGVwGO) und Sachsen-Anhalt (§ 8 AGVwGO LSA) für Landesbehörden.

927 Hufen, Verwaltungsprozessrecht, 11. Aufl. 2019, § 12 Rn. 32; Schenke, Verwaltungsprozessrecht, 16. Aufl. 2019, Rn. 550.

928 Hufen, Verwaltungsprozessrecht, 11. Aufl. 2019, § 12 Rn. 40; Meissner/Schenk, in: Schoch/ Schneider/Bier, VwGO, 36. EL Februar 2019, § 78 Rn. 48.

929 Schenke, in: Kopp/Schenke, VwGO, 25. Aufl. 2019, § 78 Rn. 1; Schenke, Verwaltungsprozessrecht, 16. Aufl. 2019, Rn. 545 f.; Ehlers, in: Festschrift für Christian-Friedrich Menger, 1985, 379 (383); Hufen, Verwaltungsprozessrecht, 11. Aufl. 2019, § 12 Rn. 29 ff. m.w. N.

930 Rozek, JuS 2007, 601 (601). Die aktive Prozessführungsbefugnis ist die Befugnis des Klägers, im eigenen Namen über das streitige Recht einen Prozess zu führen. Die aktive Prozessführungsbefugnis ist im Verwaltungsrecht mit der Klagebefugnis in § 42 II VwGO geregelt, s. Rn. $281 \mathrm{ff}$. 
417 Examenswissen: Die Gegenansicht prüft $\S 78$ VwGO als Passivlegitimation zu Beginn der Begründetheitsprüfung des Rechtsbehelfs. ${ }^{931}$ Die Passivlegitimation ist das materielle Gegenstück zur passiven Prozessführungsbefugnis, denn passivlegitimiert ist derjenige, der durch das materielle Recht tatsächlich verpflichtet ist. ${ }^{932}$ Passivlegitimation und passive Prozessführungsbefugnis haben die gleichen Voraussetzungen und folgen dem Rechtsträgerprinzip. ${ }^{933}$

Im Fall des Behördenprinzips nach $\S 78$ I Nr. 2 VwGO handelt es sich in jedem Fall um eine Regelung der passiven Prozessführungsbefugnis, sodass § 78 I Nr. 2 VwGO stets innerhalb der Zulässigkeit zu prüfen ist. ${ }^{934}$

Im Übrigen sprechen gegen das Verständnis des § 78 I Nr. 1 VwGO als Passivlegitimation sowohl der Wortlaut des $\S 78$ VwGO (,Die Klage ist zu richten“) als auch die systematische Stellung im 8. Abschnitt der VwGO, der die besonderen Zulässigkeitsvoraussetzungen der Anfechtungs- und Verpflichtungsklage regelt. Demzufolge ist $§ 78 \mathrm{VwGO}$ eine Normierung der passiven Prozessführungsbefugnis.

418 Anmerkung zur Falllösung: Der Streit, ob $\S 78$ VwGO die passive Prozessführungsbefugnis oder die Passivlegitimation regelt, hat Auswirkungen auf den Klausuraufbau. Bei § 78 VwGO sollte sich ohne Darstellung des Meinungsstreits für eine Ansicht entschieden und die Falllösung dementsprechend aufgebaut werden, d.h. die Vorschrift sollte entweder kurz als Regelung der passiven Prozessführungsbefugnis im Rahmen der Zulässigkeit oder aber § 78 VwGO als Passivlegitimation erst in der Begründetheit geprüft werden. In jedem Fall sollte der Behördenaufbau auf Bundes- und Landesebene beherrscht werden (s. zu den Zuständigkeiten im Einzelnen Rn. 580 ff.), sodass das Rechtsträgerprinzip sicher angewendet werden kann.

\section{Beteiligungsfähigkeit, $§ 61 \mathrm{VwGO}$}

$419 \S 61$ VwGO regelt die Beteiligungsfähigkeit als Zulässigkeitsvoraussetzung im Verwaltungsprozess. Unter Beteiligungsfähigkeit versteht man die Fähigkeit, als Subjekt eines Prozessrechtsverhältnisses, d.h. als Kläger, Beklagter, Beigela-

931 BVerwG, Urt.v. 3.3.1989, Az.: 8 C 98/85 = NVwZ-RR 1990, 44; BVerwG, Beschl.v. 9.1.1999, Az.: 11 C 8 - 97 = NVwZ 1999, 196; BVerwG, Urt. v. 22.6.2011, Az.: 1 C 5/10 = NVwZ 2011, 1340, Rn. 9; VGH Mannheim, Urt. v. 2.8.2017, Az.: 1 S 542/17 = NVwZ-RR 2018, 358, 359, Rn. 19 ff.; Happ, in: Eyermann, VwGO, 15. Aufl. 2019, § 78 Rn. 1; Brenner, in: Sodan/Ziekow, VwGO, 5. Aufl. 2018, § 78 Rn. 3f., Rozek, JuS 2007, 601 (602f.).

932 Meissner/Schenk, in: Schoch/Schneider/Bier, VwGO, 36. EL Februar 2019, § 78 Rn. 11.

933 Hufen, Verwaltungsprozessrecht, 11. Aufl. 2019, § 12 Rn. 29.

934 Brenner, in: Sodan/Ziekow, VwGO, 5. Aufl. 2018, § 78 Rn. 5; a. A. Happ, in: Eyermann, VwGO, 15. Aufl. 2019, § 78 Rn. 4; Pietzner/Ronellenfitsch, Das Assessorexamen im Öffentlichen Recht, 14. Aufl. 2019, Rn. 252. 
dener oder sonstiger Beteiligter ( $(63$ VwGO), an einem Verwaltungsgerichtsverfahren teilnehmen zu können. ${ }^{935}$

Anmerkungen zur Falllösung: Die Prüfung der Beteiligungsfähigkeit kann in der Klausur grundsätzlich kurz ausfallen. Ausführlichere Ausführungen können erforderlich sein, wenn der Kläger keine natürliche Person ist. Fehlt die Beteiligungsfähigkeit beim Kläger oder Beklagten, ist die Klage unzulässig; fehlt sie beim Beigeladenen, erstreckt sich die Bindungswirkung des Urteils (§ 121 VwGO) nicht auf ihn und bei notwendiger Beiladung (§ 65 II VwGO) erwächst das Urteil nicht in materielle Rechtskraft. ${ }^{936}$

Teilweise wird die Beteiligungsfähigkeit auch als Beteiligtenfähigkeit bezeichnet.937 Beide Begriffe werden synonym verwendet. Empfehlenswert ist, sich für eine Begriffsvariante zu entscheiden und diese einheitlich in der Klausur anzuwenden, d.h. entweder Beteiligungsfähigkeit und beteiligungsfähig oder Beteiligtenfähigkeit und beteiligtenfähig zu verwenden.

Formulierungsvorschlag: „Kläger und Beklagter müssen nach $\S 61$ VwGO be- 421 teiligungsfähig sein.“

\section{a) Beteiligungsfähigkeit von natürlichen und juristischen Personen (§ $61 \mathrm{Nr} .1 \mathrm{VwGO})$}

Nach § 61 Nr. 1 VwGO sind natürliche und juristische Personen beteiligungs- 422 fähig.

Ist der Kläger eine natürliche Person, ist er unproblematisch beteiligungsfähig. ${ }^{938} \S 61$ Nr. 1 VwGO erfasst jedoch nicht die Fälle, in denen eine natürliche Person lediglich als Organwalter um Rechte dieses Organs streitet. ${ }^{939}$

935 Schenke, Verwaltungsprozessrecht, 16. Aufl. 2019, Rn. 455.

936 Schenke, in: Kopp/Schenke, VwGO, 25. Aufl. 2019, § 61 Rn. 2.

937 Vgl. u.a. Hufen, Verwaltungsprozessrecht, 11. Aufl. 2019, § 12 Rn. 18.

938 Umstritten ist die Beteiligungsfähigkeit des nasciturus (Leibesfrucht): Bejahend für eigene Rechte des nasciturus in entsprechender Anwendung der zivilrechtlichen Grundsätze der Rechtsfähigkeit Schenke, in: Kopp/Schenke, VwGO, 25. Aufl. 2019, § 61 Rn. 5; a. A. im Rahmen der Endlagerung radioaktiver Abfälle BVerwG, Beschl. v. 5.2.1992, Az.: 7 B 13/92 = NJW 1992, 1524 (1524).

939 Schenke, in: Kopp/Schenke, VwGO, 25. Aufl. 2019, § 61 Rn. 5; Schoch, JuS 1987, 783 (786); Dolde, in: Festschrift für Christian-Friedrich Menger, 1985, 423 (427f.); Schenke, Verwaltungsprozessrecht, 16. Aufl. 2019, Rn. 457 m.w. N. 
423 Examenswissen: Umstritten ist die Beteiligungsfähigkeit des nasciturus (Leibesfrucht; bereits gezeugtes, aber noch ungeborenes Kind). Der nasciturus kann soweit er in entsprechender Anwendung der zivilrechtlichen Grundsätze als rechtsfähig behandelt wird oder ihm nach öffentlichem Recht eigene Rechte zustehen beteiligungsfähig nach $\S 61 \mathrm{Nr} .1$ VwGO sein. ${ }^{940}$ Im verwaltungsgerichtlichen Verfahren auf Einstellung des Betriebs eines Endlagers für radioaktive Abfälle ist der nasciturus jedoch nicht beteiligungsfähig. ${ }^{941}$

424 Juristische Personen i.S.d. § 61 Nr. 1 VwGO sind alle juristischen Personen des Privatrechts und des öffentlichen Rechts.

425 Juristische Personen des Privatrechts sind die Kapitalgesellschaften, eingetragene Genossenschaften sowie rechtsfähige Vereine oder Stiftungen des Privatrechts. Auch wenn es sich nicht um juristische Personen des Privatrechts, sondern um Personengesellschaften handelt, sind die OHG und die KG, die GbR, der „nichtrechtsfähige Verein“ (§ 54 BGB), religiöse Vereinigungen nach Art. 4 GG (sofern nicht bereits Körperschaft des öffentlichen Rechts) und politische Parteien (auch Gebietsverbände der höchsten Stufe, § 3 PartG) ebenfalls beteiligungsfähig i.S.v. § 61 Nr. 1 VwGO. ${ }^{942}$

426 Examenswissen: Bei ausländischen juristischen Personen des Privatrechts ist maßgeblich, ob deren Rechtsfähigkeit von der deutschen Rechtsordnung anerkannt wird. ${ }^{943}$ Dabei ist zwischen Fällen innerhalb und außerhalb der EU zu unterscheiden: Innerhalb der EU kommt es für die nationale Zuordnung und rechtliche Beurteilung einer juristischen Person auf das Gründungsland an (sog. Gründungstheorie). ${ }^{944}$ Ist die im EU-Ausland gegründete juristische Person nach dortigem Recht rechtsfähig, ist dies auch in der deutschen Rechtsordnung anzuerkennen. Außerhalb der EU gilt grundsätzlich die Sitztheorie, also das Recht des Staates, in dem die juristische Person ihren tatsächlichen Verwaltungssitz hat. ${ }^{945}$

427 Juristische Personen des öffentlichen Rechts sind die Gebietskörperschaften (Bund, Länder, Gemeinden), sonstige rechtsfähige Körperschaften des öffentli-

940 Schenke, in: Kopp/Schenke, VwGO, 25. Aufl. 2019, § 61 Rn. 5; Dolde, in: Festschrift für Christian-Friedrich Menger, 1985, 423 (427); a. A. Hoppe, in: Eyermann, VwGO, 15. Aufl. 2019, § 61 Rn. 5.

941 BVerwG, Beschl. v. 5.2.1992, Az.: 7 B 13/92 = NJW 1992, 1524 (1524).

942 Kintz, in: Posser/Wolff, VwGO, 50. Ed., Stand: 1.4.2019, § 61 Rn. 1.1, 5; Schenke, in: Kopp/ Schenke, VwGO, 25. Aufl. 2019, § 61 Rn. 6; BGH, Urt. v. 29.1.2001, Az.: II ZR 331/00 = NJW 2001, 1056 (1056).

943 Behm, DVBl 2009, 94 (95); Decker, in: Wolff/Decker, VwGO, 3. Aufl. 2012, § 61 Rn. 7.

944 EuGH (Plenum), Urt. v. 5.11.2002, Rs.: C-208/00 („Überseering BV“) = NJW 2002, 3614; BGH, Urt. v. 12.7.2011, Az.: II ZR 28/10 = NJW 2003, 1461 (1461); Kintz, Öffentliches Recht im Assessorexamen, 10. Aufl. 2018, Rn. 289.

945 Bier/Steinbeiß-Winkelmann, in: Schoch/Schneider/Bier, VwGO, 36. EL Februar 2019, § 61 Rn. 4; anders bei abweichender völkerrechtlicher Regelung: BGH, Urt. v. 29.1.2003, Az.: VIII ZR 155/02 = NJW 2003, 1607 (1607).

Carola Creemers 
chen Rechts (z. B. Industrie- und Handelskammern (§ 3 I IHKG), Rechtsanwaltskammern (§62 I BRAO), Ärztekammern, anerkannte Religionsgemeinschaften (Art. 4 GG), Universitäten (§ 5 I HRG)), rechtsfähige Anstalten des öffentlichen Rechts sowie Stiftungen des öffentlichen Rechts.

\section{b) Beteiligungsfähigkeit von Vereinigungen ( $\$ 61 \mathrm{Nr} .2$ VwG0)}

Nach § 61 Nr. 2 VwGO sind Vereinigungen beteiligungsfähig, soweit ihnen 428 ein Recht zustehen kann. Eine Vereinigung ist dann gegeben, wenn ein Mindestmaß an innerer Organisation vorliegt. ${ }^{946} \S 61 \mathrm{Nr} .2$ VwGO stellt nicht auf die Rechtsfähigkeit, sondern auf die Zuordnung einzelner subjektiv-öffentlicher Rechte ab. Die Vereinigung muss folglich Zuordnungssubjekt eines Rechtssatzes sein, durch welchen für sie Rechte oder Pflichten begründet werden, wobei sogar innerorganisatorische Rechte und Pflichten genügen. ${ }^{947}$ Ob der Vereinigung das Recht tatsächlich zusteht, ist sodann keine Frage der Beteiligungsfähigkeit, sondern des materiellen Rechts und damit der Begründetheit. Beteiligungsfähig nach § 61 Nr. 2 VwGO können z.B. Organe und Teilorgane einer Gemeinde im Kommunalverfassungsstreit, Organe der Hochschulen oder ein ausländischer Verein sein. ${ }^{948}$

\section{c) Beteiligungsfähigkeit von Behörden nach Landesrecht ( $\$ 61 \mathrm{Nr} .3 \mathrm{VwG0}$ )} Nach § 61 Nr. 3 VwGO sind Behörden beteiligungsfähig, sofern das Landes- 429 recht dies bestimmt. Behörden sind unselbständige Teile ihres jeweiligen Rechtsträgers, sodass sie grundsätzlich nicht beteiligungsfähig sind. Daher sieht $\S 61$ Nr. 3 VwGO vor, dass das Landesrecht die Beteiligungsfähigkeit von Landesbehörden bestimmen kann. ${ }^{949}$ Die betreffenden Landesbehörden machen im Prozess keine eigenen Rechte geltend, sondern werden nur in Prozessstandschaft für ihren Rechtsträger, die Körperschaft, der sie angehören, tätig. ${ }^{950}$ Die Er-

946 BVerwG, Beschl. v. 21.1.2004, Az.: 6 A 1/04 = NVwZ 2004, 887 (887).

947 Schenke, Verwaltungsprozessrecht, 16. Aufl. 2019, Rn. $461 \mathrm{f}$.

948 Hufen, Verwaltungsprozessrecht, 11. Aufl. 2019, § 12 Rn. 21 mit weiteren Beispielen; Schenke, in: Kopp/Schenke, VwGO, 25. Aufl. 2019, § 61 Rn. 9 ff. m.w. N.; zur Beteiligungsfähigkeit des ausländischen Vereins BVerwG, Beschl. v. 21.1.2004, Az.: 6 A 1/04 = NVwZ 2004, 887 (887) Ls. 1. 949 Von der Ermächtigung Gebrauch gemacht haben Brandenburg (§ 8 I VwGG), MecklenburgVorpommern (§ 14 I AGGerStrG), Niedersachsen (§ 79 I NJG), Saarland (§ 19 I AGVwGO), SchleswigHolstein (§ 6 AGVwGO), Sachsen-Anhalt ( 8 AGVwGO LSA) und Rheinland-Pfalz (für die Bezirksregierung im Fall der Beanstandungsklage, § 17 II AGVwGO).

950 Kintz, in: Posser/Wolff, VwGO, 50. Ed., Stand: 1.4.2019, § 61 Rn. 16; Schenke, Verwaltungsprozessrecht, 16. Aufl. 2019, Rn. 463. 
mächtigung des $\S 61$ Nr. 3 VwGO bezieht sich nur auf Landesbehörden. ${ }^{951}$ Durch Bundesrecht kann jedoch aus der allgemeinen Kompetenz des Art. 74 I Nr. 1 GG Behörden ebenfalls die Beteiligungsfähigkeit zuerkannt werden. ${ }^{952}$

\section{Prozessfähigkeit, § $\mathbf{6 2}$ VwGO}

430 Von der Beteiligungsfähigkeit ist die Prozessfähigkeit zu unterscheiden, denn nicht jeder Beteiligungsfähige ist auch prozessfähig.

431 Anmerkung zur Falllösung: Die Prüfung der Prozessfähigkeit kann in der Klausur grundsätzlich kurz ausfallen. Ausführlicher sollte auf die Prozessfähigkeit eingegangen werden, sofern es sich um einen minderjährigen Kläger handelt. Zudem sollte kurz auf die entsprechende Vertretungsbefugnis von Vereinigungen und Behörden eingegangen werden. Regelmäßig können die Beteiligungs- und Prozessfähigkeit innerhalb eines Prüfungspunktes kurz zusammengeprüft werden.

432 Formulierungsvorschlag: „Zudem muss die Prozessfähigkeit nach $\S 62$ VwGO vorliegen."

$433 \S 62$ VwGO regelt die Fähigkeit, selbst oder durch einen Prozessbevollmächtigten (§ 173 VwGO i.V.m. § 51 ZPO) wirksam Prozesshandlungen (z. B. Klageerhebung, Antragstellung) vorzunehmen. Prozessfähig sind gem. § 62 I Nr. 1 VwGO die nach bürgerlichem Recht Geschäftsfähigen und nach § 62 I Nr. 2 VwGO die nach bürgerlichem Recht in der Geschäftsfähigkeit Beschränkten (vgl. $\S \S 2$, $104 \mathrm{ff}$. BGB), soweit sie durch Vorschriften des bürgerlichen oder öffentlichen Rechts für den Gegenstand des Verfahrens als geschäftsfähig anerkannt sind. Wer nicht selbst prozessfähig ist, muss sich vertreten lassen. ${ }^{953}$ Dabei beurteilt sich nach materiellem Recht, wer gesetzlicher Vertreter ist und wie weit die entsprechende Vertretungsmacht reicht. ${ }^{954}$

951 Kintz, in: Posser/Wolff, VwGO, 48. Ed., Stand: 1.4.2019, §61 Rn. 19; Schenke, in Kopp/ Schenke, VwGO, 25. Aufl. 2019, § 61 Rn. 13; a. A. Hufen, Verwaltungsprozessrecht, 11. Aufl. 2019, $\S 12$ Rn. 22.

952 So z.B. in § 47 II 1 VwGO für den Normenkontrollantrag; Bier/Steinbeiß-Winkelmann, in: Schoch/Schneider/Bier, VwGO, 36. EL Februar 2019, § 61 Rn. 8.

953 Detterbeck, Allgemeines Verwaltungsrecht mit Verwaltungsprozessrecht, 17. Aufl. 2019, Rn. 1347.

954 Kintz, in: Posser/Wolff, VwGO, 50. Ed., Stand: 1.4.2019, § 62 Rn. 13. 


\section{a) Prozessfähigkeit Geschäftsfähiger ( $\$ 62$ I Nr. 1 VwG0)}

Unbeschränkt prozessfähig sind gem. § 61 I Nr. 1 VwGO die nach bürgerlichem 434 Recht voll Geschäftsfähigen. Das sind grundsätzlich alle natürlichen Personen, die das 18. Lebensjahr vollendet haben (§ 2 BGB) und deren Geistesfähigkeit nicht dauerhaft gestört ist (§ $104 \mathrm{Nr} .2$ BGB).

\section{b) Prozessfähigkeit beschränkt Geschäftsfähiger ( 62 I Nr. 2 VwG0)}

Beschränkt (partiell) prozessfähig gem. § 62 I Nr. 2 VwGO können Minder-

jährige über sieben Jahre (§ 106 BGB) nach Maßgabe der $\S \S 107 \mathrm{ff}$. BGB oder nach öffentlich-rechtlichen Vorschriften sein. Eine beschränkte Prozessfähigkeit i.S.d. §62 I Nr. 2 VwGO ergibt sich zivilrechtlich insbesondere aus §112 BGB oder $\S 113$ BGB. Im öffentlichen Recht ergibt sich eine beschränkte Prozessfähigkeit u. a. für Minderjährige nach Vollendung des 14. Lebensjahres bei religiösen Entscheidungen aus $§ 5$ S. 1 des Gesetzes über die religiöse Kindererziehung i.V.m. Art. $4 \mathrm{GG}^{955}$, für Minderjährige ab 15 oder 16 Jahren im Verfahren auf Erteilung einer Fahrerlaubnis gem. § 10 I, III i.V.m. §§ 4, 5 FeV, für Sozialleistungen ab 15 Jahren (§ 36 I SGB I) oder ab 16 Jahren im Melderecht nach § 17 III BMG.

Hausarbeitswissen: Für minderjährige Ausländer gelten grundsätzlich $\S 12$ AsylG und $\S 80$ Auf436 enthG, wonach die Fähigkeit zur Vornahme von Verfahrenshandlungen vom Eintritt der Volljährigkeit abhängig ist. Im Übrigen beurteilt sich die Prozessfähigkeit eines Ausländers nach ungeschriebenem deutschem Verfahrenskollisionsrecht grundsätzlich nach dem Prozessrecht seines Heimatstaates. ${ }^{956}$

Darüber hinaus können Minderjährige beschränkt prozessfähig sein, sofern höchstpersönliche Rechte, insbesondere Grundrechte, betroffen sind und der minderjährige Kläger hinreichend einsichtsfähig und grundrechtsmündig ist. ${ }^{957}$ Im Zweifel ist durch Auslegung der Norm zu ermitteln, ob der Minderjährige im konkreten Fall als beschränkt prozessfähig anzusehen ist.

Ist der beschränkt Geschäftsfähige unter den Voraussetzungen des § 62 I Nr. 2438 VwGO selbst für das konkrete Verfahren prozessfähig, kann statt oder neben ihm

955 BVerwG, Urt. v. 30.11.2011, Az.: 6 C 20/10 = NVwZ 2012, 162 (163) Rn. 15.

956 Hoppe, in: Eyermann, VwGO, 15. Aufl. 2019, § 62 Rn. 8; Bier/Steinbeiß-Winkelmann, in: Schoch/Schneider/Bier, VwGO, 36. EL Februar 2019, § 62 Rn. 15, 10; Kintz, in: Posser/Wolff, VwGO, 50. Ed., Stand: 1.4.2019, § 62 Rn. 7.

957 Schenke, in: Kopp/Schenke, VwGO, 25. Aufl. 2019, § 62 Rn. 6 m.w.N.; insbesondere zur Grundrechtsmündigkeit Schenke, Verwaltungsprozessrecht, 16. Aufl. 2019, Rn. 480.

Carola Creemers 
auch sein gesetzlicher Vertreter zum Handeln befugt sein, wenn durch Gesetz nichts anderes bestimmt ist. ${ }^{958}$

\section{c) Fehlende Prozessfähigkeit}

439 Kinder unter sieben Jahren (§104 Nr. 1 BGB) und dauerhaft Geistesgestörte (§ 104 Nr. 2 BGB) sind geschäftsunfähig und damit prozessunfähig.

440 Fehlt die Prozessfähigkeit muss sich der Betroffene durch den oder die gesetzlichen Vertreter (z.B. für Minderjährige die Eltern gem. §§ 1626, 1629 BGB) vertreten lassen. Ansonsten ist die Klage bei fehlender Prozessfähigkeit unzulässig. Prozesshandlungen durch oder gegenüber einem Prozessunfähigen sind unwirksam (s. zur vergleichbaren Problematik im Verwaltungsverfahren auch Rn. 641). Dies kann aber durch Genehmigung des gesetzlichen Vertreters geheilt werden. Eine nachträgliche Genehmigung wirkt auf den Zeitpunkt der Prozesshandlungen zurück, sofern die Genehmigung vor Rechtskraft des Urteils erfolgt. 959

\section{d) Vertreter von Vereinigungen und Behörden ( $\$ 62$ III VwG0)}

441 Gem. § 62 III VwGO handeln für Vereinigungen sowie für Behörden ihre gesetzlichen Vertreter und Vorstände. §62 III VwGO erfasst mit dem Merkmal „Vereinigungen“ sowohl juristische Personen des öffentlichen Rechts und des Privatrechts ( $\S 61$ Nr. 1 VwGO) als auch beteiligungsfähige Personenvereinigungen i.S.d. § 61 Nr. 2 VwGO, wobei sie alle ebenfalls wie Behörden als solche nicht prozessfähig sind, sondern durch ihre gesetzlichen Vertreter und Vorstände handeln. ${ }^{960}$ Wer gesetzlicher Vertreter ist und wie weit die jeweilige Vertretungsmacht reicht, ergibt sich aus dem materiellen Recht. ${ }^{961}$

\section{Postulationsfähigkeit und Prozessvertretung, $\S 67$ VwGO}

442 Anmerkung zur Falllösung: In der Klausur ist regelmäßig ausreichend, wenn die Norm des $\S 67$ VwGO bekannt ist sowie auf die Postulationsfähigkeit und die

958 Bier/Steinbeiß-Winkelmann, in: Schoch/Schneider/Bier, VwGO, 36. EL Februar 2019, § 62 Rn. 10; Schenke, in: Kopp/Schenke, VwGO, 25. Aufl. 2019, § 62 Rn. 9.

959 Schenke, in: Kopp/Schenke, VwGO, 25. Aufl. 2019, § 62 Rn. 17.

960 Bier/Steinbeiß-Winkelmann, in: Schoch/Schneider/Bier, VwGO, 36. EL Februar 2019, § 62 Rn. 17; Kintz, in: Posser/Wolff, VwGO, 50. Ed., Stand: 1.4.2019, § 62 Rn. 14.

961 So z.B. aus GG, Geschäftsordnungen, Landesverfassung, Gemeindeordnung, Verwaltungsvorschriften, BGB, HGB, GmbHG, AktG usw. 
Prozessvertretung nur bei entsprechenden Anhaltspunkten im Sachverhalt eingegangen wird.

Grundsätzlich ist jeder Prozessfähige im Verwaltungsprozess auch postulationsfähig, d.h. fähig Anträge zu stellen und selbst Prozesshandlungen vorzunehmen. ${ }^{962}$

Gem. § 67 I VwGO besteht vor dem Verwaltungsgericht kein Vertretungs- 444 zwang, sodass sich jeder Beteiligte selbst vertreten kann. Lassen Beteiligte sich jedoch vertreten, sind nur die in $\S 67$ II VwGO abschließend aufgezählten Prozessvertreter vertretungsbefugt. Zudem besteht vor dem BVerwG und OVG nach $\S 67$ IV VwGO Vertretungszwang. Treten die Beteiligten dennoch ohne tauglichen Vertreter auf, fehlt ihnen die Postulationsfähigkeit und sie können keine wirksamen Prozesshandlungen vornehmen. ${ }^{963}$

\section{Beiladung, $\S 65$ VwGO}

Nach $\S 63$ Nr. 3 VwGO zählt auch der Beigeladene nach § 65 VwGO zu den Betei- 445 ligten im Verwaltungsprozess, wobei die einfache (fakultative) Beiladung nach § 65 I VwGO sowie die notwendige (obligatorische) Beiladung gem. § 65 II VwGO zu unterscheiden sind. Bei der einfachen Beiladung (§ 65 I VwGO) kann das Gericht Dritte beiladen und bei der notwendigen Beiladung (§ 65 II VwGO) muss das Gericht bei Vorliegen der Voraussetzungen Dritte beiladen. Beigeladen werden können nur Dritte, die nach $\S 61$ VwGO beteiligungsfähig sind, aber nicht selbst Partei des Rechtsstreits, d.h. Kläger oder Beklagter sind. ${ }^{964}$

Zweck der Beiladung ist, Dritte am Rechtsstreit $\mathrm{zu}$ beteiligen, wenn ihre $\mathbf{4 4 6}$ rechtlichen Interessen durch den Streit berührt werden. Zudem soll durch die Rechtskrafterstreckung (§ 121 Nr. 1 i.V.m. § 63 Nr. 3 VwGO) aus Gründen der Prozessökonomie etwaigen weiteren Rechtsstreitigkeiten über dieselbe Sache vorgebeugt werden (Rechtsschutz und Rechtssicherheit für den Beigeladenen). ${ }^{965}$ Die Beiladung kommt bei allen Verfahrensarten in Betracht; nach § 47 II 4 VwGO auch im Normenkontrollverfahren. Beiladungsfähig ist jeder Beteiligungsfähige. ${ }^{966}$

962 Hufen, Verwaltungsprozessrecht, 11. Aufl. 2019, § 12 Rn. 27; Schenke, Verwaltungsprozessrecht, 16. Aufl. 2019, Rn. 483.

963 Schenk, in: Schoch/Schneider/Bier, VwGO, 36. EL Februar 2019, § 67 Rn. 73; Hoppe, in: Eyermann, VwGO, 15. Aufl. 2019, § 67 Rn. 20.

964 Bier, in: Schoch/Schneider/Bier, VwGO, 36. EL Februar 2019, § 65 Rn. 9 f.; Schenke, in: Kopp/ Schenke, VwGO, 25. Aufl. 2019, § 65 Rn. 5.

965 Kintz, in: Posser/Wolff, VwGO, 50. Ed., Stand: 1.4.2019, § 65 Rn. 1; Hufen, Verwaltungsprozessrecht, 11. Aufl.2019, § 12 Rn. 4; ausführlich zur Beiladung Guckelberger, JuS 2007, $436 \mathrm{ff.}$

966 Schenke, Verwaltungsprozessrecht, 16. Aufl. 2019, Rn. 464. 
Der Beigeladene ist kein Hauptbeteiligter, sondern er beteiligt sich als Nebenbeteiligter an einem ursprünglich fremden Rechtsstreit. ${ }^{967} \mathrm{Gem} . \S 65$ IV VwGO ist der Beiladungsbeschluss allen Beteiligten zuzustellen. Der Beigeladene erhält die Rechtsstellung eines Beteiligten ( $§ 63$ Nr. 3 VwGO) erst mit der Zustellung des Beiladungsbeschlusses oder bei Anwesenheit in der mündlichen Verhandlung mit dessen Verkündung. ${ }^{968}$ Zulässig ist die Beiladung nur, solange das Verfahren noch nicht rechtskräftig abgeschlossen ist (§ 65 I VwGO). Die Rechte des Beigeladenen ergeben sich aus $\S 66$ VwGO: Der Beigeladene kann innerhalb der Anträge eines Beteiligten selbständig Angriffs- und Verteidigungsmittel geltend machen und alle Verfahrenshandlungen wirksam vornehmen. Abweichende Sachanträge kann er nur stellen, sofern eine notwendige Beiladung vorliegt.

\section{a) Einfache (fakultative) Beiladung ( $\$ 65$ I VwG0)}

447 Bei der einfachen (fakultativen) Beiladung nach § 65 I VwG0 können nach dem Ermessen des Gerichts von Amts wegen oder auf Antrag Dritte beigeladen werden, sofern die Entscheidung rechtliche Interessen des Dritten berührt. Eine solche Berührung rechtlicher Interessen liegt vor, wenn die Möglichkeit besteht, dass sich die Rechtsposition des Dritten durch den Prozessausgang jedenfalls faktisch verbessern oder verschlechtern könnte. ${ }^{969}$ Nicht ausreichend sind allerdings rein ideelle, soziale oder wirtschaftliche Interessen. ${ }^{970}$

448 So kann regelmäßig der Grundstücksnachbar bei der Anfechtungsklage des Bauherrn gegen die Rücknahme eines Bauvorbescheids ${ }^{971}$ oder bei der Verpflichtungsklage des Bauherrn auf Erteilung einer Baugenehmigung unter den Voraussetzungen des $\S 65$ I VwGO einfach beigeladen werden. ${ }^{972}$

967 Czybulka/Kluckert, in: Sodan/Ziekow, VwGO, 5. Aufl. 2018, § 66 Rn. 3; Hufen, Verwaltungsprozessrecht, 11. Aufl. 2019, § 12 Rn. 16; Guckelberger, JuS 2007, 436 (436); Stober, in: Festschrift für Christian-Friedrich Menger, 1985, 401 (401).

968 Kintz, in: Posser/Wolff, VwGO, 50. Ed., Stand: 1.4.2019, § 66 Rn. 1.

969 BVerwG, Urt. v. 16.9.1981, Az.: 8 C 1/81 = NJW 1982, 951 (952); BVerwG, Beschl. v. 19.11.1998, Az.: 11 A 50/97 = NVwZ-RR 1999, 276, 276; Erbguth/Guckelberger, Allgemeines Verwaltungsrecht, 9. Aufl. 2018, § 20 Rn. 33.

970 Hoppe, in: Eyermann, VwGO, 15. Aufl. 2019, § 65 Rn. 9; Schenke, in: Kopp/Schenke, VwGO, 25. Aufl. 2019, § 65 Rn. 12.

971 OVG Koblenz, Beschl.v. 14.5.2013, Az.: 8 A 10043/13 = NVwZ-RR 2013, 747 (749); Hoppe, in: Eyermann, VwGO, 15. Aufl. 2019, § 65 Rn. 13.

972 BVerwG, Beschl. v. 21.6.1973, Az.: IV B 38.73 = DÖV 1975, 99 (99). Weitere Beispielsfälle einfacher Beiladung bei Kintz, Posser/Wolff, VwGO, 49. Ed., Stand: 1.4.2019, § 65 Rn. $9 f$. 
Examenswissen: Das Unterbleiben der einfachen Beiladung nach § 65 I VwGO hat keine unmittelbaren Folgen: Es handelt sich um keinen Verfahrensmangel, aber das Urteil entfaltet gegenüber dem Nicht-Beigeladenen auch keine Bindungswirkungen nach $\S 121$ VwGO. ${ }^{973}$ Für die Wirksamkeit der Gerichtsentscheidung im Verhältnis zwischen Kläger und Beklagtem hat die fehlerhaft unterbliebene einfache Beiladung grundsätzlich keine Konsequenzen. ${ }^{974}$

\section{b) Notwendige (obligatorische) Beiladung ( $\$ 65$ II VwG0)}

Die notwendige (obligatorische) Beiladung setzt gem. § 65 II VwGO voraus, 450 dass Dritte an dem streitigen Rechtsverhältnis derart beteiligt sind, dass die gerichtliche Entscheidung auch ihnen gegenüber nur einheitlich ergehen kann. Das ist dann der Fall, wenn mit dem Urteil gleichzeitig unmittelbar und zwangsläufig in Rechte der Dritten eingegriffen wird, d.h. ihre Rechte gestaltet, bestätigt, festgestellt, verändert oder aufgehoben werden, sodass aus Rechtsgründen die Entscheidung den Hauptbeteiligten und dem Beigeladenen gegenüber nur einheitlich ergehen kann. ${ }^{975}$ Die Rechte des Dritten müssen durch die Entscheidung unmittelbar berührt werden.

Um Fälle notwendiger Beiladung ${ }^{976}$ handelt es sich insbesondere bei Anfechtungsklagen gegen Verwaltungsakte mit Drittwirkung, d.h. Verwaltungsakte, die für eine Person begünstigend und für eine andere Person belastend wirken (vgl. dazu den Fall 3 in: Eisentraut, Fälle zum Verwaltungsrecht, 2020).

Examenswissen: Eine unterbliebene notwendige Beiladung stellt grundsätzlich einen wesentlichen Verfahrensfehler dar (Verletzung von Art. 103 GG), der im Rechtsmittelverfahren zur Aufhebung des Urteils und zur Zurückverweisung der Sache führt. ${ }^{977} \S 142$ I 2 VwGO lässt allerdings notwendige Beiladungen in der Revisionsinstanz zu. Damit soll eine Zurückverweisung der Sache im Interesse unnötiger Verfahrensverzögerungen vermieden werden, wenn der Beizuladende ein berechtigtes Interesse an der Zurückverweisung nicht haben kann, da weitere Tatsachenfeststellungen nicht notwendig sind. ${ }^{978}$ Unschädlich ist der Verfahrensmangel der unterbliebenen notwendigen Beiladung auch dann, wenn der Beizuladende durch die ergangene

973 Bier, in: Schoch/Schneider/Bier, VwGO, 36. EL Februar 2019, § 65 Rn. 38; Pietzner/Ronellenfitsch, Das Assessorexamen im Öffentlichen Recht, 14. Aufl. 2019, Rn. 223.

974 Guckelberger, JuS 2007, 436 (441).

975 Schenke, in: Kopp/Schenke, VwGO, 25. Aufl. 2019, § 65 Rn. 14; BVerwG, Beschl. v. 13.6. 2007, Az.: 6 VR 5/07 = NVwZ 2007, 1207 (1207) Rn. 6; BVerwG; Beschl. v. 9.1.1999, Az.: 11 C 8/97 = NVwZ 1999, 296 (296).

976 Auflistung wichtiger Fälle notwendiger Beiladung bei Hufen, Verwaltungsprozessrecht, 11. Aufl. 2019, § 12 Rn. 8.

977 Schenke, in: Kopp/Schenke, VwGO, 25. Aufl. 2019, § 65 Rn. 42; Kintz, in: Posser/Wolff, VwGO, 50. Ed., Stand: 1.4.2019, § 65 Rn. $31 \mathrm{f}$.

978 BVerwG, Beschl.v. 20.10.2000, Az.: 7 B 58/00 = NVwZ 2001, 202 (202). 
Entscheidung nicht in seinen Rechten berührt wird. ${ }^{979}$ Sofern der Verfahrensfehler nicht im Revisionsverfahren behoben wird, ist ein Gestaltungsurteil (z. B. Aufhebung eines Verwaltungsakts) bei fehlerhaft unterlassener notwendiger Beiladung absolut unwirksam, d.h. auch im Verhältnis zwischen den Hauptbeteiligten. ${ }^{980}$ Hingegen bleibt ein Verpflichtungsurteil gegenüber den Hauptbeteiligten wirksam, da der eigentlich beizuladende Dritte, den aufgrund dieses Urteils ergehenden Verwaltungsakt anfechten kann. ${ }^{981}$

453 Anmerkung zur Falllösung: Das Unterbleiben der Beiladung führt sowohl bei der einfachen als auch bei der notwendigen Beiladung nicht zur Unzulässigkeit einer Klage, sondern zu anderen prozessrechtlichen Folgen (vgl. Rn. 449, 452). ${ }^{922} \mathrm{Zu}$ den Zulässigkeitsvoraussetzungen der Klage gehört daher nicht, ob ein Dritter zum Rechtsstreit beizuladen ist oder rechtmäßig beigeladen wurde. ${ }^{983}$ Folglich handelt es sich bei der Beiladung nicht um eine „echte“ Zulässigkeitsvoraussetzung, sodass es sich empfiehlt, die Beiladung zwischen Zulässigkeit und Begründetheit zu prüfen (empfohlener Prüfungsaufbau: A. Zulässigkeit, B. Beiladung, C. Begründetheit; s. dazu $\S 1$ Rn. 63 ff. sowie Fall 3, Fall 4 und Fall 5 sowie den Fall 15 in: Eisentraut, Fälle zum Verwaltungsrecht, 2020). Sofern die Beiladung dennoch im Rahmen der Zulässigkeit geprüft wird, ist zu beachten, dass das Fehlen der Voraussetzungen bzw. das Unterbleiben der Beiladung nicht zur Unzulässigkeit der Klage führt, sondern nur Auswirkungen auf die Rechtskrafterstreckung des Urteils hat.

454 Die Voraussetzungen der Beiladung sind nur bei entsprechenden Anhaltspunkten im Sachverhalt zu prüfen. Im Fall der Drittanfechtungsklage sollte immer an die Prüfung der notwendigen Beiladung gedacht werden; wobei stets die Bearbeitervermerke zu berücksichtigen sind.

\section{Subjektive Klagehäufung (Streitgenossenschaft), § 64 VwGO}

455 Bei der subjektiven Klagehäufung treten mehrere Personen als Streitgenossen auf der Klägerseite (aktive Streitgenossenschaft) oder auf der Beklagtenseite (passive Streitgenossenschaft) auf. Mit Hilfe der subjektiven Klagehäufung kön-

979 Kintz, in: Posser/Wolff, VwGO, 50. Ed., Stand: 1.4.2019, § 65 Rn. 31; BVerwG, Beschl. v. 30.7. 1990, Az.: 7 B 71/90 = NVwZ 1991, 470 (471) m.w. N.

980 Guckelberger, JuS 2007, 436 (441); Czybulka/Kluckert, in: Sodan/Ziekow, VwGO, 5. Aufl. 2018, $\S 65 \mathrm{Rn} .191$.

981 BVerwG, Urt. v. 20.3.1997, Az.: 7 A 1/96 = VIZ 1997, 415 (416); Schmidt, in: Eyermann, VwGO, 15. Aufl. 2019, § 65 Rn. 19.

982 Schenke, Verwaltungsprozessrecht, 16. Aufl. 2019, Rn. 465.

983 Guckelberger, JuS 2007, 436 (441); Decker, in: Wolff/Decker, VwGO, 3. Aufl. 2012, § 65 Rn. 3.

Carola Creemers 
nen somit mehrere Klagen zur gemeinsamen Entscheidung und Verhandlung miteinander verbunden werden.

Nach $\S 64$ VwGO sind im Verwaltungsprozess die Vorschriften der $\S 59$ bis 456 63 ZPO über die Streitgenossenschaft entsprechend anzuwenden. Gem. § 59 ZPO besteht Streitgenossenschaft, wenn mehrere Beteiligte hinsichtlich des Streitgegenstandes in Rechtsgemeinschaft stehen oder wenn sie aus demselben tatsächlichen und rechtlichen Grund berechtigt oder verpflichtet sind oder nach $\S 60 \mathrm{ZPO}$, wenn gleichartige und auf einem im Wesentlichen gleichartigen tatsächlichen und rechtlichen Grund beruhende Ansprüche oder Verpflichtungen den Gegenstand des Rechtsstreits bilden. Anders als Beigeladene sind die Streitgenossen als Kläger oder Beklagte immer Hauptbeteiligte des Verfahrens.

Im Verwaltungsprozess handelt es sich in der Regel um aktive Streitgenos- 457 senschaft, d.h. um eine Mehrheit von Klägern. Für jeden Streitgenossen müssen gesondert die Zulässigkeitsvoraussetzungen seiner Klage gegeben sein. ${ }^{984}$ Wie bei der Beiladung unterscheidet man auch hier zwischen einfacher (fakultativer) Streitgenossenschaft gem. §64 VwGO i.V.m. §§59, 60 ZPO und notwendiger (obligatorischer) Streitgenossenschaft nach § 64 VwGO i.V.m. § 62 ZPO.

\section{a) Einfache Streitgenossenschaft ( $\$ 64$ VwGO i.V.m. $\S \S 59,60$ ZPO)} Die einfache Streitgenossenschaft nach § 64 VwGO i.V.m. §§ 59, 60 ZPO 458 ist nur die organisatorische Verbindung mehrerer Klagen (Prozessrechtsverhältnisse) zu einem Verfahren, d.h. die Entscheidung kann einheitlich ergehen, muss es aber nicht. ${ }^{985}$ Die einzelnen Streitgenossen bleiben hinsichtlich ihrer Prozesse selbständig und sind an Erklärungen und sonstige Prozesshandlungen der übrigen Streitgenossen nicht gebunden. ${ }^{986}$ Sofern die Voraussetzungen der einfachen Streitgenossenschaft nicht vorliegen, muss das Gericht die Verfahren gem. §93 S. 2 VwGO trennen. ${ }^{987}$ Um eine einfache subjektive Klagehäufung handelt es sich zum Beispiel bei mehreren Nachbarklagen gegen eine Baugenehmigung.

\footnotetext{
984 Hufen, Verwaltungsprozessrecht, 11. Aufl.2019, § 12 Rn. 16; Kintz, in: Posser/Wolff, VwGO, 50. Ed., Stand: 1.4.2019, § 64 Rn. 14.

985 Hufen, Verwaltungsprozessrecht, 11. Aufl.2019, § 12 Rn. 17.

986 Schenke, in: Kopp/Schenke, VwGO, 25. Aufl. 2019, § 64 Rn. 10.

987 Kintz, in: Posser/Wolff, VwGO, 50. Ed., Stand: 1.4.2019, § 64 Rn. 7; Schenke, in: Kopp/ Schenke, VwGO, 25. Aufl. 2019, § 64 Rn. 4 a.E.
} 


\section{b) Notwendige Streitgenossenschaft ( 64 VwGO i.V.m. §§62 ZP0)}

459 Eine notwendige Streitgenossenschaft liegt nach § 64 VwGO i.V.m. § 62 ZPO vor, wenn eine Sachentscheidung des Gerichts einheitlich ausfallen muss, sodass sich die Rechtskraft des Urteils auch auf die anderen Streitgenossen erstreckt. Hier wird nochmals zwischen unechter (uneigentlicher bzw. prozessualer) und echter (eigentlicher bzw. materiell-rechtlicher) notwendiger Streitgenossenschaft differenziert. Die unechte notwendige Streitgenossenschaft (§ 62 I Alt. 1 ZPO) liegt vor, wenn mehrere Kläger derart miteinander verbunden sind, dass zwar eine gesonderte Klage einzelner möglich ist, andererseits aber, wenn sie gemeinschaftlich klagen, die Sachentscheidung für alle identisch sein muss (z. B. wenn alle Miteigentümer gemeinsam auf die Erteilung einer Baugenehmigung klagen). ${ }^{988}$ Bei der echten notwendigen Streitgenossenschaft (§ 62 I Alt. 2 ZPO) sind nur alle Kläger gemeinsam klagebefugt und Klagen Einzelner nicht möglich (z. B. bei einer Klage von Ehegatten auf Änderung des Familiennamens oder gegen eine Namensänderung). ${ }^{989}$ Der Zwang zur gemeinschaftlichen Klage ergibt sich hier aus dem materiellen Recht ${ }^{990}$ - es kann materiell-rechtlich nur eine einheitliche Entscheidung ergehen.

460 Anmerkung zur Falllösung: Bei der subjektiven Klagehäufung handelt es grundsätzlich nicht um eine ,echte“ Zulässigkeitsvoraussetzung, sodass es sich empfiehlt die subjektive Klagehäufung zwischen Zulässigkeit und Begründetheit zu prüfen (empfohlener Prüfungsaufbau: A. Zulässigkeit, B. Subjektive Klagehäufung, C. Begründetheit). Eine Ausnahme hiervon bildet die echte notwendige Streitgenossenschaft: Diese muss bereits im Rahmen der Klagebefugnis angesprochen werden, da nur alle Kläger gemeinsam klagebefugt sind. Auf die subjektive Klagehäufung ist jedoch nur dann einzugehen, sofern der Sachverhalt entsprechende Anhaltspunkte enthält.

\section{Literaturhinweise}

461 Ehlers, Der Beklagte im Verwaltungsprozess, in: Festschrift für Christian-Friedrich Menger zum 70. Geburtstag, 1985, 379; Guckelberger, Die Beiladung im Verwaltungsprozess, JuS 2007, 436; Hufen, Verwaltungsprozessrecht, 11. Aufl. 2019, § 12 (Die Beteiligten und die auf sie bezogenen Zulässigkeitsvoraussetzungen); Pietz-

\footnotetext{
988 Schenke, Verwaltungsprozessrecht, 16. Aufl. 2019, Rn. 474a; Bier, in: Schoch/Schneider/Bier, VwGO, 36. EL Februar 2019, § 64 Rn. 13.

989 Kintz, in: Posser/Wolff, VwGO, 50. Ed., Stand: 1.4.2019, § 64 Rn. 12; Schenke, in: Kopp/ Schenke, VwGO, 25. Aufl. 2019, § 64 Rn. 7; BVerwG, Urt. v. 29.11.1982, Az.: 7 C 34/80 = NJW 1983, 1133 (1133).
}

990 Bier, in: Schoch/Schneider/Bier, VwGO, 36. EL Februar 2019, § 64 Rn. 17. 
ner/Ronellenfitsch, Das Assessorexamen im Öffentlichen Recht, 14. Aufl. 2019, $\S 7$ (Beteiligtenbezogene Sachurteilsvoraussetzungen); Rozek, Verwirrspiel um $\S 78$ VwGO? - Richtiger Klagegegner, passive Prozessführungsbefugnis und Passivlegitimation, JuS 2007, 601; Schenke, Verwaltungsprozessrecht, 16. Aufl. 20197, $\S 12$ (Die Beteiligungsfähigkeit), Rn. 446 ff., $§ 13$ (Prozessfähigkeit, Prozessvertretung, Postulationsfähigkeit), Rn. 477 ff., §15 (Die Prozessführungsbefugnis), Rn. $538 \mathrm{ff}$.

\section{Das zuständige Gericht (Katharina Goldberg)}

Bei der Frage des zuständigen Gerichts liegt häufig kein Schwerpunkt der Klau- 462 surlösung. Dennoch müssen die sachliche und örtliche Zuständigkeit in jeder Klausur zumindest angesprochen und die relevanten Normen benannt werden.

Formulierungsvorschlag Obersatz: „Das Verwaltungsgericht müsste sachlich 463 gem. $\S 45$ VwGO und örtlich gem. $\S 52$ VwGO zuständig sein.“

Hausarbeitswissen: Die Vorschriften über die Zuständigkeit eines Gerichts sind Ausfluss des Gebots 464 des gesetzlichen Richters (Art. $101 \mathrm{GG}$ ). Sie dienen dazu, dass sich Parteien ihre Richter nicht aussuchen können, sondern diese zuvor gesetzlich bestimmt wurden. ${ }^{991}$ Grundsätzlich ist nach $\S 45$ VwGO das Verwaltungsgericht das Eingangsgericht (das erste Gericht, das sich mit einer Rechtssache beschäftigt).

\section{Sachliche Zuständigkeit}

Das Verwaltungsgericht ist sachlich in der ersten Instanz für alle Streitigkei- 465 ten zuständig, für die der Verwaltungsrechtsweg gem. §40 VwGO eröffnet ist, § 45 VwG0. ${ }^{992}$

In wenigen geregelten Ausnahmefällen kann auch das Oberverwaltungs- 466 gericht (in Bayern, Baden- Württemberg und Hessen: Verwaltungsgerichtshof, vgl. § 184 VwGO) oder das Bundesverwaltungsgericht das Eingangsgericht sein. Die erstinstanzliche Zuständigkeit der Oberverwaltungsgerichte/Verwaltungsgerichtshöfe richtet sich nach den $\S \S 47$ und 48 VwGO. § 47 VwGO bestimmt die Zuständigkeit für Normenkontrollverfahren (s. hierzu § 7 Rn. 49). § 48 VwGO bestimmt eine konkrete erstinstanzliche Zuständigkeit der Oberverwaltungsgerichte/Verwaltungsgerichtshöfe für bestimmte Bereiche: Streitigkeiten im Bereich der Kernenergieanlagen, Kraftwerke, Abfallverbrennungsanlagen und Flughäfen und

991 Morgenthaler, in: Epping/Hillgruber, GG, 41. Ed., Stand: 15.02.2019, § 101 Rn. 15. 992 Berstermann, in: Posser/Wolf, VwGO, 49. Ed., Stand: 1.10.2018, § 45 Rn. 2. 
bei Planfeststellungsverfahren im Energiewirtschaftsbereich, bei Windenergieanlagen auf See, Bahnstrecken, Bundesfernstraßen, Bundeswasserstraßen und im Küsten- und Hochwasserschutz (§ 48 I Nr. 1-10 VWGO) sowie für Vereinsverbote (§ 48 II VwGO).

467 Das Bundesverwaltungsgericht ist in erster Instanz zuständig in den in $\S 50$ VwGO aufgezählten Fällen: bei öffentlich-rechtlichen Streitigkeiten nichtverfassungsrechtlicher Art zwischen dem Bund und den Ländern oder zwischen verschiedenen Ländern, bei bestimmten Vereinsverboten, bei bestimmten $\mathrm{Ab}$ schiebeanordnungen, bei Bundesnachrichtendienst-Angelegenheiten, in bestimmten Fällen des Abgeordnetengesetzes und in sämtlichen Streitigkeiten über bestimmte Planfeststellungs- und Plangenehmigungsverfahren (§50 I Nr. 1-6 VwGO).

Wenn sich das angerufene Verwaltungsgericht für örtlich oder sachlich unzuständig hält, muss es die Sache von Amts wegen gem. § 83 VwGO an das zuständige Gericht verweisen. Dies geschieht entsprechend der §§17a, 17b GVG (s. dazu bereits $\S 1$ Rn. 49, 163). ${ }^{993}$

469 Examenswissen: Die instanzielle Zuständigkeit regelt, ob ein Gericht im Instanzenzug als Berufungs-, Revisions- oder Beschwerdegericht zuständig ist. So sind die Oberverwaltungsgerichte/ Verwaltungsgerichtshöfe zuständig für Berufungen gegen Urteile und Beschwerden gegen andere Entscheidungen des Verwaltungsgerichts ( $\$ 46 \mathrm{Nr}$. 1 und 2 VwGO) und das Bundesverwaltungsgericht gem. § 49 VwGO für Revisionen gegen Entscheidungen der OVG/VerwGH (§ 132 VwGO) oder Sprungrevisionen bzw. Revisionen bei Ausschluss der Berufung (§§ 134, 135 VwGO). In der Klausur wird dies in den seltensten Fällen Relevanz haben.

470 Hausarbeitswissen: In einigen Fällen kann es dazu kommen, dass die gleiche Rechtsfrage von unterschiedlichen Bundesgerichten (BGH, BFH, BVerwG, BSG, BAG) beantwortet werden muss. Dies kommt z.B. im Steuerrecht gelegentlich vor, wenn ein Sachverhalt vom BGH aus gesellschaftsrechtlicher Perspektive und dann vom BFH aus steuerrechtlicher Perspektive entschieden wird. Um hier eine einheitliche Rechtsprechung zu gewährleisten besteht die Möglichkeit, dass das Bundesgericht, das einen Fall derzeit verhandelt und eine Entscheidung in einer Sache anstrebt, die entgegen einer bereits ergangenen Entscheidung eines anderen Bundesgerichts lauten würde, vor seiner Entscheidung den Gemeinsamen Senat der obersten Gerichtshöfe des Bundes anruft. Dieser trifft in der speziellen Rechtsfrage eine Entscheidung, damit diese dann in der Zukunft einheitlich gehandhabt werden kann. Der Gemeinsame Senat der obersten Gerichtshöfe des Bundes kann jedoch nicht von einem Kläger selbst angerufen werden.

471 Hausarbeitswissen: Die Arbeitsweise der Verwaltungsgerichte wird in einem sog. Geschäftsverteilungsplan geregelt. Dieser legt fest, welcher Richter über welche Rechtssachen entscheidet. Mit dem Geschäftsverteilungsplan wird dem Gebot des gesetzlichen Richters (Art. 101 GG) nachge-

993 Weitergehend hierzu Schenke, Verwaltungsprozessrecht, 16. Aufl. 2019, Rn. 444; Hufen, Verwaltungsprozessrecht, 11. Aufl. 2019, Rn. 87.

Katharina Goldberg 
kommen: Dadurch, dass bereits vor Anhängigkeit einer Rechtssache diese einem bestimmten Richter zugeordnet ist kann sich weder dieser seine Fälle noch der Kläger sich seinen Richter aussuchen.

\section{2. Örtliche Zuständigkeit}

Die örtliche Zuständigkeit richtet sich bei allen Klagearten nach $\$ 52$ VwGO. 472

Sie muss bestimmt werden, wenn verschiedene Gerichte sachlich zuständig sind. In den meisten Klausuren wird die örtliche Zuständigkeit durch den Klausursteller vorgegeben. Wenn dies nicht der Fall ist müssen die einzelnen Nummern des $\S 52$ VwGO gründlich gelesen werden. Sie geben eine Reihenfolge vor, nach der die örtliche Zuständigkeit bestimmt werden muss.

Bei Anfechtungsklagen gilt zunächst $§ 52$ Nr. 1 VwGO, nach dem bei Strei- 473 tigkeiten, die sich auf unbewegliches Vermögen oder ein ortsgebundenes Recht oder Rechtsverhältnis beziehen nur das Verwaltungsgericht örtlich zuständig ist, in dessen Bezirk das Vermögen oder der Ort liegt.

Weiterhin ist gem. \$ $\mathbf{5 2} \mathbf{~ N r . ~} \mathbf{4}$ VwGO das Gericht zuständig, in dem der Kläger seinen dienstlichen Wohnsitz bzw. in Ermangelung dessen seinen Wohnsitz hat, wenn es sich um Anfechtungsklagen aus dem Beamten-, Richter-, Wehrpflicht-, Wehrdienst-, oder Zivildienstverhältnis handelt.

§ 52 Nr. 2 VwGO enthält dann eine besondere örtliche Zuständigkeit für Anfechtungsklagen gegen Bundesbehörden, bundesunmittelbare Körperschaften, Stiftungen des öffentlichen Rechts, für Streitigkeiten nach dem Asylgesetz und für Klagen gegen den Bund in Gebieten, die in die Zuständigkeit der diplomatischen und konsularischen Auslandsvertretungen fallen.

Nach § 52 Nr. 3 VwGO ist dann bei allen anderen Anfechtungsklagen das Verwaltungsgericht örtlich zuständig, in dessen Bezirk der Verwaltungsakt erlassen wurde.

Als Auffangregelung greift der $\mathbf{\$} \mathbf{5 2} \mathbf{N r} \mathbf{5} \mathbf{~ V w G O}$ für alle anderen Fälle, in denen das Verwaltungsgericht zuständig ist, in dessen Bezirk der Beklagte seinen Sitz, Wohnsitz oder in Ermangelung dessen seinen Aufenthalt hat bzw. seinen letzten Wohnsitz oder Aufenthalt hatte. $\S 52$ Nr. 5 VwGO hat bei der Anfechtungsklage jedoch keinen Anwendungsbereich, da $\S 52 \mathrm{Nr}$. 3 bereits alle möglichen Konstellationen auffängt.

In der Klausur ist die Bestimmung der örtlichen Zuständigkeit des Gerichts in 474 den Stadtstaaten Hamburg, Berlin und Bremen einfach, da sie jeweils nur ein Verwaltungsgericht haben. 


\section{Literaturhinweise}

475 Hufen, Verwaltungsprozessrecht, 11. Aufl. 2019, Rn. 77-87; Schenke, Verwaltungsprozessrecht, 16. Aufl. 2019, Rn. 437-437; Würtenberger/Heckmann, Verwaltungsprozessrecht, 4. Aufl. 2018, Rn. 255-262

\section{Das Rechtsschutzbedürfnis (Dana-Sophia Valentiner)}

476 Die Inanspruchnahme gerichtlichen Rechtsschutzes im Wege der Anfechtungsklage setzt voraus, dass die rechtsschutzsuchende Person ein von der Rechtsordnung anzuerkennendes Interesse hat. Dieses Interesse wird als allgemeines Rechtsschutzbedürfnis bezeichnet.

\section{Das Rechtsschutzbedürfnis als allgemeine Sachentscheidungsvoraussetzung}

477 Wer gerichtlichen Rechtsschutz begehrt, muss ein berechtigtes Interesse an der avisierten Entscheidung des Gerichts haben, also des Rechtsschutzes bedürfen. Die Sachentscheidungsvoraussetzung des Rechtsschutzbedürfnisses, auch als Rechtsschutzinteresse bezeichnet, sichert diesen Grundsatz für alle Verfahrensarten verwaltungsprozessual ab. ${ }^{994}$

478 Das Rechtsschutzbedürfnis wird in der VwGO an keiner Stelle ausdrücklich genannt. Lediglich für die Feststellungklage und die Fortsetzungsfeststellungsklage verlangen $\S \S 43,113$ I 4 VwGO das Vorliegen eines „berechtigten Interesses“, das als besonderes Rechtsschutzbedürfnis qualifiziert wird.

\section{a) Herleitung}

479 Dogmatisch hergeleitet wird das allgemeine Rechtsschutzbedürfnis aus dem allgemeinen Rechtsgedanken ${ }^{995}$, der in $\S \S 43$, 113 I 4 VwGO zum Ausdruck kommt, aus dem Grundsatz der Prozessökonomie ${ }^{996}$, dem für die Gerichte geltenden Grundsatz der Effizienz staatlichen Handelns ${ }^{997}$ sowie dem Gebot

994 Vgl. BVerfG, Beschl. v. 19.10.1982, Az.: 1 BvL 34/80, 1 BvL 55/80 = BVerfGE 61, 126 (135); BVerfG, Beschl. v. 14.12.2004, Az.: 2 BvR 1451/04 = NJW 2005, 1855 (1856).

995 BVerwG, Urt. v. 17.1.1989, Az.: 9 C 44/87 = BVerwGE 81, 164 (165f.).

996 Mann/Wahrendorf, Verwaltungsprozessrecht, 4. Aufl. 2015, § 13 Rn. 163.

997 BVerfG, Beschl.v. 14.12.2004, Az.: 2 BvR 1451/04 = NJW 2005, 1855 (1856); BVerwG, Beschl.v. 11.02.2019, Az.: 4 B 28/18, juris Rn. 7. 
von Treu und Glauben ${ }^{998}$, welches einen Missbrauch prozessualer Rechte verbietet. $^{999}$

Hausarbeitswissen: Das allgemeine Rechtsschutzbedürfnis wird in der Literatur zutreffend als 480 verfassungsimmanente Schranke der Rechtsschutzgarantie beschrieben. ${ }^{1000}$ Es bewegt sich in einer Spannungslage zwischen den vorgenannten Grundsätzen und dem verfassungsrechtlich garantierten Anspruch auf Rechtsschutz aus Art. 19 IV GG. Die Sachentscheidungsvoraussetzung des allgemeinen Rechtsschutzbedürfnisses begrenzt den allgemeinen Justizgewährleistungsanspruch. Nur wer ein berechtigtes Interesse mit der angestrengten gerichtlichen Entscheidung verfolgt, hat einen Anspruch auf die sachliche Entscheidung. Fehlt das Rechtsschutzbedürfnis, ist der Antrag bzw. die Klage unzulässig und wird auf prozessualer Ebene abgewiesen. Vereinzelt wird die Sachentscheidungsvoraussetzung des allgemeinen Rechtsschutzbedürfnisses dafür kritisiert, dass sie auf diese Weise Prozessentscheidungen hervorbringe, sachliche Entscheidungen sperre und überdies ein „Einfallstor außerrechtlicher Wertungen“ öffne. ${ }^{1001}$

\section{b) Prüfungsanforderungen und -umfang}

Examenswissen: Das Bundesverfassungsgericht hat festgestellt, dass es mit dem Gebot des effektiven Rechtsschutzes aus Art. 19 IV 1 GG vereinbar sei, die Gewährung gerichtlichen Rechtsschutzes von einem Rechtsschutzinteresse abhängig zu machen. ${ }^{1002}$ Um die Spannungslage zwischen allgemeinen Rechtsschutzbedürfnis und Rechtsschutzgarantie aus Art. 19 IV GG in verhältnismäßiger Weise aufzulösen, werden geringe Anforderungen an die Prüfung des Vorliegens des allgemeinen Rechtsschutzbedürfnisses gestellt. Das allgemeine Rechtsschutzbedürfnis liegt vor, „solange der Rechtsschutzsuchende gegenwärtig betroffen ist und mit seinem Rechtsmittel ein konkretes praktisches Ziel erreichen kann". ${ }^{1003}$ Nur ausnahmsweise fehlt das allgemeine Rechtsschutzbedürfnis.

Der Grundsatz effektiven Rechtsschutzes verlangt, dass die rechtschutzsuchende Person ihr Rechtsschutzbedürfnis grundsätzlich nicht positiv nachweisen muss. Deshalb formuliert die für die Klausurpraxis entwickelte Merkformel „K-E-S-E“ negative Voraussetzungen zur Prüfung des allgemeinen Rechtsschutzbedürfnisses: Das Rechtsschutzbedürfnis fehlt nur dann, wenn das Rechtsschutzziel auf

998 Würtenberger/Heckmann, Verwaltungsprozessrecht, 4. Aufl. 2018, § 20 Rn. 305.

999 Grundlegend zu dogmatischer Herleitung und Geltungsgrund des Rechtsschutzbedürfnisses: Stein, Die Sachentscheidungsvoraussetzung des allgemeinen Rechtsschutzbedürfnisses im Verwaltungsprozeß, 2000, 34 ff.; aus der älteren Literatur Stephan, Das Rechtsschutzbedürfnis, $1967,19 \mathrm{ff}$.

1000 Würtenberger/Heckmann, Verwaltungsprozessrecht, 4. Aufl. 2018, § 20 Rn. 305.

1001 Vgl. aus zivilprozessualer Perspektive: Schumann, in: Festschrift Fasching, 1988, 439 (441 f., 445).

1002 Vgl. BVerfG, Beschl. v. 5.12.2001, Az.: 2 BvR 527/99, 2 BvR 1337, 1777/00 = BVerfGE 104, 220 (232).

1003 BVerfG, Beschl.v. 5.12.2001, Az.: 2 BvR 527/99, 2 BvR 1337, 1777/00 = BVerfGE 104, 220 (232). 
einem kostengünstigeren, einfacheren, schnelleren oder effektiveren Weg verfolgt werden kann. ${ }^{1004}$

Bei Gestaltungs- und Leistungsklagen folgt das allgemeine Rechtsschutzbedürfnis bereits aus dem Umstand, dass die klagende bzw. antragstellende Person einen auf Leistung an sich selbst gerichteten, bislang nicht erfüllten Anspruch geltend macht. ${ }^{1005}$ Das Bundesverwaltungsgericht postulierte insoweit den Grundsatz, dass die Rechtsordnung immer dann, wenn sie ein materielles Recht gewährt, in aller Regel auch das Interesse desjenigen, der sich als der Inhaber dieses Rechtes sieht, am gerichtlichen Schutze dieses Rechtes anerkennt. ${ }^{1006}$

Für Feststellungsklagen wird ein besonderes (auch: qualifiziertes) Rechtsschutzbedürfnis verlangt. § 43 I VwGO setzt für die Feststellungsklage ein „berechtigtes Interesse an der baldigen Feststellung“, § 113 I 4 VwGO für die Fortsetzungsfeststellungsklage ein „berechtigtes Interesse“ an der Feststellung der Rechtswidrigkeit eines zurückgenommenen oder anders erledigten Verwaltungsakts voraus. Anders als bei Leistungs- und Gestaltungsklagen, bei denen grundsätzlich davon ausgegangen werden darf, dass die Person, die sich eines materiellen Rechts berühmt, auch ein berechtigtes Interesse auf gerichtlichen Schutz dieses Rechts hat, ist das besondere Rechtsschutzbedürfnis bei Feststellungsklagen stets zu begründen (s. hierzu $\S 4 \mathrm{Rn}$. 51 sowie $\S 6 \mathrm{Rn}$. 96).

Abzugrenzen ist das allgemeine Rechtsschutzbedürfnis von der Klage- bzw. Antragsbefugnis, (analog) § 42 II VwGO. Die Klage- bzw. Antragsbefugnis verlangt als Ausdruck des subjektiven Rechtsschutzes die Geltendmachung einer Rechtsverletzung, während das allgemeine Rechtsschutzbedürfnis das Vorliegen schutzwürdiger Interessen beurteilt. ${ }^{1007}$ Das allgemeine Rechtsschutzbedürfnis zielt im Unterschied zu der Klage- bzw. Antragsbefugnis darauf zu prüfen, ob die Rechtsverfolgung des begehrten gerichtlichen Rechtsschutzes bedarf. ${ }^{1008}$

In der Klausur ist darauf zu achten, bei der Sachentscheidungsvoraussetzung des allgemeinen Rechtsschutzbedürfnisses das Vorliegen eines berechtigten Interesses an der Rechtsverfolgung zu prüfen, nicht jedoch das Bestehen eines materiellen Anspruchs, welches einschließlich der Sachlegitimation in der Begründetheit der Klage bzw. des Antrags geprüft wird.

Das allgemeine Rechtsschutzbedürfnis ist in der Klausur in unproblematischen Fällen nicht anzusprechen, weil es - jedenfalls bei Leistungs- und Gestal-

1004 Gersdorf, Verwaltungsprozessrecht, 6. Aufl. 2019, Rn. 49; Mann/Wahrendorf, Verwaltungsprozessrecht, 4. Aufl. 2015, § 13 Rn. 164.

1005 BVerwG, Urt. v. 17.1.1989, Az.: 9 C 44/87 = BVerwGE 81, 164 (165f.).

1006 BVerwG, Urt. v. 17.1.1989, Az.: 9 C 44/87 = BVerwGE 81, 164 (165f.).

1007 Ehlers, in: Schoch/Schneider/Bier, VwGO, 36. EL Februar 2019, Vorbem. § 40 Rn. 77.

1008 Brüning, JuS 2004, 882 (884). 
tungsklagen - regelmäßig vorliegt. Eine ausführlichere Prüfung ist nur in atypischen Konstellationen erforderlich, wenn der Sachverhalt besondere Umstände schildert, die einen Ausnahmetatbestand nahelegen. ${ }^{1009}$

\section{c) Relevante Fallgruppen}

Es lassen sich verschiedene Konstellationen unterscheiden, in denen das allge- 488 meine Rechtsschutzbedürfnis nicht vorliegt.

\section{aa) Rechtsschutzziel kann auf einfachere Art und Weise erreicht werden}

Das Rechtsschutzbedürfnis fehlt, wenn die rechtsschutzsuchende Person ihr Ziel kostengünstiger, einfacher, schneller oder effektiver erreichen kann.

Beispiel: Das Rechtsschutzziel kann außergerichtlich verfolgt werden, z.B. durch eine Antragstellung gegenüber der Verwaltung.

Eine vorherige Antragstellung ist dem Bürger aber nur zumutbar, wenn sie pro490 zessrechtlich vorgesehen ist. ${ }^{1010}$

Das Rechtsschutzbedürfnis eines Verwaltungsträgers fehlt insbesondere, 491 wenn bereits ein vollstreckbarer Titel in Form eines Verwaltungsakts besteht. ${ }^{1011}$

Examenswissen: Kann eine Behörde einen Verwaltungsakt erlassen, hat dies aber noch nicht getan, nimmt die Rechtsprechung teilweise eine Wahlmöglichkeit der Behörde zwischen dem Erlass eines Verwaltungsakts und der Erhebung einer allgemeinen Leistungsklage an. ${ }^{1012}$ Für diese Möglichkeit spricht der Grundsatz der Verfahrenseffizienz, insbesondere wenn bei Erlass eines Verwaltungsakts ohnehin mit einer gerichtlichen Auseinandersetzung des Rechtsstreits zu rechnen ist. Dagegen wird die Aufgabenverteilung zwischen Judikative und Exekutive ins Feld geführt. ${ }^{1013}$ Die Verwaltung dürfe erst dann gerichtlichen Rechtsschutz in Anspruch nehmen, wenn sie die eigenen Handlungsmöglichkeiten ausgeschöpft hat. ${ }^{1014}$ Außerdem können dem Betroffenen Rechtsschutzmöglichkeiten abgeschnitten werden, die ihm beispielsweise im Widerspruchsverfahren offen stehen würden.

1009 Vgl. Ipsen, Allgemeines Verwaltungsrecht, 11. Aufl. 2019, Rn. 1174.

1010 Ehlers, in: Schoch/Schneider/Bier, VwGO, 36. EL Februar 2019, Vorbem. § 40 Rn. 82.

1011 BVerwG, Urt. v. 12.12.1974, Az.: V C 25.74, juris Rn. 5.

1012 Vgl. BVerwG, Urt. v. 24.11.1966, Az.: II C 27/64 = NJW 1967, 946 (948).

1013 Ehlers, in: Schoch/Schneider/Bier, VwGO, 36. EL Februar 2019, Vorbem. § 40 Rn. 85.

1014 Würtenberger/Heckmann, Verwaltungsprozessrecht, 4. Aufl. 2018, § 20 Rn. 309. 
493 Das Rechtsschutzbedürfnis fehlt außerdem, wenn der rechtsschutzsuchenden Person ein einfacheres gerichtliches Verfahren oder eine rechtschutzintensivere Rechtsschutzform zur Verfügung steht.

Beispiel: Die Klägerin begehrt Aufhebung eines Verwaltungsakts mittels Verpflichtungsklage.

In diesem Fall fehlt das allgemeine Rechtsschutzbedürfnis, weil die Anfechtungsklage als Gestaltungsklage die effektivere Rechtsschutzform darstellt. In der Klausur wird dies in der Regel bereits bei der statthaften Klageart angesprochen.

494 Hausarbeitswissen: Es existieren einige (gesetzliche) Konkurrenzregelungen, die den Fall betreffen, dass das begehrte Rechtsschutzziel mit verschiedenen Verfahren erreicht werden könnte. Solche Verfahrenskonkurrenzregelungen sehen beispielsweise § 43 II 1 VwGO (s. dazu § 6 Rn. 63ff.) und $\S 44 a$ VwGO vor. ${ }^{1015}$ Diese Vorschriften können als gesetzliche Ausprägung eines Unterfalls des allgemeinen Rechtsschutzbedürfnisses verstanden werden. ${ }^{1016}$ In der Literatur wird hingegen auch vertreten, diese Konkurrenzregeln nicht im Rahmen des Rechtsschutzbedürfnisses zu prüfen, weil sie nicht zwingend Ausdruck mangelnden rechtsschutzwürdigen Interesses, sondern einer verfahrenseffizienten Entscheidung des Gesetzgebers seien (s. auch die Ausführungen zur Statthaftigkeit der Leistungsklage $\$ 5$ Rn. 2ff. sowie zur rechtsschützenden Funktion der Subsidiarität der Feststellungsklage $§ 6$ Rn. 63ff.). ${ }^{1017}$

\section{bb) Rechtsschutz verspricht keinerlei Vorteil für die rechtsschutzsuchende Person}

Das Rechtsschutzbedürfnis fehlt außerdem, wenn das gerichtliche Verfahren keinerlei Vorteile rechtlicher oder tatsächlicher Art mit sich brächte.

Beispiel: Der Kläger begehrt die Verbesserung einer Note, der jedoch keinerlei praktische Bedeutung mehr zukommt. ${ }^{1018}$

Beispiel: Begehrt wird die Festsetzung eines über den gesetzlichen Mindestwert hinausgehenden Gegenstandswertes für eine Verfassungsbeschwerde, die jedoch nicht zur Entscheidung angenommen wurde. ${ }^{1019}$

1015 Schenke, Verwaltungsprozessrecht, 16. Aufl. 2019, Rn. 566.

1016 Hufen, Verwaltungsprozessrecht, 10. Aufl. 2016, § 23 Rn. 20; Mann/Wahrendorf, Verwaltungsprozessrecht, 4. Aufl. 2015, § 13 Rn. 163.

1017 Schenke, Verwaltungsprozessrecht, 16. Aufl. 2019, Rn. 564 f.

1018 Detterbeck, Allgemeines Verwaltungsrecht mit Verwaltungsprozessrecht, 17. Aufl. 2019, Rn. 1349.

1019 BVerfG, Beschl. v. 19.1.2019, Az.: 1 BvR 3165/15, juris Rn. 2. 
Die Rechtsstellung der rechtsschutzsuchenden Person verbessert sich auch dann 496 nicht dergestalt, dass ein Rechtsschutzbedürfnis angenommen werden könnte, wenn die Wiederherstellung der aufschiebenden Wirkung eines bereits vollzogenen Verwaltungsakts verlangt wird. ${ }^{1020}$

Das Rechtsschutzbedürfnis kann auch während des gerichtlichen Verfahrens entfallen.

Beispiel: Die Klägerin begehrt die Erteilung einer Aufenthaltsgenehmigung, die zwischenzeitlich durch die Behörde erteilt wird. ${ }^{1021}$

\section{cc) Rechtsmissbräuchliche Inanspruchnahme des gerichtlichen Verfahrens}

Das Rechtsschutzbedürfnis ist zu verneinen, wenn die Inanspruchnahme des 498 gerichtlichen Rechtsschutzes nicht in Einklang mit der Rechtsordnung steht, insbesondere wenn sie gegen das Gebot von Treu und Glauben verstößt ${ }^{1022}$. Von einem Missbrauch ist auszugehen, wenn das gerichtliche Verfahren ausschließlich angestrengt wird, um die gegnerische Partei oder Dritte zu schädigen, ${ }^{1023}$ wobei nicht zwingenderweise Umstände vorliegen müssen, die im materiellen Recht einen Verstoß gegen das Schikaneverbot aus § 226 BGB bedeuten würden. ${ }^{1024}$

Examenswissen: Zweifel an dem Vorliegen des allgemeinen Rechtsschutzbedürfnisses können sich auch ergeben, wenn ein sogenanntes Sperrgrundstück ausschließlich mit dem Ziel der Bekämpfung einer planerischen Entscheidung erworben wird. Diese Problematik ist regelmäßig bereits bei der Klage- bzw. Antragsbefugnis zu erörtern. ${ }^{1025}$ Der Eigentumsschutz kann in solchen Fällen mit Blick auf die Rechtsschutzgarantie aus Art. 19 IV GG nicht pauschal versagt werden. ${ }^{1026}$ Die fehlende oder nur geringe wirtschaftliche Nutzung des Grundstücks ist vielmehr im Rahmen der materiellen Prüfung zu berücksichtigen.

\section{(1) Verspätete Geltendmachung}

Das Rechtsschutzbedürfnis kann insbesondere entfallen, wenn die verspätete $\mathbf{5 0 0}$ Geltendmachung eines Anspruchs gegen Treu und Glauben verstößt. Das Bundesverfassungsgericht geht von einem fehlenden Rechtsschutzbedürfnis aus,

1020 Ehlers, in: Schoch/Schneider/Bier, VwGO, 36. EL Februar 2019, Vorbem. § 40 Rn. 94. 1021 Mann/Wahrendorf, Verwaltungsprozessrecht, 4. Aufl. 2015, § 13 Rn. 165.

1022 BVerwG, Beschl. v. 11.02.2019, Az.: 4 B 28/18, juris Rn. 7.

1023 Hufen, Verwaltungsprozessrecht, 10. Aufl. 2016, § 23 Rn. 16.

1024 Ehlers, in: Schoch/Schneider/Bier, VwGO, 36. EL Februar 2019, Vorbem. § 40 Rn. 98.

1025 So BVerwG, Urt. v. 27.10.2000, Az.: 4 A 10/99 = NVwZ 2001, 427 (428).

1026 Vgl. BVerwG, Urt. v. 9.7.2008, Az.: 9 A 14/07 = NVwZ 2009, 302 (304). 
wenn die rechtsschutzsuchende Person sich verspätet auf ihr Recht beruft und unter Verhältnissen untätig bleibt, „unter denen vernünftigerweise etwas zur Wahrung des Rechts unternommen zu werden pflegt “ “. ${ }^{1027}$ Das öffentliche Interesse an der Wahrung des Rechtsfriedens könne in derartigen Fällen verlangen, die Anrufung des Gerichts nach langer Zeit untätigen Zuwartens als unzulässig anzusehen. Von einer solchen rechtsmissbräuchlichen verspäteten Antragstellung wird jedoch nur ausnahmsweise ausgegangen.

Beispiel: Der Antragsteller hat mehrere ihm zur Verfügung stehende Zeitpunkte verstreichen lassen, um den von ihm vorgebrachten Wiederaufgreifensgrund überhaupt im behördlichen Verfahren geltend machen zu können. ${ }^{1028}$

\section{(2) Verwirkung}

501 Die rechtsschutzsuchende Person kann ihren Rechtsschutz auch durch ihr vorangegangenes Verhalten verwirkt haben. Von einer prozessualen Verwirkung ist auszugehen, wenn der Klage- bzw. Antragsgegner infolge eines bestimmten Verhaltens der Klägerin bzw. Antragstellerin darauf vertrauen durfte, dass das in Rede stehende Recht nicht mehr geltend gemacht wird, und darauf tatsächlich vertraut hat, sodass ihm durch die verspätete Durchsetzung unzumutbare Nachteile entstehen. ${ }^{1029}$

\section{Das allgemeine Rechtsschutzbedürfnis als Sachentscheidungsvoraussetzung der Anfechtungsklage}

502 Bei der Prüfung der Anfechtungsklage sind regelmäßig keine Ausführungen zum allgemeinen Rechtsschutzbedürfnis erforderlich.

503 Das allgemeine Rechtsschutzbedürfnis fehlt, wenn die Anfechtungsklage keinerlei Vorteil für die rechtsschutzsuchende Person verspricht. Deshalb liegt für die mit der Anfechtungsklage begehrte Aufhebung eines Verwaltungsakts kein Rechtsschutzbedürfnis vor, wenn sich der Verwaltungsakt ex nunc erledigt hat und mit der Aufhebung für den Zeitraum vor Eintritt der Erledigung keinerlei Vorteil verbunden wäre. ${ }^{1030}$ Der Kläger wäre in diesem Fall vielmehr auf die Fortsetzungsfeststellungsklage zu verweisen (s. § 4 Rn. 9 ff.).

1027 BVerfG, Beschl. v. 14.12.2004, Az.: 2 BvR 1451/04 = NJW 2005, 1855 (1856); vgl. BVerfG, Beschl. v. 16.1.1972, Az.: 2 BvR 255/67 = BVerfGE 32, 305 (308f.).

1028 BVerfG, Beschl. v. 17.1.2019, Az.: 2 BvQ 1/19, juris Rn. 31.

1029 Ehlers, in: Schoch/Schneider/Bier, VwGO, 36. EL Februar 2019, Vorbem. § 40 Rn. 103.

1030 Schenke, Verwaltungsprozessrecht, 16. Aufl. 2019, Rn. 588.

Dana-Sophia Valentiner 
Examenswissen: Umstritten ist das Vorliegen des Rechtsschutzbedürfnisses bei der isolierten

Anfechtungsklage, die gegen einen Versagungsbescheid gerichtet wird, ohne zugleich die Verpflichtung zum Erlass des begünstigenden Verwaltungsakts zu begehren. In der Rechtsprechung wurde für die Zulässigkeit der isolierten Anfechtungsklage jedenfalls gegen den Bund, die Länder oder andere öffentlich-rechtliche Körperschaften angeführt, dass es sich um Beklagte handele, von denen angesichts ihrer verfassungsmäßig verankerten Bindung an Recht und Gesetz die Respektierung von gerichtlichen Entscheidungen auch ohne dahinterstehenden Vollstreckungsdruck erwarten werden dürfe. ${ }^{1031}$ Gegen das Vorliegen des Rechtsschutzbedürfnisses spricht, dass die Verpflichtungsklage weitergehenden Rechtsschutz gegen die Ablehnung eines begehrten Verwaltungsakts bietet. ${ }^{1032}$ In der Literatur wird diese Frage bereits bei der statthaften Klageart unter dem Aspekt des Spezialitätsverhältnisses der Versagungsgegenklage gegenüber der isolierten Anfechtungsklage erörtert. ${ }^{1033}$

\section{Literaturhinweise}

Ehlers, in: Schoch/Schneider/Bier, VwGO, 36. EL Februar 2019, Vorbem. § 40; 505 Schenke, Verwaltungsprozessrecht, 16. Aufl. 2019, § 16: Das Rechtsschutzbedürfnis; Würtenberger/Heckmann, Verwaltungsprozessrecht, 4. Aufl. 2018, § 20: Allgemeines Rechtsschutzbedürfnis

\section{Begründetheit}

Ist die Anfechtungsklage zulässig, ist in einem zweiten Schritt zu prüfen, ob sie 506 auch begründet ist.

\section{Die Struktur der Begründetheitsprüfung (Dominik Marek Kowalczyk)}

Im Rahmen der Begründetheitsprüfung der Anfechtungsklage stellt sich zu aller $\mathbf{5 0 7}$ erst die Frage nach der richtigen Einstiegsnorm. Die Anfechtungsklage war im Rahmen der Zulässigkeit nach § 42 I 1 Alt. 1 VwGO statthaft, soweit die Aufhebung eines Verwaltungsakts begehrt wird (s. Rn. 10). Einschlägig ist daher die Norm, welche dem Gericht aufträgt, den Verwaltungsakt aufzuheben. So stößt man unweigerlich auf § 113 I 1 VwGO, der die Aufhebung des Verwaltungsakts anordnet („hebt das Gericht den Verwaltungsakt [...] auf“). Die Norm für die Begründetheitsprüfung der Anfechtungsklage - wie auch sonst für alle anderen

1031 BVerwG, Urt. v. 30.4.1971, Az.: VI C 35/68 = NJW 1971, 2004 (2005).

1032 Vgl. BVerwG, Urt. v. 21.11.1986, Az.: 8 C 127/84 = NVwZ 1987, 330.

1033 Vgl. Schaks/Friedrich, JuS 2018, 860 (867).

Dana-Sophia Valentiner/Dominik Marek Kowalczyk 